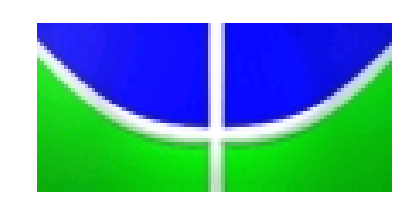

UNIVERSIDADE DE BRASÍLIA

FACULDADE DE TECNOLOGIA

DEPARTAMENTO DE ENGENHARIA ELÉTRICA

\title{
ANÁLISE MULTIVARIADA DE FATORES CRÍTICOS DE SUCESSO EM GOVERNANÇA DE TI NA ADMINISTRAÇÃO PÚBLICA FEDERAL À LUZ DOS DADOS DE CONTROLE EXTERNO
}

\section{KAROLL HAÜSSLER CARNEIRO RAMOS}

ORIENTADOR: RAFAEL TIMÓTEO DE SOUSA JÚNIOR, Dr.

TESE DE DOUTORADO EM

ENGENHARIA ELÉTRICA 


\title{
UNIVERSIDADE DE BRASÍLIA \\ FACULDADE DE TECNOLOGIA \\ DEPARTAMENTO DE ENGENHARIA ELÉTRICA
}

\section{ANÁLISE MULTIVARIADA DE FATORES CRÍTICOS DE SUCESSO EM GOVERNANÇA DE TI NA ADMINISTRAÇÃO PÚBLICA FEDERAL À LUZ DOS DADOS DE CONTROLE EXTERNO}

\section{KAROLL HAUSSLER CARNEIRO RAMOS}

\begin{abstract}
TESE DE DOUTORADO SUBMETIDA AO DEPARTAMENTO DE ENGENHARIA ELÉTRICA DA FACULDADE DE TECNOLOGIA DA UNIVERSIDADE DE BRASÍLIA, COMO PARTE DOS REQUISITOS NECESSÁRIOS PARA A OBTENÇÃO DO GRAU DE DOUTOR.
\end{abstract}

APROVADA POR:

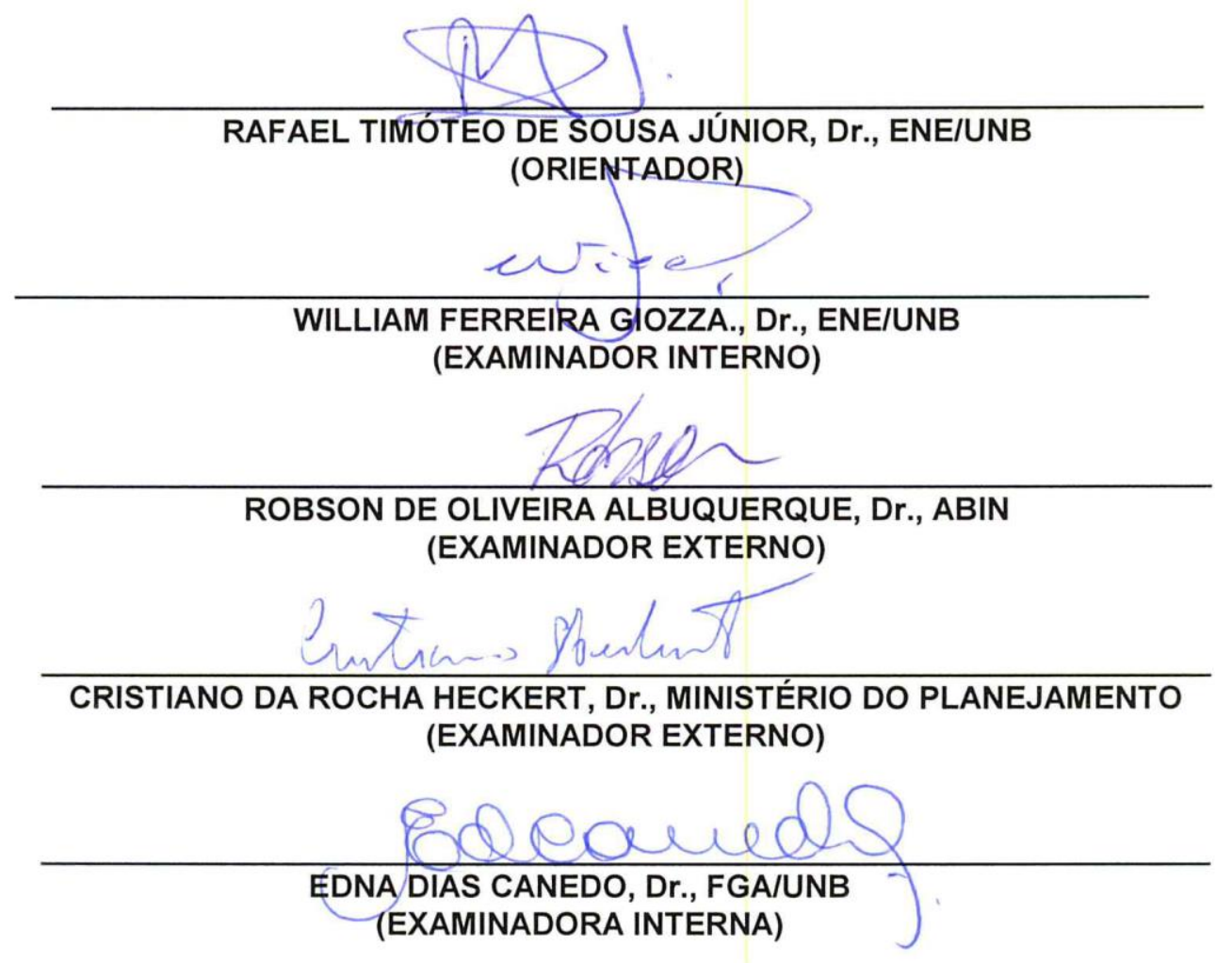




\section{FICHA CATALOGRÁFICA}

\section{RAMOS, KAROLL HAÜSSLER CARNEIRO}

Análise multivariada de fatores críticos de sucesso em governança de TI na administração pública federal à luz dos dados de controle externo. [Distrito Federal], 2015. xiv, 229p., 297 mm (ENE/FT/UnB, Doutor, Engenharia Elétrica, 2015). Tese de Doutorado - Universidade de Brasília. Faculdade de Tecnologia. Departamento de Engenharia Elétrica.

1. Governança de Tecnologias da Informação

2. Fatores Críticos de Sucesso

3. Análise Multivariada

4. Análise de Componentes Principais

5. Administração Pública Federal

I.ENE/FT/UnB Título (série) II. Título (série)

\section{REFERÊNCIA BIBLIOGRÁFICA}

Ramos, K. H. C. (2015). ANÁLISE MULTIVARIADA DE FATORES CRÍTICOS DE SUCESSO EM GOVERNANÇA DE TI NA ADMINISTRAÇÃO PÚBLICA FEDERAL À LUZ DOS DADOS DE CONTROLE EXTERNO. Tese de Doutorado em Engenharia Elétrica, Publicação PPGEE 093/2015 TD, Departamento de Engenharia Elétrica, Universidade de Brasília, Brasília, DF, xiv, 229p.

\section{CESSÃO DOS DIREITOS AUTORAIS}

NOME DO AUTOR: Karoll Haüssler Carneiro Ramos

TÍTULO DA TESE DE DOUTORADO: ANÁLISE MULTIVARIADA DE FATORES CRÍTICOS DE SUCESSO EM GOVERNANÇA DE TI NA ADMINISTRAÇÃO PÚBLICA FEDERAL À LUZ DOS DADOS DE CONTROLE EXTERNO.

\section{GRAU/ ANO: Doutor / 2015}

É concedida à Universidade de Brasília permissão para reproduzir cópias deste trabalho de doutorado e para emprestar ou vender tais cópias somente para propósitos acadêmicos e científicos. Do mesmo modo, a Universidade de Brasília tem permissão para divulgar este documento em biblioteca virtual, em formato que permita o acesso via redes de comunicação e a reprodução de cópias, desde que protegida a integridade do conteúdo dessas cópias e proibido o acesso a partes isoladas desse conteúdo. $\mathrm{O}$ autor reserva a si outros direitos de publicação e nenhuma parte deste documento pode ser reproduzida sem a autorização por escrito do autor.

Karoll Haüssler Carneiro Ramos

SHIS QI 27 conjunto 16 - Lago Sul

71.675.160 - Brasília - DF - Brasil / karoll.ramos@gmail.com.br 
Aos meus pais

Omyr Haüssler da Silva Ramos $\dagger$ e Marlene Carneiro Ramos 


\section{AGRADECIMENTOS}

Agradeço primeiramente a Deus e a Meishu-Sama por toda proteção recebida ao longo desta jornada.

Aos meus antepassados pelos bons alicerces que me deram.

A minha mãe Marlene C. Ramos por toda paciência durante este período e pelos ensinamentos ao longo da minha vida, pela proteção, amor e carinho e pelo esforço em me oferecer o melhor.

Ao Professor Dr. Rafael Timóteo de Sousa Júnior pela salvação, pela orientação, pelo tratamento digno e profissional a esta pesquisadora. Gratidão pelo incentivo e pelo apoio na realização de um trabalho desafiador e gratificante.

A Professora Sueli Menelau pela orientação durante a qualificação deste trabalho.

Ao Professor Dr. Carlos André de Mello Souza pela ajuda na construção da metodologia.

Ao Professor Dr. João Paulo Lustosa pelo apoio e pela orientação em análises multivariadas e por todo o incentivo ao longo desta pesquisa.

Ao doutorando Thiago Vieira pela ajuda e pela contribuição na análise multivariada e na execução dos algoritmos fundamentais a esta pesquisa.

Aos amigos que me ajudaram a contatar o seleto grupo de entrevistados, meus eternos agradecimentos a:

Antonio Netto, MSc da Presidência da República; Romilson Rodrigues Pereira, MSc do Tribunal de Contas da União, Tomas da Cotta Orlandi, MSc. da Empresa de Correios e Telégrafos; Fabio Jacinto Barreto de Souza, MSc. do Ministério da Fazenda; Gilberto Alves Maranhão Bezerra, da Polícia Civil do Distrito Federal; Ana Patrícia Sobreira do Ministério da Fazenda; Demerval Bruzzi, MSc.; José Queiroz da Silva, Adv.; Renato Uirá.

Durante o desenvolvimento deste trabalho, fui bolsista da CAPES, a quem agradeço pelo apoio. 


\title{
ANÁliSe MULTIVARIAdA DE FATORES CRÍTICOS DE SUCESSO EM GOVERNANÇA DE TI NA ADMINISTRAÇÃO PÚBLICA FEDERAL À LUZ DOS DADOS DE CONTROLE EXTERNO
}

\author{
Autora: Karoll Haüssler Carneiro Ramos \\ Orientador: Rafael Timóteo de Sousa Júnior \\ Programa de Pós-graduação em Engenharia Elétrica \\ Brasília, Março de 2015
}

Com expressivos gastos em tecnologia da informação (TI) na administração pública federal (APF), a governança de TI (GTI) das instituições públicas envolvidas é monitorada e diagnosticada pelo Tribunal de Contas da União (TCU), por meio do instrumento denominado Levantamento de GTI, o qual leva em particular ao cálculo de um índice de governança de TI (iGovTI). Tal levantamento utiliza um questionário baseado em boas práticas governamentais e de mercado em TI e em negócio. Desde o ano de 2007, quando se iniciaram as pesquisas, esse questionário passou por mudanças substanciais que impactam na gestão e na governança de TI das instituições públicas, que precisam se adequar às mais de 100 questões do questionário. A pesquisa vinculada a esta tese objetiva primeiramente identificar e verificar por meio de análises estatísticas questões que podem ser consideradas fatores críticos de sucesso (FCS). Adicionalmente, são comparados os FCS identificados com aqueles mencionados em entrevistas com executivos de TI de instituições públicas que contribuam para desempenho das organizações públicas com alto desempenho no índice iGovTI. Para o objetivo específico de classificar as instituições conforme o iGovTI, empregam-se algoritmos que sejam mais eficientes na classificação das instituições de acordo com o resultado do iGovTI, a partir de suas respostas ao questionário. Os algoritmos utilizados para a identificação das questões mais importantes para a classificação são o Máquina de Vetores de Suporte (MVS), obtendo sucesso de classificação em 91,4\% dos testes, e o Eliminação Recursiva de Variáveis (ERV), que produz resultado de $66,66 \%$ de semelhança ao comparar os FCS identificados em entrevistas (estes classificados por ERV) com a classificação provida pelo banco de dados do TCU, ou seja, identificando FCS comuns às duas fontes e considerados como fatores de altíssimo impacto.

Palavras-chave: Governança de Tecnologias da Informação ; Fatores Críticos de Sucesso; Análise Multivariada; Análise de Componentes Principais; Administração Pública Federal. 


\begin{abstract}
MULTIVARIATE ANALYSIS OF OF CRITICAL SUCCESS FACTORS FOR IT GOVERNANCE WITHIN THE BRAZILIAN FEDERAL PUBLIC ADMINISTRATION IN THE LIGHT OF EXTERNAL AUDITING DATA
\end{abstract}

\author{
Author: Karoll Haüssler Carneiro Ramos \\ Supervisor: Rafael Timóteo de Sousa Júnior \\ Electrical Engineering Graduate Program
}

Brasilia, March 2015

With the significant public spending on information technology (IT) in the Brazilian Federal Public Administration, IT governance (ITG) of the related public institutions is monitored and diagnosed by the Federal Court of Accounts, in Portuguese Tribunal de Contas da União (TCU), which gathers governance data via surveys in light of market and governmental best practices for IT and for business. Although these surveys started only in 2007 with 39 questions, nowadays they already contain more than 100 questions impacting on the ITG of Brazilian public institutions. Moreover, these questions encourage public institutions to adopt best practices in all areas not only in IT. In this paper, we propose the identification and the verification of the critical success factors (CSFs) of the survey variables by means of statistical analysis. The CSFs are defined as the factors that most contributed for the high performance of the institutions and they are measured by using the ITG index created by TCU. Therefore, in order to validate our results, the statistically identified CSFs are compared with the CSFs mentioned by the IT executives in interviews. Besides the statistical analysis, we successfully apply the Support Vector Classification (SVC) algorithm to classify public institutions in terms of their ITG index. By comparing the SVC based classification with the CSFs obtained from the interviews, we show that there is a very high level of similarity. Hence, the CSFs identified with SCV provide a very high impact.

Keywords: Information Technology Governance; Critical Success Factors; Multivariate Analysis; Principal Component Analysis; Brazilian Federal Public Administration. 


\section{ÍNDICE DE FIGURAS}

Figura 1 - Negócio e Funções de Governança Corporativa ....................................................9

Figura 2 - Alinhamento entre governança corporativa e demais governanças ........................ 10

Figura 3 - Sistema de Governança Corporativa .................................................................. 11

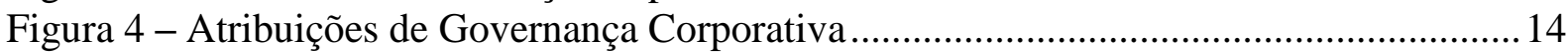

Figura 5 - Modelo de Processo Global de Responsabilidade. ............................................... 18

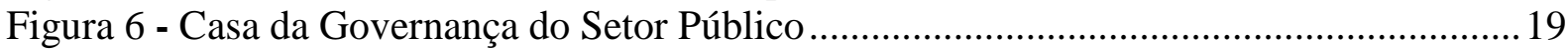

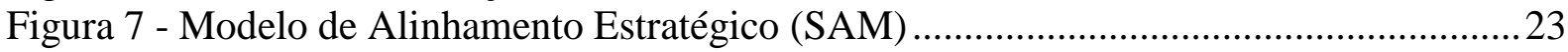

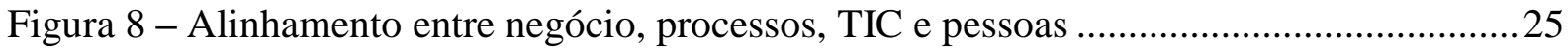

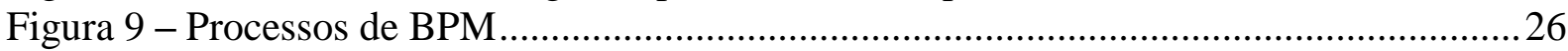

Figura 10 - SAM e o alinhamento entre negócios, processos, TIC e pessoas ........................227

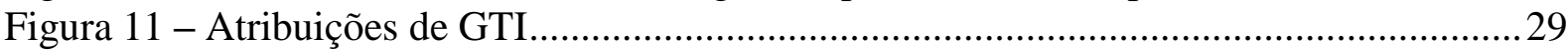

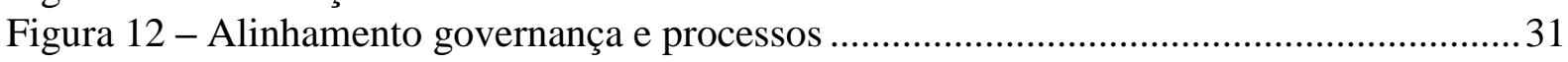

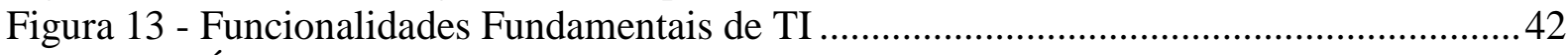

Figura 14 - Área de TI Decomposta em Competências Essenciais ......................................... 43

Figura 15 - Modelo de Arquitetura Corporativa de TI .......................................................... 44

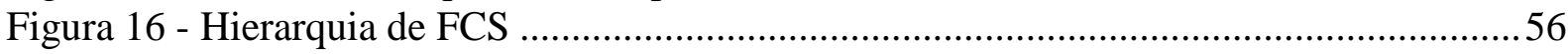

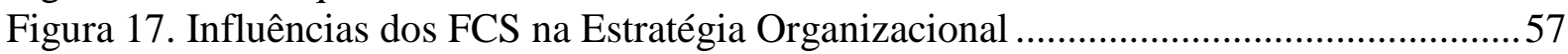

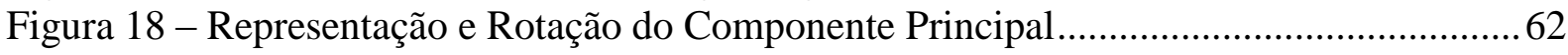

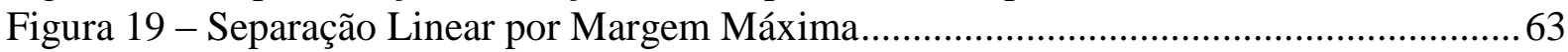

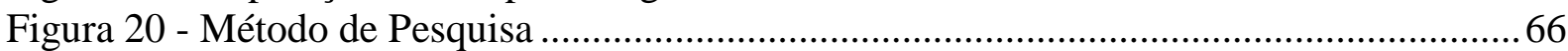

Figura 21 - Evolução das Publicações em AC + Administração Pública................................. 82

Figura 22 - Termos Isolados da Área de Concentração em AC + Administração Pública ...... 84

Figura 23 - Relacionamento entre as principais palavras-chave .......................................... 86

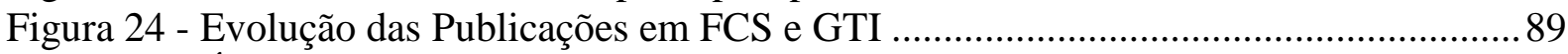

Figura 25 - Área de Concentração de FCS e GTI................................................................. 91

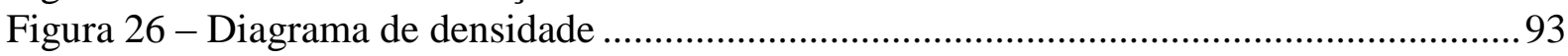

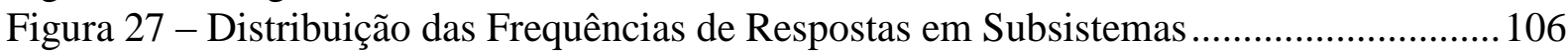

Figura 28 - Maturidade do alinhamento entre TI e o negócio ............................................ 111

Figura 29 - Maturidade da estrutura organizacional de TI ............................................... 113

Figura 30 - Maturidade da priorização de projetos de TI ...................................................... 114

Figura 31 - Maturidade do controle de GTI........................................................................ 116

Figura 32 - Maturidade dos direcionadores de estratégia de TI......................................... 117

Figura 33 - Maturidade da formulação e planejamento de estratégia de TI .......................... 119

Figura 34 - Maturidade do modelo de gestão de negócio de TI ........................................... 120

Figura 35 - Maturidade da utilizaçãa de boas práticas ........................................................ 122

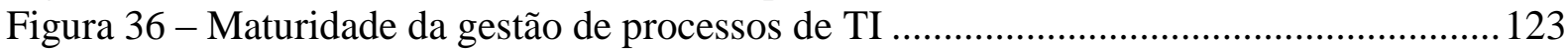

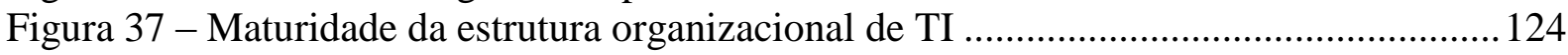

Figura 38 - Maturidade da gestão do usuário de TI ......................................................... 126

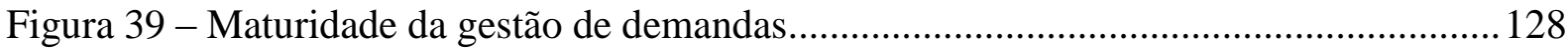

Figura 40 - Maturidade da definição de arquiteturas ............................................................ 129

Figura 41 - Maturidade das Políticas e diretrizes de GTI ..................................................... 130

Figura 42 - Maturidade do PDTI ........................................................................................ 132

Figura 43 - Maturidade da comunicação com as partes interessadas .................................... 133

Figura 44 - Maturidade das Normas e diretrizes para GTI ................................................ 134

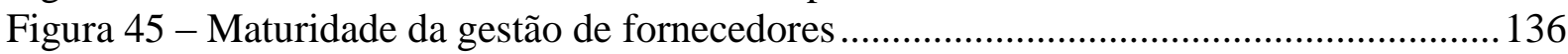

Figura 46 - Maturidade da gestão do pessoal de TI .......................................................... 139

Figura 47 - Maturidade da gestão de recursos financeiros e orçamentários ........................... 140 
Figura 48 - Maturidade da gestão de contratos ............................................................... 142

Figura 49 - Maturidade da gestão do conhecimento .......................................................... 143

Figura 50 - Maturidade da gestão de processos para desenvolvimento de soluções ............. 144

Figura 51 - Maturidade da gestão de projetos de TI ........................................................... 146

Figura 52 - Maturidade dos princípios para o desenvolvimento de soluções ........................ 148

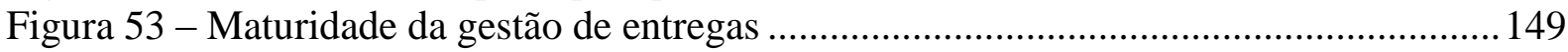

Figura 54 - Maturidade da gestão de infraestrutura ............................................................. 151

Figura 55 - Maturidade dos processos de gestão de serviços de TI em desenho do serviço .152

Figura 56 - Maturidade dos processos de gestão de serviços de TI em transição de serviços

Figura 57 - Maturidade dos processos de gestão de serviços de TI em operação do serviço 155

Figura 58 - Maturidade da gestão de serviços ......................................................................157

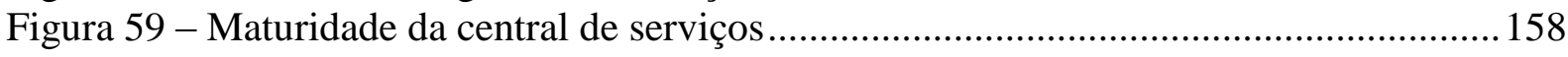

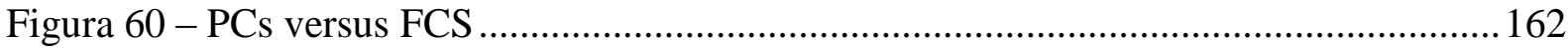

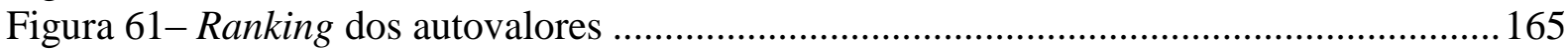

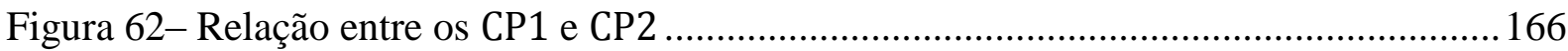

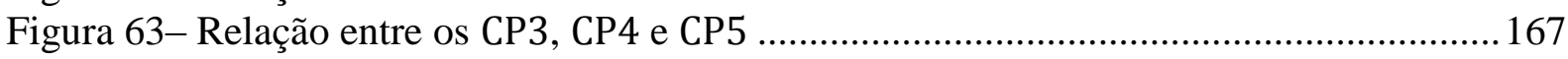

Figura 64- Dados brutos da pesquisa Fonte: Dados da pesquisa ....................................... 170

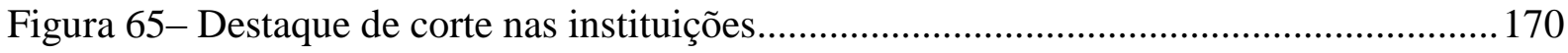




\section{LISTA DE QUADROS}

Quadro 1 - Boas práticas utilizadas nos Levantamentos em GTI do TCU . 3

Quadro 2 - Variação do número de itens dos questionários de Levantamento de GTI do TCU nos quatro ciclos

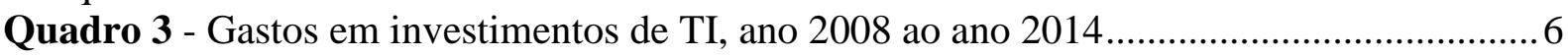

Quadro 4 - Compreensão do Modelo de Alinhamento .............................................................24

Quadro 5 - Diagnóstico da GTI pelos Levantamentos do TCU-Setfi .................................... 33

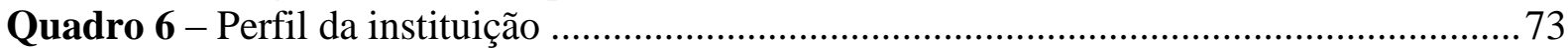

Quadro 7- Anos que o órgão participou no levantamento da GTI realizado pelo TCU/Sefti 73

Quadro 8- Quantidade de pessoas que fazem parte dos trabalhos em GTI da instituição...... 74

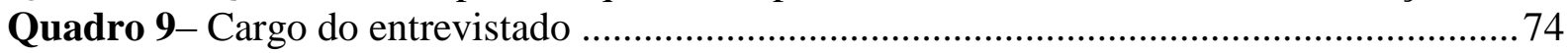

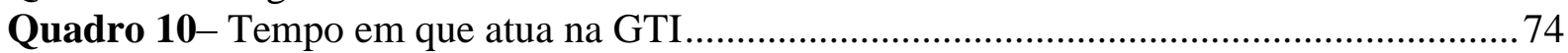

Quadro 11-Curso/treinamento sobre governança de TI ................................................. 75

Quadro 12- Horas em treinamentos recebidos em GTI...................................................... 75

Quadro 13 - Órgãos que divulgaram relatório de feedback em site no ano de 2012 .............. 77

Quadro 14 - Órgãos que divulgaram informações do relatório de feedback em site no ano de

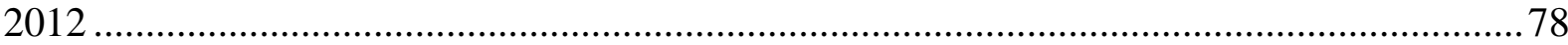

Quadro 15 - Anos das Publicações de FCS e Arquitetura de Corporativa...............................82

Quadro 16 - Periódicos mais relevantes em AC + Administração Pública.............................. 83

Quadro 17 - Área de concentração de AC + Administração Pública........................................ 83

Quadro 18 - Publicações Relevantes em Arquitetura de Corporativa + Administração Pública

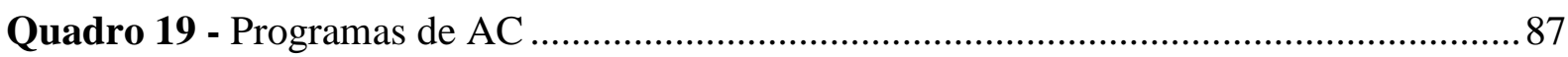

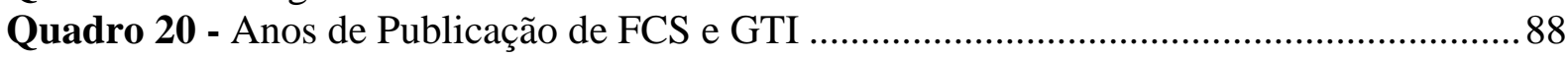

Quadro 21 - Periódicos e Editoras em FCS e GTI ............................................................... 90

Quadro 22 - Publicações Relevantes em FCS e GTI ............................................................. 92

Quadro 23 - Publicações de FCS em GTI para Categorização ............................................. 94

Quadro 24 - Categorias de Direcionamento - Parte I: Negócio de TI ...................................95

Quadro 25 - Categorias de Direcionamento - Parte II: Gestão de TI.................................... 100

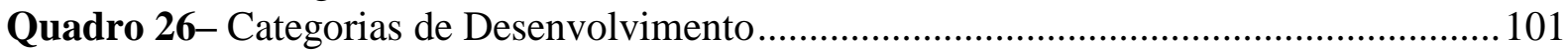

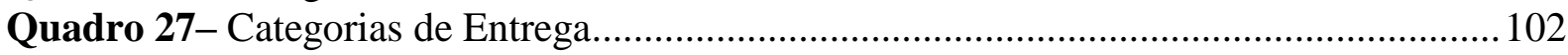

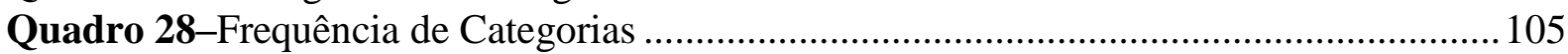

Quadro 29- Categorias por instituição pesquisada .......................................................... 106

Quadro 30 - Categorias de Direcionamento em Negócio em GTI na APF .......................... 107

Quadro 31 - Categorias de Direcionamento em Gestão de TI na APF................................ 108

Quadro 32 - Categorias de Desenvolvimento em GTI na APF ....................................... 108

Quadro 33 - Categorias de Entrega em GTI na APF ....................................................... 109

Quadro 34 - FCS do alinhamento entre TI e o negócio................................................... 110

Quadro 35 - Maturidade dos FCS do alinhamento entre TI e o negócio.............................. 111

Quadro 36 - FCS da estrutura organizacional de TI...................................................... 112

Quadro 37 - Maturidade dos FCS da estrutura organizacional de TI ................................ 112

Quadro 38 - FCS da priorização de projetos de TI............................................................ 113

Quadro 39 - Maturidade dos FCS da priorização de projetos de TI................................... 114

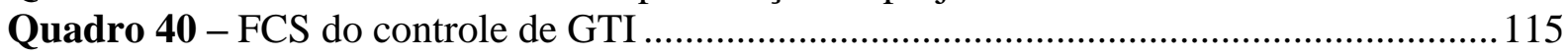

Quadro 41 - Maturidade dos FCS do controle de GTI .................................................... 115

Quadro 42 - FCS dos direcionadores de estratégia de TI ................................................116

Quadro 43 - Maturidade dos FCS dos direcionadores de estratégia de TI ......................... 117

Quadro 44 - FCS da formulação e planejamento de estratégia de TI..................................118

Quadro 45 - Maturidade dos FCS da formulação e planejamento de estratégia de TI.........118

Quadro 46 - FCS do modelo de gestão de negócio de TI................................................... 119

Quadro 47 - Maturidade dos FCS do Modelo de gestão de negócio de TI ........................... 120 
Quadro 48 - FCS da utilização de boas práticas ................................................................ 121

Quadro 49 - Maturidade dos FCS da utilização de boas práticas ........................................ 121

Quadro 50 - FCS da gestão de processos de TI................................................................ 122

Quadro 51 - Maturidade dos FCS da gestão de processos de TI.......................................122

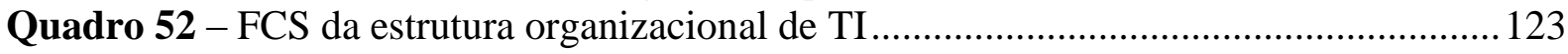

Quadro 53 - Maturidade dos FCS da estrutura organizacional de TI ................................. 124

Quadro 54 - FCS da gestão do usuário de TI ................................................................. 125

Quadro 55 - Maturidade dos FCS da gestão do usuário de TI ........................................ 125

Quadro 56 - FCS da gestão de demandas ................................................................... 127

Quadro 57 - Maturidade dos FCS da gestão de demandas ................................................127

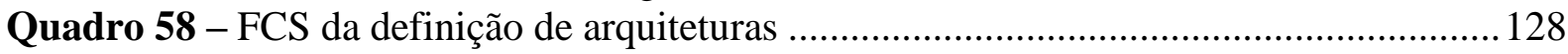

Quadro 59 - Maturidade dos FCS da definição de arquiteturas ......................................... 128

Quadro 60 - FCS das Políticas e diretrizes de GTI............................................................ 129

Quadro 61 - Maturidade dos FCS das Políticas e diretrizes de GTI.................................... 130

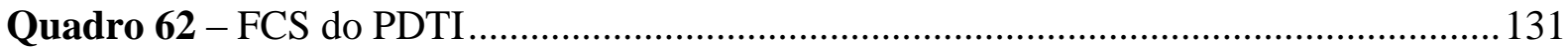

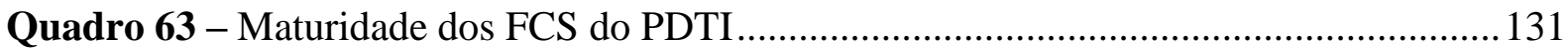

Quadro 64 - FCS da comunicação com as partes interessadas ........................................... 132

Quadro 65 - Maturidade dos FCS da comunicação com as partes interessadas.................... 133

Quadro 66 - FCS das Normas e diretrizes para GTI....................................................... 134

Quadro 67 - Maturidade dos FCS das Normas e diretrizes para GTI................................... 134

Quadro 68 - FCS da gestão de fornecedores ................................................................. 135

Quadro 69 - Maturidade dos FCS da gestão de fornecedores .......................................... 136

Quadro 70 - FCS da gestão do pessoal de TI ............................................................... 137

Quadro 71 - Maturidade dos FCS da gestão do pessoal de TI ...........................................138

Quadro 72 - FCS da gestão de recursos financeiros e orçamentários ..................................139

Quadro 73 - Maturidade dos FCS da gestão de recursos financeiros e orçamentários .........140

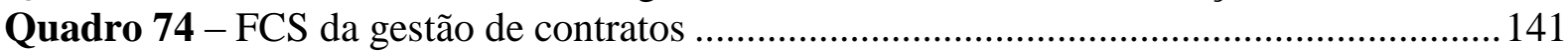

Quadro 75 - Maturidade dos FCS da gestão de contratos ................................................. 141

Quadro 76 - FCS da Gestão do conhecimento ................................................................ 142

Quadro 77 - Maturidade dos FCS da gestão do conhecimento ............................................ 142

Quadro 78 - FCS da gestão de processos para desenvolvimento de soluções...................... 143

Quadro 79 - Maturidade dos FCS da gestão de processos para desenvolvimento de soluções

Quadro 80 - FCS da gestão de projetos de TI

Quadro 81 - Maturidade dos FCS da gestão de projetos de TI.......................................... 145

Quadro 82 - FCS dos princípios para o desenvolvimento de soluções ................................. 147

Quadro 83 - Princípios para o desenvolvimento de soluções ............................................ 147

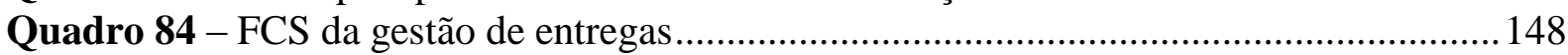

Quadro 85 - Maturidade dos FCS da gestão de entregas.................................................. 149

Quadro 86 - FCS da gestão de infraestrutura ............................................................... 150

Quadro 87 - Maturidade dos FCS da gestão de infraestrutura ...........................................150

Quadro 88 - FCS dos processos de gestão de serviços de TI em desenho do serviço........... 151

Quadro 89 - Maturidade dos FCS dos processos de gestão de serviços de TI em desenho do

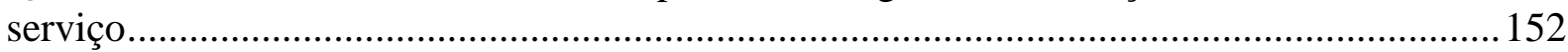

Quadro 90 - FCS dos processos de gestão de serviços de TI em transição de serviços ........ 153 Quadro 91 - Maturidade dos FCS dos processos de gestão de serviços de TI em transição de

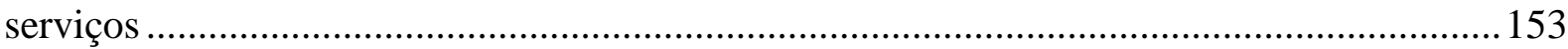

Quadro 92 - FCS dos processos de gestão de serviços de TI em operação do serviço ......... 154 Quadro 93 - Maturidade dos FCS dos processos de gestão de serviços de TI em operação do

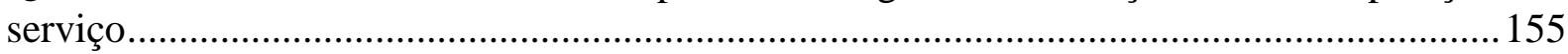

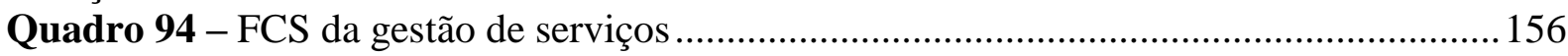

Quadro 95 - Maturidade dos FCS da gestão de serviços ................................................ 156 


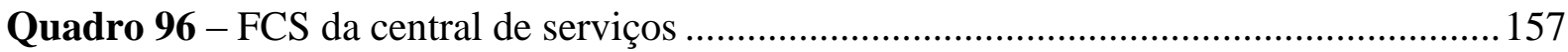

Quadro 97 - Maturidade dos FCS da central de serviços ................................................. 158

Quadro 98 - Maturidade dos FCS da central de serviços .................................................. 159

Quadro 99 - Maturidade dos FCS da central de serviços ................................................ 161

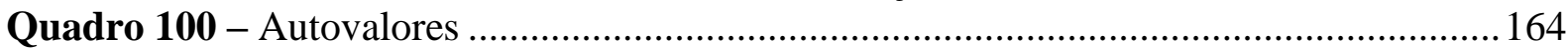

Quadro 101- Variáveis com alta variância CP1 a CP20 .................................................. 168

Quadro 102- Variáveis com alta variância CP 21 a CP 51 ................................................. 169

Quadro 103 - Algoritmos de Classificação Avaliados ..................................................... 171

Quadro 104 - Fatores críticos de sucesso de alto impacto................................................ 173

Quadro 105 - Questões relevantes para a classificação e não correlacionadas aos FCS ...... 174

Quadro 106 - Categorias com maior porcentual....................................................... 175

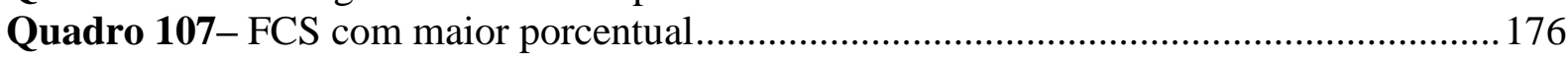

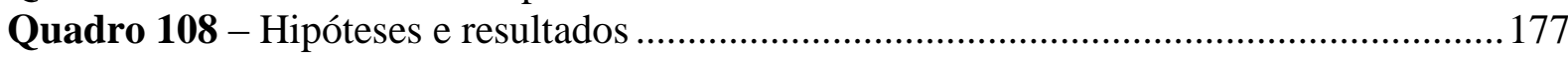

Quadro 109 - Questões relevantes para a classificação e não correlacionadas aos FCS ......178 


$\begin{array}{ll}\text { AC } & \text { Arquitetura Corporativa } \\ \text { ACP } & \text { Análise dos Componentes Principais } \\ \text { ANAO } & \text { Australian National Audit Office } \\ \text { APF } & \text { Administração Pública Federal } \\ \text { BSC } & \text { Balanced Scorecard } \\ \text { CMMI } & \text { Capability Maturity Model - Integration } \\ \text { COBIT } & \text { Control Objectives for Information and related Technology } \\ \text { CP } & \text { Componentes Principais } \\ \text { EGIT } & \text { Enterprise Governance of Information Technology } \\ \text { ERV } & \text { Eliminação Recursiva de Variáveis } \\ \text { FCS } & \text { Fatores Críticos de Sucesso } \\ \text { GC } & \text { Governança Corporativa } \\ \text { GCTI } & \text { Governança Corporativa de Tecnologia da Informação } \\ \text { GEA } & \text { Government Enterprise Architecture } \\ \text { GTI } & \text { Governança de Tecnologia da Informação } \\ \text { IBGC } & \text { Instituto Brasileiro de Governança Corporativa } \\ \text { IFAC } & \text { Federação Internacional de Contadores } \\ \text { iGovTI } & \text { Índice de Governança de TI } \\ \text { ISO 27002 } & \text { International Organization for Standardization } \\ \text { ITIL } & \text { Information Technology Infrastructure Library } \\ \text { MVS } & \text { Máquinas de Vetores de Suporte } \\ \text { NPM } & \text { New Public Management } \\ \text { PDTI } & \text { Plano Diretor de Tecnologia da Informação } \\ \text { PEI } & \text { Planejamento Estratégico Institucional } \\ \text { PETI } & \text { Planejamento Estratégico de Tecnologia da Informação } \\ \text { PMBOK } & \text { Project Management Book of Knowledge } \\ \text { Sefti } & \text { Secretaria de Fiscalisação de Tecnologia da Informação } \\ \text { SEI } & \text { Tribunal de Contas da União } \\ \text { TCU } & \text { Tecnologia da Informação } \\ \text { TIC } & \end{array}$




\section{SUMÁRIO}

1 INTRODUÇÃO

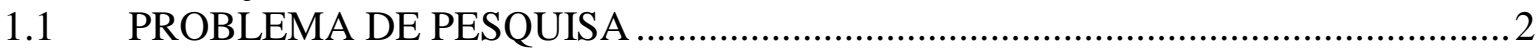

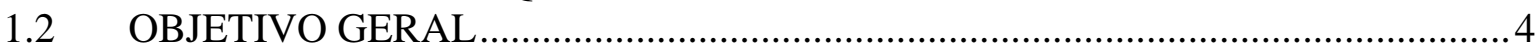

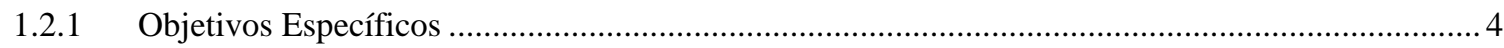

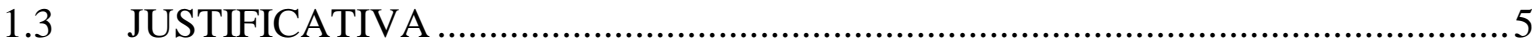

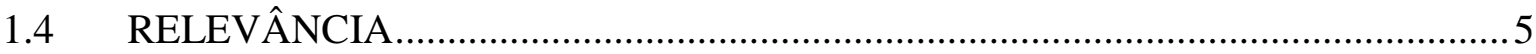

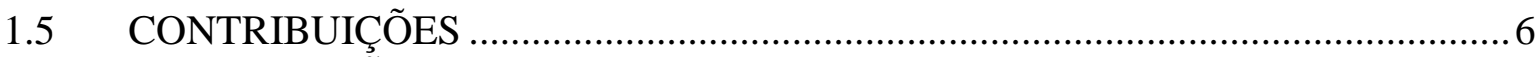

1.6 DELIMITAÇÕ๊ES ......................................................................................

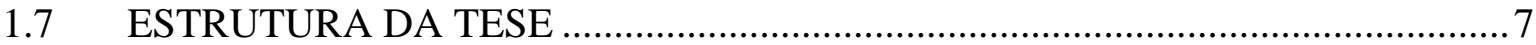

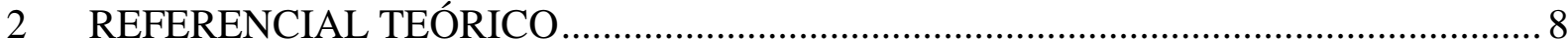

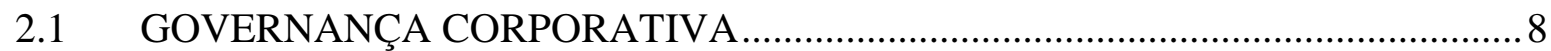

2.1.1 Governança Corporativa ...............................................................................................................

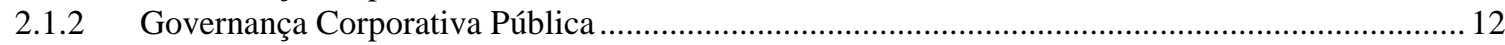

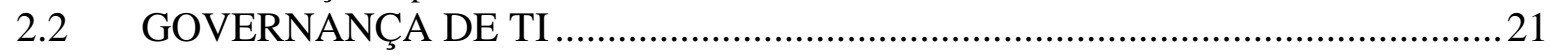

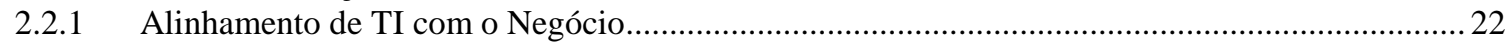

2.2.2 Governança de TI .........................................................................................................................27

2.2.3 Governança Corporativa de TI Pública ..........................................................................................30

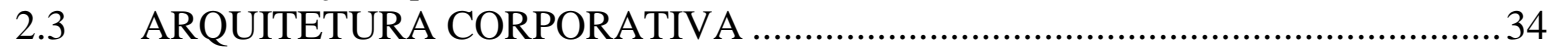

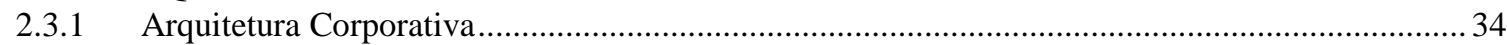

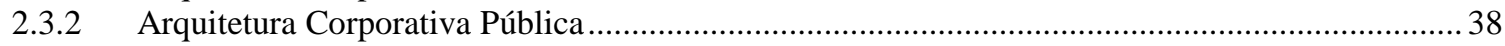

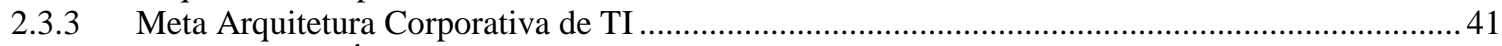

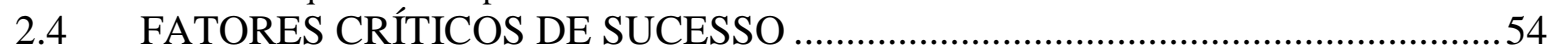

2.4.1 Metodologia de Levantamento de FCS ..............................................................................................56

2.4.2 FCS e Governança de TI ....…………………………………………………………………58

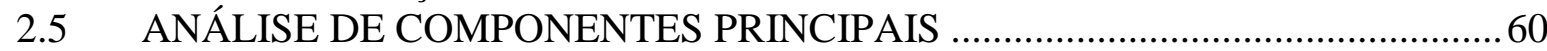

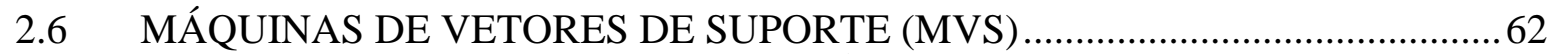

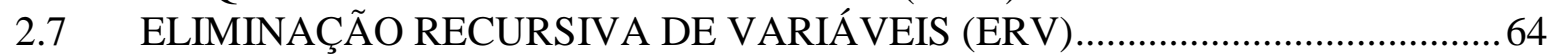

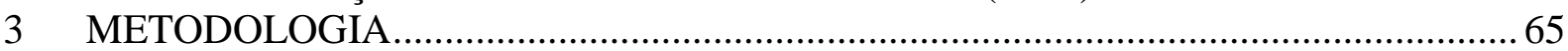

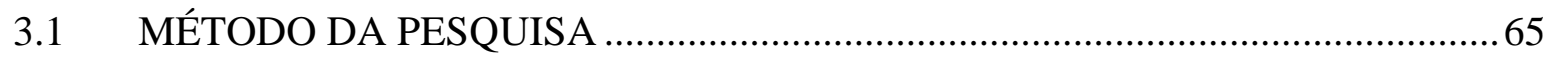

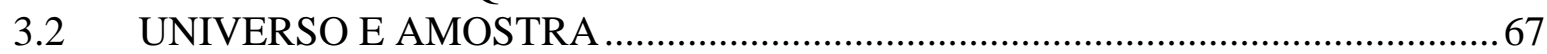

3.3 PROCEDIMENTOS DE COLETA, TRATAMENTO E ANÁLISE DOS DADOS...

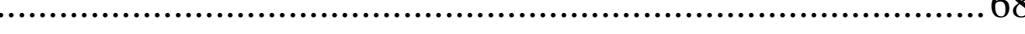

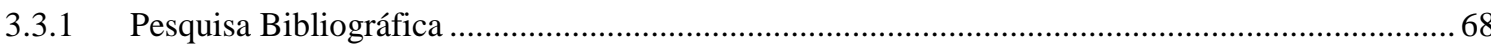

3.3.2 Entrevistas Individuais …………………………………………………………………....70

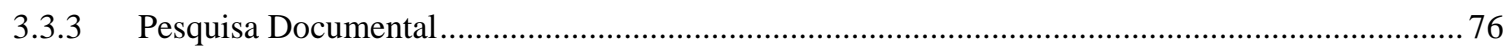

3.3.4 Pesquisa de Fatores Críticos de Sucesso de Alto Impacto ..............................................................79

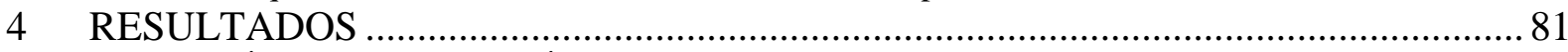

4.1 ANÁLISE BIBLIOMÉTRICA EM ARQUITETURA CORPORATIVA .................81

4.1.1 Considerações Teóricas em Arquitetura Corporativa ………………………………………………86

4.2 ANÁLISE BIBLIOMÉTRICA EM FCS EM GOVERNANÇA DE TI.....................88

4.2.1 Considerações Teóricas em FCS em Governança de TI - Identificaçẫo de Categorias ...................93

4.3 ANÁLISE DOS FCS EM GOVERNANÇA DE TI NA APF ................................... 104

4.3.1 Análise das Categorias dos FCS em GTI da APF......................................................................... 104

4.3.2 Análise dos FCS em GTI da APF - Subsistema Direcionamento em Negócio de TI ................... 109

4.3.3 Análise dos FCS em GTI da APF - Subsistema Direcionamento em Gestão de TI.........................135

4.3.4 Análise dos FCS em GTI da APF - Subsistema Desenvolvimento ............................................... 143

4.3.5 Análise dos FCS em GTI da APF - Subsistema Entrega ..............................................................148

4.4 VERIFICAÇÃO DOS FCS EM GTI DA APF COM O LEVANTAMENTO DE

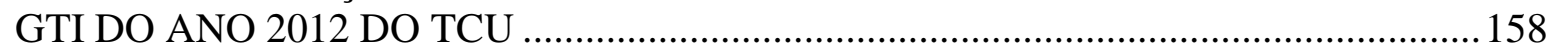

4.5 ANÁLISE DAS COMPONENTES PRINCIPAIS VERSUS FCS ...........................162

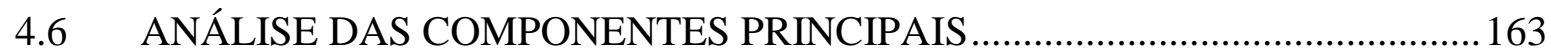

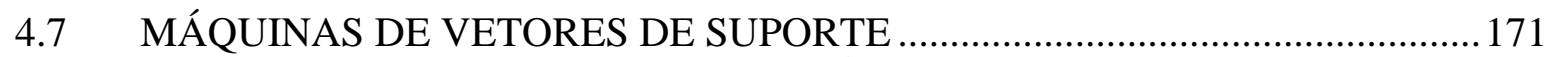

4.8 ELIMINAÇÃO RECURSIVA DE VARIÁVEIS ...............................................172

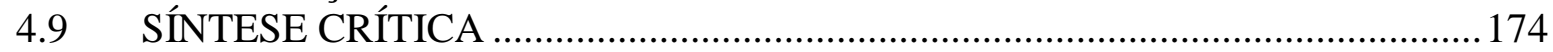




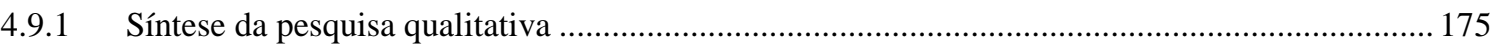

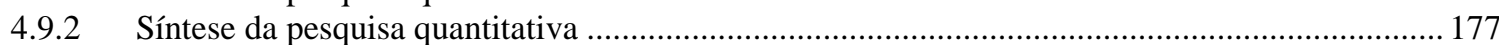

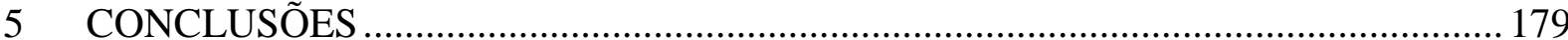

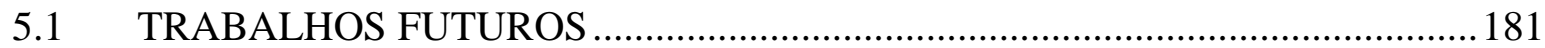

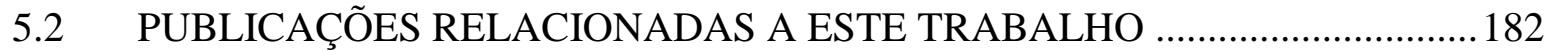

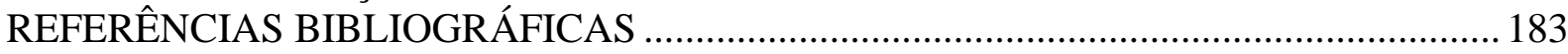

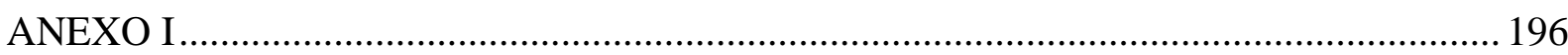

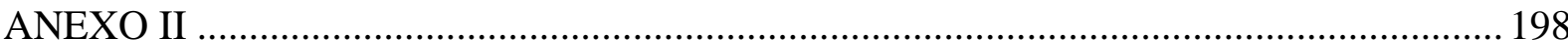

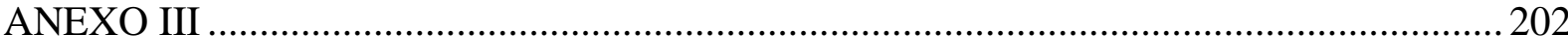

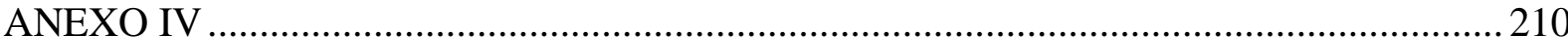

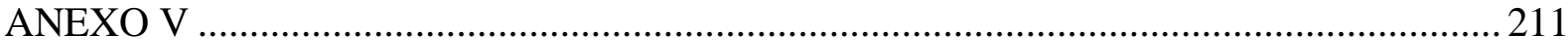




\section{INTRODUÇÃo}

Este trabalho aborda a identificação dos fatores críticos de sucesso (FCS) de governança de tecnologia da informação (GTI) na Administração Pública Federal do Brasil (APF). Os estudos sobre FCS são motivados pelas necessidades de informações de gestores e de executivos que, muitas vezes, não estão claramente determinadas (DIAS JUNIOR; GUSSONI; MUNIZ JUNIOR, 2009; ROCHA et al, 2010; ROCHA; DELAMARO, 2013). Além disso, os FCS indicam as áreas principais em que as coisas devem ser bem feitas para atingir o sucesso na organização (CLAVER et al, 2003; TARÍ, 2005), mas também sinalizam que se não houver atenção nessas áreas o desempenho organizacional será sofrível (KHANDELWAL, 2003).

Considerando que os FCS indicam quais informações serão as mais importantes para a tomada de decisão, logo esses podem ser úteis para as questões de Governança Corporativa (GC) e Governança de TI (GTI). Vale frisar que o termo governança designa os instrumentos para conduzir coordenações eficazes por meio de protocolos internos, de contratos e de aplicações de normas (COASE, 1988; WILLIAMSON, 1996), que no contexto corporativo auxiliam na definição de um conjunto de mecanismos de incentivo e de controle, internos e externos, que minimizarão os custos decorrentes do problema de agência (SILVEIRA, 2004). Já no contexto da TI, a governança definirá um modelo operacional de como a organização tomará decisões sobre o uso da TI (LUFTMAN, 2003).

Especificamente em GTI, são utilizadas boas práticas que auxiliam os gestores à tomada de decisão, tais como Project Management Book of Knowledge (PMBOK) para gerenciamento de projetos; Capability Maturity Model - Integration (CMMI) para o desenvolvimento de software com qualidade; Information Technology Infrastructure Library (ITIL) para gestão de serviços; International Organization for Standardization - ISO 27002 para segurança; Control Objectives for Information and related Technology (COBIT) para governança e auditoria; Balanced Scorecard (BSC) para planejamento estratégico. Essas boas práticas contribuem para o desenvolvimento de sistemas e para a revisão contínua das iniciativas de TI, sendo um indício de que os executivos, em geral, têm buscado mais informações e conhecimento sobre a função da TI na organização (VERHOEF, 2007). 
Estudos realizados em 2005 pelo Information Tecnology Process Institute (ITPI) e pelo Software Engineering Institute $(\mathrm{SEI})^{1}$ com organizações de alto-desempenho em TI demonstraram que essas boas práticas funcionam conforme a lógica de Pareto, ou seja, apenas $20 \%$ de seus controles resultam em $80 \%$ de eficiência e eficácia. Assim, a customização da GTI surge como ferramenta-chave para a determinação de controles organizacionais e para a racionalização dos custos de TI na criação de valor no processo produtivo da organização (MCLANE, 2003). De acordo com Hu e Plant (2001), pesquisas indicam que a vantagem competitiva advinda do uso eficiente da TI e da monitoração via processos de governança, pode ser revertida em melhorias na produtividade, rentabilidade e, principalmente, na lucratividade das organizações.

Nesse contexto, a TI se desenvolve para facilitar o fluxo sistêmico de informação na organização, servindo, inicialmente, como instrumento de apoio ou suporte às rotinas operacionais. Os gerentes de TI têm de conviver em um ambiente competitivo, em que tudo parece estar mudando no mercado, tais como: demandas dos clientes, tecnologias, globalização, produtos e processos. No meio destas mudanças, esses gerentes têm que tomar decisões críticas que afetarão não só a posição presente da organização, mas também o seu futuro sucesso ou fracasso (ANTAO, 2005).

\subsection{PROBLEMA DE PESQUISA}

A partir de análises conduzidas pelo Tribunal de Contas da União (TCU) se verifica que a situação da GTI na APF é preocupante devido ao grande número de falhas em gestão de TI que incluem problemas em contratos para aquisição de bens e serviços de TI (GUARDA; DE SOUSA JR, 2014), em segurança da informação, em planejamento estratégico institucional e de TI, em projetos básicos, entre outros (Tribunal de Contas da União - TCU, 2008a, 2008b, 2008c, 2009, 2010a, 2010b, 2012a, 2012b, 2012c, 2013a, 2013b, 2013c; Pacheco, 2011). Assim, o TCU, com o intuito de monitorar e de incentivar o uso de boas práticas em GTI, desde o ano 2007 iniciou levantamentos e fiscalizações em GTI na APF. Estes levantamentos foram realizados por meio de questionários baseados em boas práticas, apresentado no Quadro 1.

\footnotetext{
${ }^{1}$ O ITPI e o SEI têm estudado as características de organizações de alto desempenho buscando investigar, identificar e definir os indicadores de desempenho, os objetivos de controle e os processos comuns a todas elas.
} 
Quadro 1 - Boas práticas utilizadas nos Levantamentos em GTI do TCU

\begin{tabular}{|l|l|l|l|l|}
\hline \multicolumn{1}{|c|}{ Boas Práticas } & \multicolumn{1}{|c|}{$\begin{array}{c}\text { Questionário } \\
\mathbf{2 0 0 7}\end{array}$} & \multicolumn{1}{|c|}{$\begin{array}{c}\text { Questionário } \\
\mathbf{2 0 1 0}\end{array}$} & $\begin{array}{l}\text { Questionário } \\
\mathbf{2 0 1 2}\end{array}$ & \multicolumn{1}{|c|}{$\begin{array}{c}\text { Questionário } \\
\mathbf{2 0 1 4}\end{array}$} \\
\hline Governança de TI & COBIT 4.1 & COBIT 4.1 & COBIT 5 & COBIT 5 \\
\hline Segurança da informação & $\begin{array}{l}\text { NBR ISO/IEC } \\
17799: 2005\end{array}$ & $\begin{array}{l}\text { NBR ISO/IEC } \\
27002: 2005\end{array}$ & $\begin{array}{l}\text { NBR ISO/IEC } \\
27002: 2005\end{array}$ & $\begin{array}{l}\text { NBR ISO/IEC } \\
27002: 2005\end{array}$ \\
\hline $\begin{array}{l}\text { Gestão de continuidade de } \\
\text { negócios }\end{array}$ & $\begin{array}{l}\text { NBR ISO/IEC } \\
15999-1: 2007\end{array}$ & Não consta & Não consta & $\begin{array}{l}\text { NBR ISO/IEC } \\
15999-1: 2008\end{array}$ \\
\hline $\begin{array}{l}\text { Governança corporativa de } \\
\text { TI }\end{array}$ & Não consta & $\begin{array}{l}\text { NBR ISO/IEC } \\
38500: 2009\end{array}$ & $\begin{array}{l}\text { NBR ISO/IEC } \\
38500: 2009\end{array}$ & $\begin{array}{l}\text { NBR ISO/IEC } \\
38500: 2009\end{array}$ \\
\hline $\begin{array}{l}\text { Tecnologia da informação - } \\
\text { técnicas de segurança }\end{array}$ & Não consta & Não consta & Não consta & $\begin{array}{l}\text { NBR ISO/IEC } \\
27005: 2008\end{array}$ \\
\hline $\begin{array}{l}\text { Gestão de riscos } \\
\text { Gerenciamento de serviços }\end{array}$ & Não consta & Não consta & Não consta & $\begin{array}{l}\text { NBR ISO/IEC } \\
31000-1: 2009\end{array}$ \\
\hline $\begin{array}{l}\text { Engenharia de sistemas e } \\
\text { software } \text { - processos de ciclo } \\
\text { de vida de software }\end{array}$ & Não consta & Não consta & Não consta & $\begin{array}{l}\text { NBR ISO 20000- } \\
2: 2008\end{array}$ \\
\hline $\begin{array}{l}\text { Infraestrutura de TI } \\
\text { Gestão da qualidade }\end{array}$ & Não consta & Não consta & Não consta & $\begin{array}{l}\text { NBR ISO/IEC } \\
12207: 2009\end{array}$ \\
\hline $\begin{array}{l}\text { Gestão de projetos } \\
\text { Não consta }\end{array}$ & $\begin{array}{l}\text { ITIL Version 3 } \\
\text { Service Design. }\end{array}$ \\
\hline
\end{tabular}

Fonte: Desenvolvido pelo autor

Os dados mostrados no Quadro 1 foram extraídos dos relatórios de Levantamento de GTI (TCU, 2008a, 2010a, 2012a; Ministério do Planejamento, Orçamento e Gestão - MPOG, 2014). No Quadro 1 é possível observar que o primeiro Levantamento (ano 2007) continha três boas práticas; já no último ano, constam onze boas práticas de mercado utilizadas para a elaboração do questionário do Levantamento de GTI.

Além disso, durante os quatro ciclos de avaliação, a quantidade de itens varia constantemente, apresentado no Quadro 2.

Quadro 2 - Variação do número de itens dos questionários de Levantamento de GTI do TCU nos quatro ciclos

\begin{tabular}{|c|c|c|c|}
\hline $\begin{array}{l}\text { Quant. de Questões do } \\
\text { Questionário 2007 }\end{array}$ & $\begin{array}{c}\text { Quant. de Questões do } \\
\text { Questionário } 2010\end{array}$ & $\begin{array}{c}\text { Quant. de Questões do } \\
\text { Questionário } 2012\end{array}$ & $\begin{array}{l}\text { Quant. de Questões } \\
\text { do Questionário } 2014\end{array}$ \\
\hline $\begin{array}{l}\text { Trinta e nove } \\
\text { perguntas. }\end{array}$ & $\begin{array}{l}\text { Trinta questões, sub- } \\
\text { divididas em cento e } \\
\text { cinquenta e dois itens, } \\
\text { organizadas segundo } \\
\text { sete (das oito) } \\
\text { dimensões do } \\
\text { Gespública. }\end{array}$ & $\begin{array}{l}\text { Trinta e seis questões, } \\
\text { subdivididas em } \\
\text { quatrocentos e noventa } \\
\text { e quatro itens, } \\
\text { contemplando as oito } \\
\text { dimensões do } \\
\text { GesPública. }\end{array}$ & $\begin{array}{c}\text { Trinta questões, } \\
\text { subdivididas em cento } \\
\text { e noventa e um itens, } \\
\text { contemplando as seis } \\
\text { dimensões do } \\
\text { GesPública. }\end{array}$ \\
\hline
\end{tabular}

Fonte: Desenvolvido pelo autor

Atualmente, o Levantamento de GTI do TCU é o principal instrumento de avaliação e de análise em GTI na APF. Vale notar que as questões do questionário desse levantamento servem como direcionador para o desenvolvimento da GTI em órgãos públicos. Além disso, o 
resultado insatisfatório nesse levantamento implica em autuação pelo TCU (TCU, 2012b). Após a realização desses levantamentos, o TCU encaminha às instituições participantes um relatório com o feedback dos resultados gerais e do desempenho individual do órgão, instrumento pelo qual é informada a posição da instituição no ranking por meio do índice de governança de TI (iGovTI), este calculado com base em uma fórmula matemática (TCU, 2012c).

A partir dos resultados apresentados pelos levantamentos, não há informação sobre quais questões são fatores críticos de sucesso que contribuem para o desempenho das instituições melhor posicionadas no ranking do iGovTI. Além disso, as análises dos levantamentos são univariadas, ou seja, cada variável é tratada de forma isolada. Segundo Vicini (2005), quando existem muitas variáveis envolvidas, a análise univariada pode falhar, uma vez que além das informações provenientes das estatísticas isoladas, é necessário conhecer a totalidade das informações oriundas do conjunto das variáveis, bem como suas relações.

Assim, o principal problema da pesquisa é identificar, por meio de inteligência artificial, as questões do Levantamento de GTI do TCU do ano 2012, que possuem maior relevância na classificação das instituições públicas.

\subsection{OBJETIVO GERAL}

O objetivo geral deste trabalho é identificar, por meio de inteligência artificial, variáveis que podem ser consideradas FCS em GTI no contexto dos dados de controle externo da APF.

\subsubsection{Objetivos Específicos}

1. Identificar os FCS em GTI, com base em pesquisa bibliográfica;

2. Coletar a percepção de gestores de TI da APF, especificamente de instituições públicas consideradas "Aprimoradas" pelo índice iGovTI do TCU, referente ao ano de 2012, sobre FCS em GTI;

3. Definir método de agrupamento para análise dos FCS em GTI; 
4. Identificar e verificar, por meio de análise multivariada e de inteligência artificial, variáveis que podem ser consideradas FCS.

\section{$1.3 \quad$ JUSTIFICATIVA}

Em 2007, o Information Tecnology Process Institute (ITPI), a Carnegie Melon University, a Florida State University e a Triwiew Inc pesquisaram 1.000 (mil) empresas classificadas como de alto-desempenho pela Revista Fortune (ITAUDIT, 2007). Essa pesquisa objetivou analisar os aspectos comuns da gestão de TI no setor privado, uma vez que se detectou o aumento da burocracia e a diminuição do desempenho das empresas ao adotarem uma série de objetivos de controle e indicadores, essencialmente os oriundos das boas práticas ITIL e COBIT. Constatou-se que o princípio de Pareto se aplica aos controles dessas disciplinas, ou seja, $20 \%$ do conteúdo desses controles terão impacto próximo ao total (ITAUDIT, 2007).

Por outro lado, a APF vive um momento particular, quanto ao excesso de mecanismos de controle, que leva as gestões a uma espécie de miopia da medição e loucura da medição (NEELY; ADAMS, 2000; ATTADIA; MARTINS, 2003), correlato à grande quantidade de itens de avaliações da GTI. A miopia da medição ocorre quando um novo sistema de indicadores de desempenho é desenvolvido, entretanto o mesmo não é adequado como controle. Já a loucura da medição se refere à obsessão das empresas pela medição, em que tudo deve ser medido, sem necessariamente saber o porquê e o para quê (NEELY e AUSTIN, 2000; ATTADIA e MARTINS, 2003).

\subsection{RELEVÂNCIA}

De fato, de janeiro a julho de 2014, os órgãos e unidades da Administração Federal Direta (AFD), autárquica e fundacional gastaram R 2,86 bilhões em contratação de bens e serviços de TI, por meio de 8.539 processos de compras (MPOG, 2014). Desse total, 2,129 processos $(25 \%)$, ocorreram por meio de pregão eletrônico, contabilizando o gasto de $\mathrm{R} \$ 2,48$ bilhões (MPOG, 2014). Os gastos dos anos anteriores, bem como o volume de processos em contratação de bens e serviços de TI, podem ser visualizados no Quadro 3. 
Quadro 3 - Gastos em investimentos de TI, ano 2008 ao ano 2014

\begin{tabular}{|c|c|c|c|c|}
\hline Ano & $\begin{array}{c}\text { Processos de } \\
\text { compra }\end{array}$ & $\begin{array}{c}\text { \% relativo dos } \\
\text { processos }\end{array}$ & Valor dos gastos $^{\mathbf{1}}$ & $\begin{array}{c}\text { \% relativo } \\
\text { dos valores }\end{array}$ \\
\hline $2014^{2}$ & 17.680 & $13 \%$ & $6.035 .015 .409,78$ & $17 \%$ \\
\hline 2013 & 15.265 & $11 \%$ & $5.029 .326 .094,46$ & $14 \%$ \\
\hline 2012 & 13.971 & $10 \%$ & $6.939 .305 .500,78$ & $20 \%$ \\
\hline 2011 & 18.207 & $14 \%$ & $3.917 .603 .325,63$ & $11 \%$ \\
\hline 2010 & 21.298 & $16 \%$ & $5.411 .732 .469,12$ & $16 \%$ \\
\hline 2009 & 24.110 & $18 \%$ & $4.282 .244 .882,39$ & $12 \%$ \\
\hline 2008 & 24.240 & $18 \%$ & $3.187 .130 .596,28$ & $9 \%$ \\
\hline Total & $\mathbf{1 3 4 . 7 7 1}$ & $\mathbf{1 0 0 \%}$ & $34.802 .358 .278,44$ & $\mathbf{1 0 0 \%}$ \\
\hline
\end{tabular}

${ }^{1}$ Valores corrigidos pelo IPCA Dessazonalizado.

2 janeiro a dezembro.

Fonte: MPOG (2014)

Conforme apresentado no Quadro 3, verifica-se que à medida que os anos passam existe uma tendência de diminuição da quantidade processos, entretanto em relação ao volume de gastos não é possível estabelecer uma tendência, constatando-se tão somente que a média total de gastos em TI na está na ordem de R \$ 4 bilhões/ano. Os gastos e quantidades de atividades relacionadas às compras na AFD pressupõem controles robustos e conduções eficazes das ações relacionadas à gestão da TI.

Identificados tais problemas, e considerados os montantes financeiros envolvidos, busca-se nesta pesquisa uma modelagem estatística em que as questões são representadas como variáveis de modo que se consiga a identificação de variáveis significativas para a boa governança de TI.

\subsection{CONTRIBUIÇÕES}

A identificação e análise dos FCS em GTI da APF possibilita a órgãos com pouca maturidade em GTI definirem prioridades focando no desempenho da TI com o negócio e a observância aos critérios regulatórios.

A tese leva ao aperfeiçoamento do Levantamento de GTI realizado pelo TCU, por meio da priorização de variáveis que contribuem para o desempenho da GTI e consequentemente da TI. Esta otimização propicia na diminuição de investimentos que não geram valor para a TI e, consequentemente, para negócio e que não contribuem para a eficiência e eficácia da GTI. 
Por fortalecer o conceito de GTI centrado no alinhamento da TI com o negócio, a tese contribui para melhores resultados da TI dos órgãos públicos e para melhores resultados nas avaliações de controle interno e externo.

\subsection{DELIMITAÇÕES}

Há um importante detalhe acerca do foco de análise deste trabalho. De fato, aqui são analisados órgãos públicos ao invés de organizações públicas porque o levantamento da GTI pelo TCU considera as ações do orçamento que são específicas de órgãos, mesmo quando os órgãos são agrupados dentro da mesma organização pública. Desse modo, um Ministério do Poder Executivo é uma organização que pode ser dividida em várias ações do orçamento, ou seja, vários órgãos. Cada órgão possui orçamento próprio e é avaliado independentemente da organização a que pertence. A organização Ministério de Fazenda, por exemplo, compreende o ministério propriamente dito e também cinco áreas de ações do orçamento (Tesouro Nacional, Receita Federal, ESAF, SEAI, SE/SPOA). Essa forma de divisão precisa ser esclarecida com vistas às possíveis interpretações que seriam causadas sem a devida separação.

Apesar do último Levantamento em GTI ter sido no ano de 2014, a pesquisa analisa os dados do Levantamento em GTI do ano de 2012, uma vez que as entrevistas de identificação dos FCS, parte inicial do método, foram iniciadas e finalizadas antes da disponibilização da base de dados do Levantamento em GTI de 2014 pelo TCU.

\subsection{ESTRUTURA DA TESE}

Esta tese está dividida em seis capítulos, incluindo esta introdução. No Capítulo 2 é apresentado o Referencial Teórico; no Capítulo 3 é verificada a Metodologia; no Capítulo 4 é mostrado o desenvolvimento e o resultado desta pesquisa; no Capítulo 5 estão as discussões e; no Capítulo 6 apresentam-se as conclusões, considerações finais e trabalhos futuros. 


\section{REFERENCIAL TEÓRICO}

Neste capítulo é revisado o referencial teórico utilizado neste trabalho. No Subcapítulo 2.1 são apresentados conceitos em GC no setor privado e no setor público e no Subcapítulo 2.2 são apontadas noções de GTI no setor privado e no setor público. O Subcapítulo 2.3 abordará a meta arquitetura corporativa de TI utilizada na organização das categorias de FCS e o Subcapítulo 2.4 discorrerá sobre FCS. Depois são sumarizados os métodos desta pesquisa, por meio dos seguintes subcapítulos: o Subcapítulo 2.5 mostrará Análise de Componentes Principais - ACP; no Subcapítulo 2.6 é visto o conceito de Máquinas de Vetores de Suporte (MVS), enquanto que no Subcapítulo 2.7 se verifica a Eliminação Recursiva de Variáveis (ERV). Para esta pesquisa o MVS e o ERV serão utilizados para especificar problemas de classificação.

\subsection{GOVERNANÇA CORPORATIVA}

O Subcapítulo 2.1 é dividido em duas seções terciárias: Seção 2.1.1 que mostra algumas definições sobre GC e a Seção 2.1.2 que aborda a GC na administração pública.

\subsubsection{Governança Corporativa}

O termo GC foi cunhado a partir das implicações dos "problemas de agência" (JENSEN; MECKLING, 1976; RODRIGUES; MACCARI; SIMÕES, 2009). Para introduzir esse termo, Jensen e Meckling (1976) explicam que os gestores não detém a totalidade dos direitos sobre o retorno do fluxo de caixa residual, que é decorrente da aplicação dos recursos. Consequentemente, esse fato, torna-se um potencial conflito de interesses, oriundo da relação entre proprietários, acionistas, administradores e demais partes interessadas. É importante frisar que tais interesses se referem não só aos resultados financeiros, mas também às diretrizes e às políticas do negócio (CARVALHO, 2002).

Segundo Jensen e Meckling (1976), para resolver esse problema é necessária separação entre propriedade (partes interessadas, acionistas, proprietários), controle e gestão (gestores). Essa separação é obtida por contrato estabelecido entre a propriedade e um 
determinado agente que tomará decisões para garantir a perenidade e sustentabilidade do negócio, bem como os interesses dos proprietários (JENSEN; MECKLING, 1976).

A sumarização das circunstâncias descritas direciona o conceito de GC.

Primeiramente, destacamos o termo governança, o qual designa os instrumentos que conduzem a coordenações eficazes por meio de protocolos internos e dos contratos e das aplicações de normas (WILLIAMSON, 1975; COASE, 1988). Logo, GC é uma extensão desse conceito, sendo que centrada na organização e em seus respectivos problemas de agência.

Conforme Silveira (2014), GC é um conjunto de mecanismos de incentivo e de controle, internos e externos, que visam a minimizar os custos decorrentes do problema de agência.

Para Carvalho (2002), GC é o mecanismo que governa o processo decisório dentro de uma empresa, representando o conjunto de regras que objetivam minimizar os problemas de agência.

A Figura 1 apresenta uma representação dos conceitos de GC. Na Figura, o negócio representa os objetivos da organização. Nesse interim, cabe à GC garantir por meio de controles, políticas e diretrizes à gestão que tais objetivos sejam respeitados. É válido destacar que a definição desses objetivos do negócio é de responsabilidade dos proprietários e não da GC. Finalmente, a GC promove e corrige os caminhos adotados para o alinhamento entre as gestões da organização com o negócio, por meio de feedback.

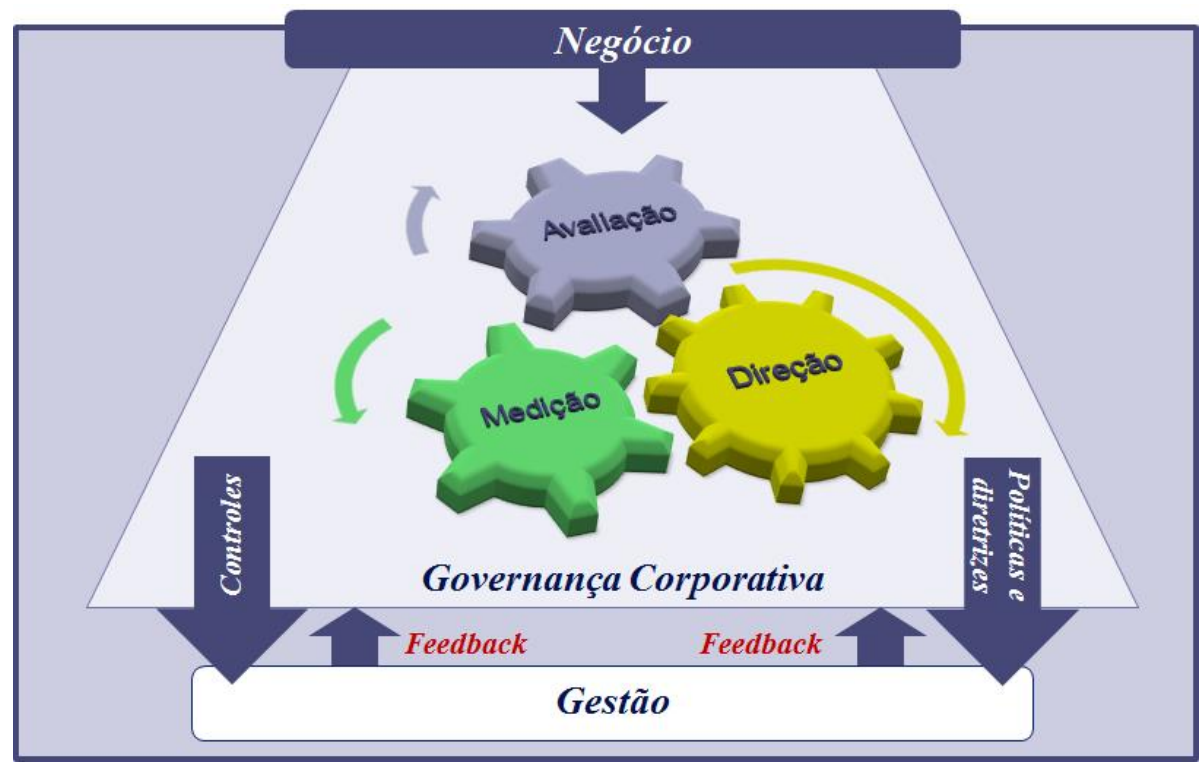

Figura 1 - Negócio e Funções de Governança Corporativa Fonte: Desenvolvido pelo autor 
Quanto à estrutura de GC, frisa-se que para a GC pode contemplar outras governanças que apoiem o cumprimento da missão da GC (IBGC, 2009). Para este trabalho essas governanças serão denominadas de governanças funcionais. Por exemplo, governança de TI, de recursos humanos $(\mathrm{RH})$, de finanças, de projetos, de auditoria, entre outros. Essas governanças definem as políticas e diretrizes específicas, além de monitorar e de avaliar as respectivas gestões, que podem ser relacionadas a unidades organizacionais ou a macroprocessos afins.

A Figura 2 destaca a relação entre GC e alguns tipos de governança.

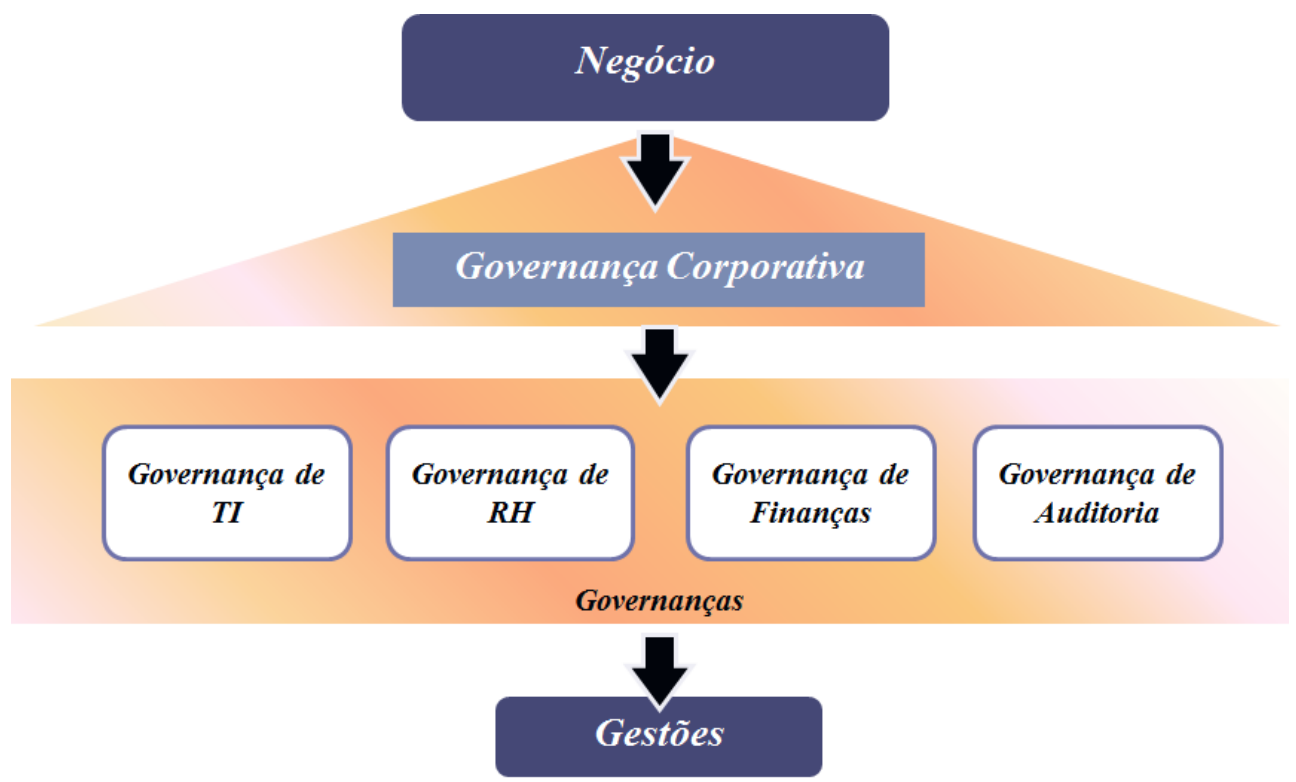

Figura 2 - Alinhamento entre governança corporativa e demais governanças Fonte: Desenvolvido pelo autor

É importante frisar que para esta tese a GTI é parte da estrutura de GC. Além disso, frisamos que a estrutura de GC desempenha função crítica para o monitoramento e aconselhamento da alta administração, sendo, portanto independentes (OECD, 2004; COLES; DANIEL; NAVEEN, 2007).

Sobre a estrutura organizacional de GC, toma-se o Conselho de Administração (do inglês Board of Directors) como unidade máxima, em que se subordinam auditorias e os comitês de governanças. A Figura 3 apresenta a estrutura organizacional de GC publicada pelo Instituto Brasileiro de Governança Corporativa (IBGC), sob a denominação de Sistema de Governança Corporativa. 


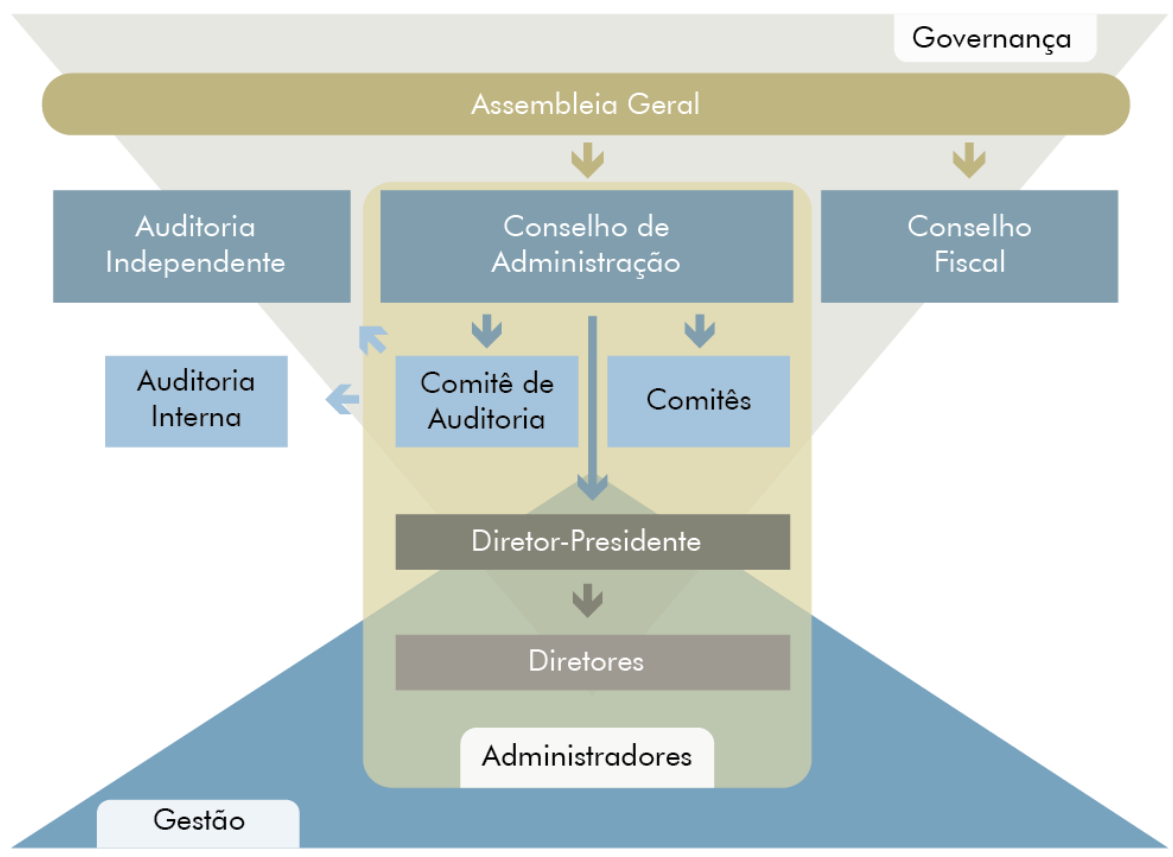

Figura 3 - Sistema de Governança Corporativa Fonte: IBGC (2009, p.16).

A respeito do Conselho de Administração, estudos apontam que quanto maior for a sua independência, mais eficiente será o seu monitoramento e as melhorias para o desempenho organizacional (DUTRA; SAITO, 2002; COLES; DANIEL; NAVEEN, 2007; BOONE et al., 2007; SILVEIRA, 2014).

Segundo a Organisation for Economic Co-Operation and Development - OECD (2004), um conselho independente possui maior quantidade de conselheiros independentes. Os autores Dutra e Saito (2004) enfatizam que a independência do conselho está relacionada à maior ou menor influência dos acionistas controladores sobre seus membros.

Conforme Carvalho (2002), os conceitos sobre GC partem do princípio de que as empresas pertencem aos acionistas e que, portanto, a administração deve ser feita em benefício deles. Porém, na realidade os acionistas majoritários têm maior poder de influência do que os acionistas minoritários. Assim, a preocupação em assegurar os interesses dos acionistas minoritários faz com que a GC ganhe um status de boa governança (MARQUES, 2007).

Para Marques (2007), a boa GC agrega valor, apesar de, isoladamente, não ser capaz de criá-lo. Para isso, a boa GC se relaciona a um negócio de qualidade, lucrativo e bem administrado, contribuindo para a melhoria do desempenho organizacional. A boa GC é amarrada aos seguintes princípios: 


\subsubsection{Governança Corporativa Pública}

Crew e Twight (1990) discorrem sobre a eficiência e contribuição do Direito e a importância do comportamento dos custos de transação para avaliar a eficiência de qualquer estrutura de governança seja pública ou privada. Nessa pesquisa os autores destacam Williamson (1985), que aborda as estruturas de governança privada, reconhecendo o potencial para a extensão às estruturas de governança pública. Para Williamson (1985), as estruturas de governança privadas fornecem um método de atenuar o oportunismo e ajudam a economizar por meio de uma racionalidade limitada que conduz à diminuição dos custos de transação. Contudo, Crew e Twight (1990) afirmam que é desafiador criar estruturas de governança pública que incorporem algumas das propriedades de aumento da eficiência que existem nas estruturas de governança privada. Além disso, na governança privada existem incentivos para o desenvolvimento de estruturas de governança que atenuam o oportunismo e economizam em racionalidade limitada.

Já no contexto público, o tomador de decisões governamental tem geralmente o incentivo para aumentar os custos de transação, enquanto o contribuinte individual tem poucos incentivos para cobrar estruturas de governança eficientes, uma vez que ele se apropria de apenas uma pequena parte dos ganhos. Crew e Twight (1990) também frisam o aumento do custo social dos programas redistributivos, assegurando preferências políticas.

A justificativa para a governança no setor público repousa nesses problemas e na inexistência de contratos completos, ineficiências nos processos organizacionais, falta de informações e mau uso dos recursos públicos (HART, 1995; ANTUNES et al, 2008).

Consequentemente, é necessário o controle e a direção sobre tais interesses políticos. Assim, a governança corporativa pública (GCP), ou simplesmente governança pública, aparece na administração pública com o objetivo de mitigar os conflitos advindos dos interesses dos agentes políticos, dos agentes públicos, da sociedade e demais partes interessadas, como ocorre no setor privado. A GCP administra as agências ${ }^{2}$ do setor público, por meio dos seguintes princípios:

- transparência: necessidade dos altos dirigentes das organizações públicas apresentar toda informação relevante aos interessados e se colocarem à disposição para esclarecimentos, de forma que os interessados confiem nos

\footnotetext{
${ }^{2} \mathrm{O}$ conceito de agência, conforme apresentado por Giddens (2009), deve ser compreendido enquanto a capacidade dos atores de fazer uma diferença.
} 
processos de tomada de decisão, na gestão e nos agentes públicos (IFAC, 2001; BARRET, 2005; MARQUES, 2007);

- integridade: necessidade dos altos dirigentes serem honestos e objetivos, adotando voluntariamente altos padrões de comportamento que conduzam os interessados ao reconhecimento de que seu comportamento é probo e apropriado. O cumprimento deste princípio depende da efetividade do modelo de controle e do profissionalismo dos agentes públicos (IFAC, 2001);

- prestação de contas ou responsabilização: necessidade de que os altos dirigentes assumam integralmente a responsabilidade por decisões e ações de sua alçada e prestem contas por estas ações, inclusive pelos resultados alcançados. Para que esse princípio seja cumprido, é essencial haver uma clara definição de artigos e responsabilidades dos agentes (IFAC, 2001; BARRET, 2005; MARQUES, 2007); e

- conformidade: conselheiros e executivos devem zelar pela perenidade das organizações e, portanto, devem incorporar considerações sociais e ambientais na definição dos negócios e nas operações das empresas. Em outras palavras, é a função social da organização que inclui oportunidades de emprego, qualificação e diversidade da força de trabalho, estímulo ao desenvolvimento científico por meio da estrutura organizacional (ALVARES; GIACOMETTI; GUSSO, 2008).

Para Australian National Audit Office (ANAO), cuja função assemelha-se a um tribunal de contas do governo australiano, é necessário que as práticas em governança conduzam a boa governança pública, ou seja, que as lideranças da organização, do governo e da população se mobilizem para que as instituições públicas façam bem o seu trabalho (ANAO, 2003). Segundo essa instituição, a palavra boa se concentra em dois requisitos:

- desempenho - por meio do qual a organização usa seu sistema de governo para contribuir para o seu desempenho global e a entrega de seus bens, serviços ou programas; e

- conformidade - em que a organização utiliza os seus arranjos de governança para assegurar que se cumpram os requisitos da lei, regulamentos e normas. 
Segundo Fontes Filho (2003), a GCP também aponta para as questões que incluem a gestão das políticas públicas $^{3,}$ o exercício de poder e o controle na sua aplicação. Para Procopiuck (2013), a governança em órgãos públicos se certifica que os empreendimentos públicos terão efetivo potencial de enfrentar problemas presentes e futuros, sendo entendida como o sistema de proteção dos interesses dos cidadãos contra os atos lesivos que os agentes públicos podem causar ao patrimônio público.

Com o objetivo de explorar e delimitar o âmbito de atuação da GCP, este trabalho identificou por meio de pesquisa bibliográfica atribuições baseadas em FCS de GC no setor público. Essas atribuições resultaram em dez tipologias: $i$ ) auditorias; ii) código de conduta; iii) relacionamento com grupos de interessados; $i v$ ) perfil do conselho; $v$ ) comitês; vi) gestão da mudança; vii) gestão de riscos; viii) gestão da informação; ix) ouvidoria; $x$ ) planejamento e monitoramento do desempenho. A Figura 4 sumariza as atribuições apresentadas.

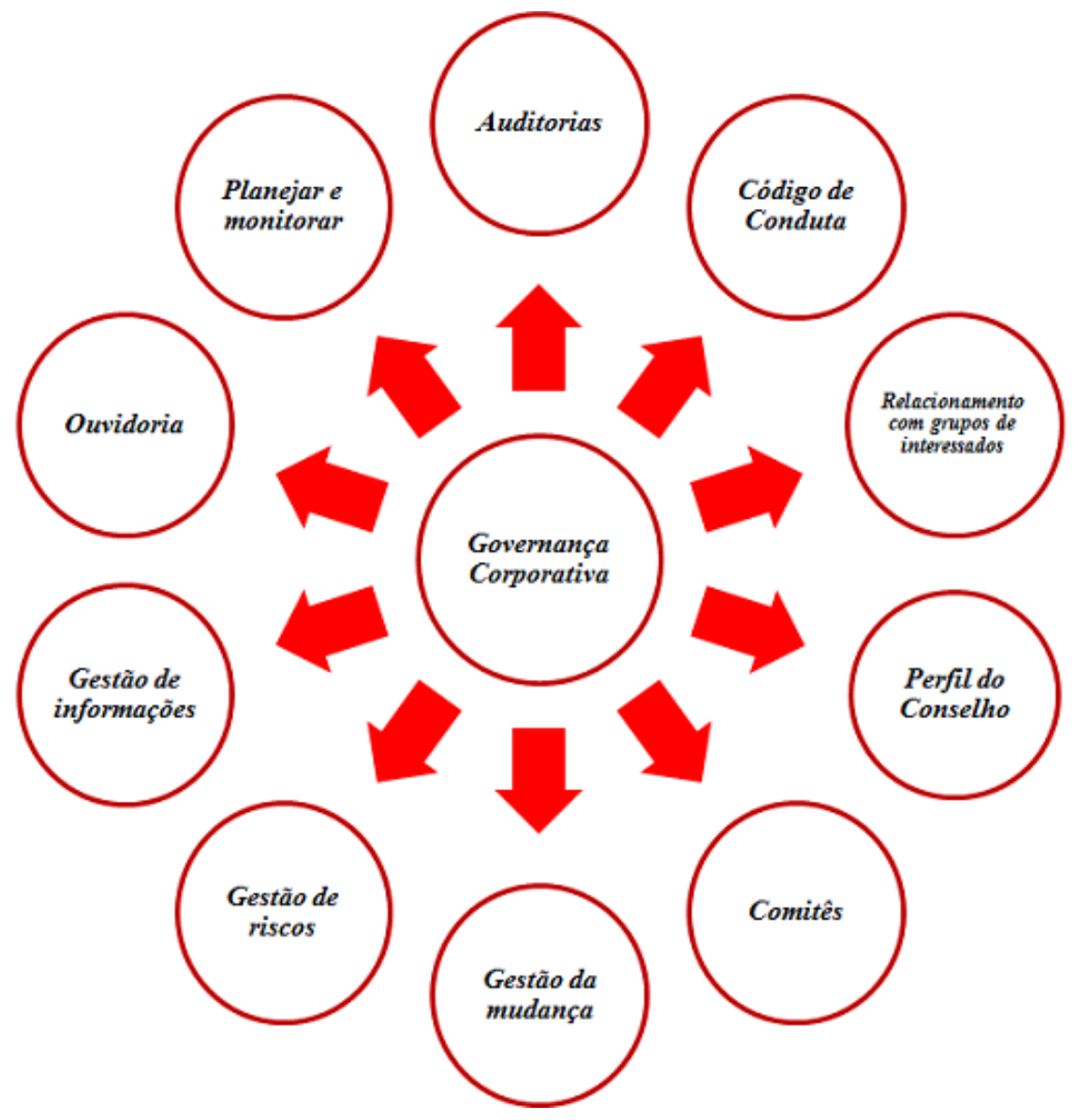

Figura 4 - Atribuições de Governança Corporativa Fonte: Desenvolvido pelo autor

\footnotetext{
3 Segundo Procopiuk (2013), as políticas públicas são relacionadas ao interesse público porque afetam, direta ou indiretamente, todos os membros da sociedade. Sendo formuladas a partir de atividades parlamentares e administrativas para a resolução de problemas reais. Frisa-se que essas políticas apresentam diretrizes gerais para a ação envolvendo interesses coletivos articulados na esfera pública. Para isso, os mecanismos utilizados são orientações normativas para elaboração de estratégias, programas e planos que procuram adequar meios para atingir determinados fins.
} 
A primeira atribuição são Auditorias. As auditorias realizam o exame das contas de cada unidade da instituição, averiguando o desempenho ocasional realizado de acordo com o programa de trabalho da auditoria (ANAO, 2003; SILVEIRA, 2014). As auditorias são internas e o foco é a revisão dos processos e das funções (ANAO, 2003).

A segunda atribuição é o Código de Conduta, que define políticas amplamente comunicadas sobre conflitos de manipulação de interesses e padrões de comportamento profissional e ético. É importante que o gerenciamento de conflitos de interesse considere as partes interessadas internas e externas (ANAO, 2003).

A terceira atribuição é Relacionamento com Grupos de Interessados. Este relacionamento trata de interessados internos e externos. Sobre os externos são explicitados os seguintes fatores (ANAO, 2003; BARRET, 2005; MARQUES, 2007; ALMEIDA et al., 2008;SILVEIRA, 2014):

- Relatório anual de demonstrações financeiras preparadas de acordo com especificações das autoridades competentes para o congresso nacional;

- Informação detalhada por meio das demonstrações contábeis apresentadas ao congresso nacional como parte do orçamento federal a cada ano;

- Comunicar com as partes interessadas por meio de meios eletrônicos e site, contendo informações atualizadas sobre pedidos;

- Inquéritos parlamentares transparentes em questões de interesse público;

- Influência das agências do governo;

- Agenda dos grupos de interesse;

- Apoio da comunidade.

A respeito dos interessados internos, os autores Anao (2003), e Kappler e Love (2002), especificam que o diretor executivo e o diretor financeiro sejam exigentes com Conselho de Administração a respeito de relatórios financeiros verdadeiros e apropriados.

A quarta atribuição é o Perfil do Conselho. Primeiramente, precisam ser documentados os objetivos, as funções e os poderes do conselho ou comitê executivo, bem como os arranjos de governança revistos em base contínua e de forma detalhada a cada ano ou dois (ANAO, 2003; RAMAGE, 2009). Segundo Silveira (2014), os cargos de Diretor Executivo e Presidente do Conselho de Administração devem ser ocupados por pessoas diferentes. Especificamente sobre o Conselho de Administração, esse deve ter de cinco a nove membros. Outro aspecto importante é que mais de $80 \%$ do Conselho de Administração seja composto por conselheiros externos com mandato unificado de um ano. Dentro dessa 
atribuição, incluímos ainda o perfil dos conselheiros (ANAO, 2003; BARRET, 2005; RAMAGE, 2009; IFAC, 2013):

- Conhecimento em governança corporativa;

- Pensamento estratégico;

- Alcance de resultados;

- Cultivo de relações produtivas de trabalho;

- Integração e integridade pessoal;

- Atitudes em relação à inovação;

- Comunicação influente.

Outro aspecto relevante ao perfil do conselho é a clara definição do processo sucessório dos conselheiros (RAMAGE, 2009), que garanta a continuidade da liderança e não dos conselheiros.

A quinta atribuição são os Comitês, que são estruturas de governança específicas que definem as políticas e diretrizes de determinadas funções do negócio. A GC deve possuir a documentação com as definições, com os objetivos, com as funções e com os poderes desses comitês corporativos (ANAO, 2003).

A sexta atribuição é Gestão da Mudança, que definem as políticas e diretrizes a fim de mitigar o "cansaço" das organizações frente a mudanças (RAMAGE, 2009). Segundo Ramage (2009), a busca por mudanças faz parte da natureza inerente das organizações que buscam estabilidade em resposta a alterações internas ou externas.

A sétima é a Gestão de Riscos. Abordagem da GC tem de ser estruturada, detalhada e integrada à gestão de riscos. Para isso, a identificação detalhada dos riscos enfrentados pela organização como um todo é necessária (ANAO, 2003; BARRET, 2005; MARQUES, 2007; IFAC, 2013). Adicionalmente, citam-se: estabelecimento de gestão de processos adequados e as práticas de gestão de riscos (ANAO, 2003); análise e revisão das abordagens de gestão de riscos (ANAO, 2003; BARRET, 2005; MARQUES, 2007; ALMEIDA et al, 2008; BRANCO; CRUZ, 2013); e envolvimento ativo na gestão de riscos de todos na organização (ANAO, 2003).

A oitava atribuição é a Gestão da Informação. Essa atribuição implica na boa manutenção de registros, tais como manutenção de arquivo, minutas de reuniões (ANAO, 2003). Além disso, tecnologias de informação e comunicação (TIC) agregam à gestão da informação por meio da criação, armazenamento e recuperação do conhecimento, da informação e dos dados em tempo hábil (ANAO, 2003; BARRET, 2005). O resultado dessa 
atribuição seria fazer com que a pessoa certa (tomador de decisão), tenha a informação certa, no momento certo, a fim de que tome a decisão correta.

A nona atribuição é Ouvidoria. Segundo ANAO (2003), a GC deve contar com uma ouvidoria própria para investigações, que seja disponível às partes interessadas, sejam essas internas ou externas.

A décima atribuição é o Planejamento e Monitoramento do Desempenho que inclui planejamento organizacional e de negócios (KAPPLER; LOVE, 2002; ANAO, 2003; BARRET, 2005). Especificamente sobre orçamento e planejamento financeiro, esses devem contar com um sistema claro e robusto (KAPPLER; LOVE, 2002; ANAO, 2003). Para o setor público, o planejamento da GC deve fazer considerações a respeito das questões das agências e de governo na elaboração de políticas e execução do programa (KAPPLER; LOVE, 2002; ANAO, 2003). Outros fatores considerados críticos para o planejamento são: revisão interna e externa; restrições de tempo; escopo bem definido; arranjos corporativos e planejamento de negócios; atualização de regras consistentes relativas às delegações financeiras e outros; processos de tomada de decisão.

Ainda sobre essa atribuição é válido citar que sejam definidos os sistema de controles internos, além de sistemas estruturados que monitoram o desempenho; planejamento de desempenho e monitoramento de sistemas; planos de controle de fraude e processos; e processos de controle organizacionais (KAPPLER; LOVE, 2002; ANAO, 2003; BARRET, 2005; MARQUES, 2007).

Segundo Marques (2007), para a GCP, reforçam que é de fundamental importância considerar a complexidade do setor público, que amplia o âmbito da GCP organizacional até o poder legislativo. A Figura 5 apresenta a separação das funções executivas e legislativas de governo, uma vez que o parlamento ${ }^{4}$ (legislatura) tem autoridade para financiar a aquisição e uso de recursos de todo o setor público, sendo o governo eleito (executivo) responsável pelos recursos específicos, planejamento, direção e controle das operações deste setor.

\footnotetext{
${ }^{4}$ Parlamento pode ser definido como congresso nacional que exerce as funções de fiscalização do executivo e da administração pública e da legitimidade da representação política decorrente de eleições competitivas.
} 


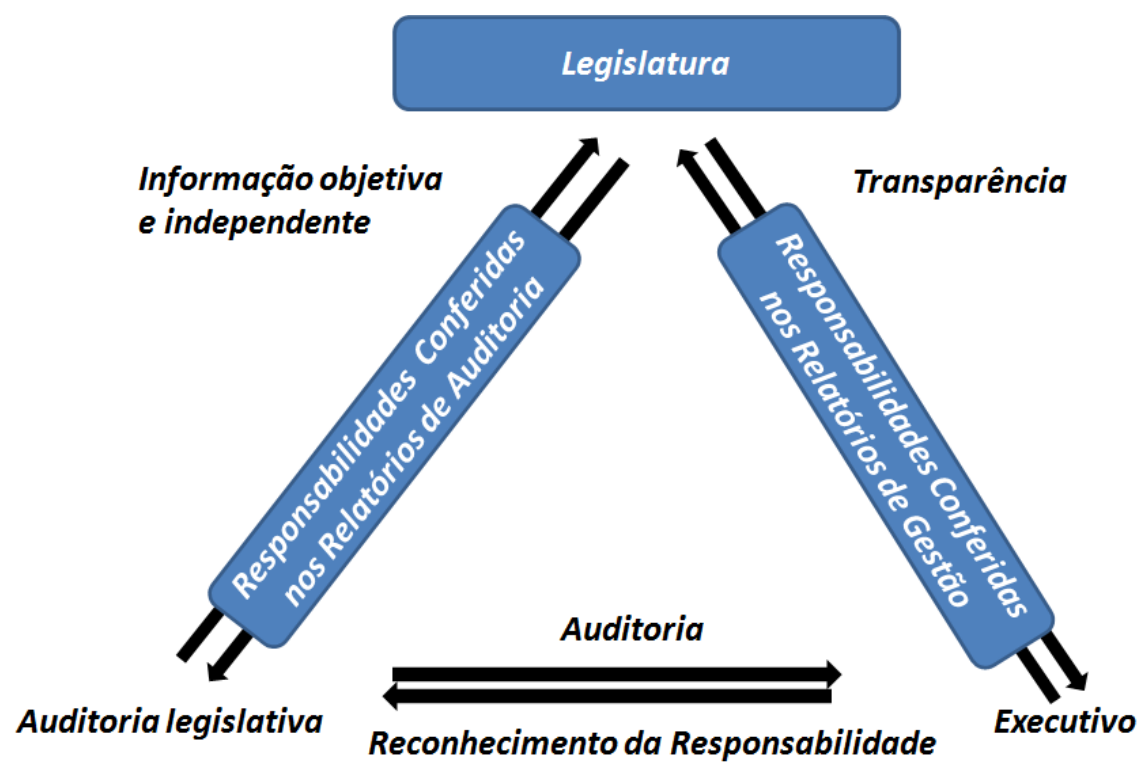

Figura 5 - Modelo de Processo Global de Responsabilidade.

Fonte: Barret (2005).

A legislatura tem o direito e a responsabilidade de manter o governo responsável pela gestão e atividades. Uma das formas para viabilizar esta responsabilidade é por meio de auditorias e relatórios elaborados pelo auditor legislativo.

A finalidade da boa governança no setor público é garantir que as suas organizações atuem sempre conforme o interesse público. Com base nessa premissa, a Federação Internacional de Contadores (IFAC) entende que governança compreende a estrutura (administrativa, política, econômica, social, ambiental, legal e outras) posta em prática para garantir que os resultados pretendidos pelas partes interessadas sejam definidos e alcançados (IFAC, 2001).

Para ilustrar a aplicação de uma estrutura de governança pública, toma-se como exemplo a estrutura da ANAO, denominada de "A Casa da Governança do Setor Público", conforme apresentada na Figura 6. 


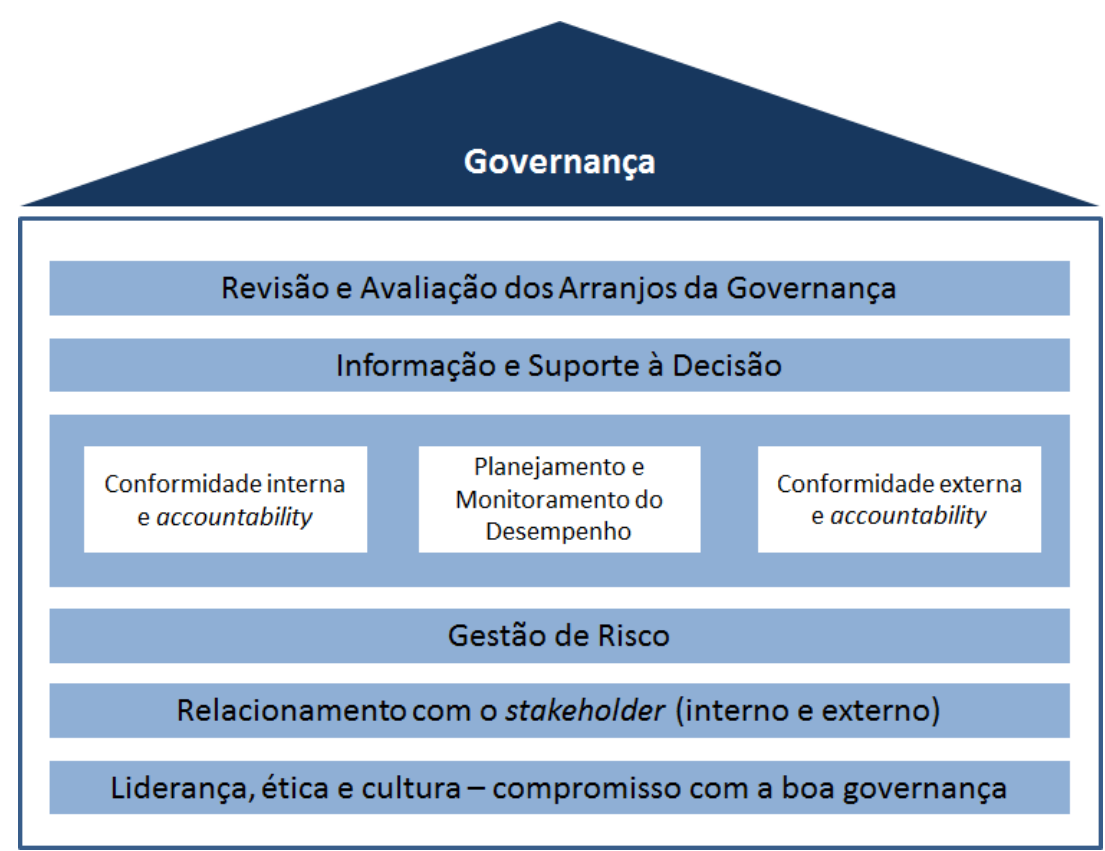

Figura 6 - Casa da Governança do Setor Público

Fonte: ANAO (2003, p.14).

A compreensão da Figura 6 é feita pela leitura bottom-up da Casa, em que a base de sustentação são os valores liderança, ética e cultura. Depois, consultam-se os grupos de interessados (internos e externos) para o estabelecimento das regras e para o planejamento das entregas de GCP. Essa base sustenta a tomada de decisão. Por fim, toda a estrutura é avaliada e revisada, como o ciclo de melhoria contínua PDCA (plan, do, check and act). Conforme ANAO (2003), sempre que esses elementos são executados, mantidos e melhorados, a organização desfruta do aumento de confiança das partes interessadas, uma vez que são informados sobre o processo de tomada de decisões.

Conforme observado pela ANAO (2003), nesta "Casa", as relações com as partes interessadas influenciam a eficácia dos componentes centrais, os quais são: conformidade interna e acountability; planejamento e monitoramento de desempenho e; conformidade externa e acountability. 


\subsubsection{Governança Corporativa Pública Brasileira}

Segundo o Relatório de Levantamento TC 000.390/2010-0 (BRASIL, 2010c), a definição adotada de GC para APF é a mesma do IBGC (2009, p.19):

Governança Corporativa é o sistema pelo qual as organizações são dirigidas, monitoradas e incentivadas, envolvendo os relacionamentos entre proprietários, Conselho de Administração, Diretoria e órgãos de controle. As boas práticas de Governança Corporativa convertem princípios em recomendações objetivas, alinhando interesses com a finalidade de preservar e otimizar o valor da organização, facilitando seu acesso a recursos e contribuindo para sua longevidade.

A adoção dessa citação visa enfatizar que governança e gestão são termos diferentes, já que a governança tem por finalidade a direção e controle da gestão da instituição (TCU, 2010a).

Vale destacar que na legislação Brasileira também estão presentes vários princípios relacionados à governança, tais como:

- $\quad$ planejamento e controle (DL200/1997, art. 6º);

- transparência e publicidade (CF, art. 37 e LRF);

- $\quad$ moralidade (CF, art. 37);

- impessoalidade (CF, art. 37);

- $\quad$ economicidade (CF, art. 70);

- legalidade (CF, arts. 37 e 70$)$;

- legitimidade (CF, art. 70);

- eficiência (CF, art. 37);

- $\quad$ eficácia e efetividade (L10180/2001, arts. 7º, III, 20, II).

Segundo Branco e Cruz (2013), estão previstos, ainda, diversos mecanismos de governança para as instituições públicas, quais sejam:

- conselhos de representantes da sociedade civil - participação da sociedade na gestão da coisa pública, como principal interessada;

- planejamento organizacional - alocação ótima dos recursos disponíveis e dá maior transparência, permitindo o controle pelos interessados; 
- comitês internos - alinhamento dos vários gestores quanto a assuntos complexos e evitam conflitos;

- excelência de pessoal e descentralização administrativa - metas legais para que as organizações sejam eficazes e eficientes;

- gestão de riscos - redução do impacto negativo dos riscos sobre as metas organizacionais;

- publicação de planos, portfólios e resultados - instrumentos de transparência para a sociedade;

- avaliações de desempenho individual e organizacional - práticas fundamentais para a melhoria contínua da eficiência e da eficácia das organizações;

- auditoria interna - detecção precoce de riscos;

- controle externo - exercido pelo Congresso Nacional com apoio do TCU, é o meio pelo qual a sociedade poderá saber se aqueles que administram o Estado estão cumprindo as normas de conduta (legalidade), agindo no estrito interesse do povo Brasileiro (legitimidade) e utilizando os recursos públicos nas alternativas que dão o melhor retorno à sociedade (economicidade).

Para Branco e Cruz (2013), os mecanismos de GCP são úteis para aumentar o valor obtido da aplicação dos recursos, conferir maior transparência, assegurar a conformidade com as normas, mitigar riscos de não alcance de metas e melhorar a prestação de serviços à sociedade. Assim, a sociedade se beneficia e as organizações públicas amadurecem, tornandose mais sustentáveis. Ademais, os gestores e altos administradores podem ser reconhecidos pelo seu valor agregado e pela sua atuação responsável, beneficiando-se também pelo menor risco jurídico.

\subsection{GOVERNANÇA DE TI}

O Subcapítulo 2.2 é dividido em três seções terciárias: Seção 2.2.1 que apresenta o conceito de alinhamento de TI com o negócio que introduz o tema GTI; a Seção 2.2 que mostra algumas definições sobre GTI e; a Seção 2.3 que aborda a GTI na APF. 


\subsubsection{Alinhamento de TI com o Negócio}

O alinhamento entre TI e negócio é o princípio básico da GTI que serve como ferramenta de gestão para mitigar as frustrações decorrentes do mau uso dos investimentos em TI e, consequentemente, conseguir obter vantagens competitivas.

Segundo Luftman, Papp e Brier (1999) a importância do alinhamento é bem conhecida e tem sido documentada desde o final da década de 1970. Para os autores, o desafio é estabelecer a ligação entre TI e negócio para o alcance da eficácia (fazer as coisas certas) e da eficiência (fazendo as coisas direito).

Para Teixeira Júnior (2003), o alinhamento entre TI e negócio ocorre por meio da coesão entre a área de TI e as áreas funcionais e de negócios, proporcionando a redução de custos, a geração de receitas e a melhoria da capacidade de atingir objetivos organizacionais. Vale frisar que os princípios que orientam a GC também se aplicam a GTI, e o principal deles é a separação entre governança e gestão. Assim, a coesão entre TI e áreas funcionais que busca o alinhamento deve ser vista com cautela pela GTI, justamente para não haver uma série de conflitos de interesse.

A grande questão é como promover e manter esse alinhamento. Para Reich e Benbasat (2000), o alinhamento acontece realmente quando todos os envolvidos estão cientes e comprometidos com os objetivos, as metas e os planos das empresas, e com a forma como TI pode ajudar a alcançá-los, demonstrando-o no dia-a-dia das organizações e nas suas operações.

\subsubsection{Strategic Alignment Model}

Segundo Plazaola (2006), o modelo de alinhamento mais aceito para o alinhamento entre TI e negócio é o Strategic Alignment Model (SAM) apresentado por Henderson e Venkatraman (1990) que é mostrado na Figura 7. 


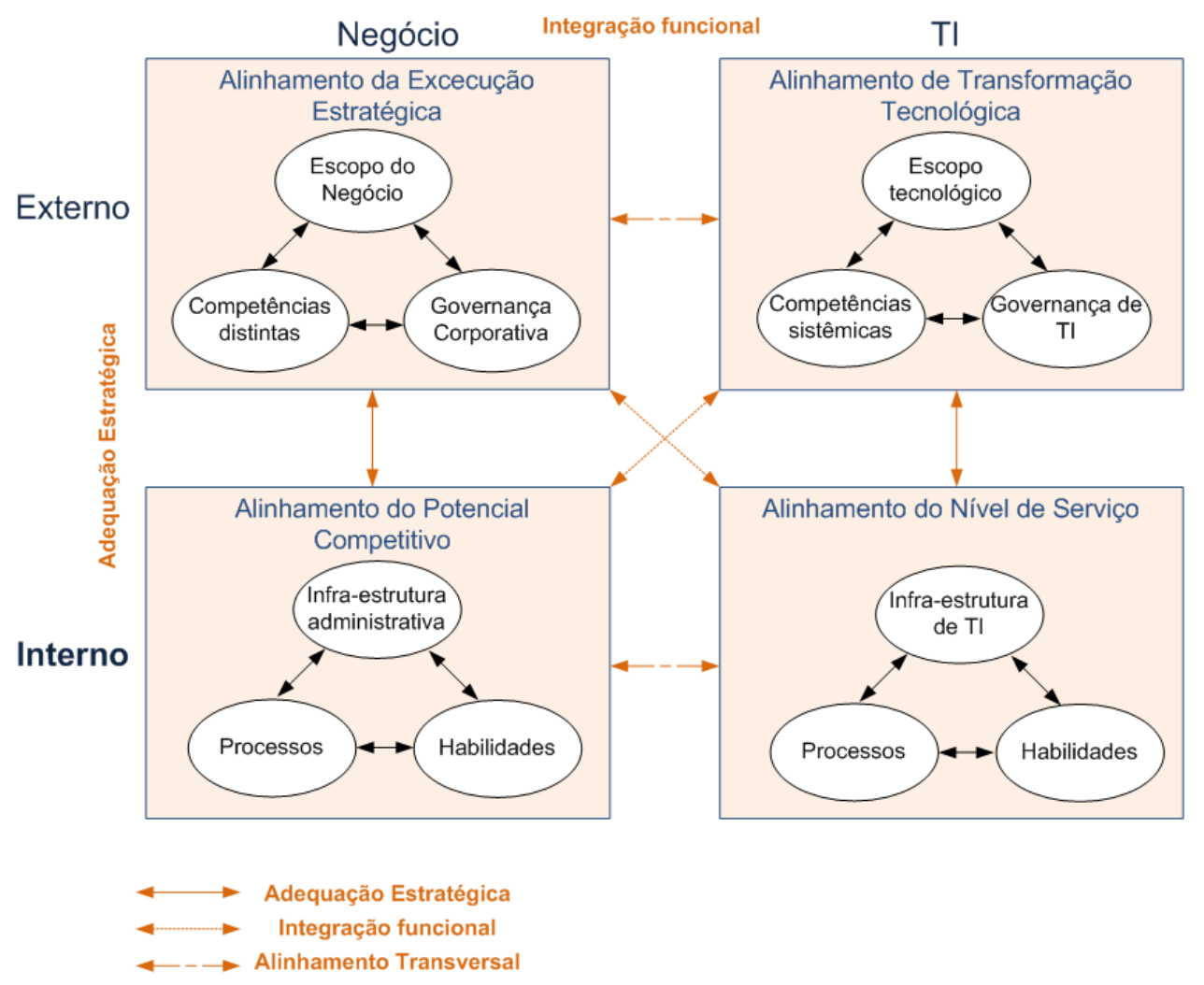

Figura 7 - Modelo de Alinhamento Estratégico (SAM)

Fonte: Henserson, J. C. e Venkatraman, N. (1990).

Conforme apresentado na Figura 7, o alinhamento é conquistado a partir da sintonia entre estratégia institucional e estratégia de TI, por conseguinte a mesma sintonia deve ser estabelecida com as infraestruturas, os processos e as habilidades. O Quadro 4 mostra detalhadamente o significado dos elementos da Figura 7. 
Quadro 4 - Compreensão do Modelo de Alinhamento

\begin{tabular}{|c|c|}
\hline \multicolumn{2}{|l|}{ ÁREAS } \\
\hline \multicolumn{2}{|c|}{ ESTRATÉGIA DO NEGÓCIO } \\
\hline Componentes & Descrição \\
\hline $\begin{array}{l}\text { 1. Escopo do } \\
\text { Negócio }\end{array}$ & $\begin{array}{l}\text { Inclui o mercado, produtos, serviços, grupos de clientes e locações em que uma } \\
\text { organização está inserida, bem como os competidores, fornecedores e potenciais } \\
\text { competidores que afetam a competitividade do ambiente de negócio. }\end{array}$ \\
\hline $\begin{array}{l}\text { 2. Competências } \\
\text { Distintas }\end{array}$ & $\begin{array}{l}\text { Os fatores críticos de sucesso e as competências principais que fornecem a uma empresa } \\
\text { potencial vantagem competitiva. Isso inclui a marca, pesquisa, produção e } \\
\text { desenvolvimento de produtos, estrutura de custos e de preços, vendas e os canais de } \\
\text { distribuição. }\end{array}$ \\
\hline $\begin{array}{l}\text { 3. Governança } \\
\text { Corporativa }\end{array}$ & $\begin{array}{l}\text { Como as empresas definem o relacionamento entre acionistas de gestão e do conselho de } \\
\text { administração. Também estão incluídos como a empresa é afetada por regulamentações } \\
\text { governamentais, e como a empresa gerencia suas relações e alianças com parceiros } \\
\text { estratégicos. }\end{array}$ \\
\hline \multicolumn{2}{|c|}{ INFRAESTRUTURA E PROCESSOS DA ORGANIZAÇÃO } \\
\hline $\begin{array}{l}\text { 4. Estrutura } \\
\text { Administrativa }\end{array}$ & $\begin{array}{l}\text { A forma como a empresa organiza seus negócios. Exemplos incluem centralização, } \\
\text { descentralização; matriz horizontal, vertical, geográfica, federal e funcional. }\end{array}$ \\
\hline 5. Processos & $\begin{array}{l}\text { Como as atividades de negócios da empresa (o trabalho realizado pelos funcionários) } \\
\text { operam ou fluxo. As principais questões incluem atividades de valor agregado e melhoria } \\
\text { de processos. }\end{array}$ \\
\hline 6. Habilidades & $\begin{array}{l}\text { Considerações dos Recursos Humanos, tais como a forma de contratação, demissão, } \\
\text { motivação, treinamento, educação e cultura. }\end{array}$ \\
\hline \multicolumn{2}{|c|}{ ESTRATÉGIA DE TI } \\
\hline $\begin{array}{l}\text { 7. Escopo da } \\
\text { Tecnologia }\end{array}$ & As aplicações e as $\mathrm{t}$ \\
\hline $\begin{array}{l}\text { 8. Competências } \\
\text { Sistêmicas }\end{array}$ & $\begin{array}{l}\text { Recursos (por exemplo, acesso à informação que é importante para a criação e realização } \\
\text { de estratégias de uma empresa) que distingue os serviços de TI. }\end{array}$ \\
\hline 9. GTI & $\begin{array}{l}\text { Como a autoridade de recursos, risco e responsabilidade são compartilhadas entre os } \\
\text { parceiros de negócios, gestão de TI e provedores de serviços. }\end{array}$ \\
\hline \multicolumn{2}{|c|}{ INFRAESTRUTURA E PROCESSOS DE TI } \\
\hline 10. Arquitetura & $\begin{array}{l}\text { As prioridades tecnológicas, políticas e escolhas que aplicativos, software, redes, } \\
\text { hardware e gerenciamento de dados a serem integrados a uma plataforma coesa. }\end{array}$ \\
\hline 11. Processos & Essas práticas e atividades realizadas para desenvolver e gerenciar a infraestrutura de TI. \\
\hline 12. Habilidades & $\begin{array}{l}\text { Considerações dos Recursos Humanos sobre a TI, tais como a forma de contratação, } \\
\text { demissão, motivação, treinamento, educação e cultura. }\end{array}$ \\
\hline
\end{tabular}

Fonte: Luftman, Papp e Brier (1999).

\subsubsection{Alinhamento por Negócio, Processos, TIC e Pessoas}

Conforme os autores Harmon (2007); Bio (1996); Pereira e Santos (2001); Rummler e Brache, (1998), para o entendimento sobre a complexidade organizacional, inicialmente, devem-se considerar a organização como um sistema. Assim, a organização é um sistema dinâmico que interage com outros sistemas externos e com seus subsistemas que podem ser unidades organizacionais, estações de serviços, entre outros. 
A Figura 8 mostra uma forma de compreensão da organização como um sistema, bem como revela o alinhamento organizacional por meio de quatro componentes organizacionais, as quais são: negócio, processos, TIC e pessoas. Na Figura 8 existem sobreposições entre esses componentes, destacando que nenhum é independente do outro.

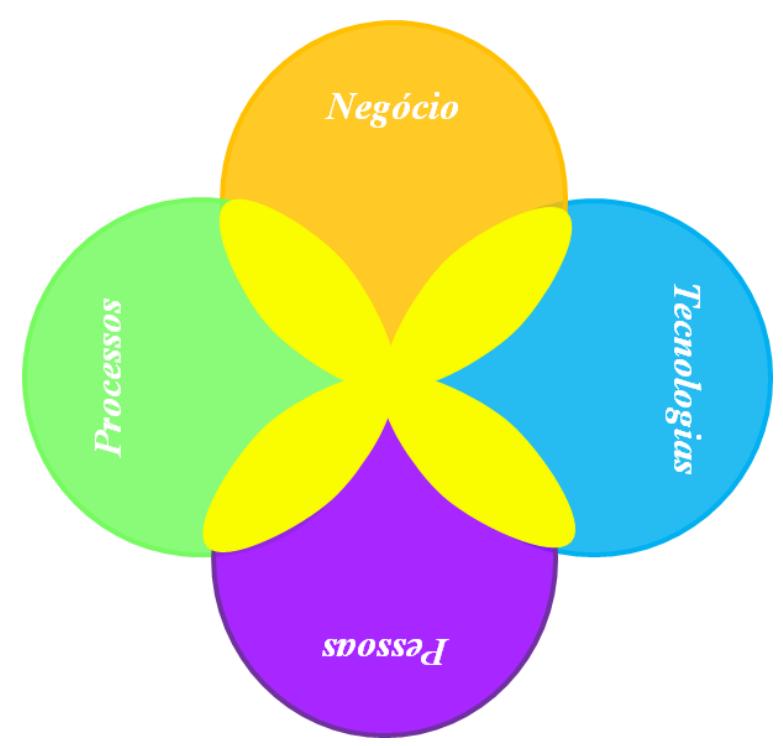

Figura 8 - Alinhamento entre negócio, processos, TIC e pessoas Fonte: Adaptado de Ramos (2009)

Os componentes são derivados dos níveis organizacionais de Harmon (2007), os quais são: nível empresarial, nível de processos e nível de implementação. O negócio representa o nível empresarial em que são apresentadas as estratégias, a GC e as demais governanças, as estruturas organizacionais e arquiteturas corporativas. Os processos representam o nível de processos, em que as variáveis devem representar o fluxo de processos e procedimentos. As tecnologia e as pessoas representam o nível de implementação. A tecnologia se refere às tecnologias da organização. Sobre a TI, considera-se nesta pesquisa a definição de Keen (1993), que envolve o processamento de dados, sistemas de informação, engenharia de software, informática ou o conjunto de hardware e software, e os aspectos humanos, administrativos e organizacionais. A Figura 8 inclui ainda a gestão, representada pela interseção entre os componentes. Tais componentes são à base da metogologia Business Process Management (BPM) sobre gestão de processos.

A Figura 9 mostra como ocorre o alinhamento entre os componentes citados anteriormente. Essa Figura é uma adaptação do modelo de Scheer (1998), sobre Business Process Management (BPM). 


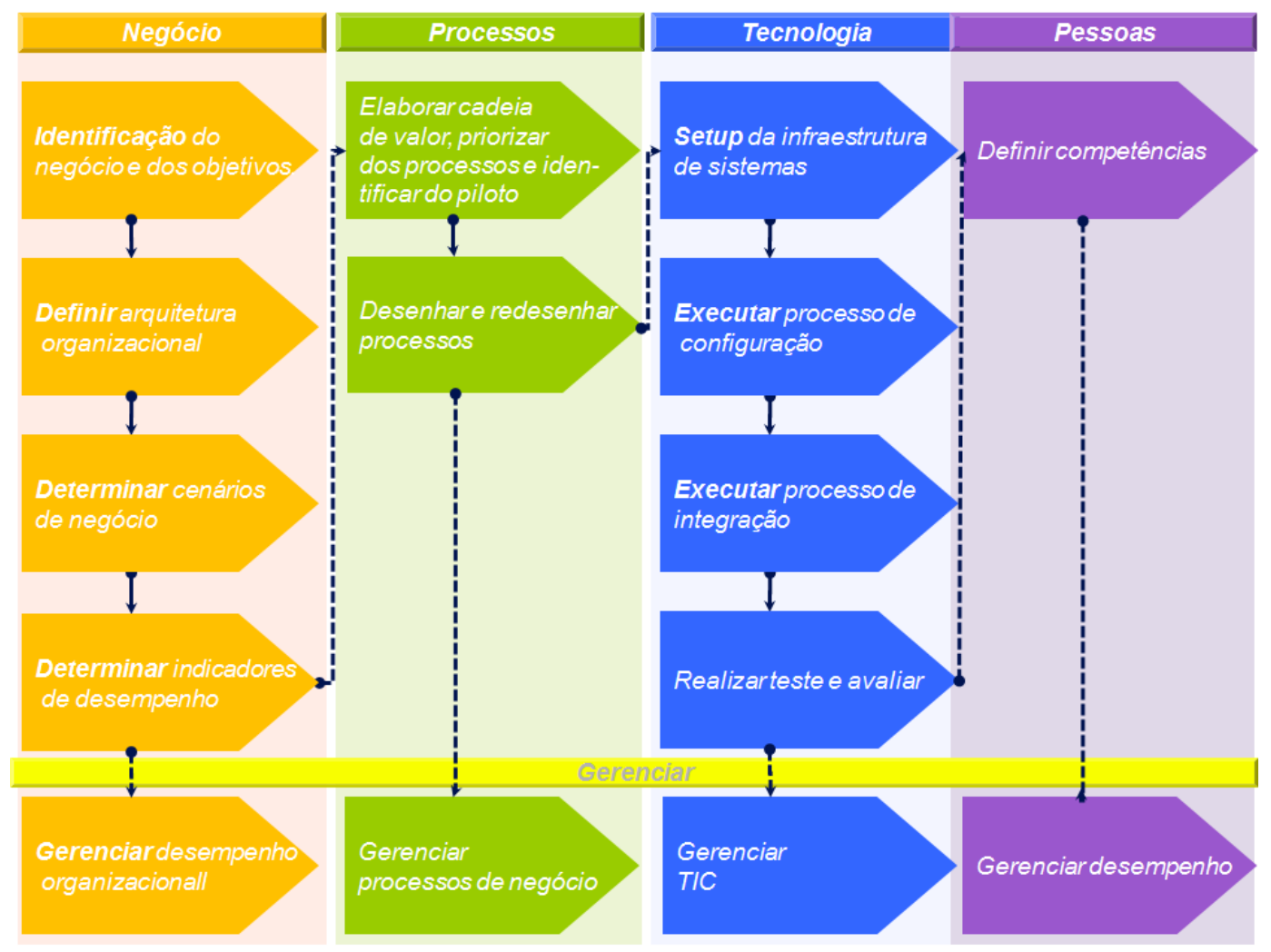

Figura 9 - Processos de BPM

Fonte: Adaptado de Scheer (1998)

Durante essa pesquisa, verificou-se que o esquema apresentado na Figura 9 é parcialmente utilizado por instituições públicas de alto desempenho em GTI. Além disso, nota-se a utilização da ferramenta Balanced Sorecard (BSC) como instrumento que permite o alinhamento do planejamento estratégico e orçamentário com a organização (DE SOUSA JR; FELIX; FELIX, 2001).

Conforme Benzi e De Sousa Jr (2008), a formalização de mecanismos de alinhamento entre TI e negócio na APF afasta conceitos relacionados a relacionamentos interpessoais e aproxima a gestão da racionalidade. Para esses autores, infere-se que a confiança em tais instrumentos proporciona resultados altamente desejáveis à gestão, desde que sejam controlados e medidos. Especificamente, para as organizações de TI, modelos para avaliação do nível de confiança em gestão de TI possibilitam maior eficácia no alinhamento da mesma com a estratégia organizacional (BENZI; DE SOUSA JR, 2008).

A compreensão do funcionamento dos quatro componentes auxilia na interpretação do SAM. O modelo do SAM considera os componentes de negócio e de TI, contudo internamente se busca o alinhamento entre os processos e entre as pessoas (Figura 10). 


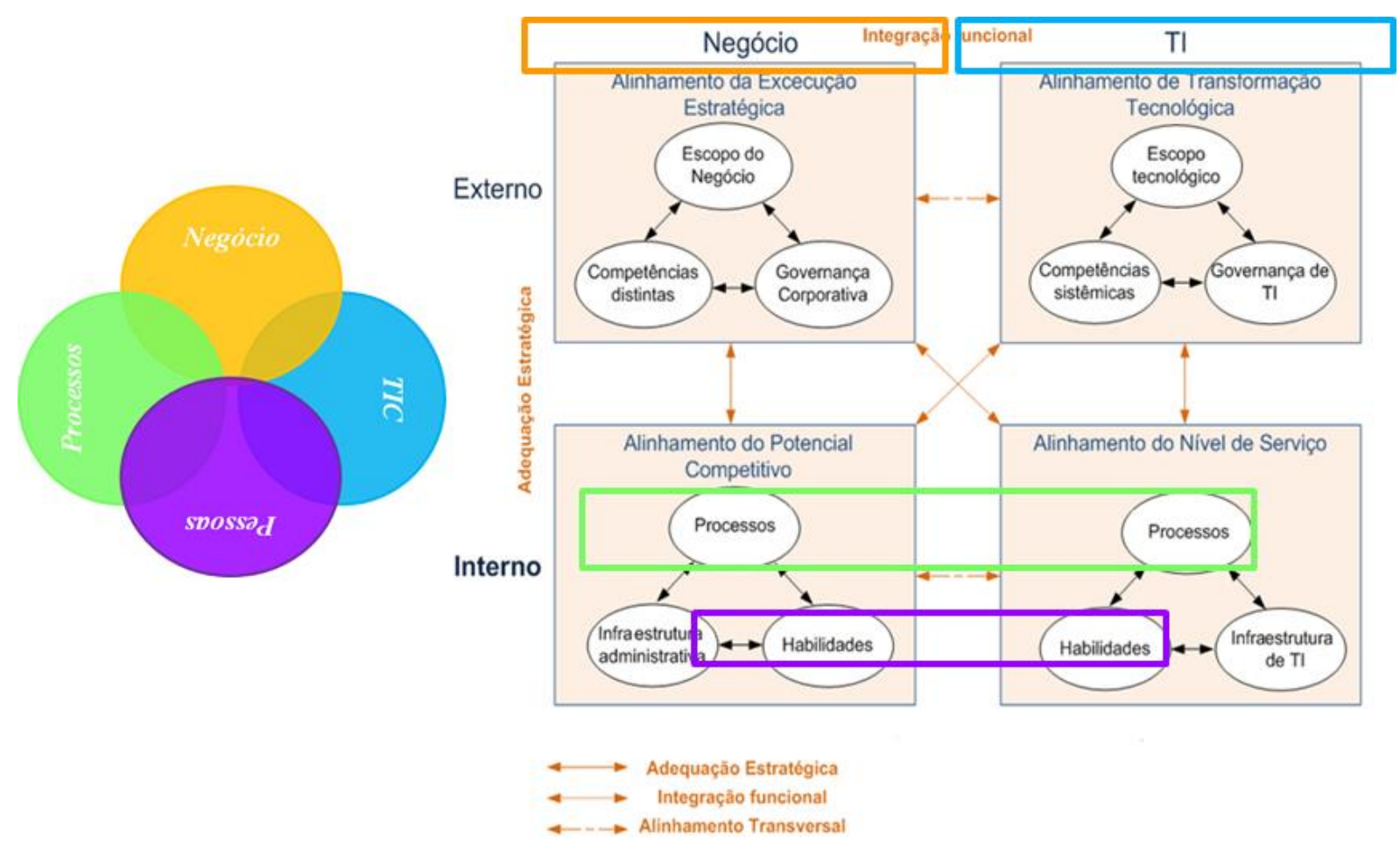

Figura 10 - SAM e o alinhamento entre negócios, processos, TIC e pessoas

Fonte: Desenvolvido pelo autor

\subsubsection{Governança de TI}

A GTI surgiu como uma tentativa de GC para certificar que os investimentos realizados em tecnologia estejam agregando valor aos negócios da organização (DE HAES; VAN GREMBERGEN, 2005, 2009).

Para o Information Technology Governance Institute (ITGI), a GTI é de responsabilidade do Conselho de Administração, sendo parte integrante da GC (ITGI, 2005). Segundo Van Grembergen (2004), a GTI deve assegurar o alinhamento da TI com a organização por meio da formulação e da implementação da estratégia de TI.

Embora a GTI esteja em evidência, muitos dos seus conceitos e definições continuam mal definidos (PETERSON, 2004; MCLANE, 2003, SANTOS; QUITAIROS; OLIVEIRA, 2012), mal compreendidos e empregados (MCLANE, 2003).

Artigos publicados sobre GTI, geralmente, discutem sua definição (KORACKAKABADSE; KAKABADSE, 2001), sua estrutura (VAN GREMBERGEN, 2004; WEILL, 2004; VERHOEF, 2007), suas práticas (HARDY, 2006; PETERSON, 2004), sua relação com 
a Lei Sarbanes-Oxley (HAWORTH; PIETRON, 2006) e seus potenciais benefícios (DE HAES; VAN GREMBERGEN, 2005, 2008).

Para Van Grembergen (2003), a GTI é a capacidade organizacional exercida pelo Conselho, Gerência Executiva e Gerência de TI para controlar a formulação e implementação da estratégia de TI e, com isso, assegurar o alinhamento da TI com o negócio.

Segundo Weill e Ross (2006, p. 2), a GTI é a especificação dos direitos decisórios e do framework de responsabilidades para estimular comportamentos desejáveis na utilização de TI. Reflete princípios amplos da GC, ao mesmo tempo em que se concentra na administração e utilização da TI para concretizar metas de desempenho corporativo.

Para Lunardi (2008), a GTI consiste no sistema responsável pela distribuição de responsabilidades e direitos sobre as decisões de TI, bem como pelo gerenciamento e controle dos recursos tecnológicos da organização, buscando, dessa forma, garantir o alinhamento da TI com as estratégias e objetivos organizacionais.

Outros autores focam a GTI para apoiar o processo decisório, por meio de domínio, de tomada de decisão e de níveis de escopo (LUFTMAN, 2003; SIMONSSON; EKSTEDT, 2006).

Do ponto de vista do domínio, devem-se identificar objetivos (incluem indicadores, metas, resultados, diretrizes e objetivos de controle), processos (abarcam gestão de processos de TI), pessoas (incluem organograma, artigos e responsabilidades de diferentes patrocinadores) e infraestrutura tecnológica (abrangem implantação e gestão dos sistemas e infraestruturas tecnológicas) necessária à consecução das metas e resultados de cada uma das fases de tomada de decisão (SIMONSSON; EKSTEDT, 2006).

A tomada de decisão envolve aspectos tangíveis e intangíveis na transformação de informação em conhecimento. Essa dimensão identifica as principais etapas no processo decisório, para estabelecer um programa de governança que apoie um plano de ação o qual desenvolva uma melhoria geral de indicadores de desempenho da Área de TI.

Os níveis de escopo preocupam-se com os diferentes impactos de cada decisão. Para isso, considera-se que existe um aspecto de curto e longo prazo associado a cada decisão. A dimensão é usada para diferenciar os diversos níveis de tomada de decisão da organização.

Finalizando a discussão sobre conceitos, um novo termo de GTI foi cunhado recentemente, governança corporativa de TI (GCTI) (do inglês, enterprise governance of information technology - EGIT). O objetivo dessa mudança de nomenclatura visa destacar a 
preocupação com a entrega de valor ao negócio e a gestão de riscos por meio da aplicação adequada da TI (DE HAES; VAN GREMBERGEN, 2013; BARTENS et al, 2014). Entretanto, tal foco em valor gerado pela TI para o negócio não é uma visão tão recente e pode ser encontrado nos trabalhos de ITGI (2005), Peterson (2004) e Hardy (2006).

Para este trabalho, o conceito de GTI a ser utilizado é o alinhamento da TI com o negócio que contribui para o melhor desempenho da organização, por meio do processo contínuo de decisões mais precisas, fundamentadas em informações confiáveis e necessárias, oriundas de uma gestão de TI eficaz e eficiente, alinhada e amparada pela GC.

De acordo com Luftman (2003), a GTI é um modelo operacional de como a organização tomará decisões sobre o uso da TI, atuando sobre os seguintes aspectos:

- alocação de recursos;

- avaliação de iniciativas e os riscos de negócios;

- priorização de projetos;

- medidas de desempenho e os mecanismos de rastreamento;

- determinação de custos e de alocação desses; e

- avaliação do valor de investimento de TI.

Estes aspectos se relacionam às atribuições da GTI, apresentadas na Figura 11. A atribuição de recursos é uma atribuição que revela o relacionamento entre GTI e gestão de TI.

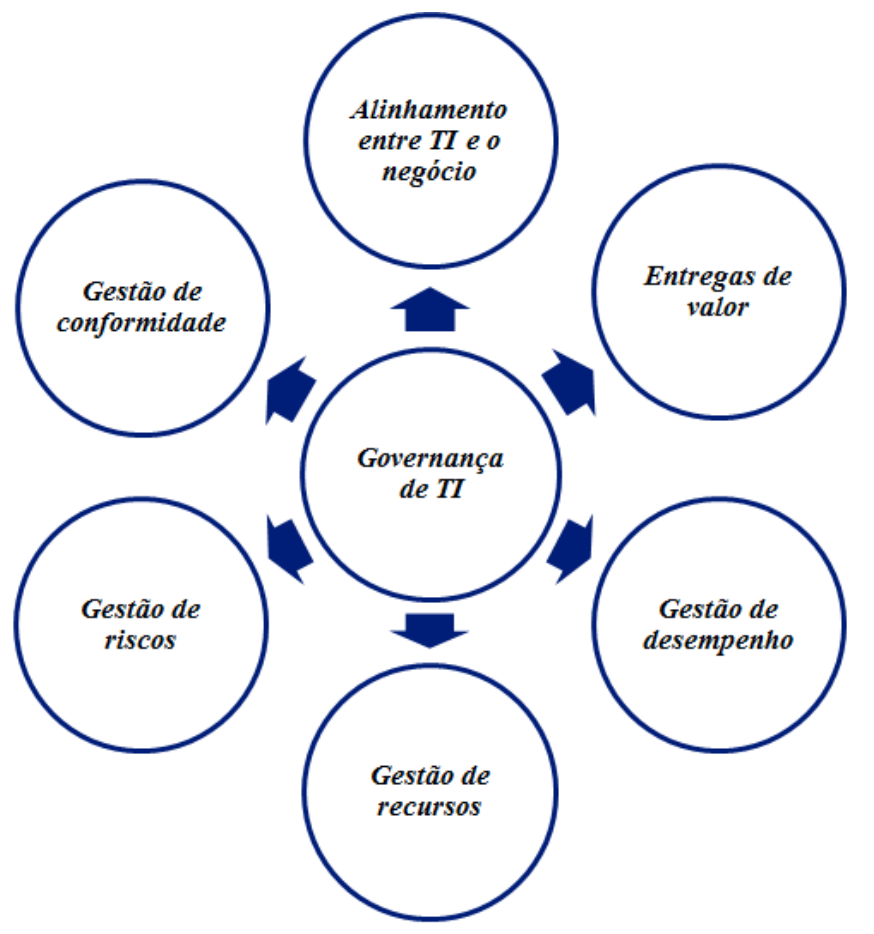

Figura 11 - Atribuições de GTI

Fonte: Desenvolvido pelo autor 
Segundo Van Grembergen (2004), a gestão de TI delibera sobre o fornecimento interno de insumos para a gestão de serviços e de produtos de TI. Weill e Ross (2006) delimitam tais insumos a assuntos relacionados a investimentos de TI, recursos humanos e contratações.

Para Weill (2004), as empresas com melhor desempenho conseguem obter valor por meio da GTI que apoia as suas estratégias e institucionaliza as boas práticas na organização.

\subsubsection{Governança Corporativa de TI Pública}

Segundo Barbosa (2008) as políticas públicas específicas de TI são denominadas GTI no setor público. Em países como Estados Unidos, Canadá e Reino Unido as práticas de GTI alinham-se à arquitetura corporativa $(\mathrm{AC})$ e às boas práticas de mercado para a gestão de TI, conforme preconizadas pelas estruturas de referência, como o COBIT $^{5}$ e ITIL $^{6}$ (RAMOS; DE SOUSA JR., 2014).

Entretanto, no caso do Brasil, os esforços para o atingimento da GTI no setor público, alinhadas à $\mathrm{AC}$ é algo distante de ser conquistado, ainda engatinhamos na compreensão do significado de GTI. Assim, retomando a essas definições, agora sob o enfoque da APF, a GTI visa:

[...] assegurar que as ações de TI estejam alinhadas com o negócio da organização, agregando-lhe valor. O desempenho da área de TI deve ser medido, os recursos, propriamente alocados e os riscos inerentes, mitigados.

Assim, é possível gerenciar e controlar as iniciativas de TI nas organizações para garantir o retorno de investimentos e a adoção de melhorias nos processos organizacionais. A governança adequada da área de tecnologia da informação na Administração Pública Federal (APF) promove a proteção a informações críticas e contribui para que essas organizações atinjam seus objetivos institucionais. (TCU ,2010a, p. 1, grifo nosso).

O Caderno Sumário do TCU (2010a, p. 8, grifo nosso) complementa que a responsabilidade pela GTI é dos executivos e da alta administração da instituição, sendo "perfeitamente cabível que os órgãos de controle externo [...] cobrem dos altos dirigentes a

\footnotetext{
${ }^{5}$ COBIT - Control Objectives for Information and Related Technology é um modelo publicado pelo ISACF (Information Systems Audit and Control Foundation) para difundir as boas práticas de gestão de recursos de TI. ${ }^{6}$ ITIL - IT Infrastructure Library é uma biblioteca de boas práticas, de domínio público, que busca promover a gestão com foco no cliente na qualidade dos serviços de tecnologia da informação (TI). A estrutura proposta pelo ITIL descreve estruturas de processos para a gestão de uma organização de TI apresentando um amplo conjunto de processos e procedimentos gerenciais organizados em disciplinas, com os quais uma organização pode fazer sua gestão tática e operacional para alcançar o alinhamento estratégico com os negócios.
} 
adequada governança dessa área tão crítica para a obtenção dos resultados institucionais". Contudo, tal como abordado anteriormente, a responsabilidade pela GTI cabe ao Conselho de Administração. Assim, ressaltamos que o Comitê de TI deve ser parcialmente distinto do corpo executivo da organização, a fim de mitigar os conflitos de interesse entre governança e gestão, assegurando a boa governança (Figura 12).

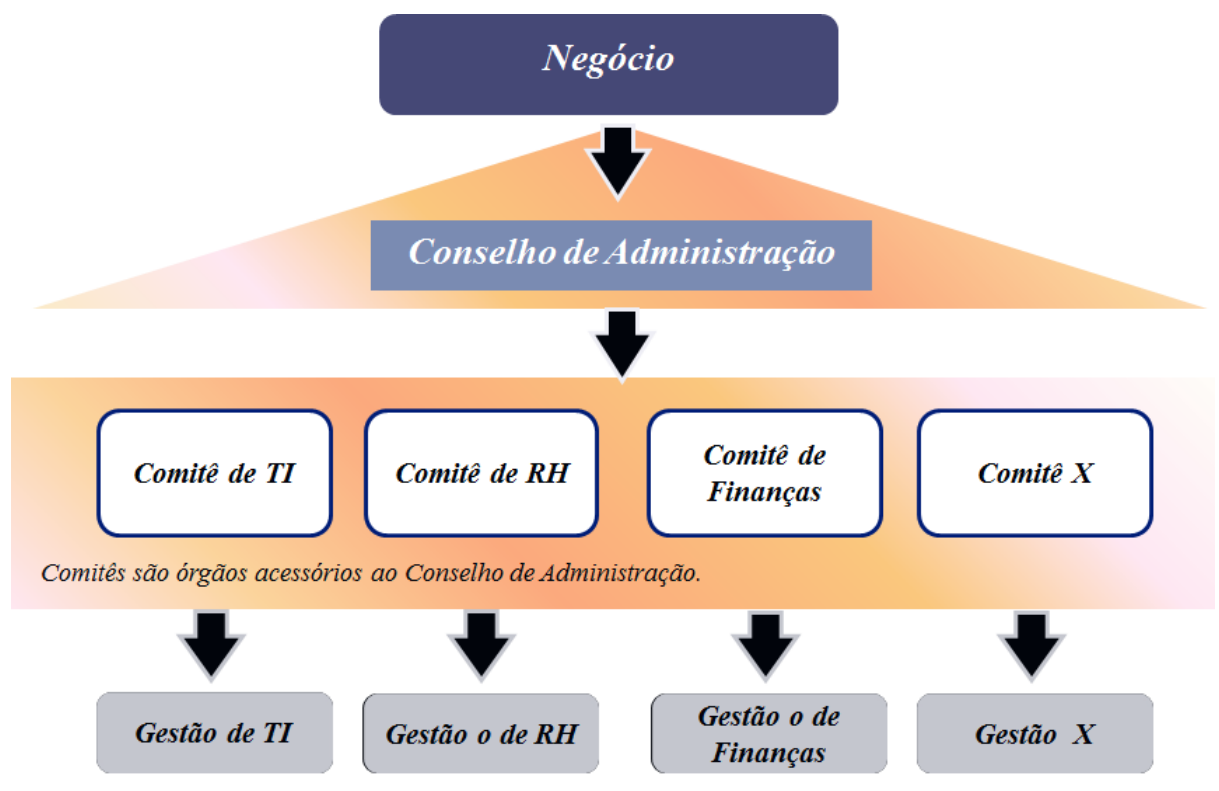

Figura 12 - Alinhamento governança e processos

Fonte: Desenvolvido pelo autor

Sobre as atribuições da GTI pública o TCU (2012c) cita as estratégias e as políticas de uso da TI dentro da instituição. Contudo, a governança deve auxiliar a gestão com a entrega das diretrizes para a formulação de estratégias e não com a execução da mesma. Ainda sobre as atribuições da GTI, o Acórdão 1233 (BRASIL, 2012a, p.11) destaca a gestão de contratos, tema crítico da GTI na APF, em que cabe a instituição pública possuir estrutura de GTI, "que direcione e controle a gestão desses contratos bem como a gestão de todos os processos de TI da organização".

Os conceitos do COBIT também contribuem para a lista de definições de GTI para a APF. A primeira versão utilizada do COBIT pelo TCU foi a 4.1. Atualmente, o COBIT está na versão 5 (ISACA, 2014) e com isso suas atualizações também refletem mudanças para o Levantamento de GTI da APF, por exemplo, segundo Brasil (2012c, p.5, grifo nosso):

COBIT, mantido pelo Instituto de Governança de TI, órgão ligado à Associação Internacional de Auditores de TI (Isaca). Na sua versão COBIT 5, lançada neste ano, destacam-se a maior distinção entre gestão e governança de TI e a integração da governança de TI na governança corporativa das instituições, 
ambas derivadas do lançamento da norma internacional ISO/IEC 38500:2008 (no Brasil, ABNT NBR ISO/IEC 38500:2009).

No entanto, é importante salientar que essa adoção do COBIT 5 nas organizações é amplamente descrita como desafiadora devido à alta complexidade percebida (BARTEN et al, 2014).

Apesar dos esforços do TCU em instruir a GTI para a APF, elementos básicos de governança ainda estão para serem conquistados nos órgãos avaliados, conforme os dados dos Relatórios de Levantamento dos anos 2010 e 2012 (TCU, 2010a, 2012c).

O primeiro Acordão do TCU sobre a saúde da GTI na APF, Acórdão n 1.603/2008, autorizado pelo Acórdão $n^{\circ}$ 435/2007-TCU-Plenário, identificou que o aumento dos gastos públicos com TI na administração pública e a quantidade crescente de denúncias e representações sobre aquisições nessa área, levaram, em agosto de 2006, à criação da Secretaria de Fiscalização da Tecnologia da Informação (Sefti). A Sefti tem por finalidade fiscalizar a gestão e o uso de recursos de TI pela AP e induzir melhorias na GTI.

O Quadro 5 mostra os problemas diagnosticados pela Sefti, desde o ano 2007 até o ano 2013. Nesse quadro, os problemas que mais se repetem ao longo dos anos são relacionados a falhas na segurança da informação, que em todos os anos de avaliação tiveram deficiências apontadas; falhas no planejamento estratégico institucional (PEI), falhas no planejamento estratégico de TI (PETI), diagnosticadas nos anos 2007 e 2013; falhas nos projetos básicos de contratações de TI, ressaltadas nos anos 2007 e 2012 e; falhas na análise de riscos de TI, citadas nos anos de 2007 e 2010. 
Quadro 5 - Diagnóstico da GTI pelos Levantamentos do TCU-Setfi

\begin{tabular}{|c|c|c|c|}
\hline Ano & Tema da pesquisa & Problemas diagnosticados & Acordão/Referências \\
\hline 2007 & $\begin{array}{l}1^{\circ} \text { Levantamento de } \\
\text { GTI realizado pelo TCU }\end{array}$ & 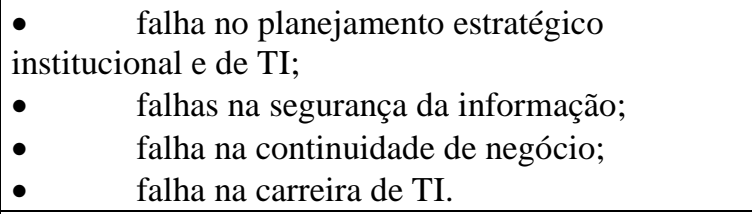 & $\begin{array}{c}\text { Acórdão } 1.603 / 2008- \\
\text { TCU-Plenário. (TCU, } \\
\text { 2008b) }\end{array}$ \\
\hline 2007 & $\begin{array}{l}\text { Fiscalização de } \\
\text { Orientação Centralizada } \\
\text { - Terceirização em TI }\end{array}$ & $\begin{array}{l} \\
\text { corporativos e de TI } \\
\bullet \quad \text { falha na análise de riscos de TI; } \\
\bullet \quad \text { inexistência de plano de continuidade do } \\
\text { negócio; } \\
\bullet \quad \text { falhas nos projetos básicos das contratações } \\
\text { de TI. }\end{array}$ & $\begin{array}{c}\text { Acórdão 2.471/2008 - } \\
\text { TCU Plenário. (TCU, } \\
\text { 2008c) }\end{array}$ \\
\hline 2010 & $\begin{array}{l}2^{\circ} \text { Levantamento de } \\
\text { GTI realizado pelo TCU }\end{array}$ & $\begin{array}{l}\text { • } \\
\text { falhas na gestão de ativos de informação; } \\
\text { da informação; } \\
\bullet \quad \text { falhas na gestão de riscos; } \\
\bullet \quad \text { falhas na gestão de continuidade do } \\
\text { negócio. }\end{array}$ & $\begin{array}{c}\text { Acórdão 2.308/2010- } \\
\text { TCU-Plenário (TCU, } \\
\text { 2010b) }\end{array}$ \\
\hline 2010 & $\begin{array}{l}\text { Fiscalização de } \\
\text { Orientação Centralizada } \\
\text { - Avaliação da gestão e } \\
\text { do uso da TI na APF. } \\
\text { Verificação da } \\
\text { conformidade da } \\
\text { situação declarada à } \\
\text { realidade da instituição } \\
\end{array}$ & $\begin{array}{l}\text { - em treze das catorze instituições auditadas, } \\
\text { verificou-se que a situação era pior do que a } \\
\text { declarada; } \\
\text { - } \quad \text { somente uma instituição estava em situação } \\
\text { melhor do que a declarada. }\end{array}$ & $\begin{array}{c}\text { Acórdão 1.233/2012- } \\
\text { TCU-Plenário. (TCU, } \\
\text { 2012a) }\end{array}$ \\
\hline 2012 & $\begin{array}{l}3^{\circ} \text { Levantamento de } \\
\text { GTI realizado pelo TCU }\end{array}$ & $\begin{array}{l}\text { - falhas no estabelecimento de metas e no } \\
\text { acompanhamento dos resultados de TI; } \\
\text { • } \quad \text { falhas em processos de segurança da } \\
\text { informação; } \\
\text { - } \quad \text { falhas no planejamento e na gestão de } \\
\text { contratos de TI; } \\
\qquad \quad \text { falhas na gestão de serviços de TI. } \\
\end{array}$ & $\begin{array}{c}\text { Acórdão 2.585/2012- } \\
\text { TCU-Plenário. (TCU, } \\
\text { 2012b) }\end{array}$ \\
\hline 2013 & $\begin{array}{l}\text { Nova Fiscalização de } \\
\text { Orientação Centralizada } \\
\text { com foco em resultados } \\
\text { e riscos de TI }\end{array}$ & $\begin{array}{l}\text { - falta de um processo formal de } \\
\text { planejamento estratégico de TI; } \\
\text { - } \quad \text { falta de avaliação quantitativa ou } \\
\text { qualitativa dos seus recursos humanos de TI; } \\
\text { • falta de recursos humanos de TI são } \\
\text { insuficientes frente à necessidade de negócio; } \\
\text { - falhas em processos relacionados à } \\
\text { segurança da informação. }\end{array}$ & $\begin{array}{l}\text { Acórdão 3117/2014 - } \\
\text { TCU - Plenário. } \\
\text { (TCU, 2013b) }\end{array}$ \\
\hline
\end{tabular}

Além dessas falhas, Pacheco (2011) afirma que 87\% dos indicadores de benefícios dos principais sistemas de informação não são acompanhados, $71 \%$ dos gestores não avaliam regularmente o desempenho da TI, 76\% desses gestores não definem indicadores de desempenho e $57 \%$ não definem objetivos de desempenho. 


\subsection{ARQUITETURA CORPORATIVA}

O significado básico de arquitetura significa regularidade e extensibilidade de um conjunto de instruções, bem como o manuseamento em geral e simples de um sistema (PEUTO, 1979). Para o IEEE 42010-2011 arquitetura é definida como a organização fundamental de um sistema incorporado em seus componentes, suas relações uns com os outros e com o meio ambiente e os princípios que norteiam a sua concepção e evolução.

Nos últimos anos, a arquitetura surgiu como um forte tema no mundo da TI. Assim, as arquiteturas de TI ou arquiteturas de sistemas de informação e tal como a definição anterior, também se concentram no sistema. Quando se trata de sistema, é válido lembrar, que esse é um conjunto de elementos interdependentes, ou um todo organizado, ou partes que interagem formando um todo unitário e complexo. No entanto, é preciso distinguir os sistemas fechados que não interagem com o ambiente, por exemplo, computadores, dos sistemas abertos que interagem com o ambiente, por exemplo, empresas (BIO, 1996; GHARAJEDAGUI, 2006).

O conceito de sistemas no contexto organizacional denota que organização é um grande sistema aberto e dinâmico que interage plenamente com outros sistemas externos e com seus subsistemas que podem ser os departamentos, as seções, as células, os componentes e assim por diante (BIO, 1996; GHARAJEDAGUI, 2006; HARMON, 2007; PEREIRA; SANTOS, 2001; RUMMLER; BRACHE, 1994).

\subsubsection{Arquitetura Corporativa}

Nos anos de 1980, a primeira Arquitetura Corporativa (AC), foi denominada de arquitetura de sistemas de informação, The Zachman Framework (ZACHMAN, 1996; YLIMÄKI, 2006). The Zachman Framework é uma referência estrutural para o desenvolvimento da TI em uma organização. Este framework identifica descrições distintas para modelagem de soluções de tecnologia conforme as seguintes dimensões: dados, função, rede, pessoas e tempo (LAM, 2005).

Esse framework se apresenta como uma estrutura lógica para a classificação e organização das representações descritivas de uma organização, que são significativas para a gestão da organização, bem como para o desenvolvimento de sistemas (RAMOS, 2009). 
Desde então, a AC tem sido utilizada como uma das principais ferramentas de controle para o alinhamento entre a visão de negócios, os requisitos de negócios e os sistemas de informação (YLIMÄKI, 2006). A AC permite a identificação das partes focais da organização (pessoas, processos de negócios, TI e sistemas de informação), bem como os meios que identificam como essas partes colaboraram para alcançar os objetivos de negócio (HOOGERVORST, 2004; YLIMÄKI, 2006).

O desenvolvimento de um framework de arquitetura é importante para alinhar a TI com os processos de negócio e objetivos organizacionais, permitindo a gestão e a integração entre as várias dimensões inter-relacionadas da empresa (CALDEIRA; DHILLON, 2010).

A AC é um conceito em desenvolvimento, existindo várias concepções e definições (ROSS; SUBRAMANI, 2002; SCHEKKERMAN, 2004;). Segundo Janssen et al (2011, p. 25):

[...] a AC que se refere a um modelo descrito em um determinado nível de abstração. Outra maneira de olhar para a AC é como um meio de informar, orientar, direcionar e condicionar as decisões tomadas por seres humanos dentro das organizações. A AC pode melhorar a interoperabilidade, mas também pode contribuir para outros objetivos, ao mesmo tempo. A visão subjacente à AC, é que ele dará dicas sobre as oportunidades e as limitações previstas pelas visões de TIC e podem servir como um veículo para o desenvolvimento.

Para Janssen e Hjort-Madsen (2007), a AC pode ser definida como o sistema dos sistemas, o plano mestre que detalha as políticas e os padrões para os projetos de infraestrutura, tecnologias, banco de dados e aplicações. O objetivo da palavra arquitetura é sinalizar para a criação de um conjunto coerente e estruturado em ambientes caóticos, já a palavra corporativa se refere ao escopo da arquitetura que se estende à organização como um todo.

Assim, a AC mostra como funciona a organização do ponto de vista estratégico, facilitando a troca de informações entre os gestores e técnicos de negócio e TI. Cada organização deverá ter uma arquitetura única, que será construída e atualizada ao longo do tempo.

Segundo pesquisa de Foorthuis et al. (2010), os benefícios no uso da AC são:

- gerenciamento para atingir os objetivos de negócios;

- gerenciamento da complexidade organizacional;

- facilitar a integração, normalização e deduplicação de processos e sistemas;

- permitir a empresa lidar com o seu ambiente de forma eficaz;

- permitir uma comunicação eficaz entre os membros da organização;

- reduzir os custos do projeto e da duração do projeto; 
- reduzir o risco e aumentar o sucesso de um projeto.

A respeito do gerenciamento para atingir os objetivos de negócios, a AC pode fornecer a visão holística da empresa para equilibrar os diferentes interesses e soluções (LANKHORST et al., 2005). Graças à visão holística e de multicamadas, tal arquitetura é um instrumento de alinhamento entre TI e os processos de negócio (LANKHORST et al., 2005, GREGOR; JONES, 2007).

O gerenciamento da complexidade organizacional pode fornecer respostas sobre problemas complexos. A visão pode ser adquirida por meio de diferentes áreas, tais como: negócios, informação, sistemas e infraestrutura de informações (VAN DER RAADT et al., 2004). Essa complexidade pode ser gerenciada por uma abordagem modular, distinguindo as partes de um sistema, seus relacionamentos e linguagens de modelagem (LANKHORST et al. 2005). Além disso, a aplicação normalizada e processos automatizados resultam em ambientes de tecnologia menos complexos (ROSS et al. 2002).

A respeito da integração, normalização e deduplicação de processos e sistemas, a AC fornece informações sobre os processos da organização e sistemas de negócios, permitindo que a empresa identifique os processos que possam ser integrados.

A AC contribui para que os processos de negócios e sistemas sejam altamente interdependentes. Logo, a agilidade de reação da empresa ao mundo exterior pode ser melhorada, por meio da automatização dos processos de negócio. Isto resulta não só em mais recursos, mas também em informações valiosas, que podem ser utilizados em atividades inovadoras (ROSS et al. 2002) .

A AC oferece uma visão consistente e coerente dos aspectos fundamentais da organização e da situação futura desejada, permitindo uma comunicação eficaz entre os membros da organização. Para isso, inclui a definição e os conceitos que inter-relacionam modelos. Portanto, fornece aos membros da organização um quadro de referência para a comunicação eficaz.

A AC possibilita o controle dos projetos para que poupem recursos e tempo, desde o negócio até a informação, as aplicações e a tecnologia. Um projeto pode se concentrar rapidamente em projetar e desenvolver os detalhes da solução, já que a AC apresenta um panorama geral da organização.

A redução do risco do projeto e sucesso do projeto aumenta. Embora as publicações tendam a discutir assuntos apenas superficialmente, a arquitetura facilita na identificação e mitigação dos riscos do projeto. 
Segundo Boh e Yellin (2007), outro fator a destacar sobre AC são seus padrões. Os padrões especificam a organização lógica de infraestrutura de TI, os dados, de informação da empresa e os aplicativos que suportam os processos de negócio. Esses fornecem princípios para orientar a tomada de decisões relacionadas à aquisição, implantação e gerenciamento de recursos de TI. Por isso, seu forte vínculo com a GTI.

Boh e Yellin (2007) dividem em quatro dimensões para categorizar os padrões: $i$ ) gestão de infraestrutura de TI, ii) gestão de infraestrutura humana de TI, iii) integração de aplicação de negócios, iv) integração de dados empresariais.

A gestão de infraestrutura de TI padroniza as tecnologias para o negócio, como computadores, redes, roteadores, servidores, periféricos, sistemas operacionais, sistemas de gerenciamento de dados, serviços de sistemas, entre outros utilizados como plataforma para a construção de sistemas aplicados à organização (DE SOUSA JR, 1995).

A gestão de infraestrutura humana de TI se refere à gestão de pessoas da TI, incluindo a gestão de competências (conhecimentos, habilidades e atitudes).

A integração das aplicações de negócio define as direções estratégicas para gestão do portfólio de aplicação e de tecnologias para aplicações de integração.

A integração de dados da empresa são os elementos de dados críticos e de bancos de dados que integram a gestão e fornece a definição dos elementos de dados para cada foco.

Boh e Yellin (2007) citam que os mecanismos de AC se integram à GTI por meio de mecanismos de GTI horizontais. Os mecanismos são baseados em: definir os papéis fundamentais da arquitetura, institucionalizar mecanismos para o envolvimento das principais partes interessadas, institucionalizar o monitoramento dos processos de padrão de $\mathrm{AC}$, centralização das decisões de TI (PETERSON, 2004).

\subsubsection{Governança da Arquitetura Corporativa}

Recentemente, aspectos de governança recebem cada vez mais atenção, sendo considerados como cortesias aos esforços da $\mathrm{AC}$ ou considerados como parte da $\mathrm{AC}$ (JANSSEN et al, 2011).

A Governança da Arquitetura (do inglês governance architecture) (KLISCHEWSKI, 2011) ou Governança da AC (do inglês governance enterprise architecture) (MARKUS; BUI, 2012; KLISCHEWSKI, 2011) aborda como a arquitetura é utilizada para atribuir 
responsabilidades, introduzir estruturas de tomada de decisão e garantir à organização de TI que os mecanismos de governança determinem a formalização da comunicação, das responsabilidades e das estruturas de tomada de decisão (YADAV; YADAV, 2009). Dessa forma fica claro saber quem é responsável pela manutenção da arquitetura, quais projetos precisarão dela, quais são os procedimentos de desvio da AC e assim por diante (JANSSEN et al, 2011).

Para Markus e Bui (2012), a Governança da AC inclui um conjunto de modelos de domínio que descrevem o sistema de governança global, como um framework para a arquitetura de governo eletrônico (LIM; TANG, 2008) ou como um framework que fornece uma arquitetura de referência para interoperação interorganizacional (ELMIR; BOUNABAT, 2012; KLISCHEWSKI, 2011).

Ademais, quando a governança faz parte da AC, a estratégia da organização se beneficia e é beneficiada. Haja vista, a estratégia organizacional fornece insumos para a arquitetura. Como um instrumento da governança, a AC é destinada a facilitar a transição da estratégia para as operações diárias (FOORTHUIS et al, 2012). As saídas que a governança de AC oferece são: vistas, prescrições, insights sobre contexto e o significado de um sistema, além dos componentes fundamentais de uma organização e suas relações (FOORTHUIS et al, 2012).

\subsubsection{Arquitetura Corporativa Pública}

Na década de 1980 o New Public Management (NPM) associou doutrinas de boas práticas organizacionais à administração pública. O NPM apresentou iniciativas para reimpor a ordem na área de TI, especialmente às administrações Canadenses e Estadunidenses (PAPAZOGLOU; HEUVEL, 2007; PERISTERAS; TARABANIS, 2000).

Esse movimento global de incorporar essas novas mudanças se move em direção a "governança da era digital", que envolve funções de reintegração na esfera governamental, adotando visão holística, estruturas orientadas e melhorias na digitalização de processos administrativos (PAPAZOGLOU; HEUVEL, 2007). Ainda na década de 1990, a administração pública tem sido confrontada com uma série de novas exigências (BECKER et al., 2006), tais como padronização, reorganização, modernização e reinvenção do governo e sobreposição na função e conteúdo. Essas exigências são consequências de aplicações 
informáticas altamente fragmentadas e não relacionadas que resultaram em um grande problema de interoperabilidade (DUNLEAVY et al., 2006), onde o serviço público não estão integrados (JANSSEN; CRESSWELL, 2005) e os sistemas são isolados (PERISTERAS; TARABANIS, 2000). Tais fatos mostram a interoperabilidade como a questão mais crítica que os governos enfrentariam (JANSSEN et al, 2011). Interoperabilidade lidera com dificuldades semânticas, desafios técnicos e organizacionais (TRIPATHI et al, 2012).

Também iniciativas de governo eletrônico (do inglês e-Government), conhecido também como e-governo ou e-Gov, foram creditadas como peça fundamental da reforma governamental (LIM; TANG, 2008). Alguns comentários dizem que a discussão da modernização da administração pública e do e-Gov é muitas vezes limitada à prestação de serviços on-line e a portais de internet da administração pública (BECKER et al., 2006) ou que essa modernização precisa ser mais baseada no conhecimento, centrada no usuário e distribuída em rede (PANKOWSKA, 2008).

Nesse interim, Janssen et al (2011) justifica a AC na administração pública, justamente pela sua característica integrativa, uma vez que nos governos são usados aplicativos de software fragmentados heterogêneos e independentes. Além disso, os bancos de dados são desenvolvidos de forma isolada, desconsiderado a integração e a interoperabilidade entre os dados. Consequentemente, as tomadas de decisão dos governos são independentes e não consideram as relações sistêmicas do governo.

Apesar de AC ser uma ferramenta para garantir o alinhamento de negócios e de TI, existem conformidades desafiadoras, como sistematizar, identificar e descrever os elementos de design sobre o processo e da camada de sistema de integração inter-organizacional (VOGEL et al., 2008). Além disso, sem treinamento, os membros da organização podem não entender a AC, a aplicabilidade da AC, ou contribuições da AC para a organização (HAZEN et al., 2014).

A AC na administração pública tem sido um campo pouco explorado sem definição do termo e estudos empíricos suficientes. É um problema análogo devido à sua relevância em todos os governos ao redor do mundo (nesta pesquisa foram identificados 33 modelos governamentais de diversos países que foram descritos em periódicos relevantes).

Para Janssen e Madsen (2007), e Iyamu e Mphahlele (2014), a AC possui várias definições. Além disso, existem expressões sinônimas, tais como IS Architecture ou Information System Architecture em Caldeira e Dhillon (2010), que faz alusão ao The 
Zachman Framework; Government Enterprise Architecture em Elmir e Bounabat (2012); Government Architecture em Pankowska (2008), Klischewski (2011) e Janssen et al (2011).

Algumas das definições se concentram em atividades corporativas e outros no âmbito técnico. Para Iyamu e Mphahlele (2014), uma boa definição de AC fornece às organizações a capacidade de identificar e fazer alterações necessárias, proporcionando estabilidade e flexibilidade na organização.

Definição comum de AC é basicamente extraída de livros ou de artigos indexados. O livro mais citado é How to survive in the jungle of Enterprise Architecture frameworks: Creating or choosing an Enterprise Architecture framework de Schekkerman (2004). Para o autor, a AC é um programa apoiado por um quadro e uma abordagem, que é capaz de coordenar as várias facetas que criam a essência fundamental de uma empresa de uma forma holística, ou seja, a AC visa comunicar os elementos essenciais que explicam o funcionamento de uma organização, permitindo aos gestores uma ideia clara dos pontos que devem ser tratados para atingir as metas desejadas, explorando continuamente como a TI apoia e melhora a aprendizagem organizacional e a incorporação permanente de conhecimento, auxiliando os gestores na tomada de decisão.

Segundo Dunleavy et al (2006), Iyamu e Mphahlele (2014), AC serve para a compreensão da estrutura de elementos de TI e como ela está relacionada com os processos de negócio e de gestão, promovendo uma organização para alinhar seus sistemas de informação com os seus objetivos de negócio. Esse alinhamento pode ser alcançado por meio da organização lógica de processo de negócio e das capacidades de TI refletindo sobre requisitos de normalização e integração (BIDAN et al., 2012), que engloba a interconexão das aplicações dos sistemas de informação (LAM, 2005) do modelo operacional da empresa.

Hoje em dia as organizações estão cada vez mais usando AC para alinhar a TI com os processos e objetivos da organização de negócios (DUNLEAVY et al., 2006). Este alinhamento é muitas vezes realizado por documentar, visualizar e analisar as relações entre os sistemas e as necessidades organizacionais (LAM, 2005).

Outra missão AC para as organizações de TI é a de garantir a AC como uma plataforma comum que facilita a integração de suas subunidades internas de TI. Com uma AC comum, os processos podem ser integrados e, assim, fomentar o movimento eficiente de atividades ao longo do processo de desenvolvimento de software (DHALIWAL; ONITA, 2011). Há também pesquisas em curso nesta área para desenvolver extensões de modelagem e mecanismos de atendimento de consulta para acomodar a necessidade de gerenciar os 
metadados relacionados com a qualidade, como métricas de qualidade, privacidade, segurança e linhagem de dados (DUNLEAVY et al., 2006).

A justificativa para esta definição é ampla cobertura dos aspectos empresariais, como a visão holística, que abrange uma ampla gama do espectro de informações, negócios e técnicas para a gestão. Além disso, a gestão de AC se destina a apoiar e coordenar a transformação da empresa (IYAMU; MPHAHLELE, 2014).

Dentro âmbito do governo, a AC poderia ser designada como AC de Governo (do inglês Government Enterprise Architecture - GEA) (PERISTERAS et al, 2008;. ELMIR; BOUNABAT, 2012; JANSSEN et al, 2011) ou Arquitetura de Governo (do inglês Government Architecture - GA) (JANSSEN et al, 2011) para se referir a o escopo de governo. Genericamente, uma GA é a descrição conceitual do conjunto de elementos e as relações entre eles que visam criar um conjunto coerente e consistente de relações entre (sub) sistemas (JANSSEN et al, 2011). Esse pode suportar uma ampla gama de objetivos e, normalmente, vai além do aspecto interoperabilidade (LAM, 2005; JANSSEN et al, 2011). Basicamente, GA é a visão da empresa como um todo e traz possíveis futuros estados, ligando a estratégia e as políticas com tecnologia e operações, orientando a criação de novas TIC (projeto como, por exemplo, a criação de um artefato). Ao mesmo tempo, serve como um quadro para o posicionamento do projeto projetos dentro de um quadro maior (JANSSEN et al, 2011).

\subsubsection{Meta Arquitetura Corporativa de TI}

A AC pode ser decomposta em arquiteturas menores a fim de que se obtenha alinhamento entre componentes arquiteturais. Para isso, considera-se verificar os subsistemas essenciais de área. Especificamente para esta pesquisa, será abordada a AC da área de TI, uma vez que seus conceitos e disposições de tema auxiliam na compreensão da GTI.

A área de TI possui ainda três subsistemas coesos denominados: Direcionamento, Desenvolvimento e Entrega. Tais subsistemas de TI interagem entre si, permitindo o alinhamento da TI com o Negócio (Figura 13) (BETZ, 2007). 


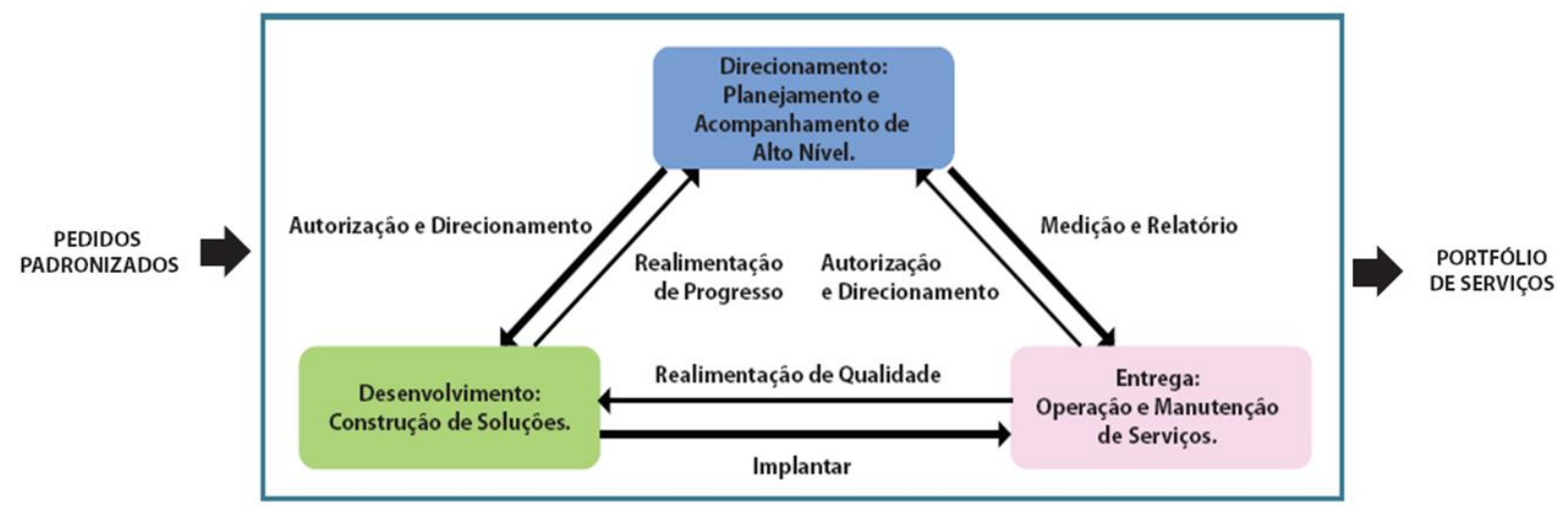

Figura 13 - Funcionalidades Fundamentais de TI Fonte: Betz (2007)

O Direcionamento cuida da estratégia geral da Área de TI e de sua arquitetura, tendo a função de planejar e exercer um controle de alto nível, acompanhar o atendimento das demandas, definir prioridades no portfólio de serviços e produtos a serem desenvolvidos ou entregues pelos outros subsistemas, conforme apresentado na Figura 13.

O Desenvolvimento tem a função de conceber e construir soluções, tipicamente com auxílio dos processos de gerenciamento de projetos, garantindo a qualidade e o gerenciamento de configuração a fim de mitigar os riscos do subsistema de desenvolvimento.

A Entrega executa a implantação dos projetos desenvolvidos e administra o catálogo de serviços, gerenciando todos os sistemas de informação, suporte e equipamentos em operação, bem como os programas de manutenção que suportam esses sistemas e equipamentos, por exemplo, a operação de centros de armazenamento de dados, suporte ao usuário (help desk), serviço de e-mail, entre outros.

Para cada um dos subsistemas de TI pode-se aplicar as camadas de AC. O objetivo dessa aplicação é proporcionar o alinhamento da TI com ela mesma e também com o negócio. Assim, o subsistema de Direcionamento é dividido nos níveis organizacional, processos e implementação, o mesmo ocorre com os dois outros subsistemas, conforme apresentado na Figura 14. 


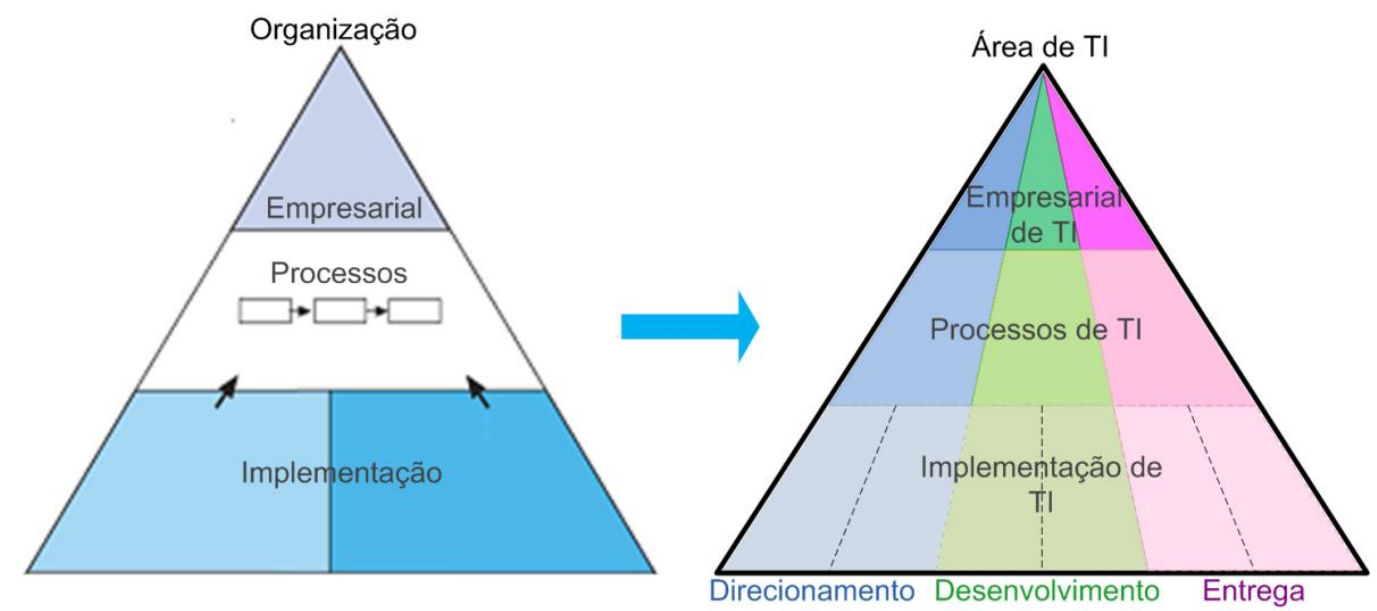

Figura 14 - Área de TI Decomposta em Competências Essenciais

Fonte: Ramos (2009, p.82)

Assim, para a compreensão do funcionamento de uma área de TI dá-se ênfase no alinhamento interno dos subsistemas de TI que incorporam as competências essenciais ou funcionalidades, considerando dois aspectos: $i$ ) inclusão dos níveis de desempenho em cada uma das competências essenciais de TI (Direcionamento, Desenvolvimento e Entrega); e ii) identificação dos padrões de entradas e saídas que caracterizam os serviços prestados pela área de TI.

Redimensionando a pirâmide da área de TI da Figura 14, tem-se a Figura 15 que ilustra a entrada e a saída da área de TI. A entrada é representada por um conjunto definido de pedidos padronizados, originados a partir de demandas do negócio e tem como saída um portfólio de serviços. Essas demandas podem ser identificadas e organizadas em quatro tipos de pedidos padronizados: exploração de ideias, projetos, serviços e relato de incidentes. Essas demandas podem ser endógenas, ou seja, da própria área de TI, ou exógenas, externas à área de TI. O portfólio de serviços é usado para gerenciar o ciclo de vida de todos os serviços e inclui serviços em espera (propostos ou em desenvolvimento), catálogo de serviços e serviços descontinuados. A representação da organização de TI é denominada de Meta Arquitetura Corporativa de TI. 


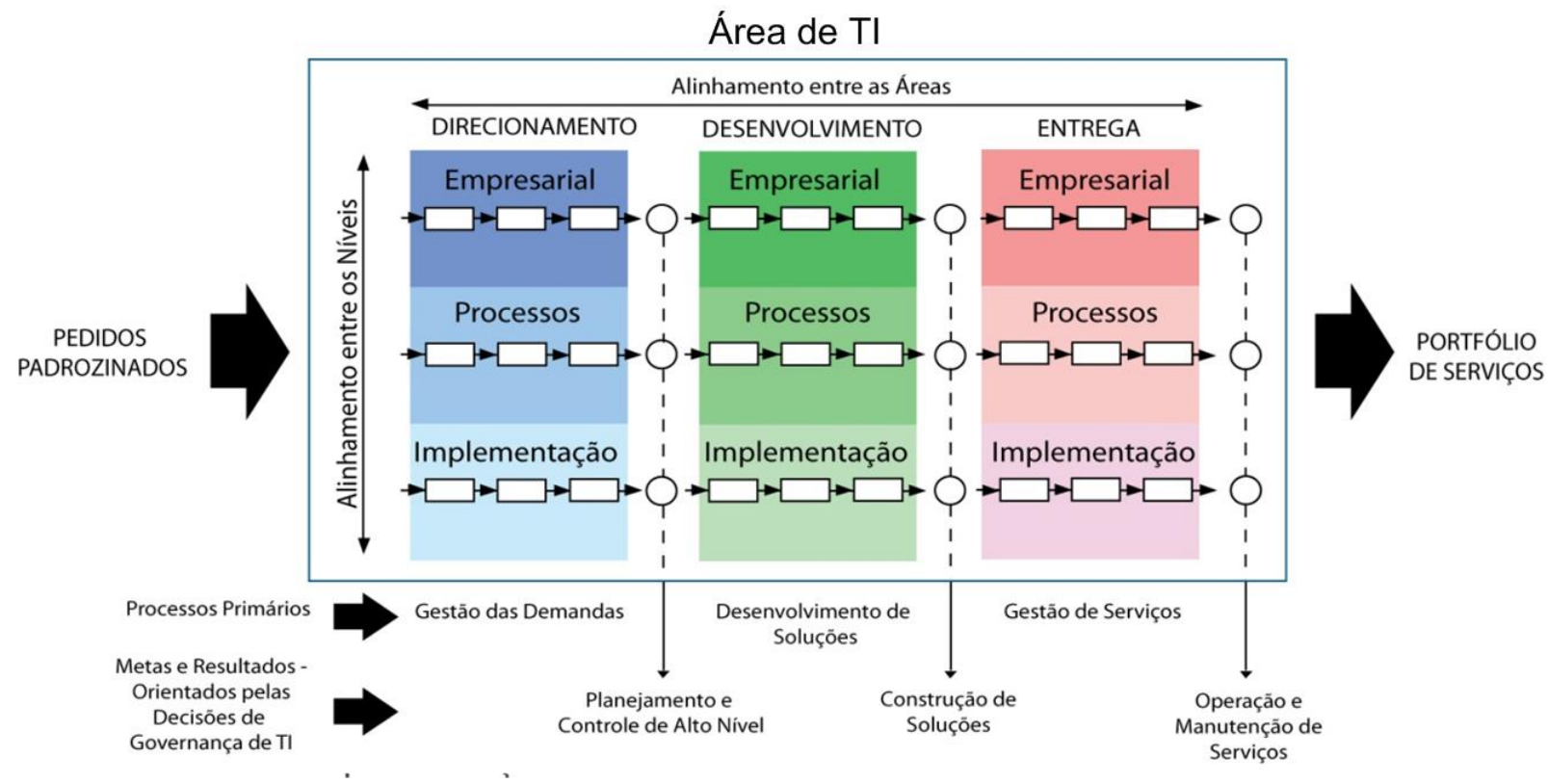

Figura 15 - Modelo de Arquitetura Corporativa de TI

Fonte: Ramos, 2009, p.83

O modelo se vale de três aspectos: estrutura arquitetural (foca no alinhamento entre os níveis e as áreas), processos e funcionalidades para explicar o funcionamento de uma organização de TI (RAMOS, 2009).

Para Ramos (2009), o formato permite o alinhamento dos subsistemas com o negócio. Esse alinhamento ocorre por meio das metas e resultados produzidos. O gestor deve ter um cuidado especial com as interfaces entre os subsistemas, pois elas representam uma das principais fontes de dificuldades de gerenciamento da área de TI. As organizações são sistemas e seus subsistemas interagem entre si (RAMOS, 2009). Na área de TI se consideram os reflexos da tomada de decisão para todos os subsistemas de TI.

\subsubsection{Subsistema de Direcionamento}

A funcionalidade principal do Direcionamento é o planejamento e controle de alto nível. A área de TI deve responder nos prazos acordados de maneira efetiva e eficaz aos pedidos de seus consumidores. Para que isso ocorra, a TI deve formular a lista de serviços que oferece, denominado de catálogo de serviços ${ }^{7}$.

7 O catálogo de serviços é um documento estruturado com informações de todos os serviços operacionais em produção da TI. O catálogo de serviços é a única parte do portfólio de serviços da organização publicado para os 
Além do catálogo de serviços, a TI precisa identificar os principais padrões de demanda. De acordo com os tipos de solicitações requeridos pelos clientes e usuários, podemse observar os seguintes padrões (BETZ, 2007):

- Pedido de exploração de ideias. Neste tipo de pedido ainda não possui um financiamento garantido. O seu objetivo é utilizar o conhecimento da organização para fazer uma pré-avaliação de um produto ou serviço.

- Pedido de projetos. Nem todos os projetos passam pelo padrão exploratório, mas todos começam com uma proposta que requisita uma avaliação geral e uma priorização frente ao uso competitivo dos recursos da organização.

- Pedido de serviços. A distinção proposta entre pedido de serviço e de projeto é a seguinte:

- Um projeto é um pedido para criar um serviço ou mudar um serviço existente.

- Um pedido de serviço é algo que pode ser atendido pela capacidade dos serviços operacionais já existentes. Por exemplo, um provisionamento de uma conta de e-mail para um usuário é um pedido de serviço e o estabelecimento de um novo serviço de e-mail é um pedido de projeto.

- Relato de incidentes. Esse relato é um tipo de serviço em que são relatados incidentes ou problemas sobre serviços operacionais existentes e espera-se um atendimento com qualidade nos tempos acordados com seus consumidores.

A aplicação da GTI no Direcionamento será limitada a análise das medidas de gestão e dos objetivos de controle que possibilitam o alcance das metas e dos resultados desejados (RAMOS, 2009).

Para o Direcionamento os indicadores de desempenho e objetivos de controle se aplicam ao gerenciamento de finanças de TI. Esses indicadores são obtidos no COBIT, do processo denominado de gerenciamento de investimentos de TI (RAMOS, 2009).

No Nível de Processos o macroprocesso principal é de Gestão das Demandas. Nesse macroprocesso os pedidos são analisados, um escopo preliminar é estabelecido e os pedidos

seus usuários. O catálogo de serviços inclui diversas informações, tais como, serviços operacionais de produção, preços, pontos de contato e uma descrição de processos de requisição de serviços. As especificações das condições de uso dos serviços operacionais de produção estão descritas em contratos denominado Acordos de Níveis de Serviço (ANS), do inglês Service Level Agreement (SLA). 
são priorizados de acordo com os objetivos estratégicos. Esses pedidos são avaliados em diversas dimensões, tais como os benefícios do projeto, complexidade, custo e retorno econômico. Isso lembrando que as demandas podem ser endógenas, e algumas delas são originadas da necessidade de renovação tecnológica e outras demandas da necessidade de melhoria contínua da TI (BETZ, 2007).

O perfil do profissional de TI que atua no Direcionamento deve valorizar competências que estimulem o planejamento e o controle de alto nível da TI. Algumas habilidades técnicas esperadas são: domínio de contabilidade gerencial e governança e gerenciamento de projetos, além da habilidade no manuseio dos sistemas de informação e suporte mais utilizados nessa área. Como habilidades comportamentais destacam-se a capacidade de liderança e o gerenciamento de conflitos e de negociação, considerando a cultura organizacional.

Os sistemas de informação e suporte típicos que podem apoiar a automatização do Direcionamento são (BETZ, 2007):

- Gerenciamento de demanda e portfólio. Auxilia no planejamento e controle das decisões de investimento de TI, incluindo, dentre outras, ideias de planejamento, projetos, serviços, processos e aplicações.

- Acompanhamento do desempenho de serviços. É utilizado para acompanhar em nível gerencial o desempenho dos acordos de níveis de serviços, mediante painéis de controle, portais ou outros meios.

- Planejamento de capacidade. Possui um histórico de dados de desempenho, acoplado a ferramentas especializadas. Essas ferramentas permitem análise e modelagem de projetos submetendo-os a simulação em diversos cenários (consumo de banda, armazenamento e capacidade de processamento), a qual permite uma avaliação técnica e financeira.

- $\quad$ Arquitetura organizacional. Pode ser utilizado para diversos propósitos. Seu objetivo principal é permitir inter-relacionamentos de diversos conceitos, tais como objetivos de negócio, funções organizacionais, processos, sistemas e infraestrutura. Esses relacionamentos podem ser registrados e deverá existir um mecanismo de busca desses inter-relacionamentos.

- Gerenciamento de continuidade de negócio. É focado em procedimentos de certificação que garantem a recuperação de determinado serviço, processo ou aplicação. 
- Gerenciamento de risco. Apoia a investigação e a análise do ambiente de TI, para verificar se a organização atende aos requisitos regulatórios e de negócios considerados prioritários.

- Gerenciamento financeiro de TI. É um grupo lógico de sistemas que apoiam a contabilidade gerencial e a demonstração contábil nas organizações de TI.

- Acompanhamento de compras. É utilizado para rastrear os fornecedores definidos, acompanhando as compras efetuadas.

- Gerenciamento de contratos. É utilizado para o gerenciamento e armazenamento de acordos contratuais documentados.

- Gerenciamento de ativos. É utilizado para acompanhar os investimentos organizacionais em propriedades tangíveis e suficientemente valoráveis, permitindo manter o seu registro.

- Gerenciamento de infraestrutura física. Apoia o inventário associado a construções físicas como prédios, torres, etc.

- Gerenciamento de configuração. Repositório de dados produzidos pelo Direcionamento, que serão úteis para comunicação e troca de informações com os subsistemas Desenvolvimento e Entrega.

\subsubsection{Subsistema de Desenvolvimento}

A funcionalidade principal do Desenvolvimento é a construção de soluções. O Desenvolvimento executa as suas atividades de acordo com os projetos autorizados e com as diretrizes de governança expedidas pelo Direcionamento.

São quatro os macroprocessos de Desenvolvimento: gerenciamento de projetos, concepção e construção de soluções, garantia de qualidade e gerenciamento de conFigurações (BETZ, 2007).

Porém será dada maior ênfase no processo de gerenciamento de projetos, por ele ser considerado crítico para o sucesso. O gerenciamento de projetos apoia a aplicação de conhecimentos, habilidades e técnicas na elaboração e na execução de atividades que visam atingir um conjunto de objetivos predefinidos. 
Tendo em vista a intenção de aumentar o desempenho do processo de gerenciamento de projetos do Desenvolvimento, precisamos buscar referências que caracterizam uma gestão de alto desempenho em gerenciamento de projetos.

A área de TI de alto desempenho possui procedimentos operacionais com requisitos de qualidade que as distinguem de outras organizações. Esses requisitos são (BETZ, 2007):

- Respostas no tempo acordado, com agilidade no suporte às constantes evoluções presentes nas estratégias e necessidades do negócio.

- Eficácia operacional que consiste na disponibilidade de sistemas e infraestrutura de alto desempenho.

- Eficácia, eficiência e transparência nos custos.

- Gerenciamento de segurança e risco.

A aplicação da GTI no Desenvolvimento será limitada à dimensão domínio por meio da utilização de um sistema de medição de desempenho e de objetivos de controle que alcancem os objetivos desejados.

Especificamente para o processo de gerenciamento de projetos, são identificados objetivos de eficácia e eficiência (ANTAO, 2005). Os objetivos de eficácia são:

- Alto valor percebido pelo negócio;

- Alta taxa de projetos realizados dentro do prazo e do custo; e

- Segurança satisfatória.

Já os objetivos de eficiência são:

- Baixo custo de gestão por projeto; e

- Baixo custo de segurança.

A partir desses objetivos podem ser definidos indicadores de eficácia e de eficiência de TI para mensurar a precisão com que o Desenvolvimento alcança as metas e os resultados desejados com o menor custo possível e segurança satisfatória.

Com o intuito de customizar os objetivos de controle de acordo com as decisões de governança do Desenvolvimento, o processo escolhido para se mitigar riscos é o de gerenciamento de projetos. Com o objetivo de mitigar as causas que geram os efeitos indesejados nos projetos, deve-se implementar os seguintes objetivos de controle:

- $\quad$ Alteração de escopo; 
- $\quad$ Erro de quantificação; e

- $\quad$ Erro de produtividade.

Cada objetivo de controle possui um grau de importância distinta, sendo o objetivo de controle de alteração de escopo dominante em relação aos objetivos de controle de erro de quantificação e erro de produtividade.

O nível de processos inclui as atividades que permitem a modelagem do Macroprocesso Desenvolvimento de Soluções, que é dividido em quatro processos: Gerenciamento de Projetos, Concepção e Construção de Soluções, Garantia de Qualidade e Gerenciamento de Configurações de Hardware e Software (BETZ, 2007).

O Gerenciamento de Projetos é um dos principais processos do Desenvolvimento, uma vez que haja um projeto autorizado pelo Direcionamento. Ele é comumente aplicado com o apoio de outros processos.

Na Concepção e Construção de Soluções, a análise de sistemas e sua concepção incluem a aplicação de técnicas de modelagem para descrição da estrutura do sistema a ser desenvolvido.

O Processo de Garantia de Qualidade é responsável por assegurar a qualidade do produto ou serviço desenvolvido. Os seus subprocessos podem realizar atividades que incluem testes, verificações e validações para assegurar a qualidade desejada.

Gerenciamento de Configuração de Hardware e Software utiliza o repositório Configuration Management Database (CMDB) para registro de diversos artefatos que são desenvolvidos ao longo do projeto.

O Nível de Implementação inclui os recursos que permitem a execução das atividades do Desenvolvimento, quais sejam: Recursos Humanos, e Sistemas de Informação e Suporte.

O profissional de TI que atua no Desenvolvimento é responsável pelo gerenciamento de projetos, concepção e construção de soluções, garantia da qualidade de produtos e serviços com gerenciamento de configuração.

Algumas habilidades técnicas esperadas são:

- $\mathrm{O}$ conhecimento de governança e gerenciamento de projetos, incluindo habilidade no manuseio de sistemas de informação e suporte.

- Domínio de ciclo de desenvolvimento de software e da ferramenta de desenvolvimento utilizada, por exemplo, Java. 
- $\quad$ Domínio em gestão de processos, com ênfase em garantia da qualidade de software.

Entre as habilidades comportamentais destacam-se:

- $\quad$ Capacidade de relacionamento interpessoal;

- $\quad$ Capacidade de automotivação e autogestão;

- $\quad$ Capacidade de identificar e resolver os problemas;

- $\quad$ Capacidade de trabalho colaborativo em equipe;

- $\quad$ Capacidade de liderança; e

- $\quad$ Capacidade de negociação.

Os sistemas de informação e suporte típicos que podem apoiar a automatização do Desenvolvimento são (BETZ, 2007):

- Gerenciamento de projetos. Acompanha o gerenciamento de recursos, dependências de tempo, acompanhamento de produtos intermediários a serem entregues e dependências de atividades dentro do projeto.

- Gerenciamento de requisitos. Auxilia na redução de risco e alcance do sucesso no projeto. O sistema de gerenciamento de requisitos possui, tipicamente, duas preocupações: rastreabilidade e auditoria. Algumas ferramentas utilizam a linguagem de modelagem denominada Unified Modeling Language - UML.

- Apoio à estimativa. Facilita a quantificação do trabalho a ser realizado principalmente no desenvolvimento de software.

- Gerenciamento dos questionamentos de projetos. Apoia a identificação, o rastreamento e a resolução das dificuldades que não puderam ser antecipadas no planejamento do projeto. Essas atividades que não puderam ser previstas no planejamento do projeto são também conhecidas na literatura estadunidense como bugs.

- Gerenciamento de configuração de hardware e software. Automatiza e controla as versões dos programas em desenvolvimento e/ou em produção. Esses sistemas também podem mapear os equipamentos utilizados no ambiente de TI. 


\subsubsection{Subsistema de Entrega}

A funcionalidade principal da Entrega é a operação e manutenção de serviços oriundos do portfólio de serviços.

O portfólio de serviços é o conjunto completo de serviços que são gerenciados e é usado para gerenciar todo o ciclo de vida de todos os serviços. Inclui três categorias: serviço em espera (propostos ou em desenvolvimento), catálogo de serviços (em produção ou disponível para implantação) e serviços descontinuados.

A Entrega tipicamente desenvolve as suas atividades de acordo com as diretrizes de governança do Direcionamento e as soluções desenvolvidas pelo Desenvolvimento.

O macroprocesso da Entrega é a gestão de serviços. A gestão de serviços é um conjunto de capacidades organizacionais especializadas para prover valor aos seus consumidores na forma de serviços (ITIL, 2007). A gestão de serviços de Entrega possui seis processos: gerenciamento de liberações, gerenciamento de mudanças na produção, atendimento das requisições de serviço, manutenção de serviços operacionais, resolução de incidentes e problemas e gerenciamento de itens de configuração (BETZ, 2007).

Para identificação das causas que geram uma percepção de baixa ou alta qualidade dos serviços operacionais em produção, utilizou-se como base a melhor prática ITIL.

O nível de processos inclui as atividades que permitem a modelagem do Macroprocesso de Gestão de Serviços. Esse macroprocesso é dividido em seis processos: gerenciamento de liberações; gerenciamento de mudanças na produção; atendimento das requisições de serviço; manutenção de serviços operacionais em produção; resolução de incidentes e problemas e; gerenciamento de itens de configuração (BETZ, 2007).

O gerenciamento de liberações é o processo responsável por cuidar que a implantação da solução criada pelo Desenvolvimento ocorra no ambiente de produção com sucesso. Esse processo é responsável por agendar e controlar os movimentos de liberação do ambiente de testes para a produção. O objetivo primário desse processo é o de assegurar que a integridade do ambiente de produção seja protegida e que os componentes e as versões corretas sejam liberados.

O gerenciamento de mudanças se preocupa com o planejamento e acompanhamento das modificações efetuadas no ambiente de produção (hardware ou software) com o objetivo de mitigar eventuais impactos que possam afetar os serviços operacionais. Esse processo é 
responsável pelo registro de todas as mudanças efetuadas no ambiente de produção. $\mathrm{O}$ objetivo principal desse processo é de autorizar mudanças que beneficiem e aperfeiçoem o ambiente operacional, sem causar interrupções não planejadas dos serviços operacionais em produção.

Atendimento de requisição de serviços provê serviços solicitados pelo usuário, tais como uma nova estação de trabalho, abertura de uma conta de e-mail ou acesso à internet. Os serviços operacionais de produção disponíveis podem ter as suas especificações comunicadas para os seus consumidores por intermédio de um catálogo de serviços.

Manutenção de serviços operacionais em produção está associada às atividades de suporte operacionais. Nem todos os eventos do ambiente de TI são gerados por incidentes. Por exemplo, bases de dados precisam ser desfragmentadas, registros de acesso a aplicações podem ser eventualmente inspecionados e outras atividades semelhantes podem acontecer no ambiente de TI.

Resolução de incidentes e problemas é a atividade principal da gestão de serviços que mantêm os serviços operacionais de produção em perfeito funcionamento. A resolução de incidentes está associada ao restabelecimento de serviços e a resolução de problemas à investigação, identificação e mitigação das causas principais que geram os incidentes observados. Uma base de dados de incidentes e problemas é essencial a este processo. A automação da comunicação dos incidentes pelos usuários e o acompanhamento automatizado de sua resolução é um objetivo importante, tendo em vista o alto volume de incidentes em grandes organizações de TI.

O gerenciamento de itens de configuração é responsável pelo rastreamento dos diversos itens de configuração que compõem um sistema de informação ou uma infraestrutura especializada, tais como estações de trabalho, redes e servidores de armazenamento disponíveis no ambiente de TI.

Uma das questões centrais para que haja uma baixa ou alta percepção da qualidade dos serviços disponibilizados pela Entrega está relacionada à eficácia e eficiência da gerência de mudanças na produção e da gerência de itens de configuração.

O Nível de Implementação inclui os recursos que permitem a execução das atividades da Entrega. Para isso, será apresentada uma abordagem focada em gestão de pessoas e sistemas de informação e Suporte.

O perfil do profissional de TI que atua na Entrega cuidará da gestão de serviços da organização de TI. 
Algumas habilidades técnicas esperadas são:

- Conhecimento de governança e gestão de serviços, incluindo habilidade no manuseio de sistemas de informação e suporte;

- Domínio dos produtos e ferramentas que suportam o portfólio de serviços; e

- Domínio em gestão de processos, com ênfase em garantia da qualidade de serviços.

Entre as habilidades comportamentais destacam-se:

- $\quad$ Capacidade de relacionamento interpessoal;

- $\quad$ Capacidade de automotivação e autogestão;

- $\quad$ Capacidade de trabalho colaborativo; e

- $\quad$ Capacidade de identificar e resolver os problemas.

A lista de sistemas de informação e suporte típicos que podem apoiar a automatização da Entrega de uma área de TI é (BETZ, 2007):

- Gerenciamento de mudanças. Permite que a organização de TI tenha visibilidade das mudanças que afetam o ambiente de produção, de forma que as partes interessadas possam relatar possíveis ocorrências que subsidiem a equipe responsável pelo planejamento da mudança. Esse sistema, comumente, auxilia na liberação.

- Gerenciamento de disponibilidade. Disponibiliza uma variedade de mecanismos para monitorar e controlar serviços operacionais de produção de TI, tipicamente utilizando componentes de softwares instalados nas plataformas computacionais denominadas agentes.

- Gerenciamento de incidentes e problemas. Serve para acompanhar os incidentes. Um incidente é definido como uma interrupção total ou parcial, não programada de um serviço operacional definido no ambiente de produção de TI. A interrupção de um serviço em produção pode resultar em inúmeros incidentes, relatados por usuários ou por meio de sistemas automatizados. Esse sistema de gerenciamento de incidentes e problemas pode correlacionar muitos incidentes relatados em um único esforço de resolução de problemas. Igualmente, sistemas mais maduros possuem alto nível de integração com sistemas de gerenciamento de itens de 
configuração. Uma degradação na qualidade do nível de serviço acordado também pode ser considerada um incidente. Eventos que ainda não provocaram interrupção dos serviços também são considerados incidentes.

- Gerenciamento de requisição de serviço. É similar a um sistema de gerenciamento de incidentes, uma vez que ele é um ponto focal de atendimento dos pedidos dos consumidores. Entretanto, tais pedidos não estão associados com a interrupção de serviços operacionais de produção, mas sim com a requisição de serviços rotineiros, tais como requisição de uma nova estação de trabalho ou abertura de uma conta de e-mail.

- Gerenciamento de itens de configuração. São temas centrais da gestão de serviços. O conceito de gerenciamento de itens de configuração está associado à existência de um repositório de dados denominado de Configuration Management Database (CMDB). O item de configuração é qualquer componente que necessita ser gerenciado para possibilitar a compreensão dos elementos de software e hardware, facilitando a manutenção de um serviço operacional de TI. O CMDB é um repositório centralizado de várias formas por dados usados para compreender os interrelacionamentos dos elementos de TI e da própria capacidade de TI.

\section{$2.4 \quad$ FATORES CRÍTICOS DE SUCESSO}

Em 1979, Rockart popularizou o termo "Fatores Críticos de Sucesso" (FCS) motivado pelas necessidades de informações de gestores gerais e em especial diretores executivos que não são tão claramente determinadas (DIAS JUNIOR; GUSSONI; MUNIZ JUNIOR, 2009). Os FCS são poucas áreas chaves onde as "coisas devem ocorrer adequadamente" para que o negócio floresça e para que os objetivos do gerente sejam alcançados (DIAS JUNIOR; GUSSONI; MUNIZ JUNIOR, 2009).

Segundo Laurindo et al (2001), essa abordagem foi desenvolvida para o desenvolvimento de sistemas de informação gerenciais, baseada nas necessidades de informação dos gerentes para tomada de decisão. O foco dessa proposta são os "Fatores Críticos de Sucesso", que seriam, segundo os autores, o número limitado de áreas nas quais os 
resultados, se satisfatórios, asseguram o desempenho competitivo bem sucedido para a organização.

Vale ressaltar que essa não é uma metodologia completa, pois deixa lacunas quanto aos sistemas de informação transacionais, mas é muito útil para o desenvolvimento de sistemas de informação gerenciais (LAURINDO et al, 2001).

O método de Rockart considera que os FCS advêm de cinco fontes principais que devem ser pesquisadas por um entrevistador durante a preparação para uma série de entrevistas (DIAS JUNIOR; GUSSONI; MUNIZ JUNIOR, 2009). São as cinco fontes: estratégia, objetivos, metas, medidas e problemas.

- estratégia - a estratégia é o padrão das missões, objetivos, políticas, e os planos de utilização dos recursos significativos, de tal forma declarada, que defina em quais negócios a empresa está inserida ( ou é para estar) e que tipo de companhia ela é (ou pretende ser). Uma indicação completa da estratégia definirá a linha de produto, os mercados e os segmentos de mercado para que os produtos devam ser projetados, os canais por meio de dos quais estes mercados serão alcançados, os meios por que a operação deve ser financiada, a margem de lucro, o tamanho da organização, e a "imagem" que projetará aos empregados, aos fornecedores e aos clientes.

- objetivos - os objetivos são indicações gerais sobre os sentidos em que uma empresa pretende ir, sem indicar os alvos específicos a ser alcançados em determinados momentos no tempo.

- metas - as metas são os alvos específicos que são pretendidos ser alcançados em um determinado momento. Uma meta é assim uma transformação operacional de um ou mais objetivos.

- medidas - as medidas são os padrões específicos que permitem a calibração do desempenho para cada fator crítico de sucesso, ou objetivo. As medidas podem ser qualquer uma: "soft," isto é, subjetivo e qualitativo ou "hard", isto é, objetivo e quantitativo.

- problemas - os problemas são tarefas específicas que ganham importância em consequência do desempenho insatisfatório ou das mudanças ambientais. Os problemas podem afetar a realização dos objetivos ou do desempenho em uma área do FCS. 
Segundo Rockart (1979), esses termos possuem relacionamentos e hierarquia. No topo temos a organização que possui seus FCS’s inerentes ao ramo de negócio e a estratégia e os objetivos devem de alguma forma traduzi-los.

A estratégia e os objetivos geram as metas no nível empresarial. Ao desdobrar tais metas para cada unidade gerencial são obtidas as metas individuais de cada gerente, que uma vez conhecidas é iniciado o método para identificação dos FCS baseada em entrevistas semiestruturadas. Os gerentes, ao realizar uma análise crítica, definem quais são os FCS de sua área, por conseguinte definem também as medidas de gestão destes fatores (DIAS JUNIOR; GUSSONI; MUNIZ JUNIOR, 2009).

Ao identificar os FCS podem surgir "problemas" que estão presentes nas atividades necessárias a realização dos objetivos em uma área do FCS. A Figura 16 apresenta os relacionamentos de hierarquia do FCS.

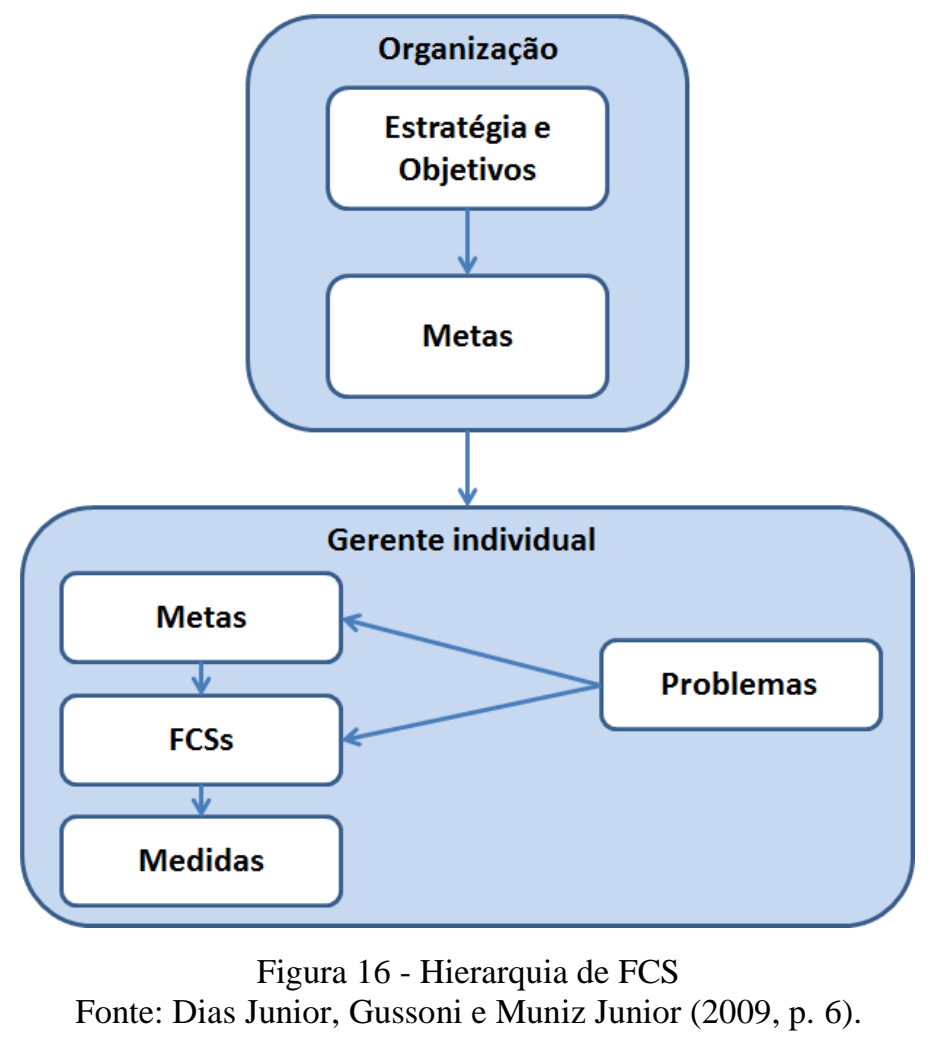

\subsubsection{Metodologia de Levantamento de FCS}

No entendimento de Bullen e Rockart (1981), o método de identificação de FCS deve ser de top-down. Esse método para obter os fatores críticos de sucesso, se baseia nas diversas 
fontes de FCS (o ramo do negócio, estratégia competitiva e posicionamento da organização, fatores ambientais, fatores temporais e posição gerencial), conforme apresentada na Figura 17.

$\mathrm{Na}$ entrevista estruturada com o gerente, são feitas perguntas que capturaram os fatores críticos de sucesso. Exemplos dessas perguntas:

- onde você deve colocar a sua atenção gerencial?

- em qualquer ordem, quais são as coisas que você vê como FCS em seu trabalho neste momento?

- suponha que você seja colocado hoje em um quarto escuro com nenhum acesso ao mundo exterior, à exceção do alimento e da água, o que você mais vai querer saber sobre o negócio quando você sair três meses mais tarde?

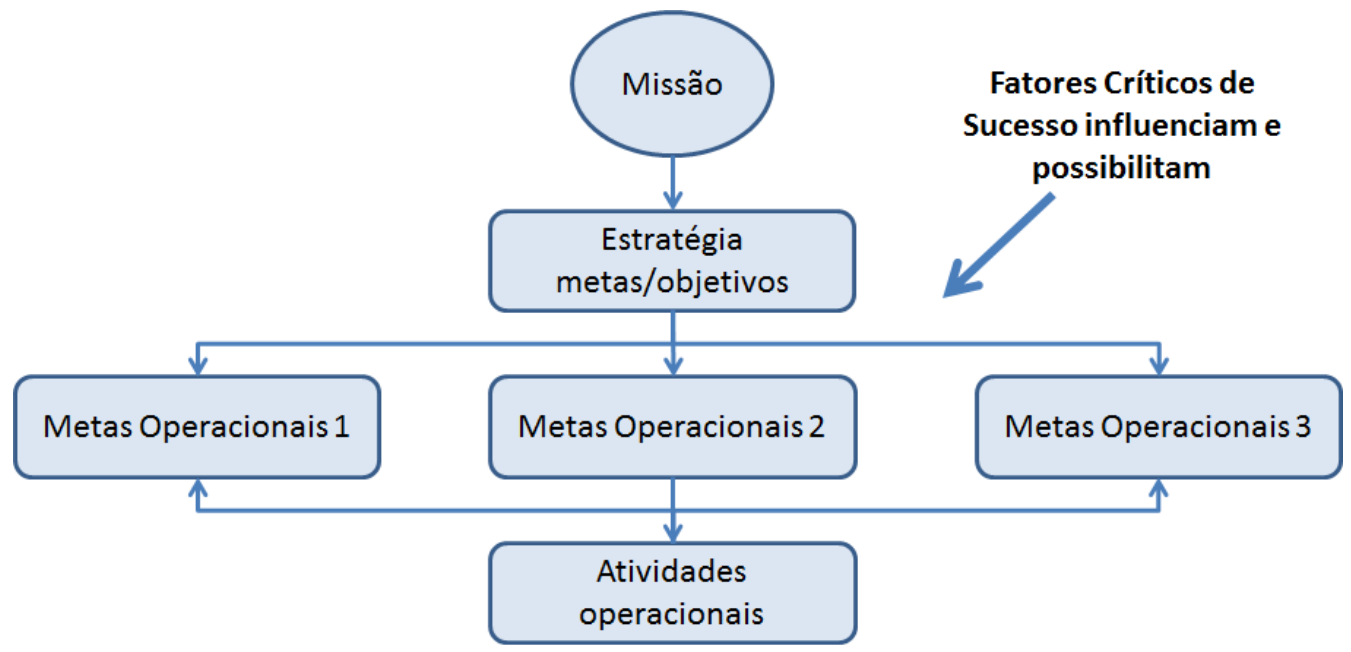

Figura 17. Influências dos FCS na Estratégia Organizacional Fonte: Dias Junior, Gussoni e Muniz Junior (2009, p.7).

Mais tarde, a ideia de FCS encontrou o seu caminho em muitas outras áreas como gerenciamento de projetos e gestão da qualidade total. Especificamente, para a Gestão da Qualidade Total, os FCS indicam as questões que devem ser muito bem feitas para atingir o sucesso na organização a fim de alcançar com êxito os objetivos e as metas. (BADRI; DONALD; DONNA; 1995; CLAVER; TARÍ; MOLINA, 2003; TARÍ, 2005)

Rockart (2002) instrui que antes das entrevistas individuais, sejam realizados três passos: i) apresentação de 30 a 45 minutos sobre os conceitos sobre FCS; ii) descrição dos passos do estudo, apresentação de exemplos e; iii) esclarecimento de dúvidas.

Bullen e Rockart (1981) e Rockart (2002) também preveem a leitura do artigo "Chief Executives Define Their Own Data Needs" de Rockart (1979), que expressa conceitos e 
utilizações dos FCS. Contudo, para esta pesquisa essa última etapa foi descartada devido ao pouco tempo que a maioria dos entrevistados disponibiliza para as entrevistas. Assim, as instruções e explicações sobre os FCS em GTI foram realizadas no início da entrevista. Em casos de dúvida, os FCS em GTI da Fase I foram apresentados como exemplo.

Durante as entrevistas, Bullen e Rockart (1981) solicitam que a postura do pesquisador não seja passiva, ou seja, limitada a coletar opiniões. Ao contrário, recomenda uma postura proativa, na qual o entrevistado é motivado e é questionado. Além disso, sugestões e perguntas são feitas, inclusive para evitar que os entrevistados se fixem em um só tipo de FCS ou que o mesmo FCS seja abordado ou discutido de diferentes formas, cabendo ao pesquisador propor a agregação dos mesmos.

Bullen e Rockart (1981) orientam que estudos prévios sejam realizados por parte do pesquisador a fim de capacitá-lo a questionar por áreas relevantes que o entrevistado pode não ter mencionado, sem, no entanto, tentar persuadir o entrevistado a incluir outros FCS se isso não for apropriado. Ou seja, o pesquisador deve auxiliar, mas não ser diretivo, nem indicar julgamento de sua parte. Tais instruções foram seguidas e se mostraram pertinentes, facilitando a comunicação e até mesmo motivando o entrevistado a refletir sobre os FCS em GTI.

\subsubsection{FCS e Governança de TI}

Para Henderson, Venkatraman e Oldach (1993), os FCS (ROCKART, 1978, 1979) fazem parte do conceito de planejamento, que visa identificar algumas questões críticas que são fundamentais para o sucesso organizacional. Assim, um sistema de medição de desempenho com poucas ou muitas medidas torna-se ineficaz.

Sobre o termo "medição de desempenho", Salem (2003) esclarece que o mesmo se refere a qualquer abordagem sistemática e integrada que promove o desempenho operacional de forma eficiente, eficaz, efetiva e econômica proporcionando o cumprimento da estratégia, da missão e da visão de uma organização. Para Attadia e Martins (2003), medição de desempenho considera que as decisões e ações sejam tomadas com base em informações, uma vez que elas quantificam a eficiência e a eficácia das ações passadas por meio da coleta, exame, classificação, análise, interpretação e disseminação dos dados adequados.

Para Kaplan e Norton (1997) medir o desempenho da organização por meio de indicadores tem sido aceito e utilizado por organizações do mundo inteiro há várias gerações. 
A trajetória histórica do gerenciamento e medição de desempenho é marcada por dois momentos distintos. O primeiro momento, que data de 1880 até o início de 1980, caracterizou-se pelo domínio do sistema de indicadores financeiros que representariam a medida mais confiável para se avaliar uma organização.

O segundo momento da medição de desempenho, que se iniciou em 1980 e está presente nos dias atuais, é a ênfase atribuída ao balanceamento do sistema de indicadores financeiros e não-financeiros. Este momento ainda pode ser desdobrado em duas gerações: a "miopia da medição" e "loucura da medição" (NEELY; ADAMS, 2000).

A "miopia da medição" ocorreu quando se detectou que o novo sistema de indicadores de desempenho não era adequado. Já a "loucura da medição", o atual período em que vivemos, refere-se à obsessão das empresas pela medição, em que tudo deve ser medido, sem necessariamente saber o por quê e o para quê (ATTADIA; MARTINS, 2003).

Saber o quê medir ou quais os FCS em GTI ganharam força a partir da pesquisa analítica e empírica do ITPI em parceria com a Carnegie Melon University, Florida State University e a Triwiew Inc (ITPI, 2005). Tal pesquisa questionou a viabilidade do uso intensivo das boas práticas, como ITIL e COBIT na gestão e GTI, uma vez que a implementação de boas práticas como ITIL e COBIT envolvem altos custos e aumentam a “burocracia”. Essa pesquisa considerou que apenas alguns controles de TI são responsáveis pela eficiência, pela eficácia, pela segurança e pela geração de valor da TI. Para isso, foram identificados os controles e indicadores de desempenho mais eficientes e eficazes que contribuem para o diferencial das empresas com alto-desempenho em TI.

O método de pesquisa adotado consistiu na análise das 1.000 (mil) empresas classificadas como de alto-desempenho pela Revista Fortune. Essa análise foi efetuada por meio da técnica de modelagem de equação estrutural para determinar quais os controles são os mais importantes.

O resultado dessa pesquisa apresentou 63 (sessenta e três) controles do COBIT que abrangem seis áreas específicas do ITIL:

- acesso,

- mudança,

- resolução,

- configuração,

- versionamento; e

- gestão de nível de serviço. 
Para analisar o impacto desses controles, a pesquisa incluiu vinte e cinco indicadores que medem o desempenho da auditoria, operações, desempenho e segurança. Estes indicadores incluem satisfação do usuário de TI; trabalho não planejado; eficácia em segurança e auditoria; e rompimento com níveis de conformidade.

Assim, compararam-se as atividades de controle com o desempenho das medidas relatadas e o resultado comprovou que o princípio de Pareto se aplica aos controles de TI, ou seja, para cada uma das seis categorias de controle, os controles podem ser reduzidos a três ou quatro controles fundamentais, que têm o mesmo impacto sobre o conjunto de controles (ITAUDIT, 2007).

Logo, a visão de Henderson, Venkatraman e Oldach (1993) sobre os FCS (ROCKART, 1989) contribui para uma gestão e governança mais otimizadas e focadas no desempenho da organização. Esse fato reforça a importância sobre a identificação desses FCS na gestão pública.

\subsection{ANÁLISE DE COMPONENTES PRINCIPAIS}

Segundo Sabin, Ferrão e Furtado (2004) e Silva et al. (2012), a Análise de Componentes Principais (ACP), do inglês Principal Component Analysis - PCA, é utilizada para compressão de dados para identificação das relações entre características dos dados. A compressão é obtida por meio da substituição das variáveis originais por um novo conjunto de variáveis, conhecidas como Componentes Principais (CPs). As CPs são obtidas pela combinação linear das variáveis que apresentam a maior variabilidade na matriz de covariância. Assim, o objetivo principal da ACP é identificar as CPs responsáveis pelas maiores variações entre os resultados. Em termos práticos eliminam-se algumas variáveis com pouca informação e determinam-se as variáveis de maior influência na formação de cada CP (VICINI, 2005).

Segundo Vicini (2005), o conjunto ortogonal de eixos não correlacionados representam as variáveis que mantém ao máximo a variabilidade do conjunto, em outras palavras, a menor perda de informação.

Conforme Vicini (2005:29), para o processo de determinação das CPs

“é necessário calcular matriz de variância-covariância $\left(\sum\right)$, ou na matriz de correlação $(R)$, encontrar os autovalores e autovetores e, por fim, escrever as 
combinações lineares, que serão as novas variáveis, denominadas de componentes principais, sendo que cada componente principal é a combinação linear de todas as variáveis originais [...] em ordem de estimação e em termos da variância total, contida nos dados iniciais".

Não são todas as CPs a serem analisadas, mas apenas aquelas com maior variância. Alguns autores (VICINI, 2005) determinam os CPs por meio da porcentagem que representam, geralmente, mais de $70 \%$ da informação.

Conforme Silva et al. (2012), para a geração dos CPs, considera-se uma matriz X = $(\mathrm{X} 1, \mathrm{X} 2, \ldots, \mathrm{Xp})$ de dimensões nxp originada a partir de um vetor aleatório. A matriz de variância-covariância $\sum_{\text {pxp }}$ das amostras da matriz $X$ é calculada por meio da seguinte expressão $\sum_{\mathrm{pxp}}=\frac{1}{\mathrm{n}} \mathrm{X}^{\mathrm{T}} \mathrm{X}$, onde ${ }^{\mathrm{T}}$ é o operador de transposição de uma matriz. Nota-se que a matriz de variância-covariância é uma matriz quadrada e não negativa. Portanto, pode-se aplicar a decomposição em autovalores, do Eigenvalue Decomposition (EVD), da matriz $\sum_{\text {pxp }}$ resultando em um produto de três matrizes.

$$
\Sigma_{p x p}=V \Lambda V^{\mathrm{T}}
$$

onde $\mathrm{V}$ é a matriz de autovetores e $\Lambda$ é a matriz cuja diagonal principal contém os autovalores. Para cada autovalor $\lambda \mathrm{i}$ da matriz $\sum_{\text {pxp }}$ existe um autovetor unitário e ortognal vi.

$$
\mathrm{V}_{\mathrm{i}}=\left(\begin{array}{c}
v_{i 1} \\
v_{i 2} \\
\cdot \\
v_{i p} \cdot
\end{array}\right)
$$

A i-nésima coluna da matriz $\mathrm{V}$ é o autovetor normalizado $\mathrm{v}_{\mathrm{i}}$ correspondente ao autovalor $\lambda_{\mathrm{i}}$. Desta forma, define-se i-ésima componente principal (Yi) como sendo

$$
\mathrm{Y}_{\mathrm{i}}=\lambda_{\mathrm{i}} \mathrm{V}_{\mathrm{i}}
$$

Salienta-se que a ACP é baseada na EVD já que parte dos autovalores e dos autovetores representam as componentes principais (CP).

A Figura 18 mostra geometricamente a ACP de duas variáveis X1 e X2. A nuvem de pontos representa o diagrama de espalhamento destas duas variáveis. O primeiro passo é o cálculo da matriz de variância-covariância e em seguida se aplica a EVD. Verifica-se que a $\mathrm{CP} 1$, denominado $\mathrm{CP}$ principal (com a maior variância), é ortogonal à segunda $\mathrm{CP}(\mathrm{CP} 2$ com a menor variância). Note que as duas variáveis são perpendiculares porque as variáveis obtidas pela ACP são independentes. Logo, após a aplicação da ACP, ao invés de representar os dados por meio de duas variáveis correlacionadas X1 e X2, eles podem ser representados por duas variáveis independentes Y1 e Y2. Dada a elevada correlação entre X1 e X2, verifica- 
se que as duas variáveis $\mathrm{X} 1$ e X2 podem ser aproximadas por uma única variável Y1 na Figura 18.

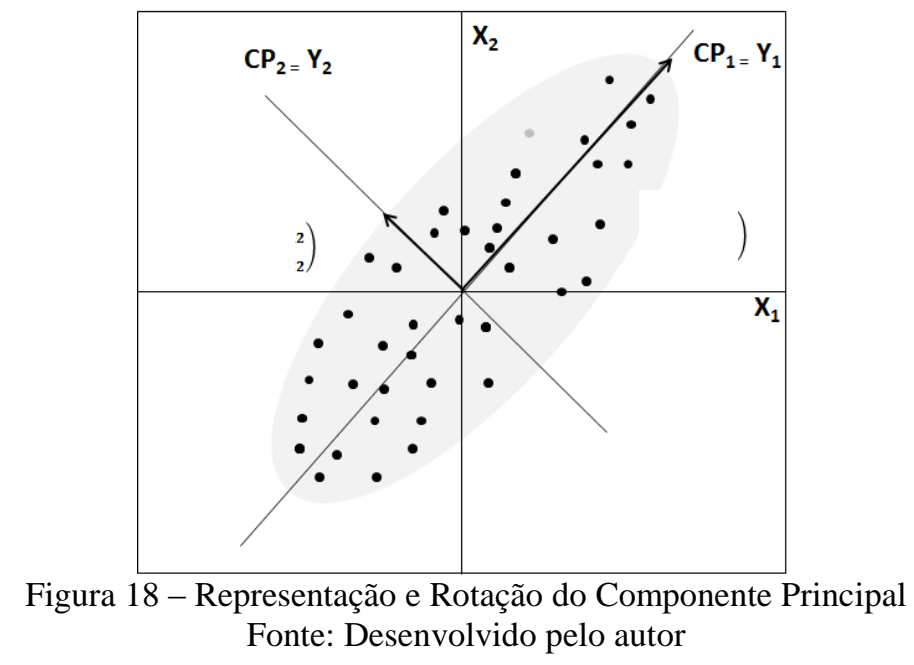

A Figura 18 reforça a ideia da ACP cujo objetivo inicial é a identificação de planos e linhas que representem um conjunto de pontos em um espaço com um número menor de variáveis tendo em vista as possíveis correlações que podem existir entre as variáveis originais.

Assim, para o método da estatística multivariada ACP utilizar todas variáveis, separase a informação útil da informação redundante (FINKLER, 2003). A ACP é um dos primeiros passos para outras análises multivariadas, sendo um dos métodos mais comuns empregados na análise de informações (SABIN; FERRÃO; FURTADO, 2004; SILVA et al.,2012).

\subsection{MÁQUINAS DE VETORES DE SUPORTE (MVS)}

Máquina de Vetores de Suporte (MVS), do inglês Support Vector Machine (SVM), é um método supervisionado de aprendizagem de máquina, não probabilístico, baseado na teoria de aprendizagem estatística, usado para classificação, regressão e detecção de padrões. MVS pode ser aplicado por meio de dois passos: o primeiro passo é o treinamento de um modelo a partir de um determinado conjunto de dados; o segundo consiste em estimar a classificação de dados a partir da aplicação do modelo treinado.

Quando aplicado para classificação, MVS busca a identificação de um hiperplano que separa os dados em classes distintas, por meio de uma margem máxima entre duas classes de 
dados. Desta forma, um conjunto de dados é linearmente separável se for possível dividir seus dados em duas classes, por meio um hiperplano, conforme apresentado na Figura 19.

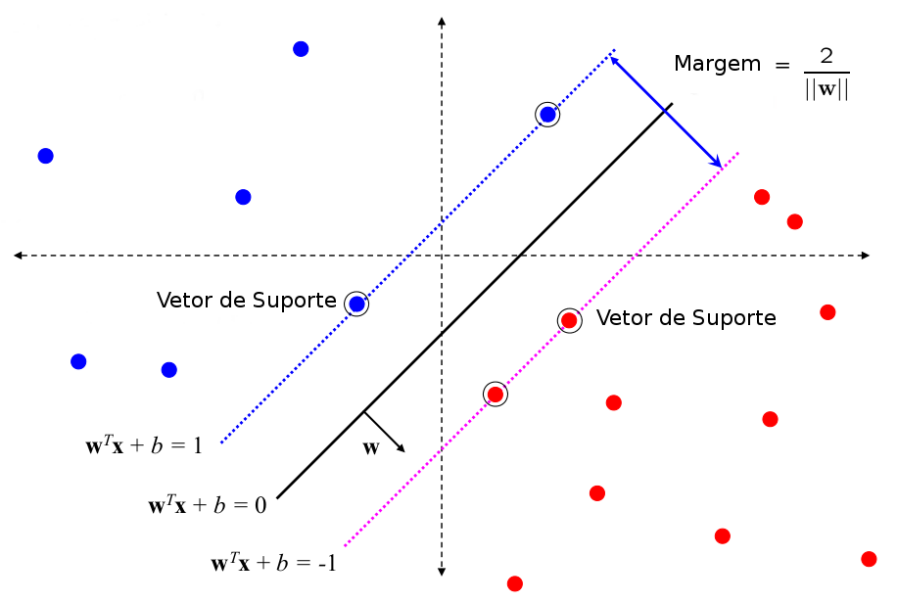

Figura 19 - Separação Linear por Margem Máxima

Dado um conjunto de dados previamente classificados, (xi, yi), xi $\in \mathrm{Rn}$, yi $\in\{1,-1\}, \mathrm{i}$ $=1, \ldots, 1$, um classificador linear pode ser definido por: $\mathrm{wT} \cdot \mathrm{x}+\mathrm{b}=0$, desta forma $\mathrm{o}$ hiperplano ótimo é definido pelos valores ótimos do vetor de pesos wi e do bias bi, de forma que $w T \cdot x+b=1$ e wT $\cdot x+b=-1$ representam respectivamente os vetores de suporte positivos e negativos, que são os pontos próximos à margem do hiperplano ideal. A margem máxima, entre os vetores de suporte, é definida por:

$$
\frac{w}{\|w\|} \cdot\left(x_{+}-x_{-}\right)=\frac{w^{T}\left(x_{+}-x_{-}\right)}{\|w\|}=\frac{2}{\|w\|}
$$

As funções de kernel têm o objetivo de projetar os vetores de variáveis de um conjunto de dados em um espaço de maior dimensão, para a classificação de classes originalmente apresentadas em espaços não separáveis linearmente. Com o aumento da dimensão, aumenta a probabilidade desses dados poderem ser linearmente separáveis.

Uma função kernel $\mathrm{K}(\mathrm{xi}, \mathrm{xj})=\varphi(\mathrm{xi}) \mathrm{T} \varphi(\mathrm{xj})$ pode ser usada para treinar a MVS. Uma MVS linear tem $\varphi(x)=x$, assim uma função kernel linear pode ser representada por $K(x i, x j)$ $=x \operatorname{Ti} \mathrm{xj}$.

Foi adotada a estratégia "um contra um" (KNERR; PERSONNAZ; DREYFUS, 1990), para a utilização de MVS para a classificação de muitas classes. Esta estratégia consiste em construir uma máquina vetor de suporte para cada par de classes. Para um problema com c classes, c(c-1)/2 MVSs são treinados para classificar as classes entre as c classes possíveis. 


\subsection{ELIMINAÇÃO RECURSIVA DE VARIÁVEIS (ERV)}

Dado um algoritmo de classificação, que possa estimar pesos para as variáveis de um conjunto de dados, o objetivo da Eliminação Recursiva de Variáveis (ERV), do inglês Recursive Feature Elimination (RFE) (GUYON, 2002), é selecionar variáveis por meio da redução recursiva da quantidade de variáveis, eliminando recursivamente as variáveis de menor peso para classificação por meio do algoritmo adotado.

Primeiramente, um modelo é treinado, utilizando o conjunto de dados inicial e o algoritmo selecionado, durante o treinamento são atribuídos pesos para cada variável, representando a importância de cada variável para a classificação. Em seguida, as variáveis com menor peso são eliminadas do conjunto de dados. Este processo, de treinamento, ordenamento de variáveis e eliminação de variáveis menos importantes, é repetido recursivamente até a obtenção do número desejado de variáveis, ou até a satisfação de alguma condição, como um limiar de taxa de erro de um algoritmo de classificação.

As variáveis com maiores pesos apresentam maior influência na classificação (GUYON, 2002). Desta forma, se um algoritmo de classificação apresenta boa acurácia, as variáveis com maiores pesos representam as variáveis que apresentam maior influência para a classificação.

MVS-ERV (GUYON, 2002) é uma aplicação da ERV utilizando os pesos obtidos por meio do treinamento utilizando MVS como algoritmo de classificação, para identificar as variáveis mais importantes para predições de classificação e eliminar recursivamente as variáveis que menos influenciam na classificação. 


\section{METODOLOGIA}

Neste capítulo são apresentados os aspectos metodológicos utilizados neste trabalho. No Subcapítulo 3.1 é apresentado o método de pesquisa; no Subcapítulo 3.2 são apontados o universo e a amostra; o Subcapítulo 3.3 abordará os procedimentos de coleta, de tratamento e de análise dos dados desta pesquisa.

\subsection{MÉTODO DA PESQUISA}

Tradicionalmente, o método utilizado para identificação dos FCS é o de Bullen e Rockart (1981). Esse método é empírico, uma vez que observa um fenômeno no mundo social, a fim de propiciar o conhecimento sobre este fenômeno (BHATTACHARYA, 2008), e baseado em entrevistas. Inicialmente, realiza-se pesquisa bibliográfica em que se busca a formulação de hipóteses que auxiliem a definição do FCS. Depois, realiza-se pesquisa de campo, com abordagem qualitativa, aplicando-se questionários contendo o roteiro para entrevistas individuais. De acordo com Merriam (2002, p. 6), o estudo qualitativo visa "descobrir e compreender um fenômeno, um processo, ou as perspectivas e visão de mundo das pessoas nele envolvidas".

Segundo Rocha et al (201) e Rocha e Delamaro (2013), a pesquisa em FCS é relativamente difícil, envolvendo subjetividade, incerteza, ambiguidades, inconsistência e eventuais contradições que surgem na análise dos dados coletados em pesquisas de opinião.

O universo desta pesquisa é a APF o que torna o trabalho ainda mais complexo pela dificuldade no acesso aos executivos da GTI, perfil adequado aos respondentes.

Para esta pesquisa, o método de Bullen e Rockart (1981) será utilizado parcialmente, uma vez que os objetivos da tese buscam além da identificação, a investigação e a aplicabilidade dos FCS em GTI na APF.

Segundo Zikmund (1997), as pesquisas objetivam compreender a natureza ambígua de determinados problemas, procurando ainda obter um melhor entendimento das dimensões envolvidas sem, no entanto, pretender produzir uma evidência conclusiva.

Quanto aos fins e natureza, esta pesquisa é exploratória, descritiva e aplicada. Inicialmente, a pesquisa é exploratória, uma vez que houve a necessidade de se ter maior entendimento do fenômeno a ser estudado (MALHOTRA, 2001). Depois a pesquisa é descritiva por expor as características de uma determinada população. Para Malhotra (2001) a 
pesquisa descritiva busca ser conclusiva tendo como principal objetivo à descrição de algo que normalmente são características ou funções do mercado. É aplicada por possuir uma finalidade prática que é contribuir para a análise de GTI na APF no Brasil.

A abordagem da pesquisa utilizou análise qualitativa e quantitativa. De acordo com Merriam (2002, p. 6) o estudo qualitativo visa "descobrir e compreender um fenômeno, um processo, ou as perspectivas e visão de mundo das pessoas nele envolvidas". Já a pesquisa quantitativa "procura quantificar os dados e aplica alguma forma da análise estatística" (MALHOTRA, 2001, p.155).

A Figura 20 apresenta o método de pesquisa que será divido em quatro fases.

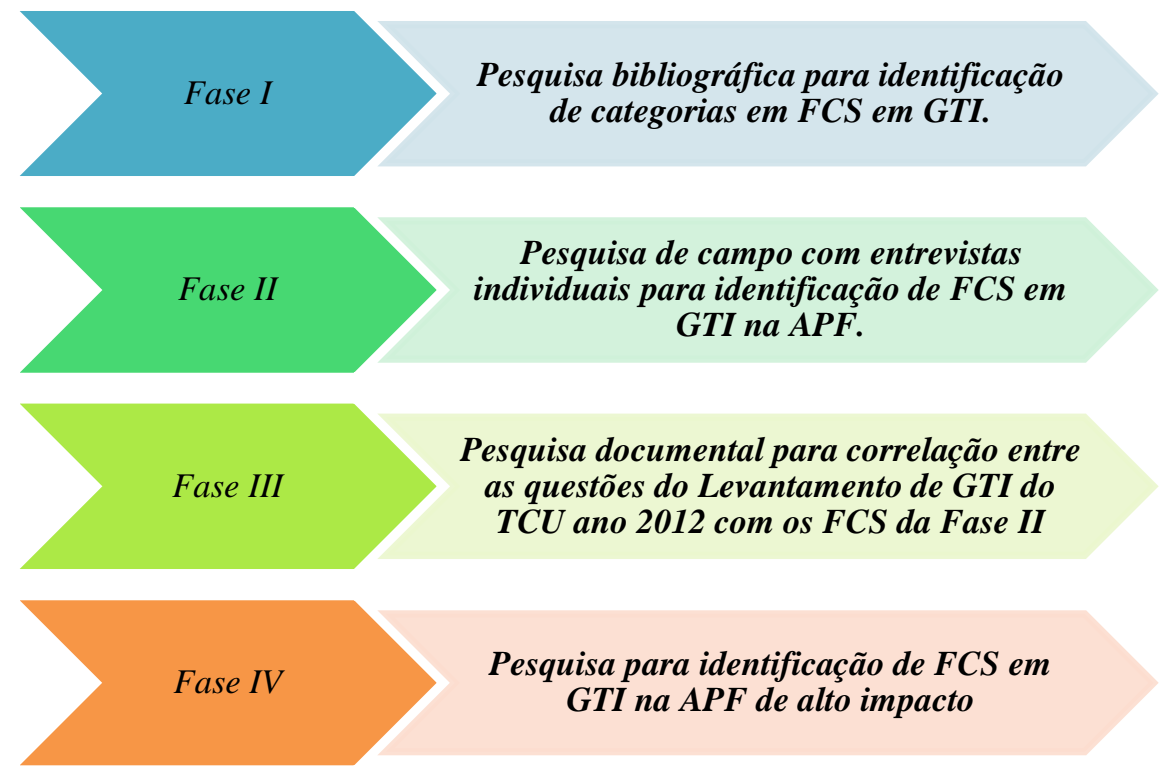

Figura 20 - Método de Pesquisa

Fonte: Dados da Pesquisa

A primeira fase da pesquisa com abordagem qualitativa contemplou duas análises, uma sobre o tema AC e outra sobre FCS em GTI.

Para a seleção das publicações, foi realizada pesquisa bibliográfica em que os artigos selecionados possuem relevância científica, conforme classificação da Thompson Reuters e Web of Science.

$\mathrm{Na}$ segunda fase, foram realizadas 26 entrevistas com executivos de TI de instituições públicas com desempenho considerado "Aprimorado" pelo Levantamento de GTI do TCU ano 2012. As entrevistas foram realizadas entre os meses de agosto e de novembro de 2014. Frisa-se que neste período não havia sido liberado o resultado do Levantamento de GTI do TCU ano 2014. 
$\mathrm{Na}$ terceira fase, foi realizada a pesquisa documental com base no questionário do Levantamento de GTI do TCU ano 2012 e em relatórios de feedback entregue por este órgão às instituições avaliadas da Fase II. Essa pesquisa objetivou a identificação das questões que possuem correlação temática com os FCS identificados na segunda fase.

$\mathrm{Na}$ quarta fase, a pesquisa se baseou em análise multivariada. Como esta pesquisa tem como objetivo a identificação estatística dos FCS, o método complementar ao levantamento de FCS identificados anteriormente, será utilizada a ACP, motivado pela complexidade do Levantamento de GTI de 2012 e pela capacidade de identificação de componentes principais por meio da análise multivariada.

\subsection{UNIVERSO E AMOSTRA}

Baseado na definição de Vergara (2006) sobre o universo da pesquisa como sendo um conjunto de elementos (empresas, produtos, pessoas, por exemplo), que possuem as características que são o objeto de estudo.

O universo dessa pesquisa são as instituições da APF jurisdicionadas pelo TCU, e a amostra considerou os mesmos critérios de seleção utilizados pelo Setfi em seus levantamentos e fiscalizações.

Assim, a amostra compreende 349 instituições públicas avaliadas no Levantamento de GTI do TCU ano 2012. Também constam universidades federais, tribunais federais, agências reguladoras, fundações, autarquias, secretarias, departamentos, empresas públicas, sociedades de economia mista, ministérios e outros órgãos da administração federal direta. Estão excluídas dessa amostra todas as instituições que, apesar de jurisdicionadas ao Tribunal, não prestam contas (p.ex. instituições que fazem parte do Sistema $S^{\mathbf{8}}$.).

Frisa-se que dentre as 349 instituições, 54 são consideradas “Aprimoradas”, 171 são "Intermediárias" e 124 órgãos são classificados pelo Levantamento de GTI do TCU ano 2012 como "Inicial".

\footnotetext{
${ }^{8}$ São os serviços sociais autônomos, "paraestatais, de cooperação com o Poder Público, com administração e patrimônio próprios, revestindo a forma de instituições particulares convencionais...SENAI, SENAC, SESC, SESI, SENAR, SEST e SEBRAE” (PIETRO, 2007, p.458)
} 


\subsection{PROCEDIMENTOS DE COLETA, TRATAMENTO E ANÁLISE DOS DADOS}

O Subcapítulo 3.3 é dividido em quatro seções terciárias: Seção 3.3.1 que mostra as diretrizes da pesquisa bibliográfica; a Seção 3.3.2 que aborda o método das entrevistas individuais; a Seção 3.3.3 que revela a pesquisa documental; e a Seção 3.3.4 que descreve o método da pesquisa quantitativa deste trabalho.

\subsubsection{Pesquisa Bibliográfica}

Para esta pesquisa bibliográfica, utilizou-se o software Publish and Perish ${ }^{\mathrm{TM}}$ (PoPTM) para busca de publicações (HARZING, 2010; HARZING;VAN DER WAL, 2008). Em 2006, o PoPтм foi elaborado pela pesquisadora Harzing da Research in International and Crosscultural e desde o início a ferramenta está disponível livremente. Adicionalmente, foram verificadas as bases de dados Capes, ProQuest, Jstor e Citeseer.

\section{Coleta}

O filtro para a busca dos artigos usou termos da língua inglesa, a fim de identificar periódicos bem conceituados internacionalmente.

Para a primeira análise empregou-se como critério de seleção as expressões 'enterprise architecture' e 'public administration'. Tal análise objetivou identificar elementos de arquitetura corporativa pública que pudessem auxiliar na análise da GTI da APF, uma vez que esse assunto é parte das discussões sobre GTI em administrações públicas internacionais (SCHEKKERMAN, 2004).

Depois, para a segunda análise se aplicou os termos 'success critical factors', 'IT governance’ e “rockart”. O objetivo específico dessa análise é extrair os FCS em GTI de publicações relevantes e com menção aos trabalhos de Rockart (1979, 2002), que é base teórica e metodológica desta pesquisa.

Não houve limitação temporal no escopo desta pesquisa, fazendo-se a ressalva de que foram selecionados artigos publicados até o mês de maio de 2014, período em que foram realizadas as análises, caracterizando-se como um estudo longitudinal. 


\section{Tratamento}

Após a tabulação, excluíram-se artigos de eventos (congressos, conferências, seminários, workshops e work paper), capítulos e livros. Depois todos os artigos foram submetidos ao indicador JCR que mede a influência científica média do artigo de um periódico, expressando a discussão científica média global de um artigo da revista, por meio da quantidade de citações por documento que mede o impacto científico de um artigo publicado. Para isso, utiliza-se a mesma fórmula de fator de impacto jornal da Web of Science. A Web of Science também foi utilizada para a análise dos periódicos.

Antes do tratamento, obtiveram-se mil artigos de "enterprise architecure" e "public administration" (mil artigos é a capacidade máxima de extração do PoPTM, que considera apenas os mil mais citados). Depois do tratamento, restaram 118 artigos que foram utilizados para a análise bibliométrica.

Antes do tratamento, levantaram-se 266 publicações de "critical success factors" e "IT governance", depois restaram 46, que foram utilizados para a análise bibliométrica. Depois, para a identificação de categorias referentes aos FCS em GTI, apenas 17 desses artigos foram usados, já que o conteúdo atendia ao objetivo proposto.

\section{Análise}

Para o tratamento dos dados oriundos da pesquisa bibliográfica da primeira fase da pesquisa, empregou-se a análise de bibliometria. A bibliometria é o estudo da produção bibliográfica, disseminação e uso da informação registrada, incluindo todos os aspectos quantitativos (SCHNEIDER; BORLUND, 2004).

Para este trabalho, os enfoques utilizados sobre a quantificação dos produtos da atividade científica são Lotka, Bradford e Zipf. Segundo Santos e Kobashi (2009), Lotka elaborou em 1926 a lei do quadrado inverso para o cálculo da produtividade de autores de artigos científicos. Em Lotka, os autores que mais produzem sobre determinado tema são mais relevantes para análise do que os que produzem menos, enquanto a lei de Zipf se refere à ocorrência de palavras ao longo de um texto e a lei de Bradford trata da dispersão dos artigos em diferentes publicações periódicas (SANTOS; KOBASHI, 2009).

Além disso, foram utilizados indicadores bibliométricos que dão uma imagem confiança, pelo menos substancial da atividade científica (SCHNEIDER; BORLUND, 2004). 
Os indicadores bibliométricos utilizados neste estudo são "área de concentração da revista" (SAUL et al, 2012; SCHNEIDER; BORLUND, 2004), "fator de impacto" (SCHNEIDER; BORLUND, 2004), "quantidade de citações por artigos publicados" (RINIA; VAN LEEUWEN; VAN VUREN, 1998), "ano de publicação", "países que participam no o estudo", "palavra-chave”, “editora”, “periódico” (SAUL et al, 2012),

\subsubsection{Entrevistas Individuais}

Para esta fase, a fonte principal de coleta de dados é a entrevista pessoal. As entrevistas individuais minimizam as respostas "politicamente corretas", que poderiam ocultar importantes informações e por evitar tendências à concordância com líderes presentes (ROCKART, 2002).

Para esta tese, as questões são semiestruturadas para identificação de FCS em GTI. Pesquisas em FCS (ROCHA et al., 2010; ROCHA; DELAMARO, 2013) realizam a pesquisa bibliográfica para identificação dos FCS e logo após realizam pesquisas estruturadas para a validação dos FCS. Portanto, os FCS em GTI identificados (Fase I) serão avaliados como hipóteses.

Para essas entrevistas, empregou-se um questionário mediante o envio da carta de apresentação. A carta de apresentação do questionário está no Anexo I e o questionário está no Anexo II.

A construção do questionário se baseou em um questionário aplicado em quinze órgãos da APF sobre maturidade em AC de TI, de setembro a outubro do ano 2009, com o objetivo de validar a maturidade dos órgãos nas dimensões da AC de TI. Além disso, essa pesquisa em maturidade de AC de TI também objetivou verificar se os respondentes teriam dificuldade na concepção dos subsistemas Direcionamento, Desenvolvimento e Entrega (RAMOS, 2009). Nesse estudo, conferiu-se que os entrevistados responderam às questões sem dificuldade, atestando a aplicabilidade desse instrumento de pesquisa.

Nesta pesquisa, o questionário foi adaptado para coletar os FCS em GTI. Foram realizados quatro pré-testes até o questionário final com 20 questões. As questões de 1 a 11 são sobre o Perfil da Organização e ao Perfil do Entrevistado. Depois as questões de 12 a 14 identificam e descrevem os FCS em GTI, para cada um dos três subsistemas de TI, explorados na Seção 2.3.3. As questões de 15 a 17 averiguam do grau de maturidade do conteúdo do 
FCS, por meio de suas respectivas práticas. Finalmente, as questões 18 a 20 perguntam sobre a forma de identificação/definição dos FCS em GTI no órgão, sobre a estrutura organizacional da TI/CGTI e sobre a arquitetura que descreve a GTI.

Para a averiguação da maturidade do FCS em GTI, optou-se por múltiplas respostas, embora existam trabalhos que optam pelo uso de escalas (COSTA; SOUZA; GOUVEA, 2007; ALVES, 2012). Neste trabalho, as questões de múltiplas respostas foram baseadas na escala utilizada por Luftman (2003), são elas:

1. se não possui as práticas formalizadas relacionadas ao FCS em GTI, com lacunas no seu entendimento pelas partes interessadas.

2. se divulga o conteúdo do FCS em GTI pelos meios de comunicação disponíveis (revistas, sites, emails, blogs e wikis) com o entendimento das partes interessadas.

3. se aprende e discute o conteúdo do FCS em GTI por meio de treinamentos, reuniões departamentais, palestras entre outros meios de aprendizado com uma boa compreensão.

4. se as partes interessadas possuem um bom entendimento e incentivam as práticas vinculadas aos FCS em GTI.

5. se existem medidas de gestão (formas de mensuração) que possibilitam o monitoramento do FCS em GTI buscando uma maior eficácia e eficiência de seus resultados.

Para análise da maturidade das práticas associadas aos FCS, essas medidas serão sumarizadas em: $i)$ práticas formalizadas; ii) práticas divulgadas; iii) práticas aprendidas e discutidas; $i v$ ) práticas compreendidas pelas partes interessads; e $v$ ) práticas com medidas de gestão.

Tal adaptação foi pertinente, uma vez que as deduções realizadas por meio de escalas podem ser falhas, por exemplo, em uma instituição o conteúdo referente a um FCS pode ser amplamente discutido, mas não está formalizado. Logo, respondendo a uma escala qualquer, a instituição pontuaria o menor grau, ou seja, a preocupação em relação ao FCS não seria computada e a evidência sobre futuras práticas estaria perdida. 


\section{Coleta}

Para a coleta dos FCS, foram realizadas 26 entrevistas com executivos de TI de 26 instituições públicas classificadas como “Aprimorada” em GTI pelo TCU, fruto do resultado do iGovTI, superior a 0,6. Entretanto, o Ministério da Fazenda, a Secretaria do Tesouro Nacional e a Secretaria da Receita Federal do Brasil que possuem resultados que divergem em "Aprimorada" e em "Intermediária" foram consideradas, uma vez que as três instâncias possuem a mesma diretriz em planejamento organizacional.

O TCU não divulgou o ranking dos órgãos com os maiores iGovTI das instituições respondentes, mas indicou como parâmetro de pesquisa a consulta ao site gestaoTI.org.br. (Anexo III), alertando sobre equívocos nas informações sobre posição e o iGovTI. Verificouse durante as entrevistas que essas informações, de fato não são fidedignas, por erro no cálculo do iGovTI (Anexo IV). Todavia, tais erros não comprometeram a qualidade das instituições entrevistadas. Assim, foram enviados 42 convites para a participação da entrevista, 32 órgãos confirmaram a participação na entrevista, entretanto 26 órgãos foram entrevistados. O contato inicial foi por email, caso a instituição não atendesse um novo contato era realizado por telefone. O período entre os contatos e as entrevistas ocorreu entre a segunda quinzena de agosto a primeira quinzena de novembro de 2014. À medida que os contatos eram realizados as reuniões eram agendadas. Durante esse período o telefone da pesquisadora foi encaminhado para o esclarecimento de quaisquer dúvidas.

Bullen e Rockart (1981) instruem que o perfil para identificação dos FCS é executivo. Assim, os cargos da APF que se adequam a esse perfil são:

1. Assessor;

2. Auditor;

3. Capitã de Corveta;

4. Chefe;

5. Coordenador Geral;

6. Diretor;

7. Especialista.

8. General;

9. Gerente Executivo;

10. Gerente;

11. Responsável de Área; 
12. Secretário;

13. Subsecretário;

14. Superintendente;

15. Vice-Presidente.

Para esta fase, além desse perfil é relevante que o entrevistado esteja engajado na GTI, sem necessariamente ser membro do Comitê de $\mathrm{TI}^{9}$.

Do Quadro 6 ao Quadro 8 é apresentado o perfil das instituições. O Quadro 6 mostra que $23,1 \%$ das instituições pesquisadas são empresas públicas.

\begin{tabular}{|l|c|c|c|c|}
\hline \multicolumn{1}{|c}{ Quadro 6 - Perfil da instituição } \\
\hline & Frequência & Porcentual & $\begin{array}{c}\text { Porcentagem } \\
\text { válida }\end{array}$ & $\begin{array}{c}\text { Porcentagem } \\
\text { acumulativa }\end{array}$ \\
\hline Autarquia & 2 & 7,7 & 7,7 & 7,7 \\
\hline Empresa pública & 6 & 23,1 & 23,1 & 30,8 \\
\hline Sociedade de economia mista & 2 & 7,7 & 7,7 & 38,5 \\
\hline Agência reguladora & 3 & 11,5 & 11,5 & 50,0 \\
\hline Tribunal de Contas & 1 & 3,8 & 3,8 & 53,8 \\
\hline Congresso Nacional & 1 & 3,8 & 3,8 & 57,7 \\
\hline Presidência da República & 1 & 3,8 & 3,8 & 61,5 \\
\hline Ministério & 4 & 15,4 & 15,4 & 76,9 \\
\hline Secretaria & 3 & 11,5 & 11,5 & 88,5 \\
\hline Organização Militar & 2 & 7,7 & 7,7 & 96,2 \\
\hline Ministério Público & 1 & 3,8 & 3,8 & 100,0 \\
\hline Total & $\mathbf{2 6}$ & $\mathbf{1 0 0 , 0}$ & $\mathbf{1 0 0 , 0}$ & - \\
\hline
\end{tabular}

Fonte: Dados da pesquisa

O Quadro 7 mostra que a maioria das instituições pesquisadas participaram dos Levantamentos de GTI do TCU nos anos 2007, 2010 e 2012.

Quadro 7- Anos que o órgão participou no levantamento da GTI realizado pelo TCU/Sefti

\begin{tabular}{|l|c|c|c|c|}
\hline $\begin{array}{c}\text { Período de Participação no } \\
\text { Levantamento de GTI }\end{array}$ & Frequência & Porcentual & $\begin{array}{c}\text { Porcentagem } \\
\text { válida }\end{array}$ & $\begin{array}{c}\text { Porcentagem } \\
\text { acumulativa }\end{array}$ \\
\hline Participação apenas ano 2012 & 2 & 7,7 & 7,7 & 7,7 \\
\hline $\begin{array}{l}\text { Participação apenas nos anos 2010 } \\
\text { e 2012 }\end{array}$ & 5 & 19,2 & 19,2 & 26,9 \\
\hline Participação em todos os três anos & 19 & 73,1 & 73,1 & 100,0 \\
\hline Total & $\mathbf{2 6}$ & $\mathbf{1 0 0 , 0}$ & $\mathbf{1 0 0 , 0}$ & \\
\hline
\end{tabular}

Fonte: Dados da pesquisa

O Quadro 8 revela que mais da metade das instituições pesquisadas possuem de 7 a 8 pessoas que atuam GTI. Essa não é a quantidade de membros do Comitê de TI, mas de profissionais que dão suporte ao Comitê, uma vez que nas instituições pesquisadas existe a

\footnotetext{
${ }^{9}$ Para a APF do Brasil não existe a obrigatoriedade da formação de Conselho Administrativo ou de Comitês de Governança Corporativa. Entretanto, a Instrução Normativa 04 do TCU orienta sobre implementação do Comitê de TI.
} 
estrutura do Comitê de TI e o grupo de apoio aos trabalhos em GTI. As frequências apresentadas variam de 1 a 8 pessoas.

Quadro 8- Quantidade de pessoas que fazem parte dos trabalhos em GTI da instituição
\begin{tabular}{|l|c|c|c|c|}
\hline \multicolumn{1}{|c|}{ Intervalo de pessoas } & Frequência & Porcentual & $\begin{array}{c}\text { Porcentagem } \\
\text { válida }\end{array}$ & $\begin{array}{c}\text { Porcentagem } \\
\text { acumulativa }\end{array}$ \\
\hline De 1 a 5 pessoas & 7 & 26,9 & 29,2 & 29,2 \\
\hline De 5 a 10 pessoas & 8 & 30,8 & 33,3 & 62,5 \\
\hline De 10 a 15 pessoas & 3 & 11,5 & 12,5 & 75,0 \\
\hline De 15 a 20 pessoas & 1 & 3,8 & 4,2 & 79,2 \\
\hline De 20 a 25 pessoas & 4 & 15,4 & 16,7 & 95,8 \\
\hline Mais de 25 pessoas & 1 & 3,8 & 4,2 & 100,0 \\
\hline Total & $\mathbf{2 4}$ & $\mathbf{9 2 , 3}$ & $\mathbf{1 0 0 , 0}$ & \\
\hline Ausente & 2 & $\mathbf{7 , 7}$ & & \\
\hline Total & $\mathbf{2 6}$ & $\mathbf{1 0 0 , 0}$ & & \\
\hline
\end{tabular}

Fonte: Dados da pesquisa

Os Quadros 9 a 11 apresentam brevemente o perfil dos entrevistados. 30,8\% são Coordenadores Gerais de TI (Quadro 9) e, em geral, a principal a atribuição desses profissionais é o suporte a implementação da GTI ou GTIC.

Quadro 9- Cargo do entrevistado

\begin{tabular}{|c|c|c|c|c|}
\hline Cargo & Frequência & Porcentual & $\begin{array}{c}\text { Porcentagem } \\
\text { válida }\end{array}$ & $\begin{array}{c}\text { Porcentagem } \\
\text { acumulativa }\end{array}$ \\
\hline Assessor & 1 & 3,8 & 3,8 & 3,8 \\
\hline Chefe & 1 & 3,8 & 3,8 & 7,7 \\
\hline Coordenador Geral & 8 & 30,8 & 30,8 & 38,5 \\
\hline Diretor & 3 & 11,5 & 11,5 & 50,0 \\
\hline Gerente & 4 & 15,4 & 15,4 & 65,4 \\
\hline Secretário & 1 & 3,8 & 3,8 & 69,2 \\
\hline Superintendente & 3 & 11,5 & 11,5 & 80,8 \\
\hline Vice-presidente & 1 & 3,8 & 3,8 & 84,6 \\
\hline Responsável de Área & 1 & 3,8 & 3,8 & 88,5 \\
\hline General & 1 & 3,8 & 3,8 & 92,3 \\
\hline Capitã de Corveta & 1 & 3,8 & 3,8 & 96,2 \\
\hline Especialista & 1 & 3,8 & 3,8 & 100,0 \\
\hline Total & 26 & 100,0 & 100,0 & \\
\hline
\end{tabular}

Fonte: Dados da pesquisa

O Quadro 10 apresenta o tempo que esses profissionais atuam na GTI. Mais da metade dos entrevistados tem experiência de mais de cinco anos em GTI.

Quadro 10- Tempo em que atua na GTI

\begin{tabular}{|l|c|c|c|c|}
\hline \multicolumn{1}{|c|}{ Anos } & Frequência & Porcentual & $\begin{array}{c}\text { Porcentagem } \\
\text { válida }\end{array}$ & $\begin{array}{c}\text { Porcentagem } \\
\text { acumulativa }\end{array}$ \\
\hline Menos de 1 ano & 2 & 7,7 & 7,7 & 7,7 \\
\hline Entre 1 e 3 anos & 6 & 23,1 & 23,1 & 30,8 \\
\hline Entre 3 e 5 anos & 3 & 11,5 & 11,5 & 42,3 \\
\hline Entre 5 e 7 anos & 6 & 23,1 & 23,1 & 65,4 \\
\hline Mais de 7 anos & 9 & 34,6 & 34,6 & 100,0 \\
\hline Total & $\mathbf{2 6}$ & $\mathbf{1 0 0 , 0}$ & $\mathbf{1 0 0 , 0}$ & \\
\hline
\end{tabular}

Fonte: Dados da pesquisa 
O Quadro 11 e o Quadro 12 são referentes aos treinamentos/cursos que os participantes da entrevista realizaram que os auxiliaram em GTI. Nota-se que a maioria dos entrevistados já participara de treinamentos para esse fim (Quadro 11).

Quadro 11- Curso/treinamento sobre governança de TI

\begin{tabular}{|l|c|c|c|c|}
\hline Participação & Frequência & Porcentual & Porcentagem válida & Porcentagem acumulativa \\
\hline Não & 3 & 11,5 & 11,5 & 11,5 \\
\hline Sim & 23 & 88,5 & 88,5 & 100,0 \\
\hline Total & $\mathbf{2 6}$ & $\mathbf{1 0 0 , 0}$ & $\mathbf{1 0 0 , 0}$ & \\
\hline
\end{tabular}

Fonte: Dados da pesquisa

O Quadro 12 expõe que os entrevistados possuem mais de 200 horas de treinamento/curso. Geralmente essa carga horária é complementada por mestrado profissionalizante, não necessariamente em GTI, mas também incluem cursos em estratégia e planejamento empresarial.

\begin{tabular}{|l|} 
Quadro 12- Horas em treinamentos recebidos em GTI \\
\begin{tabular}{|l|c|c|c|c|}
\hline \multicolumn{1}{|c|}{ Horas } & Frequência & Porcentual & $\begin{array}{c}\text { Porcentagem } \\
\text { válida }\end{array}$ & $\begin{array}{c}\text { Porcentagem } \\
\text { acumulativa }\end{array}$ \\
\hline Menos de 10 horas & 1 & 3,8 & 4,2 & 4,2 \\
\hline Entre 20 horas e 60 horas semanas & 1 & 3,8 & 4,2 & 8,3 \\
\hline Entre 60 horas e 100 horas & 4 & 15,4 & 16,7 & 25,0 \\
\hline Entre 100 horas e 200 horas & 3 & 11,5 & 12,5 & 37,5 \\
\hline Mais de 200 horas & 15 & 57,7 & 62,5 & 100,0 \\
\hline Total & $\mathbf{2 4}$ & $\mathbf{9 2 , 3}$ & $\mathbf{1 0 0 , 0}$ & \\
\hline Não informaram & 2 & 7,7 & & \\
\hline Total & $\mathbf{2 6}$ & $\mathbf{1 0 0 , 0}$ & \\
\hline
\end{tabular} \\
\hline
\end{tabular}

\section{Tratamento da Entrevista}

Os FCS foram postos em uma planilha, em que contabilizamos um total de 385 fatores das 26 entrevistas, 14,8 FCS por entrevista. Inicialmente, esses fatores foram reunidos nos três subsistemas, conforme orientação dos entrevistados. Depois, foram identificadas e separadas as redundâncias, resultando em 259 FCS.

\section{Análise da Entrevista}

Para a análise desses FCS, usou-se análise de conteúdo categorial temática que se organiza em torno de três fases: $i$ ) pré-análise; $i i$ ) exploração do material e; iii) tratamento dos 
dados, inferência e interpretação (BARDIN, 2012). Esse método permitiu a categorização por temas dos FCS identificados.

Segundo Bardin (2012), o tema é a unidade de significação que se liberta naturalmente de um texto analisado segundo certos critérios relativos à teoria que serve de guia à leitura. Depois, cada um dos "núcleos de sentido" foi denotado com o nome de uma categoria, inspiradas na literatura e nos dados obtidos no campo, designadas por grade mista (VERGARA, 2008). A partir dessas categorias foi possível identificar os conteúdos semelhantes e afins com as questões do Levantamento de GTI de 2012 do TCU.

Descobriram-se 32 "núcleos de sentido" que possuem um significado para o objeto analítico escolhido. Esses núcleos serão denominados de categorias. As categorias foram organizadas conforme a meta arquitetura corporativa de TI do Subcapítulo 2.3.2. Depois, identificaram-se dentre as questões do Levantamento de GTI de 2012 do TCU, aquelas cujo conteúdo fosse afim com fatores identificados anteriormente.

\subsubsection{Pesquisa Documental}

A Fase III desta pesquisa se refere à pesquisa documental. Segundo Bardin (2012), a pesquisa documental objetiva dar forma conveniente e representar de outro modo a informação contida no documento analisado, utilizando procedimentos de transformação.

\section{Coleta}

A coleta de dados contemplou informações disponibilizadas da base de dados do Levantamento de GTI ano 2012, do questionário de avaliação do Levantamento de GTI ano 2012, das informações públicas disponíveis nos sítios eletrônicos sobre GTI e dos relatórios de feedback do Levantamento de GTI. Para solicitação do banco de dados do Levantamento de GTI, utilizou-se o acesso à Lei de Informação do TCU; já para acesso aos relatórios de feedback com informação de posição e de índice do iGovTI, os canais são diversos.

Segundo Nota Técnica/2012/OGU/CGU-PR (Ref. 72550.000078/2012-51) sobre recurso de acesso ao relatório de feedback, o CGU cita que o TCU classifica essas informações como restritas, destinadas "apenas à administração superior da instituição à qual se refere e para uso interno do TCU”. Em consulta à Sefti /TCU, a Nota dispõe que (Parágrafo 14): 
(...), a classificação que o TCU vier a fazer das informações do Levantamento de Governança de TI 2012 não afeta a classificação que elas devam ter nessas instituições, particularmente diante da Lei 12.527/2011, cabendo às mesmas julgar a conveniência de divulgar ou não suas próprias informações, até mesmo antes da efetiva conclusão do relatório do levantamento por parte do TCU, em função da classificação de tais informações atribuída pelas instituições e de acordo com os critérios de suas Políticas de Segurança da Informação.(...).'

Conforme a Lei de Acesso a Informação a indicação de sigilo "restrito" não tem guarida na Lei. O requerente dessa Nota também alegou que

a) segundo a Lei 12.527/2011, a negativa demandaria classificação pelo órgão e disponibilização da parte não sigilosa; b) mais de uma centena de órgãos já respondeu ao mesmo questionamento.

A Nota Técnica/2012/OGU/CGU-PR (Ref.. 25820.000478/2012-59) conclui que as informações sobre posição e índice do iGovTI possuem natureza pública.

Atualmente, poucos órgãos disponibilizam o documento ou as informações parciais relativas às posições ou ao índice. Os Quadros 13 e 14 mostram os órgãos que divulgam total ou parcialmente as informações do relatório de feedback do TCU.

Quadro 13 - Órgãos que divulgaram relatório de feedback em site no ano de 2012

\begin{tabular}{|c|c|c|}
\hline $\begin{array}{l}\text { Òrgãos que divulgaram relatório } \\
\text { de feedback em site ano } 2012\end{array}$ & Sigla & Localização \\
\hline Tribunal de Contas da União & TCU & $\begin{array}{l}\text { http://portal2.tcu.gov.br/portal/page/portal/TCU/c } \\
\text { omunidades/governanca_ti }\end{array}$ \\
\hline Anvisa & Anvisa & $\begin{array}{l}\text { http://portal.anvisa.gov.br/wps/wcm/connect/edc1 } \\
\text { da804d9b27b6b9ccf9c116238c3b/2012+relatorio } \\
\text { +TCU+governa\%C3\%A7a+2012+pdf.pdf?MOD } \\
\text { =AJPERES }\end{array}$ \\
\hline Controladoria Geral da União & CGU & $\begin{array}{l}\text { http://www.cgu.gov.br/sobre/institucional/planeja } \\
\text { mento/arquivosti/governanca-ti-2012.pdf }\end{array}$ \\
\hline $\begin{array}{l}\text { Fundação da } \\
\text { Brasília }\end{array}$ & UnB & http://www.cpd.unb.br/auditoria \\
\hline Tribunal Reginal Eleitoral/PI & TRE/PI & $\begin{array}{l}\text { http://www.tre- } \\
\text { pi.jus.br/institucional/governanca/governanca-de- } \\
\text { tecnologia-da-informacao/relatorio-de- } \\
\text { governanca-de-ti }\end{array}$ \\
\hline Universidade Federal de São Paulo & $\begin{array}{l}\text { UNIFES } \\
\text { P }\end{array}$ & $\begin{array}{l}\text { http://ceti.unifesp.br/pdti/anexos-nao-incluidos- } \\
\text { no-peti/anexo-xxxi }\end{array}$ \\
\hline Ministério das Comunicações & $\mathrm{MC}$ & http://www.mc.gov.br/auditorias \\
\hline $\begin{array}{l}\text { Agência Nacional de } \\
\text { Elétrica }\end{array}$ & ANEEL & $\begin{array}{l}\text { http://www.aneel.gov.br/arquivos/PDF/igovti201 } \\
\text { 2.pdf }\end{array}$ \\
\hline
\end{tabular}

Fonte: Dados da pesquisa 
Quadro 14 - Órgãos que divulgaram informações do relatório de feedback em site no ano de 2012

\begin{tabular}{|c|c|c|}
\hline $\begin{array}{l}\text { Òrgãos que divulgaram } \\
\text { informações do relatório de } \\
\text { feedback ano } 2012\end{array}$ & Sigla & Localização \\
\hline Tribunal Regional do Trabalho/MT & TRT/MT & $\begin{array}{l}\text { http://portal.trt23.jus.br/ecmdemo/public/trt23/det } \\
\text { ail?content- } \\
\text { id=/repository/collaboration/sites\%20content/live } \\
\text { /trt23/web\%20contents/Noticias/trtmt-e- } \\
\text { destaque-em-levantamento-sobre-governanca-de- } \\
\text { ti-realizado-pelo-tcu\%5B2\%5D }\end{array}$ \\
\hline $\begin{array}{l}\text { Empresa Brasileira de Correios e } \\
\text { Telégrafos }\end{array}$ & ECT & $\begin{array}{l}\text { http://www.correios.com.br/sobre-correios/a- } \\
\text { empresa/eventos/forum-de-governanca-de- } \\
\text { ti/pdf/apresentacao-forum-de-governanca-em-ti }\end{array}$ \\
\hline $\begin{array}{l}\text { Fundação da Universidade Federal } \\
\text { Fluminense }\end{array}$ & UFF & $\begin{array}{l}\text { http://www.governancadeti.uff.br/noticias/uff- } \\
\text { melhora-indice-de-governanca-de-ti-segundo-tcu }\end{array}$ \\
\hline $\begin{array}{l}\text { Fundação da Universidade Federal } \\
\text { de Minas Gerais }\end{array}$ & UFMG & $\begin{array}{l}\text { https://www.ufmg.br/dti/phocadownload/userupl } \\
\text { oad/DPS_ApresentacaoGovernanca_v3.pdf }\end{array}$ \\
\hline $\begin{array}{l}\text { Universidade Tecnológica Federal do } \\
\text { Paraná }\end{array}$ & UTFPR & $\begin{array}{l}\text { http://www.getic.ct.utfpr.edu.br/Igetic/monografi } \\
\text { aivantuil.pdf }\end{array}$ \\
\hline $\begin{array}{l}\text { Departamento Nacional de Obras } \\
\text { Contra as Secas }\end{array}$ & DNOCS & $\begin{array}{l}\text { http://www.oestadoce.com.br/noticia/dnocs-tem- } \\
\text { avancos-na-governanca-de-ti-segundo-analise- } \\
\text { do-tcu }\end{array}$ \\
\hline $\begin{array}{l}\text { Tribunal Regional do Trabalho 13a } \\
\text { região/PB }\end{array}$ & TRT/PB & $\begin{array}{l}\text { http://www.trt13.jus.br/informe- } \\
\text { se/noticias/2013/02/trt-da-paraiba-fica-na-17a- } \\
\text { colocacao-na-avaliacao-do-tcu-em-governanca- } \\
\text { de-ti }\end{array}$ \\
\hline $\begin{array}{l}\text { Tribunal Regional do Trabalho } 14 \mathrm{a} \\
\text { região/RO/AC }\end{array}$ & $\begin{array}{l}\mathrm{TRT} / \mathrm{RO} / \\
\mathrm{AC}\end{array}$ & $\begin{array}{l}\text { http://www.trt14.jus.br/noticias/- } \\
\text { /asset_publisher/8mjI/content/desembargadores- } \\
\text { e-gestores-debatem-acoes-para-melhoria-do- } \\
\text { plano-de-governanca-de- } \\
\text { ti?redirect=http\%3A\%2F\%2Fwww.trt14.jus.br\% } \\
\text { 2Fnoticias\%3Fp_p_id\%3DI101_INSTANCE_8m } \\
\text { j1\%26p_p_lifecycle\%3DI\%26p_p_state\%3Dnor } \\
\text { ma1\%26p_p_mode\%3Dview\%26p_p_col_id\%3D } \\
\text { column- } \\
\text { 1\%26p_p_col_pos\%3DI1\%26p_p_col_count\%3 } \\
\text { D2 }\end{array}$ \\
\hline Transporte Gasoduto Bolívia Brasil & TGB & $\begin{array}{l}\text { http://web.tbg.com.br/ra2012/gestao- } \\
\text { recursos.html }\end{array}$ \\
\hline $\begin{array}{l}\text { Ministério Público do Distrito } \\
\text { Federal e Territórios }\end{array}$ & MPDFT & $\begin{array}{l}\text { http://www.mundopositivo.com.br/noticias/2013 } \\
\text { 4996- } \\
\text { para_tcu_mp_do_distrito_federal_e_o_melhor_d } \\
\text { o_pais.html }\end{array}$ \\
\hline Tribunal Regional Eleitoral/CE & TRE/CE & $\begin{array}{l}\text { http://apps.tre-ce.jus.br/tre/servicos/sessoes-do- } \\
\text { pleno/2012/12/Ata262.pdf }\end{array}$ \\
\hline $\begin{array}{l}\text { Tribunal Regional } \\
\text { região } / \mathrm{MG}\end{array}$ & TRT/MG & $\begin{array}{l}\text { http://www.trt3.jus.br/gestaoestrategica/download } \\
\text { /PDTI.pdf }\end{array}$ \\
\hline $\begin{array}{l}\text { Instituto Brasileiro do Meio } \\
\text { Ambiente e dos Recursos Naturais } \\
\text { Renováveis }\end{array}$ & IBAMA & $\begin{array}{l}\text { http://www.ibama.gov.br/phocadownload/acesso } \\
\text { _a_informacao/relatorio_de_gestao_do_ibama_e } \\
\text { xercicio_2012.pdf }\end{array}$ \\
\hline
\end{tabular}

Fonte: Dados da pesquisa 


\section{Tratamento}

Basicamente para o atingimento do objetivo desta fase, o principal documento utilizado foi o banco de dados do Levantamento de GTI do TCU ano 2012. Além disso, um relatório de feedback foi necessário para eventuais dúvidas.

\section{Análise}

Para a análise foram analisados os itens e as questões do Levantamento de GTI do ano 2012 do TCU. Depois foram verificadas as questões que possuem temática similar aos FCS e respectivamente às categorias identificadas na Fase II. Dentre essas questões, 60 foram associadas aos FCS e às respectivas categorias.

\subsubsection{Pesquisa de Fatores Críticos de Sucesso de Alto Impacto}

Esta pesquisa tem como objetivo a identificação estatística dos FCS. Logo, como método complementar ao levantamento de FCS identificados, será utilizado o método da ACP. A ACP foi motivada pela complexidade do Levantamento de GTI de 2012.

\section{Coleta}

A escolha pelo ACP foi motivada pela análise da matriz T349 174, onde 349 é o número de instituições e 174 é o número de questões do Levantamento do iGovTI de 2012. Essa matriz é proveniente do banco de dados do Levantamento no TCU.

Destaca-se que atualmente a análise realizada pelo TCU é basicamente univariada, em que as variáveis são tratadas de forma isolada, embora pequenas correlações sejam realizadas, geralmente, entre as questões de algum item do questionário. Segundo Vicini (2005), quando existem muitas variáveis envolvidas, a análise univariada pode falhar, uma vez que além das informações provenientes das estatísticas isoladas, é necessário conhecer a totalidade das informações oriundas do conjunto das variáveis, bem como suas relações. 


\section{Tratamento}

Para a análise ACP, foram utilizados dados brutos, ao invés dos dados normalizados. A análise dos dados brutos mostrou resultados mais significativos do algoritmo de classificação, com 91,4\%, enquanto os dados normalizados $85 \%$.

\section{Análise}

Esta pesquisa tem como objetivo a identificação estatística dos FCS. Logo, como método complementar ao levantamento de FCS identificados anteriormente, será utilizada a ACP, motivada pela complexidade do Levantamento de GTI de 2012 e pela capacidade de identificação de componentes principais por meio da análise multivariada.

A ACP fornece um indicativo de quais variáveis são as mais relevantes de forma abrangente, a partir da suposição de que os maiores autovalores representam os principais componentes de um determinado conjunto de dados. Entretanto, para o objetivo específico de classificar as instituições conforme o iGovTI, é necessário um complemento, que é dado por técnicas que possam identificar quais variáveis são mais importantes para classificação das instituições de acordo com o iGovTI.

Em outras palavras, é importante selecionar um algoritmo que seja mais eficiente na classificação das instituições de acordo com o resultado do iGovTI, a partir de suas respostas ao questionário. Esse algoritmo será utilizado para a identificação das variáveis mais importantes para a classificação. 


\section{RESULTADOS}

Neste capítulo é apresentado o desenvolvimento e os resultados deste trabalho. O Subcapítulo 4.1 mostra os resultados da análise bibliométrica em arquitetura corporativa; o Subcapítulo 4.2 apresenta os resultados da análise bibliométrica em FCS em GTI; no Subcapítulo 4.3 é visto os resultados da análise dos FCS em GTI da APF; no Subcapítulo 4.4 ocorre a verificação dos FCS em GTI da APF com o Levantamento de GTI do TCU ano 2012; o Subcapítulo 4.5 expõe a análise entre as componentes principais e os FCS; no Subcapítulo 4.6 é sumarizada a ACP aplicada aos dados dos questionários; nos Subcapítulos 4.7 e 4.8 serão apresentados os resultados obtidos por meio dos algoritmos MVS e ERV, respectivamente.

\subsection{ANÁLISE BIBLIOMÉTRICA EM ARQUITETURA CORPORATIVA}

A análise bibliométrica em AC realizada neste trabalho foi publicada no artigo Bibliometric analysis of enterprise architecture in the public administration (RAMOS; DE SOUSA JR., 2015).

Para a análise de bibliometria do tema $\mathrm{AC}$ em administração pública, considerou-se o idioma inglês, os termos "enterprise architecture" e "public administration" e o período entre 1999 e 2014 (Quadro 15 e Figura 21). O ano com a maior quantidade de publicações é 2009, ressalta-se que no ano 2008 o banco de investimentos Lehman Brothers foi à falência, iniciando a crise econômica mundial que impactou diretamente sobre a governança corporativa e, consequentemente, em AC. Os anos 2001, 2002 e 2003 não aparecem no Quadro 15 e na Figura 21, por constarem publicações desses anos na amostra. 
Quadro 15 - Anos das Publicações de FCS e Arquitetura de Corporativa

\begin{tabular}{|c|c|c|c|}
\hline Ano de publicação & Frequência & \% Relativo & \% Acumulado \\
\hline 1999 & 1 & $0,85 \%$ & $0,85 \%$ \\
\hline 2000 & 1 & $0,85 \%$ & $1,69 \%$ \\
\hline 2004 & 2 & $1,69 \%$ & $3,39 \%$ \\
\hline 2005 & 7 & $5,93 \%$ & $9,32 \%$ \\
\hline 2006 & 8 & $6,78 \%$ & $16,10 \%$ \\
\hline 2007 & 10 & $8,47 \%$ & $24,58 \%$ \\
\hline 2008 & 11 & $9,32 \%$ & $33,90 \%$ \\
\hline 2009 & 17 & $14,41 \%$ & $48,31 \%$ \\
\hline 2010 & 10 & $8,47 \%$ & $56,78 \%$ \\
\hline 2011 & 16 & $13,56 \%$ & $70,34 \%$ \\
\hline 2012 & 15 & $12,71 \%$ & $83,05 \%$ \\
\hline 2013 & 14 & $11,86 \%$ & $94,92 \%$ \\
\hline 2014 & 6 & $5,08 \%$ & $100,00 \%$ \\
\hline Total & $\mathbf{1 1 8}$ & $\mathbf{1 0 0 , 0 0 \%}$ & \\
\hline & &
\end{tabular}

Fonte: Ramos e De Sousa Jr., 2015

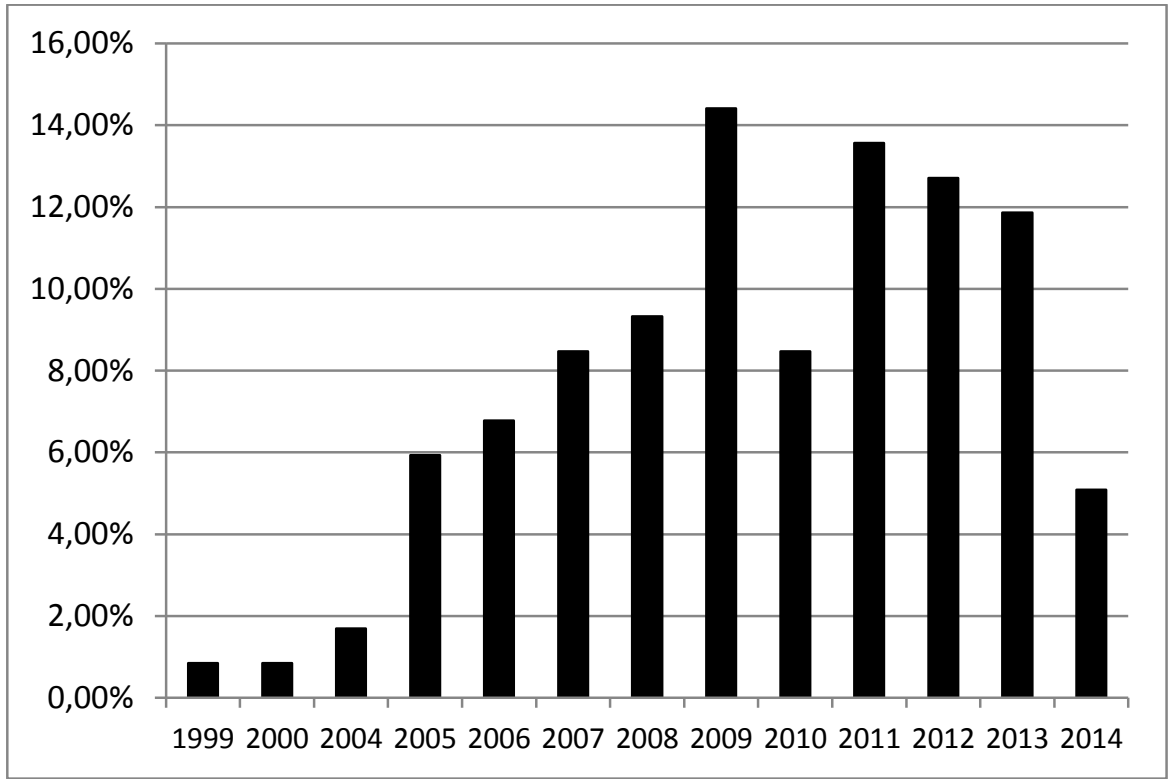

Figura 21 - Evolução das Publicações em AC + Administração Pública Fonte: Ramos e De Sousa Jr., 2015

Foram identificados 73 periódicos nesta amostra, representando 118 artigos. A principal editora é a Inderscience Enterprises Ltd, representado 26,27\% da amostra (31 artigos); em segundo é Igi Publishing, representando 11,86\% da amostra (14 artigos) e o terceiro é Emerald Group Publishing Ltd, com 10,17\% da amostra (12 artigos). Outros 28 editores representam 51,69\% da amostra sem quantidade significativa de artigos nessa área. 
Quadro 16 - Periódicos mais relevantes em AC + Administração Pública

\begin{tabular}{|c|c|c|}
\hline Nome do periódico & Ocorrências & $\begin{array}{c}\text { Porcentual } \\
\text { Relativo }\end{array}$ \\
\hline Inderscience enterprises ltd & 31 & $26,27 \%$ \\
\hline Igi publishing & 14 & $11,86 \%$ \\
\hline Emerald group publishing limited & 12 & $10,17 \%$ \\
\hline Palgrave macmillan ltd & 8 & $6,78 \%$ \\
\hline Universidad de Talca & 6 & $5,08 \%$ \\
\hline Others & 47 & $39,83 \%$ \\
\hline Total & $\mathbf{1 1 8}$ & $\mathbf{1 0 0 , 0 0 \%}$ \\
\hline
\end{tabular}

Fonte: Ramos e De Sousa Jr., 2015

Publicações ou periódicos destaques são Electronic Government da Inderscience Enterprises Ltd, 11,02\% da amostra (13 artigos) e European Journal of Information Systems da Palgrave Macmillan Ltd, 5,93\% da amostra (7 artigos).

A média do fator de impacto das publicações é 0,522143. Esses periódicos possuem 22 áreas de concentração, sendo que ciência da computação (do inglês computer science) é destaque com 23 artigos, 19,49\% da amostra (Quadro 17).

\begin{tabular}{|c|c|c|}
\hline Nome da área de concentração & Frequência & $\begin{array}{l}\text { Porcentual } \\
\text { Relativo }\end{array}$ \\
\hline Computer Science & 23 & $19,49 \%$ \\
\hline \begin{tabular}{l|l|} 
Computer Science & Social Sciences \\
\end{tabular} & 22 & $18,64 \%$ \\
\hline Business, Management and Accounting & 20 & $16,95 \%$ \\
\hline Social Sciences & 13 & $11,02 \%$ \\
\hline Business, Management and Accounting |Computer Science & 6 & $5,08 \%$ \\
\hline Computer Science | Decision Sciences & 5 & $4,24 \%$ \\
\hline \begin{tabular}{l|l} 
Business, Management and Accounting & Social Sciences \\
\end{tabular} & 5 & $4,24 \%$ \\
\hline \begin{tabular}{l|l} 
Business, Management and Accounting & Decision Sciences \\
\end{tabular} & 3 & $2,54 \%$ \\
\hline Computer Science | Social Sciences & 3 & $2,54 \%$ \\
\hline $\begin{array}{l}\text { Business, Management and Accounting | Computer Science | Decision } \\
\text { Sciences }\end{array}$ & 3 & $2,54 \%$ \\
\hline Engineering & 2 & $1,69 \%$ \\
\hline Computer Science | Engineering & 2 & $1,69 \%$ \\
\hline Medicine & 2 & $1,69 \%$ \\
\hline \begin{tabular}{l|l|l|} 
Business, Management and Accounting & Social Sciences \\
\end{tabular} & 1 & $0,85 \%$ \\
\hline Business, Management and Accounting | Decision Sciences | Engineering & 1 & $0,85 \%$ \\
\hline \begin{tabular}{l|l} 
Computer Science & Mathematics \\
\end{tabular} & 1 & $0,85 \%$ \\
\hline Economics, Econometrics and Finance & 1 & $0,85 \%$ \\
\hline $\begin{array}{l}\text { Business, Management and Accounting | Computer Science } \\
\end{array}$ & 1 & $0,85 \%$ \\
\hline Agricultural and Biological Sciences & 1 & $0,85 \%$ \\
\hline \begin{tabular}{l|l} 
Business, Management and Accounting & Engineering \\
\end{tabular} & 1 & $0,85 \%$ \\
\hline \begin{tabular}{l|l|l} 
Computer Science & Decision Sciences & Medicine \\
\end{tabular} & 1 & $0,85 \%$ \\
\hline $\begin{array}{l}\text { Business, Management and Accounting | Decision Sciences | Social } \\
\text { Sciences }\end{array}$ & 1 & $0,85 \%$ \\
\hline Total Geral & 118 & $100,00 \%$ \\
\hline
\end{tabular}

Fonte: Ramos e De Sousa Jr., 2015 
No entanto, os termos, em separado, de algumas áreas apareceram mais de uma vez. Assim, esses termos foram isolados e "ciência da computação" apareceu em 67 artigos, $25,77 \%$ da amostra (Figura 22).

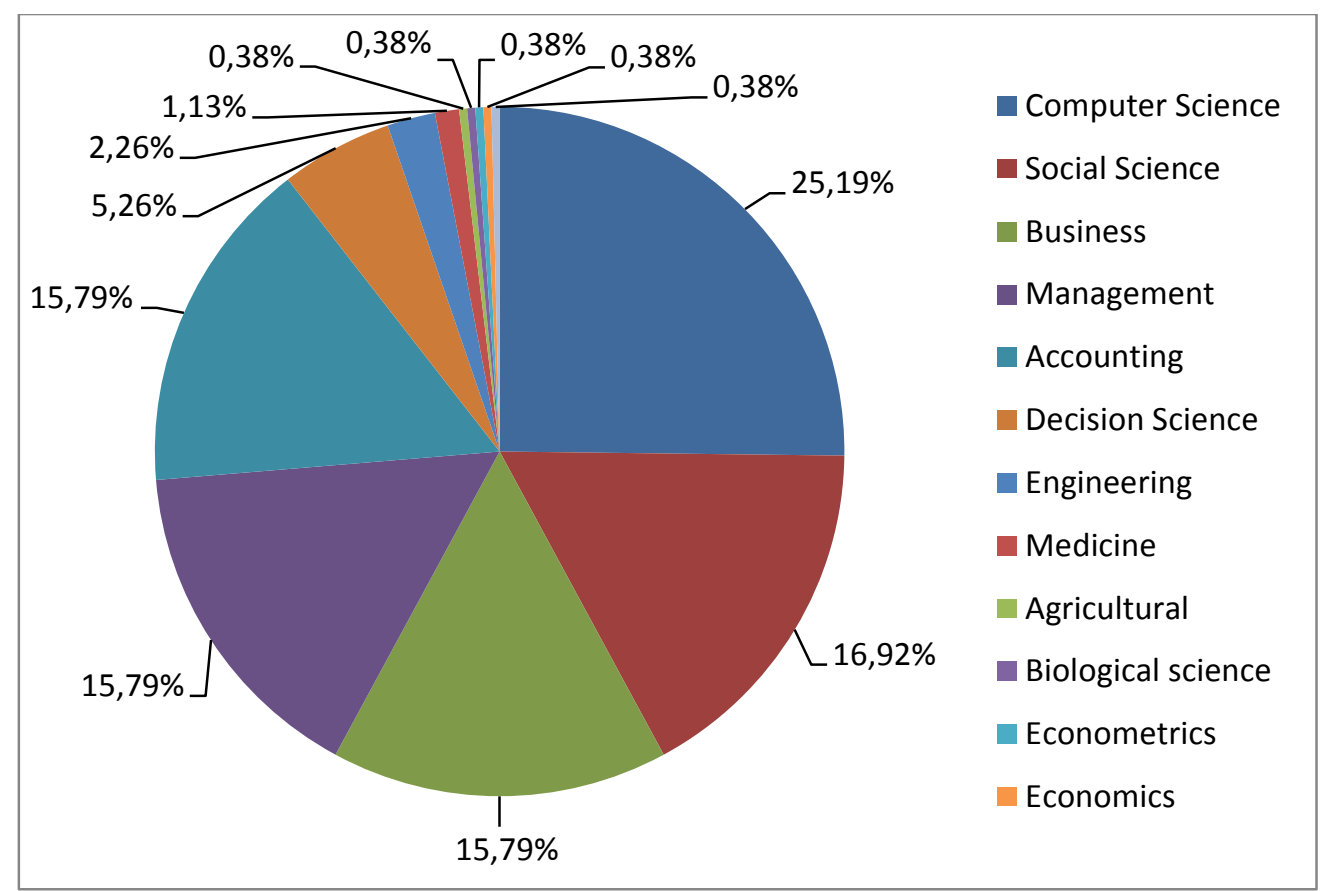

Figura 22 - Termos Isolados da Área de Concentração em AC + Administração Pública Fonte: Ramos e De Sousa Jr., 2015

Agrupando os termos isolados da Figura 22 em ciências sociais (empresas, gestão, contabilidade, ciência da decisão, econometria, economia e finanças) e em tecnologia (ciência da computação e engenharia), mostra que a ciência social, tem predominância de 70,68\%, enquanto a tecnologia tem $27,44 \%$. As áreas temáticas das publicações mostraram a divisão equilibrada entre ciência da computação e ciências sociais.

Os autores com a maior quantidade de publicações são Marijn Janssen e Vassilios Peristeras, cada um com seis artigos. Embora ambos os autores possuíssem o mesmo número de trabalhos nesta amostra, Vassilios Peristeras é o autor mais relevante, com uma média de journals fator de impacto de 1,62, enquanto a média do fator de impacto dos artigos do Janssen é 0,27. No entanto, a citação analisada mostrou que New public management is dead-long live digital-era governance por Dunleavy et al. (2006) é o artigo com o maior número de citações em artigos, cartas, notas e comentários publicados (Quadro 18). 
Quadro 18 - Publicações Relevantes em Arquitetura de Corporativa + Administração Pública

\begin{tabular}{|c|c|c|c|}
\hline $\begin{array}{l}\text { Citados } \\
\text { por }\end{array}$ & Autores & Título das Publicações & Ano \\
\hline 696 & $\begin{array}{l}\text { P Dunleavy, H } \\
\text { Margetts, S } \\
\text { Bastow, J Tinkler }\end{array}$ & $\begin{array}{l}\text { New public management is dead-long live digital- } \\
\text { era governance }\end{array}$ & 2006 \\
\hline 238 & Y Malhotra & $\begin{array}{l}\text { Integrating knowledge management technologies in } \\
\text { organizational business processes: getting real time } \\
\text { enterprises to deliver real business performance }\end{array}$ & 2005 \\
\hline 179 & $\begin{array}{l}\text { W Bandara, GG } \\
\text { Gable... }\end{array}$ & $\begin{array}{l}\text { Factors and measures of business process modelling: } \\
\text { model building through a multiple case study }\end{array}$ & 2005 \\
\hline 159 & $\begin{array}{l}\text { SE Madnick, RY } \\
\text { Wang, YW Lee, } \\
\text { H Zhu }\end{array}$ & $\begin{array}{l}\text { Overview and framework for data and information } \\
\text { quality research }\end{array}$ & 2009 \\
\hline 159 & $\begin{array}{l}\text { HJ Scholl, r } \\
\text { klischewski }\end{array}$ & $\begin{array}{l}\text { E-Government integration and interoperability: } \\
\text { framing the research agenda }\end{array}$ & 2007 \\
\hline 154 & W Lam & Barriers to e-Government integration & 2005 \\
\hline 113 & $\begin{array}{l}\text { V Peristeras, K } \\
\text { Tarabanis }\end{array}$ & $\begin{array}{l}\text { Towards an Enterprise Architecture for public } \\
\text { administration using a top-down approach }\end{array}$ & 2000 \\
\hline 55 & $\begin{array}{l}\text { m janssen, AM } \\
\text { Cresswell }\end{array}$ & $\begin{array}{l}\text { An enterprise application integration methodology } \\
\text { for e-government }\end{array}$ & 2005 \\
\hline 50 & Z Huang & $\begin{array}{l}\text { A comprehensive analysis of US counties'e- } \\
\text { Government portals: development status and } \\
\text { functionalities }\end{array}$ & 2007 \\
\hline
\end{tabular}

Fonte: Ramos e De Sousa Jr., 2015

Há 38 países que participaram do estudo. Embora os Estados Unidos da América tenham 33 artigos, 27,96\% da amostra, Grécia e Holanda contam com a maior concentração de artigos por universidades, com a Universidade da Macedónia e a Universidade de Delf. Analisando-se os departamentos e laboratórios das universidades, descobrimos que as áreas de gestão e tecnologia lideram a investigação sobre o tema desta análise.

Verificou-se que as palavras-chave nos artigos mostram uma relação com o conceito de AC. A Figura 23 mostra a correlação entre as palavras-chave. 


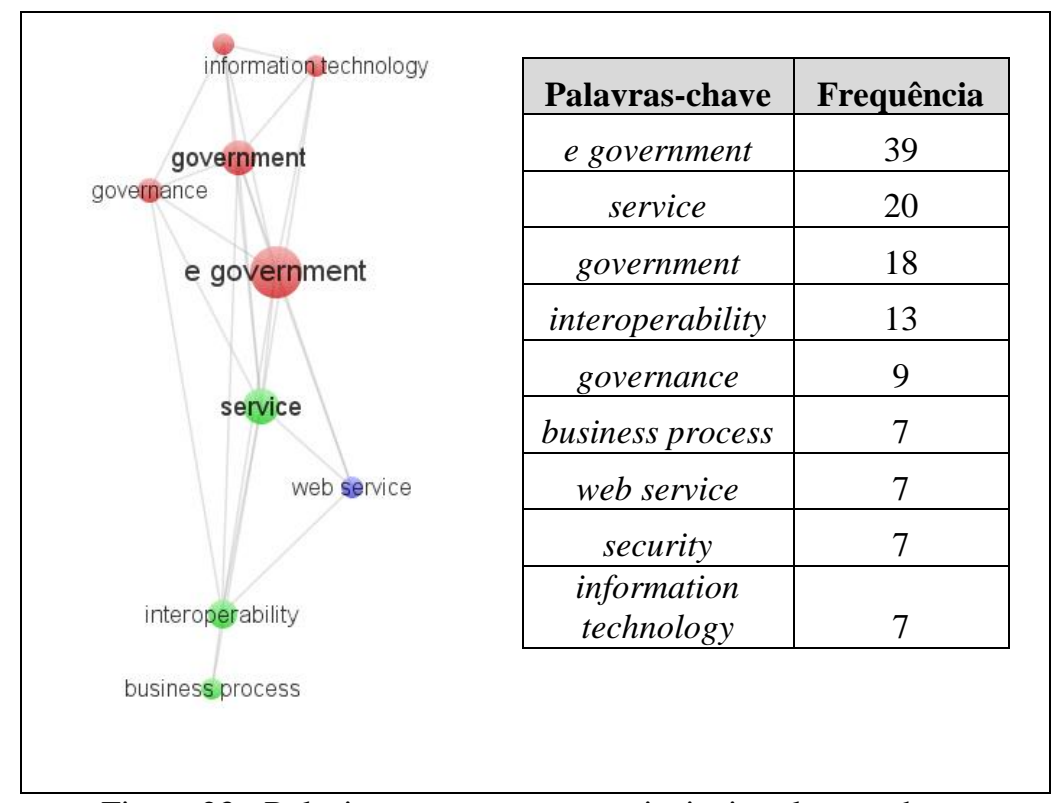

Figura 23 - Relacionamento entre as principais palavras-chave

Fonte: Ramos e De Sousa Jr., 2015

A Figura 23 mostra a interdisciplinaridade de AC e administração pública pela quantidade de frequência das palavras-chave. Assim, as palavras-chaves e-government, interoperability, web service, information technology e security são associadas à área da tecnologia ou ciência da computação, já os termos government, governance e business process são mais associadas a ciências sociais. Esses relacionamentos são explicados no referencial teórico. Sobre as palavras-chaves, e-government possui uma frequência maior, 39 artigos, seguido das palavras service que aparece em 20 artigos, government que possui 18 ocorrências em artigos, interoperability tem 13 frequência em artigos. Durante a análise desses artigos ficou evidente a forte correlação da AC em administração pública com governo eletrônico e com interoperabilidade.

\subsubsection{Considerações Teóricas em Arquitetura Corporativa}

Conforme verificado nos artigos desta análise bibliométrica, os métodos de AC têm sido amplamente utilizados em órgãos federais dos Estados Unidos da América, que são obrigados a adoptar um conjunto de Federal Enterprise Architecture (FEA) métodos de operações de TI, planejamento e orçamento (MADNICK et al., 2009). Além disso, vários governos ao redor do mundo têm estabelecido programas de interoperabilidade ou de governo 
eletrônico baseado em AC. O Quadro 19 segue os programas extraídos para esta pesquisa (Quadro 19).

\begin{tabular}{|c|c|c|}
\hline \multicolumn{3}{|c|}{ Quadro 19 - Programas de AC } \\
\hline Referência & Programas & País \\
\hline Dunleavy et al., 2006 & 1. The Toronto Virtual Enterprise (TOVE) & Canada \\
\hline Dunleavy et al., 2006 & 2. Federal Enterprise Architecture Framework (FEAF) & USA \\
\hline Dunleavy et al., 2006 & 3.Government Process Classification Scheme (PCS) & \\
\hline Im e Seo, 2005 & 4. Korea e-Government & South Korea \\
\hline Becker et al., 2006 & 5.InfoCITIZEN & \\
\hline LIM; TANG, 2008 & 6. Directgov & UK \\
\hline LIM; TANG, 2008; & 7. G4C (Government for Citizens) & Korean \\
\hline Ilshammar, 2005 & $\begin{array}{l}\text { 8. Automatic Data Processing or Administrative Data } \\
\text { Processing (ADP) }\end{array}$ & Sweeden \\
\hline Anthopoulos e Tsoukalas, 2006 & 9. E-Trikala & Greece \\
\hline Pankowska, 2008 & 10. The e-PING & Brazil \\
\hline Pankowska, 2008 & $\begin{array}{l}\text { 11. The e-Government Interoperability Framework (e- } \\
\text { GIF) }\end{array}$ & New Zealand. \\
\hline $\begin{array}{l}\text { Pankowska, 2008; Martin e } \\
\text { Gregor, 2006 }\end{array}$ & 12.Australian Government Interoperability Framework & Australia \\
\hline $\begin{array}{l}\text { Pankowska, 2008; Martin e } \\
\text { Gregor, 2006 }\end{array}$ & $\begin{array}{l}\text { 13. Business Process Interoperability Framework } \\
\text { (BPIF) }\end{array}$ & Australia \\
\hline $\begin{array}{l}\text { Pankowska, 2008; Martin e } \\
\text { Gregor, 2006 }\end{array}$ & 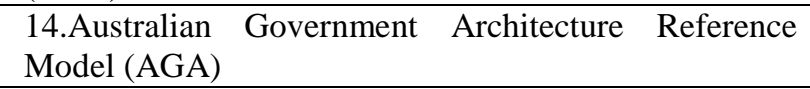 & Australia \\
\hline Pankowska, 2008 & 15. The Interoperability Framework (IF) & Hong Kong \\
\hline $\begin{array}{l}\text { Pankowska, 2008; Tripathi et al, } \\
2012\end{array}$ & 16.India e-Governance Framework & India \\
\hline Pankowska, 2008 & $\begin{array}{l}\text { 17.Malaysian Government Interoperability Framework } \\
\text { (MyGIF) }\end{array}$ & Malaysia \\
\hline Pankowska, 2008 & 18. Yesser Framework for Interoperability (YEFI) & Saudi Arabia \\
\hline Pankowska, 2008 & $\begin{array}{l}\text { 19.UK e-Government Interoperability Framework (e- } \\
\text { GIF) }\end{array}$ &. $\mathrm{UK}$ \\
\hline Pankowska, 2008 & 20.German. E-Government Applications (SAGA) & German \\
\hline Pankowska, 2008 & 21.Danish Interoperability Framework & Danish \\
\hline Pankowska, 2008 & 22.Estonian IT Interoperability Framework & Estonian \\
\hline Pankowska, 2008 & 23.European Interoperability Framework & Europa \\
\hline $\begin{array}{l}\text { PERISTERAS; TARABANIS, } \\
2000\end{array}$ & 24. E-Government Enterprise Architecture & .Italy \\
\hline Peristeras et al., 2008 & 25.Pan European e-Government Services & Europa \\
\hline Zavadskas et al., 2010 & 26. E-Vilnius & Lithuania. \\
\hline $\begin{array}{l}\text { Klischewski, 2011;Mostafa e } \\
\text { El-Masry, 2013 }\end{array}$ & 27. G2G framework & Egypt \\
\hline Roy, 2007 & 28.Service Canada & Canada \\
\hline Hanna e Qiang, 2010 & 29. E-development & China. \\
\hline Janssen, 2007 & 30Dutch Inland Revenue Service & .Netherlands. \\
\hline Santana, 2009 & $\begin{array}{l}\text { 31. ONGEI-National e-Government and Information } \\
\text { Technology Office. }\end{array}$ & Peru. \\
\hline Jain e Shrimali, 2013 & 32. e-Janraj & $\begin{array}{l}\text { India, } \\
\text { Udaipur }\end{array}$ \\
\hline Mostafa e El-Masry, 2013 & 33. Enterprise Architecture Project (EAP) & Dubai. \\
\hline
\end{tabular}

\section{Fonte: Dados da pesquisa}

Vale frisar que as AC visam à normalização abrangente para apoiar todos os níveis de interoperabilidade. Os governos tem desenvolvido o que pode ser visto, como um conjunto 
coerente de princípios, métodos e modelos que possibilitem a utilização abrangente de TI e outros recursos para apoiar os objetivos de negócios (KLISCHEWSKI, 2011).

\subsection{ANÁLISE BIBLIOMÉTRICA EM FCS EM GOVERNANÇA DE TI}

Para a análise de bibliometria do tema FCS em GTI, a pesquisa realizada considerou o idioma inglês. Assim, os termos pesquisados foram "critical success factors", "IT governance" e "rockart" com o período de publicação entre 1993 e 2014 (Quadro 20 e Figura 24). A escolha pelo idioma inglês deve-se peça opção de estudo com publicações relevantes e o nome rockart serviu como filtro, uma vez que Rockart é o principal disseminador do termo FCS e metodologia deste trabalho considera seus métodos de identificação de FCS.

A amostra desse tema localizou 46 artigos de publicações relevantes. $\mathrm{O}$ ano 2013 teve o maior número de publicações, oito artigos, 17,39\%, do total de publicações sobre o tema (Quadro 20).

\begin{tabular}{|} 
Quadro 20 - Anos de Publicação de FCS e GTI \\
\begin{tabular}{|c|c|c|c|}
\hline $\begin{array}{c}\text { Ano de } \\
\text { Publicação }\end{array}$ & Frequência & $\begin{array}{c}\text { Porcentual } \\
\text { Relativo }\end{array}$ & $\begin{array}{c}\text { Porcentual } \\
\text { Acumulado }\end{array}$ \\
\hline 1993 & 1 & $2,17 \%$ & $2,17 \%$ \\
\hline 1999 & 2 & $4,35 \%$ & $6,52 \%$ \\
\hline 2001 & 1 & $2,17 \%$ & $8,70 \%$ \\
\hline 2003 & 2 & $4,35 \%$ & $13,04 \%$ \\
\hline 2004 & 2 & $4,35 \%$ & $17,39 \%$ \\
\hline 2005 & 3 & $6,52 \%$ & $23,91 \%$ \\
\hline 2007 & 4 & $8,70 \%$ & $32,61 \%$ \\
\hline 2008 & 5 & $10,87 \%$ & $43,48 \%$ \\
\hline 2009 & 4 & $8,70 \%$ & $52,17 \%$ \\
\hline 2010 & 4 & $8,70 \%$ & $60,87 \%$ \\
\hline 2011 & 7 & $15,22 \%$ & $76,09 \%$ \\
\hline 2012 & 1 & $2,17 \%$ & $78,26 \%$ \\
\hline 2013 & 8 & $17,39 \%$ & $95,65 \%$ \\
\hline 2014 & 2 & $4,35 \%$ & $100,00 \%$ \\
\hline Total Geral & $\mathbf{4 6}$ & $\mathbf{1 0 0 , 0 0 \%}$ & $\mathbf{6 1 0 , 8 7 \%}$ \\
\hline
\end{tabular} \\
\hline
\end{tabular}




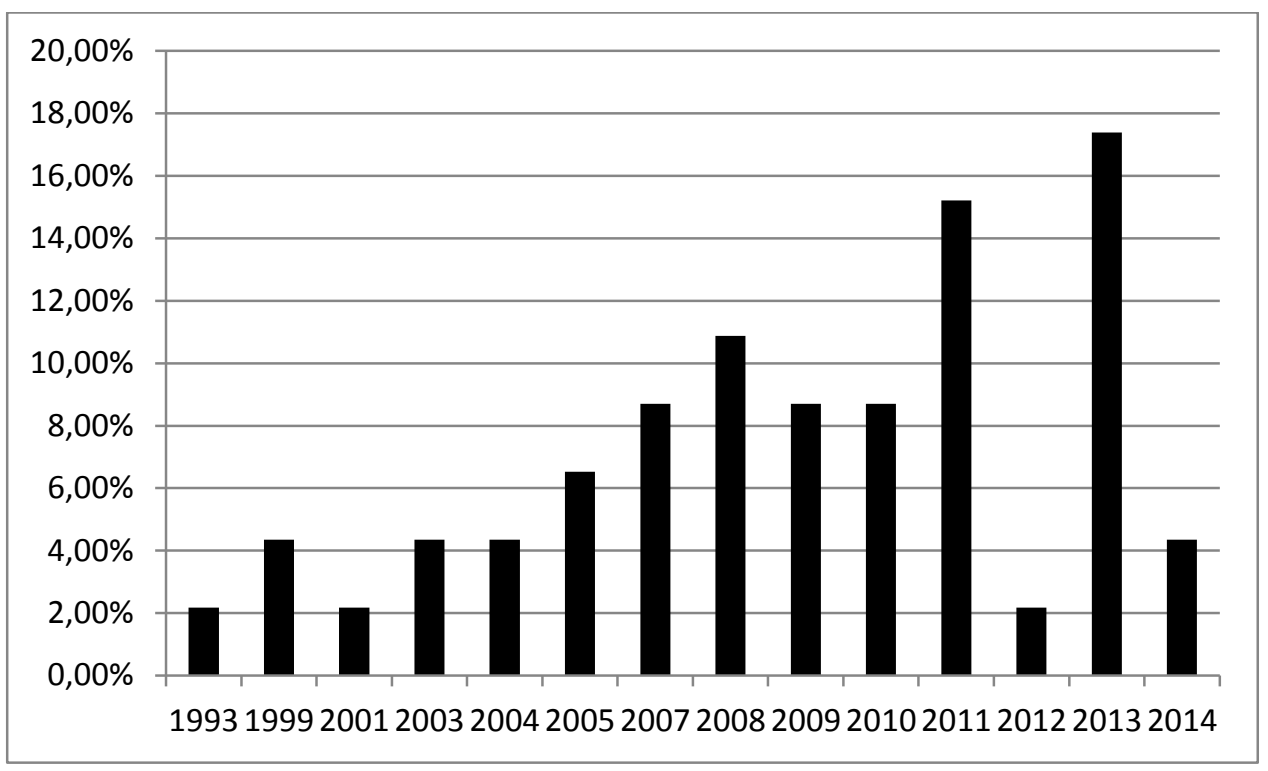

Figura 24 - Evolução das Publicações em FCS e GTI Fonte: Dados da Pesquisa

Foram identificados 29 periódicos, distribuídos em 17 editoras. A principal editora é a Elsevier, com dez artigos; a segunda é Taylor \& Francis com sete artigos e; o terceiro é IGI Publishing, com quatro artigos.

O periódico com maior número de artigos é Information Systems Management (5 artigos) e em segundo lugar aparecem os periódicos com três artigos, são eles: $i$ ) Business and Information Systems Engineering, Communications of the Association for Information Systems; ii) European Journal of Information Systems e; iii) Journal of Management Information Systems (Quadro 21). Dessas cinco publicações se destaca com a maior quantidade de artigos European Journal of Information Systems e o Journal of Management Information Systems com o maior fator de impacto medido pelo Journal Citation Report $(\mathrm{JCR})^{10}$, portanto os periódicos mais relevantes desse grupo.

\footnotetext{
${ }^{10} \mathrm{O}$ indicador JCR mede a influência científica média do artigo de um periódico, ela expressa qual é a discussão científica média global um artigo da revista, por meio da quantidade de citações por documento que mede o impacto científico de um artigo publicado. Para isso utiliza a mesma fórmula de fator de impacto jornal da Web of Science (THOMSON REUTERS, 2014).
} 
Quadro 21 - Periódicos e Editoras em FCS e GTI

\begin{tabular}{|c|c|c|c|}
\hline Periódico & $\begin{array}{c}\text { Fator } \\
\text { de } \\
\text { Impacto }\end{array}$ & $\begin{array}{l}\text { Soma de } \\
\text { Frequência }\end{array}$ & $\begin{array}{l}\text { Porcentual } \\
\text { Relativo }\end{array}$ \\
\hline Information Systems Management & 0,31 & 5 & $10,87 \%$ \\
\hline Business and Information Systems Engineering & 0,24 & 3 & $6,52 \%$ \\
\hline $\begin{array}{l}\text { Communications of the Association for Information } \\
\text { Systems }\end{array}$ & 0,49 & 3 & $6,52 \%$ \\
\hline European Journal of Information Systems & 1,47 & 3 & $6,52 \%$ \\
\hline Journal of Management Information Systems & 1,97 & 3 & $6,52 \%$ \\
\hline $\begin{array}{l}\text { Electronic Journal of Information Systems in } \\
\text { Developing Countries }\end{array}$ & 0,2 & 2 & $4,35 \%$ \\
\hline Information and Management & 1,84 & 2 & $4,35 \%$ \\
\hline International Journal of Project Management & 1,09 & 2 & $4,35 \%$ \\
\hline Journal of Computer Information Systems & 0,5 & 2 & $4,35 \%$ \\
\hline Journal of Strategic Information Systems & 0,96 & 2 & $4,35 \%$ \\
\hline Behaviour and Information Technology & 0,78 & 1 & $2,17 \%$ \\
\hline Business Process Management Journal & 0,7 & 1 & $2,17 \%$ \\
\hline Computers in Industry & 1,35 & 1 & $2,17 \%$ \\
\hline Decision Support Systems & 1,9 & 1 & $2,17 \%$ \\
\hline European Management Journal & 0,45 & 1 & $2,17 \%$ \\
\hline Human Systems Management & 0,28 & 1 & $2,17 \%$ \\
\hline Industrial Management and Data Systems & 0,98 & 1 & $2,17 \%$ \\
\hline Information Resources Management Journal & 0,25 & 1 & $2,17 \%$ \\
\hline $\begin{array}{c}\text { International Journal of Accounting Information } \\
\text { Systems }\end{array}$ & 0,59 & 1 & $2,17 \%$ \\
\hline $\begin{array}{c}\text { International Journal of Business Information } \\
\text { Systems }\end{array}$ & 0,31 & 1 & $2,17 \%$ \\
\hline International Journal of Digital Accounting Research & 0,41 & 1 & $2,17 \%$ \\
\hline $\begin{array}{c}\text { International Journal of Enterprise Information } \\
\text { Systems }\end{array}$ & 0,36 & 1 & $2,17 \%$ \\
\hline Journal of Computer Assisted Learning & 2,14 & 1 & $2,17 \%$ \\
\hline Journal of Database Management & 0,68 & 1 & $2,17 \%$ \\
\hline Journal of Global Information Management & 0,29 & 1 & $2,17 \%$ \\
\hline MIS Quarterly Executive & 1,55 & 1 & $2,17 \%$ \\
\hline MIS Quarterly: Management Information Systems & 5,74 & 1 & $2,17 \%$ \\
\hline Project Management Journal & 0,5 & 1 & $2,17 \%$ \\
\hline Service Industries Journal & 0,32 & 1 & $2,17 \%$ \\
\hline Total & 28,65 & 46 & $100,00 \%$ \\
\hline
\end{tabular}

Fonte: Dados da Pesquisa

O valor máximo de fator de impacto é do periódico Management Information Systems Research Center (5,47 no JCR) e o menor valor é do periódico Electronic Journal of Information Systems in Developing Countries (0,2 no JCR). A média dos índices do fator de impacto é 0,92 , sendo que o desvio padrão é 1,09 , relativamente baixo.

Considerando os periódicos do Quadro 21, esses são distribuídos em 70 áreas de conhecimento. A área de conhecimento que possui a maior concentração é a "ciência da 
computação" (do inglês computer science) com 36\% dos artigos da amostra. Em seguida negócio, gestão e contabilidade com 29\% dos artigos (Figura 25).

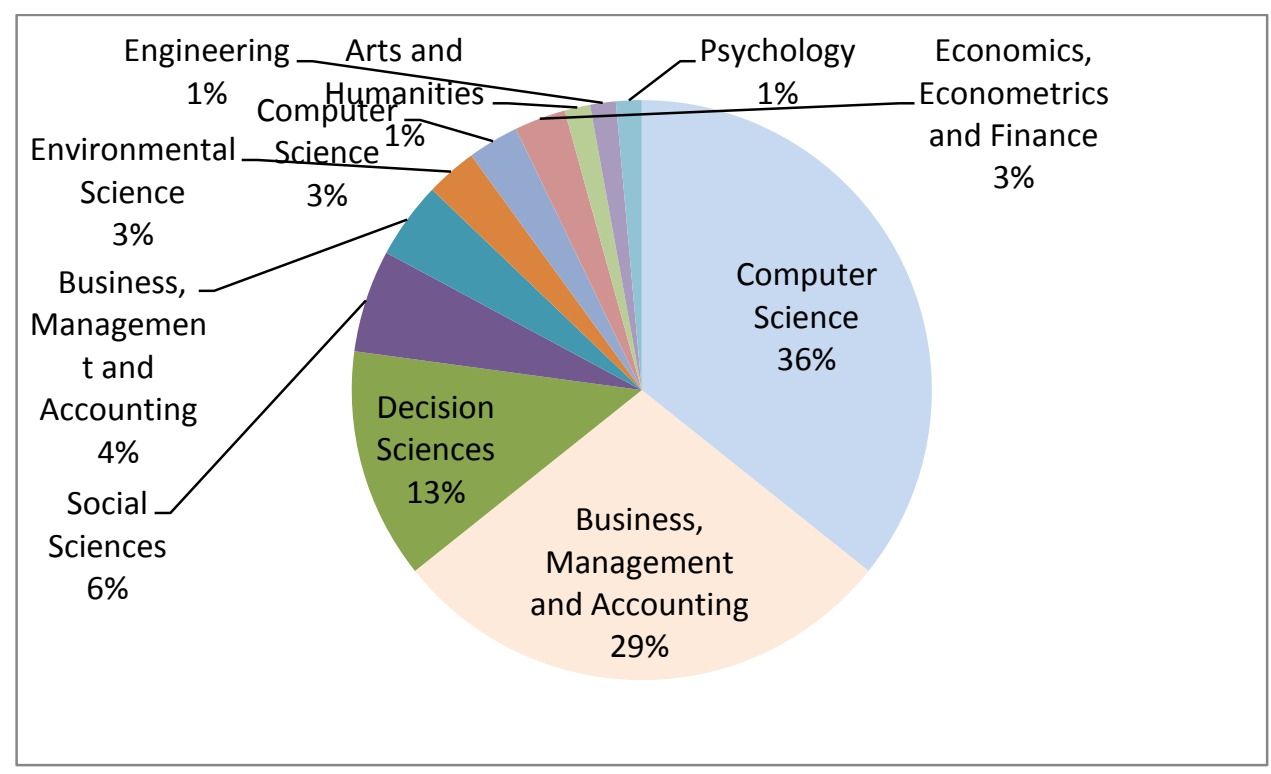

Figura 25 - Área de Concentração de FCS e GTI

Fonte: Dados da Pesquisa

Correlato à análise de bibliometria da Subcapítulo 4.1, o resultado desta análise demonstra que as pesquisas em FCS em GTI possuem domínio dividido entre ciências sociais e tecnologia.

Os autores que aparecem com a maior frequência nesta amostra são J. Luftman, R. Young, A. Cater-Steel. O autor R. Young possui 3 artigos e os autores J. Luftman e A. CaterSteel tem dois artigos cada um. Embora os artigos de R. Young possuam média no fator de impacto de 1,09, a soma dos três artigos totalizam 107 citações, consideramos J. Luftman o autor mais relevante, com um total de 1.171 citações, mesmo com uma média no fator de impacto de 0,55. J. Luftman também é o autor do artigo mais citado Assessing business-it alignment maturity com 749 citações (Quadro 22). 
Quadro 22 - Publicações Relevantes em FCS e GTI

\begin{tabular}{|c|c|c|c|}
\hline Citações & Autores & Título & Ano \\
\hline 749 & J. Luftman & Assessing business-it alignment maturity & 2000 \\
\hline 561 & N Levina, JW Ross & $\begin{array}{l}\text { From the vendor's perspective: exploring the value } \\
\text { proposition in information technology outsourcing }\end{array}$ & 2003 \\
\hline 422 & J Luftman, R Papp, T Brier & Enablers and inhibitors of business-IT alignment & 1999 \\
\hline 376 & P Weill & $\begin{array}{l}\text { Don't just lead, govern: How top-performing firms govern } \\
\text { IT }\end{array}$ & 2004 \\
\hline 263 & R Peterson & Crafting information technology governance & 2004 \\
\hline 204 & $\begin{array}{l}\text { N Venkatraman, JC } \\
\text { Henderson, S Oldach }\end{array}$ & $\begin{array}{l}\text { Continuous strategic alignment: Exploiting information } \\
\text { technology capabilities for competitive success }\end{array}$ & 1993 \\
\hline 195 & JTM Van Der Zee, B De Jong & $\begin{array}{c}\text { Alignment is not enough: integrating business and } \\
\text { information technology management with the balanced } \\
\text { business scorecard }\end{array}$ & 1999 \\
\hline 163 & M Tarafdar, SR Gordon & $\begin{array}{c}\text { Understanding the influence of information systems } \\
\text { competencies on process innovation: A resource-based } \\
\text { view }\end{array}$ & 2007 \\
\hline 138 & $\begin{array}{l}\text { P. L. Bowen, M. Y. D. } \\
\text { Cheung, F. H. Rohde }\end{array}$ & $\begin{array}{c}\text { Enhancing ITG practices: A model and case study of an } \\
\text { organization's efforts }\end{array}$ & 2007 \\
\hline 109 & WF Boh, D Yellin & $\begin{array}{c}\text { Using enterprise architecture standards in managing } \\
\text { information technology }\end{array}$ & 2007 \\
\hline 104 & J Bradley & $\begin{array}{l}\text { Management based critical success factors in the } \\
\text { implementation of enterprise resource planning systems }\end{array}$ & 2008 \\
\hline 103 & R Young, E Jordan & Top management support: Mantra or necessity? & 2008 \\
\hline
\end{tabular}

Fonte: Dados da Pesquisa

Há 21 países que participaram do estudo, sendo que Estados Unidos da América lidera com 35,19\% da amostra (19 artigos), em seguida a Australia com 16,67\% (9 artigos) e em terceiro Alemanha com 7,41\% (4 artigos). A instituição de ensino que lidera as pesquisa é o Massachusetts Instituto of Technology (MIT) com três artigos, num total de 582 citações.

Verificou-se que as palavras-chave com maior ocorrência são governança, setor público, fatores críticos de sucesso, ITIL e estudo de caso.

A Figura 26 mostra a correlação entre as palavras-chave. Ao total foram levantadas 137 palavras-chave. Selecionaram-se aquelas que possuem maior frequência e os relacionamentos pudessem ser levantados. A Figura 26 expõe um mínimo de quatro ocorrências por palavra-chave que apresentam cinco termos: $i$ ) critical success factors em 15 artigos; ii) governance em 11 artigos; iii) public sector em 6 artigos; iv) strategic plannig em 6 artigos; v) ITIL em quatro artigos. O termo strategic planning, 6 artigos, não aparece no desenho de grafos por não apresentar relacionamento com os outros quatro termos. Tais palavras-chave demonstram bom alinhamento com o critério utilizado para seleção dos artigos desta análise. 


\begin{tabular}{|l|c|}
\hline \multicolumn{1}{|c|}{ Palavras-chave } & Frequência \\
\hline Critical success factor & 15 \\
\hline ITIL & 4 \\
\hline Public setor & 6 \\
\hline Governance & 11 \\
\hline Strategic planning & 6 \\
\hline
\end{tabular}

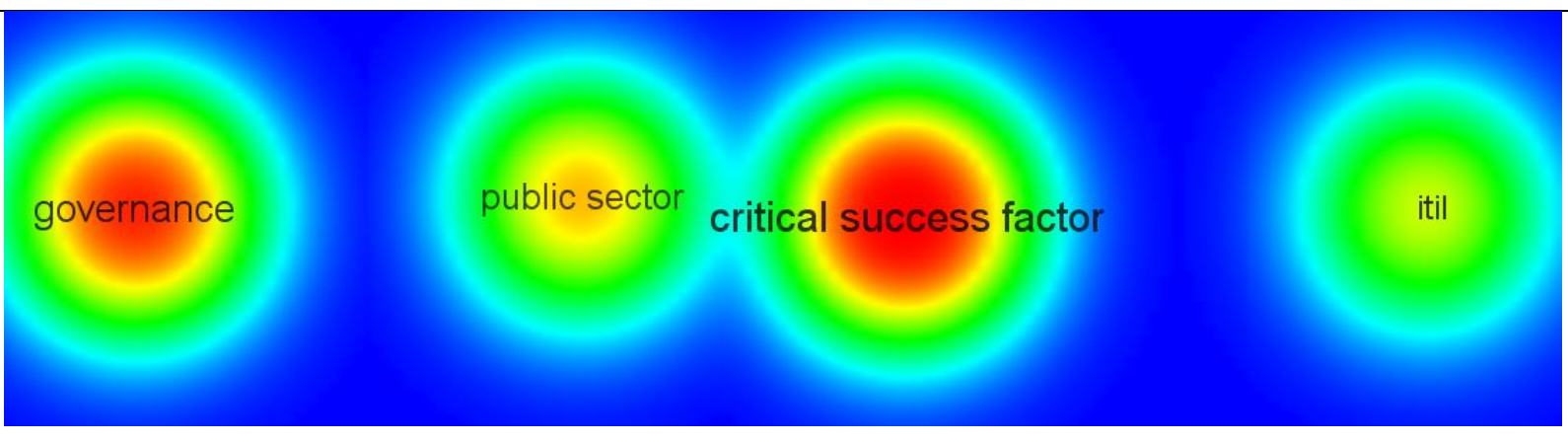

Figura 26 - Diagrama de densidade

Fonte: Dados da Pesquisa

A Figura 26 mostra a relevância de cada palavra-chave, apresentando um núcleo que representa a densidade do termo para a amostra. Como o termo critical success factors possui a maior quantidade de ocorrências (15 artigos), seu núcleo é mais denso.

\subsubsection{Considerações Teóricas em FCS em Governança de TI - Identificação de Categorias}

Após a análise bibliométrica dos 46 artigos apresentados, verificaram-se no conteúdo desses artigos, FCS em GTI e categorias ou construtos que agrupassem esses fatores. Assim, 17 artigos foram selecionados, uma vez que identificam e avaliam FCS e categorias em GTI (Quadro 23). Desse total, oito artigos utilizaram método survey; cinco artigos usaram método estudo de caso; dois artigos realizaram método Delphi; um artigo utilizou survey e estudo de caso; e um artigo é revisão da literatura. Dos oito artigos desenvolvidos com método survey, quatro utilizam análise multivariada para compreensão dos FCS. 
Quadro 23 - Publicações de FCS em GTI para Categorização

\begin{tabular}{|c|c|c|c|}
\hline Citações & Autor & Título & Ano \\
\hline 749 & J. Luftman & Assessing business-it alignment maturity & 2000 \\
\hline 422 & $\begin{array}{l}\text { J. Luftman, R. } \\
\text { Papp, T. Brier }\end{array}$ & Enablers and inhibitors of business-IT alignment & 1999 \\
\hline 376 & P. Weill & Don't just lead, govern: How top-performing firms govern IT & 2004 \\
\hline 163 & $\begin{array}{l}\text { M. Tarafdar, S. R. } \\
\text { Gordon }\end{array}$ & $\begin{array}{l}\text { Understanding the influence of information systems competencies on } \\
\text { process innovation: A resource-based view }\end{array}$ & 2007 \\
\hline 109 & $\begin{array}{l}\text { W. F. Boh, D. } \\
\text { Yellin }\end{array}$ & $\begin{array}{l}\text { Using enterprise architecture standards in managing information } \\
\text { technology }\end{array}$ & 2007 \\
\hline 103 & $\begin{array}{l}\text { R. Young, E. } \\
\text { Jordan }\end{array}$ & Top management support: Mantra or necessity? & 2008 \\
\hline 89 & $\begin{array}{l}\text { C. Pollard, A. } \\
\text { Cater-Steel }\end{array}$ & $\begin{array}{l}\text { Justifications, strategies, and critical success factors in successful ITIL } \\
\text { implementations in US and Australian companies: an exploratory study }\end{array}$ & 2009 \\
\hline 70 & $\begin{array}{l}\text { W. G. Tan, A. } \\
\text { Cater-Steel, M. } \\
\text { Toleman }\end{array}$ & $\begin{array}{l}\text { Implementing it service management: A case study focusing on critical } \\
\text { success factors }\end{array}$ & 2009 \\
\hline 37 & V. K. Khandelwal & $\begin{array}{l}\text { An empirical study of misalignment between Australian CEOs and IT } \\
\text { managers }\end{array}$ & 2001 \\
\hline 17 & $\begin{array}{l}\text { E. N. Nfuka, L } \\
\text { Rusu }\end{array}$ & The effect of critical success factors on ITG performance & 2011 \\
\hline 16 & G. M. Scott & Still not solved: the persistent problem of IT strategic planning & 2005 \\
\hline 15 & A. A. Abu-Musa & $\begin{array}{l}\text { Exploring information technology governance (ITG) in developing } \\
\text { countries: an empirical study }\end{array}$ & 2007 \\
\hline 8 & $\begin{array}{l}\text { A. Y. Chong, K. } \\
\text { B. Ooi, N. } \\
\text { Darmawan, F.T. } \\
\text { S. Chan }\end{array}$ & $\begin{array}{l}\text { Does employee alignment affect business-IT alignment? An empirical } \\
\text { analysis }\end{array}$ & 2011 \\
\hline 4 & R Young, S Poon & $\begin{array}{l}\text { Top management support-almost always necessary and sometimes } \\
\text { sufficient for success: Findings from a fuzzy set analysis }\end{array}$ & 2013 \\
\hline 0 & $\begin{array}{l}\text { I. Kurti, E. } \\
\text { Barrolli, K. } \\
\text { Sevrani } \\
\end{array}$ & $\begin{array}{l}\text { Effective ITG in the Albanian Public administration-A Critical Success } \\
\text { Factors Approach }\end{array}$ & 2014 \\
\hline 138 & $\begin{array}{l}\text { P. L. Bowen, M. } \\
\text { Y. D. Cheung, F. } \\
\text { H. Rohde }\end{array}$ & $\begin{array}{l}\text { Enhancing ITG practices: A model and case study of an organization's } \\
\text { efforts }\end{array}$ & 2007 \\
\hline 53 & $\begin{array}{l}\text { S. De Haes, W. } \\
\text { Van Grembergen }\end{array}$ & $\begin{array}{l}\text { An exploratory study into the design of an ITG minimum baseline } \\
\text { through Delphi research }\end{array}$ & 2008 \\
\hline
\end{tabular}

Fonte: Dados da Pesquisa

Inicialmente, FCS em GTI foram extraídos dessa literatura apresentada no Quadro 23. Depois, reuniram-se esses FCS em categorias com temática semelhante. Por fim, as categorias foram agrupadas nos três subsistemas de TI, apresentados no Subcapítulo 2.3.2: Direcionamento, Desenvolvimento e Entrega. Vale ressaltar que durante esta análise, o subsistema Direcionamento foi dividido em Direcionamento em Negócio de TI e Direcionamento em Gestão de TI. Essa divisão considerou a definição de Van Grembergen (2004), em que a gestão de TI delibera sobre o fornecimento interno de insumos para a gestão de serviços e de produtos de TI. Weill e Ross (2006) delimitam os insumos a assuntos relacionados a investimentos de TI, recursos humanos e contratações. 
As categorias e os FCS serão apresentados em cinco quadros (Quadro 24, Quadro 25, Quadro 26, Quadro 27 e Quadro 28). Os Quadros 24 e 25 apresentam os agrupamentos referentes ao subsistema Direcionamento. O Quadro 24 trata da governança do negócio de TI. O Quadro 25 mostra aspectos de governança, mas centrados na gestão do subsistema Direcionamento.

\section{Categorias em Direcionamento: Parte I - Negócio de TI}

O Quadro 24 possui doze categorias: i) Alinhamento entre TI e negócio; ii) Estrutura organizacional de GTI; iii) Priorização de projetos de TI; iv) Controles de GTI; v) Direcionadores da estratégia de TI; vi) Formulação e planejamento de estratégia de TI; vii) Modelo de gestão de negócio; viii) Utilização de boas práticas; $i x$ ) Gestão de processos de TI;

x) Estrutura organizacional de TI; xi) Gestão do usuário de TI; e xii) Gestão de demandas.

Quadro 24 - Categorias de Direcionamento - Parte I: Negócio de TI Subsistema: Direcionamento em Negócio de TI

\begin{tabular}{|c|c|c|}
\hline \multicolumn{3}{|c|}{ Subsistema: Direcionamento em Negócio de TI } \\
\hline Categorias & Fatores Críticos de Sucesso & Referências \\
\hline \multirow{11}{*}{$\begin{array}{l}\text { Dneg0100 - } \\
\text { Alinhamento entre TI } \\
\text { e o negócio }\end{array}$} & $\begin{array}{l}\text { TI está envolvida na estratégia de desenvolvimento da } \\
\text { instituição }\end{array}$ & Luftman, Papp e Brier (1999) \\
\hline & Alinhamento de TI com negócio & $\begin{array}{c}\text { Luftman, Papp e Brier (1999); Khandelwal (2003); } \\
\text { Scott (2005); Abu-Musa (2007); De Haes e Van } \\
\text { Grembergen (2008); Nfuka e Rusu (2011); Kurti, } \\
\text { Barrolli e Sevrani (2014) }\end{array}$ \\
\hline & CIO é membro da alta administração da organização & Scott $(2005)$ \\
\hline & $\begin{array}{c}\text { Cultura e visão compartilhada e, boa comunicação entre } \\
\text { TI e negócio }\end{array}$ & $\begin{array}{c}\text { Scott (2005); Abu-Musa (2007); Bowen, Cheung and } \\
\text { Rohde (2007); Pollard e Cater-Steel (2009); Nfuka e } \\
\text { Rusu (2011); Chong et al. (2013); Kurti, Barrolli e } \\
\text { Sevrani (2014) }\end{array}$ \\
\hline & $\begin{array}{l}\text { Alta administração possui compromisso com o } \\
\text { planejamento da TI }\end{array}$ & Scott (2005) \\
\hline & Partes interessadas engajadas na GTI & Nfuka e Rusu (2011); Kurti, Barrolli e Sevrani (2014) \\
\hline & $\begin{array}{l}\text { Alta administração de TI se reporta diretamente à alta } \\
\text { administração da instituição }\end{array}$ & De Haes e Van Grembergen (2008) \\
\hline & $\begin{array}{c}\text { Negócio é parceiro da TI e existem parcerias do negócio } \\
\text { para com a TI }\end{array}$ & $\begin{array}{l}\text { Luftman, Papp e Brier (1999); Khandelwal (2003); } \\
\text { Pollard e Cater-Steel (2009) }\end{array}$ \\
\hline & GTI projetada em vários níveis organizacionais & Weill (2004); Boh e Yellin (2007) \\
\hline & $\begin{array}{c}\text { Compreensão do planejamento do negócio e do } \\
\text { planejamento de TI }\end{array}$ & $\begin{array}{c}\text { Luftman (2000); Khandelwal (2003); Scott (2005); } \\
\text { Bowen, Cheung and Rohde (2007); Chong et al. } \\
\text { (2013) }\end{array}$ \\
\hline & Apoio da alta administração para a GTI & $\begin{array}{l}\text { Luftman, Papp e Brier (1999); Young e Jordan (2008); } \\
\text { Pollard e Cater-Steel (2009); Tan, Cater-Steel, } \\
\text { Toleman (2009); Nfuka e Rusu (2011); Young e Poon } \\
\text { (2013); Kurti, Barrolli, Sevrani (2014) }\end{array}$ \\
\hline $\begin{array}{c}\text { Dneg0200 - Estrutura } \\
\text { organizacional de GTI }\end{array}$ & Comitês diretores de TI & $\begin{array}{l}\text { Bowen, Cheung and Rohde (2007); De Haes e Van } \\
\text { Grembergen (2008); Pollard e Cater-Steel (2009) }\end{array}$ \\
\hline $\begin{array}{c}\text { Dneg0300 - } \\
\text { Priorização de projetos } \\
\text { de TI }\end{array}$ & Priorização de projetos de TI & Luftman, Papp e Brier (1999) \\
\hline \multirow{2}{*}{$\begin{array}{l}\text { Dneg0400 - Controles } \\
\text { de GTI }\end{array}$} & Transparência & Weill (2004) \\
\hline & Gestão de riscos & Abu-Musa (2007); Nfuka e Rusu (2011) \\
\hline $\begin{array}{c}\text { Dneg0500 - } \\
\text { Direcionadores de }\end{array}$ & TI demonstra liderança & $\begin{array}{l}\text { Luftman, Papp e Brier (1999); De Haes e Van } \\
\text { Grembergen (2008); Nfuka e Rusu (2011); Kurti, }\end{array}$ \\
\hline
\end{tabular}




\begin{tabular}{|c|c|c|}
\hline \multirow[t]{3}{*}{ estratégia de TI } & & Barrolli e Sevrani (2014) \\
\hline & TI como vantagem competitiva para a organização & Luftman, Papp e Brier (1999), Khandelwal (2003) \\
\hline & Avaliação do valor do negócio da TI & Khandelwal (2003) \\
\hline \multirow{3}{*}{$\begin{array}{c}\text { Dneg0600 - } \\
\text { Formulação e } \\
\text { planejamento de } \\
\text { estratégia de TI }\end{array}$} & Abrangência do valor métricas, metas e objetivos & $\begin{array}{c}\text { Bowen, Cheung and Rohde (2007); Abu-Musa (2007); } \\
\text { Pollard e Cater-Steel (2009) }\end{array}$ \\
\hline & Métricas com foco no cliente. & Pollard e Cater-Steel (2009) \\
\hline & $\begin{array}{l}\text { Metodologia de planejamento de TI com expectativas } \\
\text { realísticas, objetivos e visão clara }\end{array}$ & Young e Jordan (2008) \\
\hline \multirow{2}{*}{$\begin{array}{l}\text { Dneg0700 - Modelo de } \\
\text { gestão de negócio }\end{array}$} & $\begin{array}{c}\text { Consolidação de medidas de desempenho, benckmarks e } \\
\text { sucesso demonstrado }\end{array}$ & $\begin{array}{c}\text { Bowen, Cheung and Rohde (2007); De Haes e Van } \\
\text { Grembergen (2008); Nfuka e Rusu (2011); Kurti, } \\
\text { Barrolli e Sevrani (2014) }\end{array}$ \\
\hline & $\begin{array}{l}\text { Simplidade na tomada de decisão, com poucas metas de } \\
\text { desempenho }\end{array}$ & Weill (2004) \\
\hline \multirow{2}{*}{$\begin{array}{l}\text { Dneg0800 - Utilização } \\
\text { de boas práticas }\end{array}$} & Cultura ITIL & Pollard e Cater-Steel (2009) \\
\hline & Uso de consultores & Pollard e Cater-Steel (2009) \\
\hline $\begin{array}{l}\text { Dneg0900 - Gestão de } \\
\text { processos de TI }\end{array}$ & Maturidade nos processos internos de TI & Abu-Musa (2007) \\
\hline $\begin{array}{l}\text { Dneg1000 - Estrutura } \\
\text { organizacional de TI }\end{array}$ & Definição de uma estrutura organizacional apropriada & $\begin{array}{c}\text { Luftman, Papp e Brier (1999); Weill (2004); Boh e } \\
\text { Yellin (2007); Nfuka e Rusu (2011); Kurti, Barrolli e } \\
\text { Sevrani (2014) }\end{array}$ \\
\hline \multirow{3}{*}{$\begin{array}{l}\text { Dneg } 1100 \text { - Gestão do } \\
\text { usuário de TI }\end{array}$} & Atingir as expectativas dos usuários & Khandelwal (2003); Pollard e Cater-Steel (2009) \\
\hline & Alcançar a autonomia do usuário & Khandelwal (2003) \\
\hline & Usuários envolvidos nos projetos & Scott (2005); Young e Jordan (2008) \\
\hline \multirow{2}{*}{$\begin{array}{l}\text { Dneg } 1200 \text { - Gestão de } \\
\text { demandas }\end{array}$} & Processo de tratamento de exceção & Weill (2004) \\
\hline & Gestão de portfólio & Scott (2005); De Haes e Van Grembergen (2008) \\
\hline
\end{tabular}

Fonte: Dados da Pesquisa

a) Dneg0100 - Alinhamento entre TI e o negócio

A categoria Alinhamento da TI com o negócio inclui os fatores que objetivam o relacionamento da área de TI com as demais áreas funcionais de negócio. Esses relacionamentos consideram a participação da TI no planejamento da estratégia institucional, bem como o envolvimento de membros da gestão e da governança da organização nas decisões de GTI.

Nesta pesquisa, o artigo de Luftman, Papp e Brier (1999) é o primeiro a tratar o assunto FCS em GTI. Para isso, os autores consideram como o objeto de pesquisa o nome Alinhamento de TI com o negócio. Posteriormente, pesquisas em FCS em GTI consideram esse termo como sendo um FCS (KHANDELWAL, 2003; SCOTT, 2005; ABU-MUSA, 2007; DE HAES; VAN GREMBERGEN, 2008; NFUKA; RUSU, 2011; KURTI; BARROLLI; SEVRANI, 2014). Conforme o Quadro 24, o Alinhamento entre TI e negócio nesta pesquisa assume a função de categorias e de FCS.

\section{b) Dneg 0200 - Estrutura organizacional de GTI}

A categoria Estrutura organizacional de GTI mostra os FCS que descrevem as estruturas funcionais de GTI. No Quadro 24, cita-se o Comitê diretor de TI, mas nesta 
Categoria também são consideradas as estruturas de controle e de assessoria em GTI, bem como unidades de relacionamento entre TI e negócios, comitê de arquitetura e comitê de aprovação de capital.

Especificamente para a administração pública, o Acórdão 1233/2012 ata 19 - Plenário, solicita que o Comitê de TI observe as boas práticas sobre o tema, a exemplo do COBIT 4.1, PO 4.2 - comitê estratégico de TI e PO4.3.

A definição de uma estrutura organizacional apropriada define uma estrutura com responsabilidade, com autoridade e com recursos adequados para conduzir a iniciativa, assegurando a participação de todos os grupos de interessados (BIGIO et al., 2004; HERNANDEZ et al., 2010; MORENO JUNIOR; ANDRADE, 2011; NASTASE et al.,2009).

\section{c) Dneg0300 - Priorização de projetos de TI}

A categoria Priorização de projetos de TI aborda uma das atribuições do Comitê de TI. No Quadro 24, a Categoria e o FCS associado possuem a mesma denominação, mas nesta categoria também são incluídas critérios de priorização de projetos de TI.

Frisa-se que a priorização de projetos de TI é uma atividade de governança. A participação de maioria da gestão nesta atividade enfraquece a governança. Nessa situação, uma vez aprovados os projetos, eles serão planejados, executados e controlados pelos próprios gestores que deliberam sobre o assunto.

\section{d) Dneg0400 - Controles de GTI}

A categoria Controles de GTI trazem como FCS a Gestão de Riscos e a Transparência. Neste grupo são incluídos também os instrumentos de controle interno e externo da GTI. A customização da GTI surge como ferramenta-chave para a determinação de controles organizacionais e para a racionalização dos custos de TI na criação de valor no processo produtivo da organização (MCLANE, 2003).

e) Dneg0500 - Direcionadores da estratégia de TI

A categoria Direcionadores de estratégia de TI aborda os temas estratégicos da TI. Usa-se questões sobre liderança da TI perante a organização, a vantagem competitiva da para 
o negócio e a verificação do valor da TI. Essa categoria está fortemente relacionada à Categoria Alinhamento entre TI e negócio. Discute-se aqui que a estratégia de TI tenha comportamento top-down, do negócio para TI, da governança corporativa para GTI.

\section{f) Dneg0600 - Formulação e planejamento de estratégia de TI}

A categoria Direcionadores da estratégia de TI cuida da metodologia para formulação e planejamento da estratégia de TI, incluindo os modelos de métricas e de indicadores estratégicos a serem utilizados.

O Acórdão 1233/2012 instrui que para a estratégia de TI se estabelece o processo de planejamento estratégico de TI, observando as boas práticas sobre o tema, a exemplo do processo "PO1 - Planejamento Estratégico de TI" do COBIT 4.1. Ademais, solicita que a elaboração, com participação de representantes dos diversos setores da organização, de um documento que materialize o plano estratégico de TI que deve ser desdobrado pelas unidades executoras.

g) Dneg0700 - Modelo de gestão de negócio

A categoria Modelo de gestão de negócio especifica os critérios de tomada de decisão por meio da consolidação de medidas de desempenho, de benckmarks e de sucesso demonstrado.

h) Dneg0800 - Utilização de boas práticas

A categoria Utilização de boas práticas apresenta quais e como serão utilizadas as boas práticas do mercado específicas para GTI. Geralmente, incluem COBIT, ITIL, ISO, CMMI, entre outros. Saber como utilizar ou customizar o uso dessas práticas é crítico para o negócio, uma vez que a aplicação má planejamento pode diminuir o desempenho da área de TI (ITAUDIT, 2007).

i) Dneg0900 - Gestão de processos de TI 
A categoria Gestão de processos de TI especifica sobre o mapeamento e implementação e gestão dos processos específicos da organização de TI.

\section{j) Dneg1000 - Estrutura organizacional de TI}

A categoria Estrutura organizacional de TI define as estruturas que compõem a área de TI. Diferentemente da Estrutura organizacional de GTI, essa Categoria mostra quais as unidades de trabalho estratégico, tático e operacional que organizam as funções de TI para com a organização.

\section{k) Dneg1100 - Gestão do usuário de TI}

A categoria Gestão do usuário de TI concentra os temas que tratam dos usuários dos serviços de TI. O tratamento visa atingir as expectativas dos usuários, engajando-os nos projetos para o desenvolvimento de soluções em TI. A Categoria é fortemente associada à categoria de Direcionadores de estratégias de TI.

\section{l) Dneg1200 - Gestão de demandas}

A categoria Gestão de demandas engloba as demandas do negócio que geram um conjunto definido de pedidos padronizados e tem como saída um portfólio de serviços. As demandas são de quatro tipos: exploração de ideias, projetos, serviços e relato de incidentes. As demandas podem ser endógenas, ou seja, da própria área de TI, ou exógenas, externas à área de TI (Ramos, 2009). Especificamente sobre a gestão do portfólio, nesta Categoria são definidas as diretrizes da gestão do portfólio e não a operação do catálogo de serviços que cabe ao subsistema Entrega.

\section{Categorias em Direcionamento - Parte II: Gestão de TI}

O Quadro 25 possui três categorias: $i$ ) Gestão de fornecedores; ii) Gestão de pessoal de TI; e iii) Gestão de recursos financeiros e orçamentários. A gestão de TI considera a definição de Van Grembergen (2004), em que a gestão de TI delibera sobre o fornecimento interno de insumos para a gestão de serviços e de produtos de TI. Além disso, Weill e Ross (2006) 
delimitam que esses insumos se referem a investimentos de TI, recursos humanos e contratações/aquisições.

Quadro 25 - Categorias de Direcionamento - Parte II: Gestão de TI

\begin{tabular}{|c|c|c|}
\hline \multicolumn{3}{|c|}{ Subsistema: Direcionamento em Gestão de TI } \\
\hline Categorias & Fatores Críticos de Sucesso & Referências \\
\hline $\begin{array}{l}\text { Dges0100 - } \\
\text { Gestão de } \\
\text { fornecedores }\end{array}$ & Relacionamento com múltiplos fornecedores & Tan, Cater-Steel, Toleman (2009) \\
\hline \multirow{13}{*}{$\begin{array}{c}\text { Dges } 0200- \\
\text { Gestão de pessoal } \\
\text { de TI }\end{array}$} & $\begin{array}{c}\text { Alta administração da instituição é capacitada } \\
\text { em TI }\end{array}$ & Khandelwal (2003); Weill (2004) \\
\hline & Pessoal de TI comprometido e responsável & Abu-Musa (2007), Chong et al. (2013) \\
\hline & Pessoal de TI possui competência no negócio & $\begin{array}{c}\text { Luftman, Papp e Brier (1999), Khandelwal } \\
\text { (2003) }\end{array}$ \\
\hline & Pessoal de TI competente e motivado & Young e Jordan (2008) \\
\hline & $\begin{array}{l}\text { Atração e retenção de pessoal com } \\
\text { competências chave de TI }\end{array}$ & $\begin{array}{c}\text { Abu-Musa (2007); Nfuka e Rusu (2011); } \\
\text { Kurti, Barrolli e Sevrani (2014) }\end{array}$ \\
\hline & $\begin{array}{l}\text { Mensuração e recompensa de desempenho } \\
\text { individual e de equipe }\end{array}$ & Abu-Musa (2007) \\
\hline & $\begin{array}{l}\text { Gestão do conhecimento para melhoria do } \\
\text { desempenho }\end{array}$ & Luftman (2000); Abu-Musa (2007) \\
\hline & Incentivos alinhados & Weill (2004) \\
\hline & $\begin{array}{l}\text { Treinamento e desenvolvimento de pessoal de } \\
\text { TI }\end{array}$ & $\begin{array}{c}\text { Abu-Musa (2007); Pollard e Cater-Steel } \\
\text { (2009); Nfuka e Rusu (2011); Kurti, } \\
\text { Barrolli e Sevrani (2014) }\end{array}$ \\
\hline & $\begin{array}{l}\text { Relacionamento entre os níveis de gestão } \\
\text { sênior, pleno e junior }\end{array}$ & Tarafdar e Gordon (2007) \\
\hline & Manter os níveis de pessoal de TI & Khandelwal (2003) \\
\hline & Ambiente de trabalho adequado & Abu-Musa (2007) \\
\hline & Rotatividade & Luftman (2000) \\
\hline \multirow[b]{2}{*}{$\begin{array}{l}\text { Dges } 0300 \text { - } \\
\text { Gestão de } \\
\text { recursos } \\
\text { financeiros e } \\
\text { orçamentários }\end{array}$} & Controle da gestão de orçamento & De Haes e Van Grembergen (2008) \\
\hline & Gestão dos custos de TI & $\begin{array}{c}\text { Luftman (2000); Khandelwal (2003); Abu- } \\
\text { Musa (2007); Bowen, Cheung e Rohde } \\
\text { (2007); Nfuka e Rusu (2011); Kurti, } \\
\text { Barrolli e Sevrani (2014) }\end{array}$ \\
\hline
\end{tabular}

Fonte: Dados da Pesquisa

a) Dges 0100 - Gestão de fornecedores

A categoria Gestão de fornecedores considera os temas referentes aos fornecedores de serviços e de produtos em TI. No Quadro 25 foca basicamente no relacionamento com os vários fornecedores, focando principalmente no trato com a fábrica de software.

\section{b) Dges 0200 - Gestão de pessoal de TI}

A categoria Gestão de pessoal de TI inclui as questões como a preocupação pela capacitação da alta administração em TI e dos colaboradores da TI em negócio; também se 
preocupa com o clima organizacional, por meio dos FCS referentes à motivação e ambiente de trabalho adequado. Esta Categoria é a que apresenta a maior quantidade de FCS.

c) Dges 0300 - Gestão de recursos financeiros e orçamentários

A categoria Gestão de recursos financeiros e orçamentários engloba os FCS relacionados à gestão orçamentária e à gestão financeira da TI. Destaca-se nesta Categoria o FCS Gestão dos custos de TI (LUFTMAN, 2000; KHANDELWAL 2003; ABU-MUSA, 2007; BOWEN; CHEUNG; ROHDE, 2007; NFUKA; RUSU, 2011; KURTI; BARROLLI; SEVRANI, 2014).

\section{Categorias em Desenvolvimento}

O Quadro 26 apresenta as duas categorias do subsistema Desenvolvimento: i) Gestão de projetos de TI; e ii) Gestão de processos para desenvolvimento de soluções.

Quadro 26- Categorias de Desenvolvimento

\begin{tabular}{|c|c|c|}
\hline \multirow{2}{*}{ Categorias } & Fatores Críticos de Sucesso & Referências \\
\hline \multirow{2}{*}{$\begin{array}{c}\text { Dese0100 - Gestão } \\
\text { de projetos de TI }\end{array}$} & Ativamente projetado & Weill (2004) \\
\cline { 2 - 3 } & $\begin{array}{c}\text { Formação de time de projeto } \\
\text { Identificação dos elementos de } \\
\text { planejamento }\end{array}$ & $\begin{array}{c}\text { Tarafdar e Gordon (2007); Pollard e Cater-Steel } \\
\text { (2009) }\end{array}$ \\
\cline { 2 - 3 } & $\begin{array}{c}\text { De Haes e Van Grembergen (2008); Young e } \\
\text { Jordan (2008); Tan, Cater-Steel, Toleman (2009) }\end{array}$ \\
\cline { 2 - 3 } $\begin{array}{c}\text { Dese0200 - Gestão } \\
\text { de processos para } \\
\text { desenvolvimento de } \\
\text { soluções }\end{array}$ & $\begin{array}{c}\text { Entregar projetos de TI bem } \\
\text { sucedidos }\end{array}$ & $\begin{array}{c}\text { Abusa (2007); Bollard e Cater-Steel (2009); Tan, Cater- } \\
\text { Steel, Toleman (2009) }\end{array}$ \\
\hline
\end{tabular}

Fonte: Dados da Pesquisa

a) Dese0100 - Gestão de projetos de TI

A categoria Gestão de projetos de TI mostram os temas referentes à metodologia de gestão de projetos, incluído o planejamento, execução e controle. Nesta Categoria são abordados temas sobre equipe de projetos, nível do gerenciamento de projetos na organização, elementos das boas práticas de gerenciamento de projetos adequadas às necessidades da TI. 


\section{b) Dese0200 - Gestão de processos para desenvolvimento de soluções}

A categoria Gestão de processos para desenvolvimento de soluções trata dos temas relacionados à gestão de processos de negócio úteis para o desenvolvimento de soluções. $\mathrm{O}$ FCS apresentado nesta categoria destaca-se abaixo do porcentual de reengenharia como FCS, uma vez que constantes mudanças nos processos organizacionais influenciam no desempenho organizacional.

\section{Categorias em Entregas}

O Quadro 27 apresenta as quatro categorias que compõem o subsistema Entrega: $i$ ) Gestão de entregas; ii) Gestão de infraestrutura; iii Processos de gestão de serviços de TI em desenho do serviço; e $i v$ ) Processos de gestão de serviços de TI em operação do serviço.

Vale destacar que as categorias Processos de gestão de serviços de TI em desenho do serviço e Processos de gestão de serviços de TI em operação do serviço são oriundas do Levantamento de GTI ano 2012 do TCU. Essa escolha se justifica pelos FCS serem idênticos a questões do TCU que são agrupadas nessas categorias.

Quadro 27-Categorias de Entrega

\begin{tabular}{|c|c|c|}
\hline \multicolumn{3}{|c|}{ Subsistema: Entrega } \\
\hline Categorias & Fatores Críticos de Sucesso & Referências \\
\hline \multirow[b]{2}{*}{$\begin{array}{l}\text { Enet } 0100 \text { - Gestão } \\
\text { de entregas }\end{array}$} & Entregas de valor da TI & Abu-Musa (2007) \\
\hline & Entrega de bons serviços & $\begin{array}{l}\text { Abu-Musa (2007); Bowen, Cheung e Rohde } \\
\text { (2007) }\end{array}$ \\
\hline \multirow{6}{*}{$\begin{array}{l}\text { Enet } 0200 \text { - Gestão } \\
\text { de infraestrutura }\end{array}$} & $\begin{array}{c}\text { Consolidação, padronização e gestão } \\
\text { de infraestrutura de TI }\end{array}$ & $\begin{array}{c}\text { Abu-Musa (2007); Tarafdar e Gordon (2007); } \\
\text { Nfuka e Rusu (2011); Kurti, Barrolli e Sevrani } \\
\text { (2014) }\end{array}$ \\
\hline & $\begin{array}{l}\text { Seleção criteriosa de } \\
\text { software/ferramentas. }\end{array}$ & Pollard e Cater-Steel (2009) \\
\hline & $\begin{array}{l}\text { Sistemas de informação para } \\
\text { execução }\end{array}$ & Khandelwal (2003) \\
\hline & Infraestrutura de TI & Khandelwal (2003);Nfuka e Rusu (2011) \\
\hline & $\begin{array}{l}\text { Compreensão de tecnologias } \\
\text { emergentes }\end{array}$ & Khandelwal (2003); Abu-Musa (2007) \\
\hline & Estabelecer arquitetura de TI & $\begin{array}{l}\text { Scott (2005); Abu-Musa (2007); Pollard e Cater- } \\
\text { Steel (2009) }\end{array}$ \\
\hline $\begin{array}{c}\text { Enet } 0300 \text { - } \\
\text { Processos de gestão } \\
\text { de serviços de TI em } \\
\text { desenho do serviço }\end{array}$ & $\begin{array}{l}\text { Planejamento da continuidade do } \\
\text { negócio }\end{array}$ & Khandelwal (2003) \\
\hline $\begin{array}{c}\text { Enet } 0400 \text { - } \\
\text { Processos de gestão } \\
\text { de serviços de TI em } \\
\text { operação do serviço }\end{array}$ & $\begin{array}{c}\text { Gestão do desempenho do serviço } \\
\text { operacional }\end{array}$ & Abu-Musa (2007) \\
\hline
\end{tabular}

Fonte: Dados da Pesquisa 
a) Enet 0100 - Gestão de entregas

A categoria Gestão de entregas abarca os fatores que asseguram que os entregáveis de TI sejam de valor para o demandante. Esta Categoria é fortemente associada à categoria Direcionadores de estratégia de TI, quando neste consta como tema estratégico a entrega de valor.

b) Enet 0200 - Gestão de infraestrutura

A categoria Gestão de infraestrutura reúne os temas referentes à infraestrutura de TI. Nesta Categoria constam os fatores relacionados a consolidação, padronização e gestão de infraestrutura de TI; critérios para a seleção de software; conhecimento sobre as tecnologias emergentes e; os critérios para o estabelecimento de arquitetura de TI.

c) Enet 0300 - Processos de gestão de serviços de TI em desenho do serviço

A categoria Processos de gestão de serviços em desenho do serviço, bem como a categoria Processos de gestão de serviços de TI em operação do serviço são categorias oriundas do Levantamento de TI do ano 2012 do TCU. Entretanto, na literatura pesquisada existem fatores que correspondem a essas categorias. Especificamente para esta Categoria, fazem parte os temas relacionados ao planejamento da continuidade do negócio (KHANDELWAL, 2003).

d) Enet 0400 - Processos de gestão de serviços de TI em operação do serviço

A categoria Processos de gestão de serviços de TI em operações do serviço considera os temas relacionados à gestão do desempenho do serviço operacional (ABU-MUSA, 2007). Os serviços são vinculados à gestão de incidentes do ITIL. 


\subsection{ANÁLISE DOS FCS EM GOVERNANÇA DE TI NA APF}

O método de levantamento de FCS identifica as poucas áreas chaves onde as "coisas devem ocorrer adequadamente" para que o negócio floresça e para que os objetivos do gerente sejam alcançados (DIAS JUNIOR; GUSSONI; MUNIZ JUNIOR, 2009).

O objetivo desta análise, é identificar os FCS dessas organizações, sejam eles formalizados como FCS ou não, mas obrigatoriamente direcionadores para a tomada de decisão presente ou futura.

O Subcapítulo 4.3 é dividido em cinco seções terciárias: a Seção 4.3.1 mostra a análise das categorias. Depois as próximas seções apresentam os resultados dos FCS. A Seção 4.3.2 analisa os FCS do subsistema Direcionamento em Negócio de TI; a Seção 4.3.3 averigua os FCS do subsistema Direcionamento em Gestão de TI; a Seção 4.3.4 examina os FCS do subsistema Desenvolvimento; e por fim a Seção 4.3.5 estuda os FCS do subsistema Entrega.

\subsubsection{Análise das Categorias dos FCS em GTI da APF}

Para a análise das categorias serão consideradas as categorias apresentadas no Subcapítulo 4.2. As categorias são agrupadas pelos subsistemas de meta arquitetura corporativa de TI, Direcionamento, Desenvolvimento e Entrega. Durante o agrupamento, a meta arquitetura corporativa de TI contribuiu como um mapa de classificação dos FCS em suas respectivas categorias.

Para esta análise o subsistema Direcionamento foi dividido em negócio de TI e gestão de TI. Essa divisão considerou a definição de Van Grembergen (2004), em que a gestão de TI delibera sobre o fornecimento interno de insumos para a gestão de serviços e de produtos de TI. Weill e Ross (2006) delimitam os insumos a assuntos relacionados a investimentos de TI, recursos humanos e contratações. Um ponto a ser destacado é que a análise de GTI projeta a área de TI a fim de identificar o que a governança deve normatizar e controlar.

O Quadro 28 mostra a análise descritiva das categorias distribuídas nos subsistemas. Nesse Quadro é apresentada a quantidade de categorias de cada subsistema com o respectivo porcentual. Depois, na quarta coluna da esquerda para a direita, são as frequências das respostas dos entrevistados, seguidos dos porcentuais. 
Quadro 28-Frequência de Categorias

\begin{tabular}{|l|c|c|c|r|}
\hline \multicolumn{1}{|c|}{ Subsistema } & $\begin{array}{c}\text { Quant. de } \\
\text { Categorias }\end{array}$ & $\begin{array}{c}\text { \%.de } \\
\text { Categorias }\end{array}$ & $\begin{array}{c}\text { Freq. } \\
\text { Respostas }\end{array}$ & \%. Respostas \\
\hline Dir. em Negócio de TI & 17 & $53,13 \%$ & 126 & $45,99 \%$ \\
\hline Dir. em Gestão & 5 & $15,63 \%$ & 52 & $18,98 \%$ \\
\hline Desenvolvimento & 3 & $9,38 \%$ & 34 & $12,41 \%$ \\
\hline Entrega & 7 & $21,88 \%$ & 62 & $22,63 \%$ \\
\hline Total & $\mathbf{3 2}$ & $\mathbf{1 0 0 , 0 0 \%}$ & $\mathbf{2 7 4}$ & $\mathbf{1 0 0 , 0 0 \%}$ \\
\hline
\end{tabular}

O subsistema Direcionamento em Negócio de TI possui 17 categorias com um total de 126 respostas. A predominância de categorias neste subsistema é esperada, uma vez que concentra a atribuição principal da GTI. A descrição das categorias que compõem este subsistema é apresentada no Quadro 30.

As categorias do subsistema Direcionamento em Gestão de TI representam o porcentual de $15,63 \%$ do total de categorias. A descrição das categorias que compõem este subsistema é apresentada no Quadro 31.

As categorias do subsistema Desenvolvimento possui o menor número de categorias, representando $9,38 \%$ do total de categorias.

As categorias do subsistema Entrega conta com sete categorias que representam $21,88 \%$ do total de categorias. Este subsistema representa a operacionalização dos serviços de TI, mas são apreciados FCS em GTI. As categorias deste subsistema estão no Quadro 33.

O Quadro 29 detalha as respostas das 26 instituições. Lembramos que a quantidade de respostas é relativamente baixa porque se trata de um levantamento qualitativo. 
Quadro 29- Categorias por instituição pesquisada

\begin{tabular}{|c|c|c|c|c|c|c|c|c|c|}
\hline Entidade & $\begin{array}{c}\text { Direcionamento } \\
\text { em Negócio de } \\
\text { TI (Dneg) }\end{array}$ & $\begin{array}{c}\text { Frequência } \\
\text { em Dneg }\end{array}$ & $\begin{array}{c}\text { Direcionameneto } \\
\text { em Gestão de TI } \\
\text { (Dgest) }\end{array}$ & $\begin{array}{c}\text { Frequência } \\
\text { Dges }\end{array}$ & $\begin{array}{l}\text { Desenvol- } \\
\text { vimento } \\
\text { (Dese) } \\
\end{array}$ & $\begin{array}{c}\text { Frequência } \\
\text { Dese }\end{array}$ & $\begin{array}{c}\text { Entrega } \\
\text { (Enet) }\end{array}$ & $\begin{array}{c}\text { Frequência } \\
\text { Enet }\end{array}$ & $\begin{array}{l}\text { Total } \\
\text { Geral }\end{array}$ \\
\hline 001 & 7 & $5,56 \%$ & 2 & $3,85 \%$ & 1 & $2,94 \%$ & 3 & $4,84 \%$ & 13 \\
\hline 002 & 7 & $5,56 \%$ & 2 & $3,85 \%$ & $\mathbf{0}$ & $0,00 \%$ & 4 & $6,45 \%$ & 13 \\
\hline 003 & 4 & $3,17 \%$ & 2 & $3,85 \%$ & 1 & $2,94 \%$ & 3 & $4,84 \%$ & 10 \\
\hline 004 & 3 & $2,38 \%$ & 1 & $1,92 \%$ & 1 & $2,94 \%$ & 1 & $1,61 \%$ & 6 \\
\hline 005 & 7 & $5,56 \%$ & 2 & $3,85 \%$ & 2 & $5,88 \%$ & 4 & $6,45 \%$ & 15 \\
\hline 006 & 7 & $5,56 \%$ & 1 & $1,92 \%$ & 2 & $5,88 \%$ & 3 & $4,84 \%$ & 13 \\
\hline 007 & 4 & $3,17 \%$ & $\mathbf{0}$ & $0,00 \%$ & 2 & $5,88 \%$ & 3 & $4,84 \%$ & 9 \\
\hline 008 & 6 & $4,76 \%$ & 2 & $3,85 \%$ & $\mathbf{0}$ & $0,00 \%$ & 3 & $4,84 \%$ & 11 \\
\hline 009 & 6 & $4,76 \%$ & 3 & $5,77 \%$ & 1 & $2,94 \%$ & 2 & $3,23 \%$ & 12 \\
\hline 010 & 4 & $3,17 \%$ & 3 & $5,77 \%$ & 2 & $5,88 \%$ & 1 & $1,61 \%$ & 10 \\
\hline 011 & 8 & $6,35 \%$ & 4 & $7,69 \%$ & 3 & $8,82 \%$ & 3 & $4,84 \%$ & 18 \\
\hline 012 & 5 & $3,97 \%$ & 5 & $9,62 \%$ & 1 & $2,94 \%$ & 3 & $4,84 \%$ & 14 \\
\hline 013 & 6 & $4,76 \%$ & 2 & $3,85 \%$ & 2 & $5,88 \%$ & 1 & $1,61 \%$ & 11 \\
\hline 014 & 5 & $3,97 \%$ & 3 & $5,77 \%$ & 1 & $2,94 \%$ & 1 & $1,61 \%$ & 10 \\
\hline 015 & 3 & $2,38 \%$ & 1 & $1,92 \%$ & 1 & $2,94 \%$ & 3 & $4,84 \%$ & 8 \\
\hline 016 & 4 & $3,17 \%$ & 3 & $5,77 \%$ & 3 & $8,82 \%$ & 4 & $6,45 \%$ & 14 \\
\hline 017 & 5 & $3,97 \%$ & 2 & $3,85 \%$ & 1 & $2,94 \%$ & 1 & $1,61 \%$ & 9 \\
\hline 018 & 4 & $3,17 \%$ & 3 & $5,77 \%$ & 1 & $2,94 \%$ & 6 & $9,68 \%$ & 14 \\
\hline 019 & 3 & $2,38 \%$ & 2 & $3,85 \%$ & 2 & $5,88 \%$ & 1 & $1,61 \%$ & 8 \\
\hline 020 & 2 & $1,59 \%$ & $\mathbf{0}$ & $0,00 \%$ & $\mathbf{0}$ & $0,00 \%$ & 1 & $1,61 \%$ & 3 \\
\hline 021 & 3 & $2,38 \%$ & 2 & $3,85 \%$ & 1 & $2,94 \%$ & 3 & $4,84 \%$ & 9 \\
\hline 022 & 4 & $3,17 \%$ & 0 & $0,00 \%$ & 1 & $2,94 \%$ & 1 & $1,61 \%$ & 6 \\
\hline $\mathbf{0 2 3}$ & 7 & $5,56 \%$ & 1 & $1,92 \%$ & 1 & $2,94 \%$ & 4 & $6,45 \%$ & 13 \\
\hline 024 & 5 & $3,97 \%$ & 1 & $1,92 \%$ & 1 & $2,94 \%$ & 1 & $1,61 \%$ & 8 \\
\hline 025 & 3 & $2,38 \%$ & 3 & $5,77 \%$ & 2 & $5,88 \%$ & 0 & $0,00 \%$ & 8 \\
\hline 026 & 4 & $3,17 \%$ & 2 & $3,85 \%$ & 1 & $2,94 \%$ & 2 & $3,23 \%$ & 9 \\
\hline Geral & 126 & $100,00 \%$ & 52 & $100,00 \%$ & 34 & $100,00 \%$ & 62 & $100,00 \%$ & 274 \\
\hline
\end{tabular}

Fonte: Dados da Pesquisa

A Figura 27 mostra a distribuição das categorias nos subsistemas de cada instituição pesquisada.

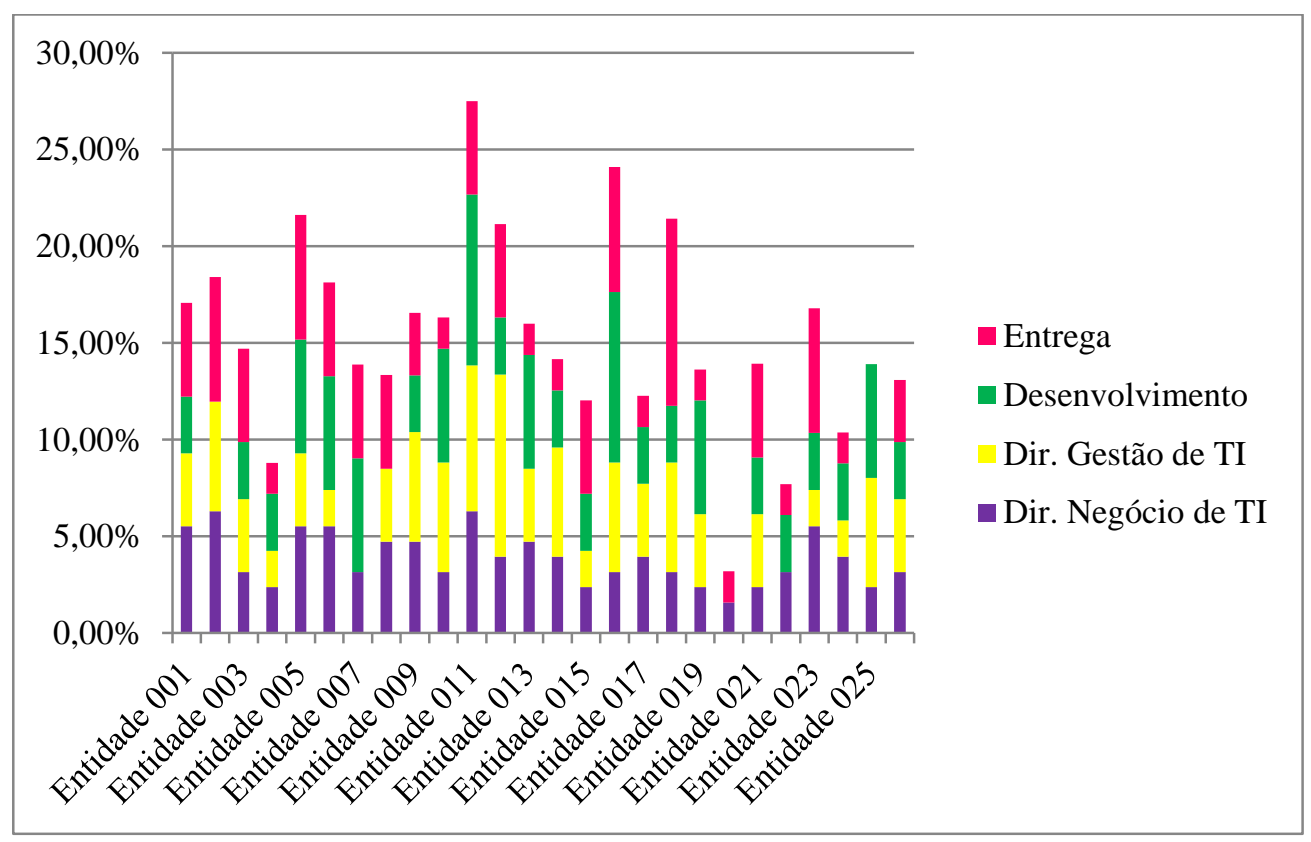

Figura 27 - Distribuição das Frequências de Respostas em Subsistemas Fonte: Dados da Pesquisa 
Nesta pesquisa são adicionadas novas categorias que agrupam os FCS com núcleos de sentido específicos que não constavam no Subcapítulo 4.2. As categorias estão destacadas em negritos no Quadro 30.

Quadro 30 - Categorias de Direcionamento em Negócio em GTI na APF

\begin{tabular}{|l|l|c|c|}
\hline \multicolumn{1}{|c|}{ Código } & \multicolumn{1}{c|}{$\begin{array}{c}\text { Categorias do Direcionamento em Negócio de } \\
\text { TI }\end{array}$} & Frequência & Porcentual \\
\hline Dneg0100 & Alinhamento entre TI e o negócio & 18 & $69,23 \%$ \\
\hline Dneg0600 & Formulação e planejamento de estratégia de TI & 13 & $50,00 \%$ \\
\hline Dneg1200 & Gestão de demandas & 11 & $42,31 \%$ \\
\hline Dneg0200 & Estrutura organizacional de GTI & 10 & $38,46 \%$ \\
\hline Dneg1500 & Plano diretor de tecnologia da informação & 10 & $\mathbf{3 8 , 4 6 \%}$ \\
\hline Dneg0300 & Priorização de projetos de TI & 8 & $30,77 \%$ \\
\hline Dneg1000 & Estrutura organizacional de TI & 8 & $30,77 \%$ \\
\hline Dneg1100 & Gestão do usuário de TI & 8 & $30,77 \%$ \\
\hline Dneg0400 & Controle de GTI & 7 & $26,92 \%$ \\
\hline Dneg0500 & Direcionadores de estratégia de TI & 7 & $26,92 \%$ \\
\hline Dneg0800 & Utilização de melhores práticas & 6 & $23,08 \%$ \\
\hline Dneg1400 & Políticas e diretrizes de GTI & 4 & $\mathbf{2 3 , 0 8 \%}$ \\
\hline Dneg0700 & Modelo de gestão de negócio de TI & 4 & $\mathbf{1 5 , 3 8 \%}$ \\
\hline Dneg1600 & Comunicação com as partes interessadas & $\mathbf{3}$ & $\mathbf{1 1 , 5 4 \%}$ \\
\hline Dneg1700 & Normas e diretrizes para GTI & $\mathbf{2}$ & $\mathbf{7 , 6 9 \%}$ \\
\hline Dneg1300 & Definição de arquiteturas & 1 & $3,85 \%$ \\
\hline Dneg0900 & Gestão de processos de TI & & 6 \\
\hline
\end{tabular}

Fonte: Dados da pesquisa

O Quadro 30 mostra as categorias do subsistema Direcionamento que foca no negócio de TI. A categoria Alinhamento entre TI e negócio possui maioria absoluta com 69,23\%. Em seguida com maioria relativa aparece a categoria Formulação e planejamento de estratégia de TI com $50 \%$.

Ainda no Quadro 30 foram incluídas cinco categorias: Definição de arquiteturas; Políticas e diretrizes de GTI; Plano diretor de tecnologia da informação (PDTI); Comunicação com as partes interessadas; e Normas e diretrizes para GTI.

- Dneg1300 Definição de arquiteturas - traz os FCS relacionados à definição de arquiteturas que orientam a GTI, por exemplo, meta arquitetura corporativa de TI.

- Dneg1400 Políticas e diretrizes de GTI- centraliza os FCS da GTI que definem as políticas e demais diretrizes para a TI.

- Dneg1500 Plano diretor de tecnologia da informação - refere-se aos FCS que direcionam sobre a construção do PDTI.

- Dneg1600 Comunicação com as partes interessadas - abarca os FCS que prestam contas às partes interessadas sobre a GTI. Os FCS também indicam meios para aproximar e coletar percepções das partes interessadas com a TI. 
- Dneg1700 Normas e diretrizes para GTI - são os FCS que orientam a formulação da GTI.

O Quadro 31 mostra as categorias do subsistema Direcionamento em Gestão de TI. A categoria Gestão de pessoal de TI possui maioria absoluta com 76,92\%. Destaca-se que essa categoria possui a maior frequência entre todas as categorias desta pesquisa. A segunda maior frequência desse quadro é Gestão de recursos financeiros e orçamentários com 42,31\%.

Quadro 31 - Categorias de Direcionamento em Gestão de TI na APF

\begin{tabular}{|l|l|c|c|}
\hline \multicolumn{1}{|c|}{ Código } & \multicolumn{1}{|c|}{ Subsistema: Direcionamento - Gestão } & Frequência & Porcentual \\
\hline Dges0200 & Gestão do pessoal de TI & 20 & $76,92 \%$ \\
\hline Dges0300 & Gestão de recursos financeiros e orçamentários & 11 & $42,31 \%$ \\
\hline Dges0100 & Gestão de fornecedores & 9 & $34,62 \%$ \\
\hline Dges0400 & Gestão de contratos & 9 & $\mathbf{3 4 , 6 2 \%}$ \\
\hline Dges0500 & Gestão do conhecimento & 3 & $\mathbf{1 1 , 5 4 \%}$ \\
\hline
\end{tabular}

Fonte: Dados da pesquisa

Ainda no Quadro 31 foram incluídas duas categorias: Gestão de contratos e Gestão do conhecimento.

- Dges0400 Gestão de contratos - reúne os FCS relacionados às políticas e diretrizes para contratos para produtos e para serviços de TI.

- Dges0500 Gestão do conhecimento- centraliza os FCS tratam da retenção do conhecimento área de TI, bem como dos trabalhadores de TI. Também é incluídos fatores relacionados à gestão da informação. Esta categoria é fortemente vinculada a Gestão de pessoal de TI.

Essas categorias se referem à administração de recursos para a TI.

Quadro 32 exibe as categorias do subsistema Desenvolvimento. A categoria Gestão de projetos de TI possui maioria absoluta com 53,85\% de citações nas instituições pesquisadas. No Quadro 32 foi incluída a categorias Princípios para o desenvolvimento de soluções que teve o segundo maior porcentual desse subsistema, 42,31\%. Essa categoria especifica sobre as soluções de TI, diferentemente da categoria Gestão de projetos de TI que define os elementos para a gestão de projetos.

Quadro 32 - Categorias de Desenvolvimento em GTI na APF

\begin{tabular}{|l|l|c|c|}
\hline \multicolumn{1}{|c|}{ Código } & \multicolumn{1}{|c|}{ Subsistema: Desenvolvimento } & Frequência & Porcentual \\
\hline Dese0200 & Gestão de projetos de TI & 14 & $53,85 \%$ \\
\hline Dese0300 & Princípios para o desenvolvimento de soluções & 11 & $\mathbf{4 2 , 3 1 \%}$ \\
\hline Dese0100 & Gestão de processos para desenvolvimento de soluções & 9 & $34,62 \%$ \\
\hline
\end{tabular}

Fonte: Dados da pesquisa 
O Quadro 33 mostra as categorias do subsistema Entrega. A categoria Processos de gestão de serviços de TI em desenho do serviço possui maioria absoluta com 53,85\% . O segundo maior porcentual é categoria Gestão de serviços com 42,31\%.

Quadro 33 - Categorias de Entrega em GTI na APF

\begin{tabular}{|l|l|c|c|}
\hline \multicolumn{1}{|c|}{ Código } & \multicolumn{1}{|c|}{ Subsistema: Entrega } & Frequência & Porcentual \\
\hline Enet0300 & Processos de gestão de serviços de TI em desenho do serviço & 14 & $53,85 \%$ \\
\hline Enet0600 & Gestão de serviços & 11 & $\mathbf{4 2 , 3 1 \%}$ \\
\hline Enet0400 & Processos de gestão de serviços de TI em operação do serviço & 10 & $38,46 \%$ \\
\hline Enet0100 & Gestão de entregas & 8 & $30,77 \%$ \\
\hline Enet0200 & Gestão de infraestrutura & 7 & $26,92 \%$ \\
\hline Enet0700 & Central de serviços & 7 & $\mathbf{2 6 , 9 2 \%}$ \\
\hline Enet0500 & Processos de gestão de serviços de TI em transição de serviços & 5 & $\mathbf{1 9 , 2 3 \%}$ \\
\hline
\end{tabular}

Fonte: Dados da pesquisa

Ainda no Quadro 33 foram incluídas três categorias: Processos de gestão de serviços de TI em operação do serviço; Gestão de serviços; e Central de serviços.

- Enet0500 Processos de gestão de serviços de TI em transição do serviço categoria oriunda do Levantamento de GTI do ano 2012 do TCU considera os temas gestão de mudança e gestão de configuração.

- Enet0600 Gestão de serviços - agrupam os FCS que tratam da manutenção dos serviços de TI.

- Enet0700 Central de serviços - fortemente vinculado à categoria de Gestão de serviços que poderia ter sido incorporada a ela. Todavia, FCS específicos aos meios de atendimento aos serviços mereceram uma categoria a parte.

\subsubsection{Análise dos FCS em GTI da APF - Subsistema Direcionamento em Negócio de TI}

Neste Subcapítulo serão mostrados os FCS da APF em suas respectivas categorias. As análises apresentadas consideram a respostas dos entrevistados em relação aos FCS. Depois são apresentadas as análises de maturidade dos FCS. A respeito desses quadros as colunas $\mathbf{1}$, 2, 3, 4 e 5 significam respectivamente: prática formalizada; práticas divulgadas às partes interessadas; práticas aprendidas e discutidas; práticas compreendidas pelas partes interessadas; e práticas com medidas de gestão. Ressalta-se que não se trata de escala, mas de múltiplas respostas, uma vez que apura mais precisamente a real situação dos FCS na instituição pesquisada. As respostas serão apresentadas em seus dados brutos, devido à quantidade das amostras. 


\section{FCS da Categoria Alinhamento entre TI e o Negócio}

O Quadro 34 referente à categoria Alinhamento entre TI e o negócio possui 17 FCS. São dois os FCS com mais citações: o Alinhamento entre Planejamento Estratégico de TI (PETI) e o Planejamento Estratégico Institucional (PEI). Em seguida o FCS Patrocínio da alta administração na GTI. Depois, tem-se o FCS Participação da alta administração nas decisões de GTI. Verifica-se que apenas um entrevistado mencionou Governança Corporativa como FCS; lembra-se que alinhamento da GTI com GC é essencial para que a TI esteja em sintonia com o negócio e com as demais gestões da organização. Nesta categoria estão reunidos todos os FCS que buscam interface com o negócio ou evocam elementos essencialmente organizacionais para o desenvolvimento da GTI, assim como o FCS Governança Corporativa ou o FCS Planejamento Estratégico Institucional.

Quadro 34 - FCS do alinhamento entre TI e o negócio

\begin{tabular}{|l|l|c|c|}
\hline Código & Categoria: Alinhamento entre TI e o negócio & Freq. & Porcentual \\
\hline Dneg0105 & Alinhamento entre PETI e o PEI & 8 & $30,77 \%$ \\
\hline Dneg0109 & Patrocínio da alta administração na GTI & 5 & $19,23 \%$ \\
\hline Dneg0110 & Participação da alta administração nas decisões de GTI & 4 & $15,38 \%$ \\
\hline Dneg0111 & Envolvimento efetivo da alta administração no PETI & 2 & $7,69 \%$ \\
\hline Dneg0113 & $\begin{array}{l}\text { Reconhecimento da TI como estratégica pela organização e pela alta } \\
\text { administração }\end{array}$ & 2 & $7,69 \%$ \\
\hline Dneg0101 & Governança corporativa & 1 & $3,85 \%$ \\
\hline Dneg0102 & $\begin{array}{l}\text { Planejamento estratégico institucional (PEI) e plano de diretrizes } \\
\text { abordam a TI }\end{array}$ & 1 & $3,85 \%$ \\
\hline Dneg0103 & PEI desenvolvida a partir de tomada de decisão estruturada & 1 & $3,85 \%$ \\
\hline Dneg0104 & Definição pelo órgão do direcionamento para a área de TI & 1 & $3,85 \%$ \\
\hline Dneg0106 & Alinhamento da GTI com a governança corporativa & 1 & $3,85 \%$ \\
\hline Dneg0107 & Considerar a cultura da organização para fazer GTI & 1 & $3,85 \%$ \\
\hline Dneg0108 & Direcionamento de TI visando ao negócio & 1 & $3,85 \%$ \\
\hline Dneg0112 & Apoio da alta administração para com projetos dos colaboradores & 1 & $3,85 \%$ \\
\hline Dneg0114 & Participação da alta administração como responsável pela GTI & 1 & $3,85 \%$ \\
\hline Dneg0115 & Monitoramento efetivo da alta administração do desempenho da TI & 1 & $3,85 \%$ \\
\hline Dneg0116 & $\begin{array}{l}\text { TI crítica com a área de negócio, a fim de que as prioridades estejam } \\
\text { relacionadas com a estratégia }\end{array}$ & 1 & $3,85 \%$ \\
\hline Dneg0502 & Compreensão plena da área de negócio sobre a estratégia de TI & 1 & $3,85 \%$ \\
\hline
\end{tabular}

Fonte: Dados da pesquisa

O Quadro 35 mostra a maturidade dos FCS do Alinhamento entre TI e o negócio. Totalizando, foram 33 respostas para essa categoria. Apenas cinco instituições possuem FCS com práticas não formalizadas. Existe o caso do FCS não ter prática formalizada, contudo são pontuadas todas as demais variáveis de maturidade, como o FCS PEI e o plano de diretrizes abordam a TI. 
Quadro 35 - Maturidade dos FCS do alinhamento entre TI e o negócio

\begin{tabular}{|l|l|c|c|c|c|c|c|}
\hline Código & Categoria: Alinhamento entre TI e o negócio & Freq. & $\mathbf{1}$ & $\mathbf{2}$ & $\mathbf{3}$ & $\mathbf{4}$ & $\mathbf{5}$ \\
\hline Dneg0101 & Governança corporativa & 1 & 1 & 1 & 1 & 1 & 1 \\
\hline Dneg0102 & $\begin{array}{l}\text { Planejamento estratégico institucional (PEI) e plano de } \\
\text { diretrizes abordam a TI }\end{array}$ & 1 & 0 & 1 & 1 & 1 & 1 \\
\hline Dneg0103 & PEI desenvolvida a partir de tomada de decisão estruturada. & 1 & 1 & 1 & 1 & 1 & 0 \\
\hline Dneg0104 & Definição pelo órgão do direcionamento para a área de TI & 1 & 1 & 0 & 1 & 0 & 0 \\
\hline Dneg0105 & Alinhamento entre PETI e o PEI & 8 & 7 & 8 & 8 & 8 & 4 \\
\hline Dneg0106 & Alinhamento da GTI com a governança corporativa & 1 & 1 & 1 & 1 & 1 & 0 \\
\hline Dneg0107 & Considerar a cultura da organização para fazer GTI & 1 & 1 & 0 & 1 & 0 & 0 \\
\hline Dneg0108 & Direcionamento de TI visando ao negócio & 1 & 1 & 1 & 1 & 1 & 1 \\
\hline Dneg0109 & Patrocínio da alta administração na GTI & 5 & 5 & 4 & 5 & 5 & 2 \\
\hline Dneg0110 & Participação da alta administração nas decisões de GTI & 4 & 3 & 4 & 3 & 3 & 2 \\
\hline Dneg0111 & Envolvimento efetivo da alta administração no PETI & 2 & 2 & 2 & 2 & 2 & 1 \\
\hline Dneg0112 & $\begin{array}{l}\text { Apoio da alta administração para com projetos dos } \\
\text { colaboradores }\end{array}$ & 1 & 0 & 0 & 0 & 0 & 0 \\
\hline Dneg0113 & $\begin{array}{l}\text { Reconhecimento da TI como estratégica pela organização e } \\
\text { pela alta administração }\end{array}$ & 2 & 2 & 1 & 2 & 1 & 1 \\
\hline Dneg0114 & Participação da alta administração como responsável pela GTI & 1 & 1 & 1 & 1 & 1 & 1 \\
\hline Dneg0115 & $\begin{array}{l}\text { Monitoramento efetivo da alta administração do desempenho } \\
\text { da TI }\end{array}$ & 1 & 1 & 1 & 1 & 0 & 0 \\
\hline Dneg0116 & $\begin{array}{l}\text { TI crítica com a área de negócio, a fim de que as prioridades } \\
\text { estejam relacionadas com a estratégia. }\end{array}$ & 1 & 0 & 0 & 0 & 0 & 0 \\
\hline Dneg0117 & Compreensão plena da área de negócio sobre a estratégia de TI & 1 & 1 & 1 & 1 & 1 & 1 \\
\hline Total & & $\mathbf{3 3}$ & $\mathbf{2 8}$ & $\mathbf{2 7}$ & $\mathbf{3 0}$ & $\mathbf{2 6}$ & $\mathbf{1 5}$ \\
\hline
\end{tabular}

Fonte: Dados da pesquisa

Na Figura 28 é apresentada a maturidade dessa categoria.

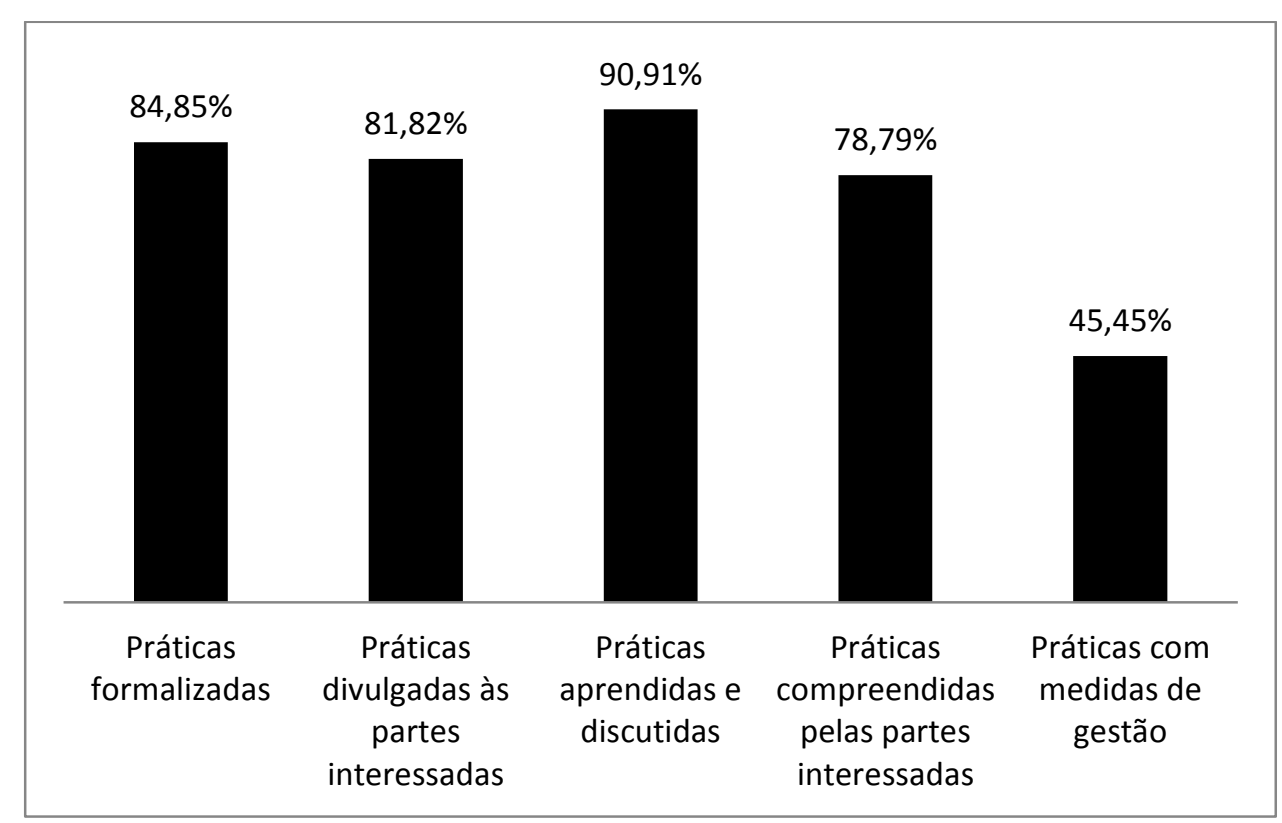

Figura 28 - Maturidade do alinhamento entre TI e o negócio

Fonte: Dados da Pesquisa 
Verifica-se que as práticas que representam essas categorias são primeiramente aprendidas e discutidas. Em seguida estão formalizadas, estão divulgadas às partes interessadas, são compreendidas pelas partes interessadas. Por último possuem medidas de gestão. Para a elaboração da Figura 28, os valores totais das variáveis foram divididos pela quantidade total de respostas.

\section{FCS da Categoria Estrutura Organizacional de TI}

O Quadro 36 referente à categoria Estrutura Organizacional de TI possui oito FCS. O FCS com mais citações pelos entrevistados é o Comitê de TI. Em seguida o FCS -Diretores da área de negócio participam do Comitê de TI e o FCS - Instâncias de discussão e deliberação técnica para apoio à GTI cada um possui o porcentual de 7,69\%.

Quadro 36 - FCS da estrutura organizacional de TI

\begin{tabular}{|l|l|c|c|}
\hline Código & Categoria: Estrutura organizacional de TI & Freq. & Porcentual \\
\hline Dneg0201 & Comitê de TI & 5 & $19,23 \%$ \\
\hline Dneg0203 & Diretores da área de negócio participam do Comitê de TI & 2 & $7,69 \%$ \\
\hline Dneg0207 & Instâncias de discussão e deliberação técnica para apoio à GTI & 2 & $7,69 \%$ \\
\hline Dneg0202 & $\begin{array}{l}\text { Comitê de TI envolve as áreas que recebem os serviços e produtos } \\
\text { de TI }\end{array}$ & 1 & $3,85 \%$ \\
\hline Dneg0204 & Participação ativa do Comitê de TI no planejamento de TI & 1 & $3,85 \%$ \\
\hline Dneg0205 & Conhecimento sobre o negócio pelo Comitê de TI & 1 & $3,85 \%$ \\
\hline Dneg0206 & Compreensão sobre GTI pelo Comitê de TI & 1 & $3,85 \%$ \\
\hline Dneg0208 & $\begin{array}{l}\text { Assessoria técnica auxiliando na elaboração e definição de projetos } \\
\text { prioritários na área de TI }\end{array}$ & 1 & $3,85 \%$ \\
\hline
\end{tabular}

Fonte: Dados da pesquisa

O Quadro 37 mostra a maturidade dos FCS - Instâncias de discussão e deliberação técnica para apoio à GTI. Apenas quatro instituições possuem FCS com práticas não formalizadas.

Quadro 37 - Maturidade dos FCS da estrutura organizacional de TI

\begin{tabular}{|l|l|c|c|c|c|c|c|}
\hline Código & $\begin{array}{l}\text { Categoria: Instâncias de discussão e deliberação técnica para } \\
\text { apoio à GTI }\end{array}$ & Freq. & $\mathbf{1}$ & $\mathbf{2}$ & $\mathbf{3}$ & $\mathbf{4}$ & $\mathbf{5}$ \\
\hline Dneg0201 & Comitê de TI & 5 & 5 & 4 & 3 & 3 & 3 \\
\hline Dneg0202 & $\begin{array}{l}\text { Comitê de TI envolve as áreas que recebem os serviços e } \\
\text { produtos de TI }\end{array}$ & 1 & 0 & 1 & 1 & 1 & 0 \\
\hline Dneg0203 & Diretores da área de negócio participam do Comitê de TI & 2 & 2 & 1 & 1 & 1 & 2 \\
\hline Dneg0204 & Participação ativa do Comitê de TI no planejamento & 1 & 1 & 0 & 1 & 0 & 0 \\
\hline Dneg0205 & Conhecimento sobre o negócio pelo Comitê de TI & 1 & 0 & 0 & 0 & 1 & 0 \\
\hline Dneg0206 & Compreensão sobre GTI pelo Comitê de TI & 1 & 1 & 1 & 1 & 1 & 0 \\
\hline Dneg0207 & Instâncias de discussão e deliberação técnica para apoio à GTI & 2 & 1 & 1 & 1 & 2 & 1 \\
\hline Dneg0208 & $\begin{array}{l}\text { Assessoria técnica auxiliando na elaboração e definição de } \\
\text { projetos prioritários na área de TI }\end{array}$ & 1 & 0 & 0 & 0 & 1 & 0 \\
\hline Total & & $\mathbf{1 4}$ & $\mathbf{1 0}$ & $\mathbf{8}$ & $\mathbf{8}$ & $\mathbf{1 0}$ & $\mathbf{6}$ \\
\hline
\end{tabular}

Fonte: Dados da pesquisa 
$\mathrm{Na}$ Figura 29 é apresentada a maturidade dessa categoria. Verifica-se que estaticamente as práticas são primeiramente formalizadas e, compreendidas pelas partes interessadas. Em seguida estão divulgadas e, aprendidas e discutidas. Finalmente, $42,86 \%$ das práticas possuem alguma medida de gestão.

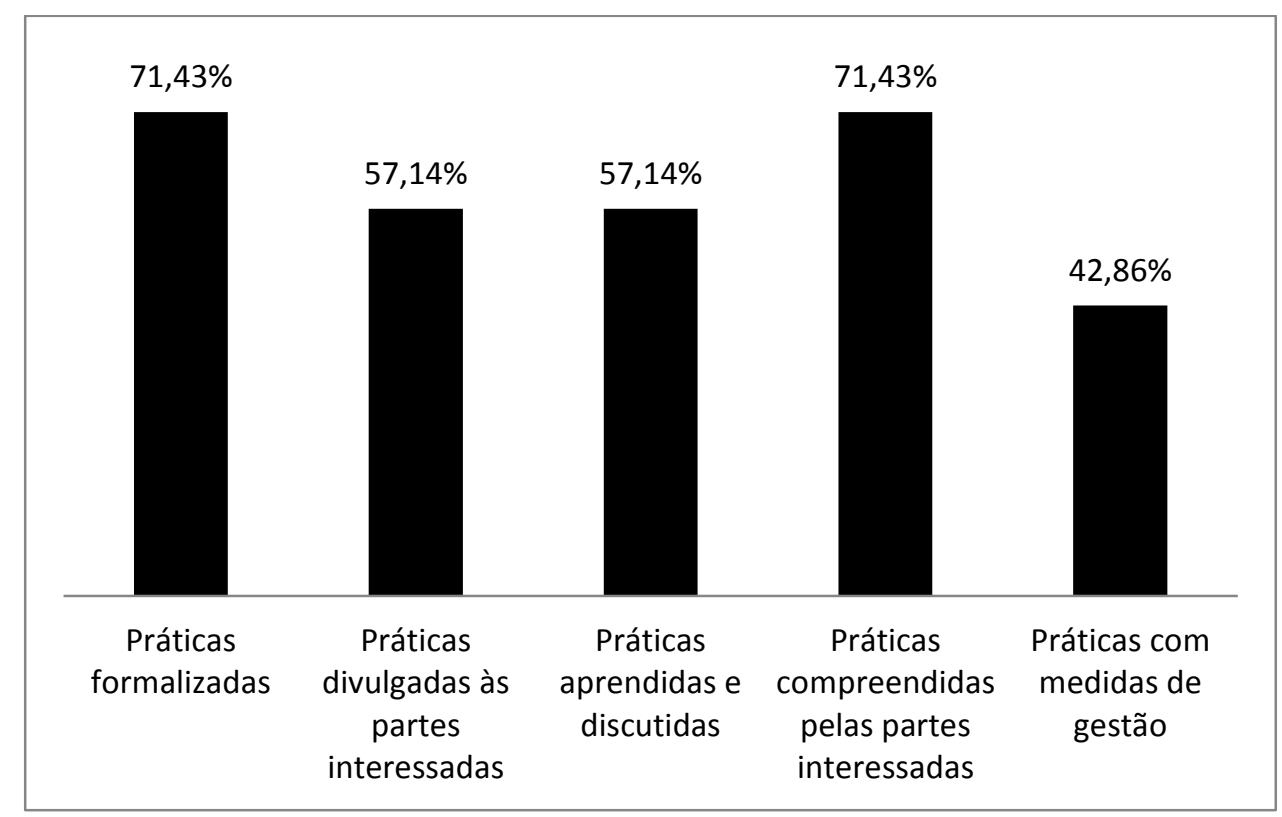

Figura 29 - Maturidade da estrutura organizacional de TI Fonte: Dados da Pesquisa

\section{FCS da Categoria Priorização de Projetos de TI}

O Quadro 38 mostra a categoria Priorização de projetos de TI com dois FCS. Embora uma categoria tenha poucos FCS isso não a torna mais ou menos relevante. Isso depende do FCS a ela associado, especificamente nessa categoria o FCS - Priorização de projetos de TI foi citado por $26,99 \%$ dos entrevistados.

Quadro 38 - FCS da priorização de projetos de TI

\begin{tabular}{|l|l|c|c|}
\hline Código & Categoria: Priorização de projetos de TI & Freq. & Porcentual \\
\hline Dneg0301 & Priorização de projetos de TI & 7 & $26,92 \%$ \\
\hline Dneg0302 & Priorização de soluções pelas áreas de negócio & 1 & $3,85 \%$ \\
\hline
\end{tabular}

Fonte: Dados da pesquisa

O Quadro 39 mostra a maturidade da categoria Priorização de projetos de TI, totalizando em oito respostas para essa categoria. Apenas uma instituição possui FCS com práticas não formalizadas. 
Quadro 39 - Maturidade dos FCS da priorização de projetos de TI

\begin{tabular}{|l|l|c|c|c|c|c|c|}
\hline Código & Categoria: Priorização de projetos de TI & Freq. & $\mathbf{1}$ & $\mathbf{2}$ & $\mathbf{3}$ & $\mathbf{4}$ & $\mathbf{5}$ \\
\hline Dneg0301 & Priorização de projetos de TI & 7 & 6 & 6 & 6 & 6 & 6 \\
\hline Dneg0302 & Priorização de soluções pelas áreas de negócio & 1 & 1 & 1 & 0 & 1 & 0 \\
\hline Total & 8 & 7 & 7 & 6 & 7 & 6 \\
\hline
\end{tabular}

Fonte: Dados da pesquisa

Na Figura 30 é apresentada a maturidade dessa categoria. Verifica-se que as práticas que representam essas categorias são formalizadas, divulgadas e compreendidas pelas partes interessadas com umo porcentual de 87,50\%. Em seguida são aprendidas e discutidas e, possuem medidas de gestão, ambas as variáveis com o porcentual em $75 \%$.

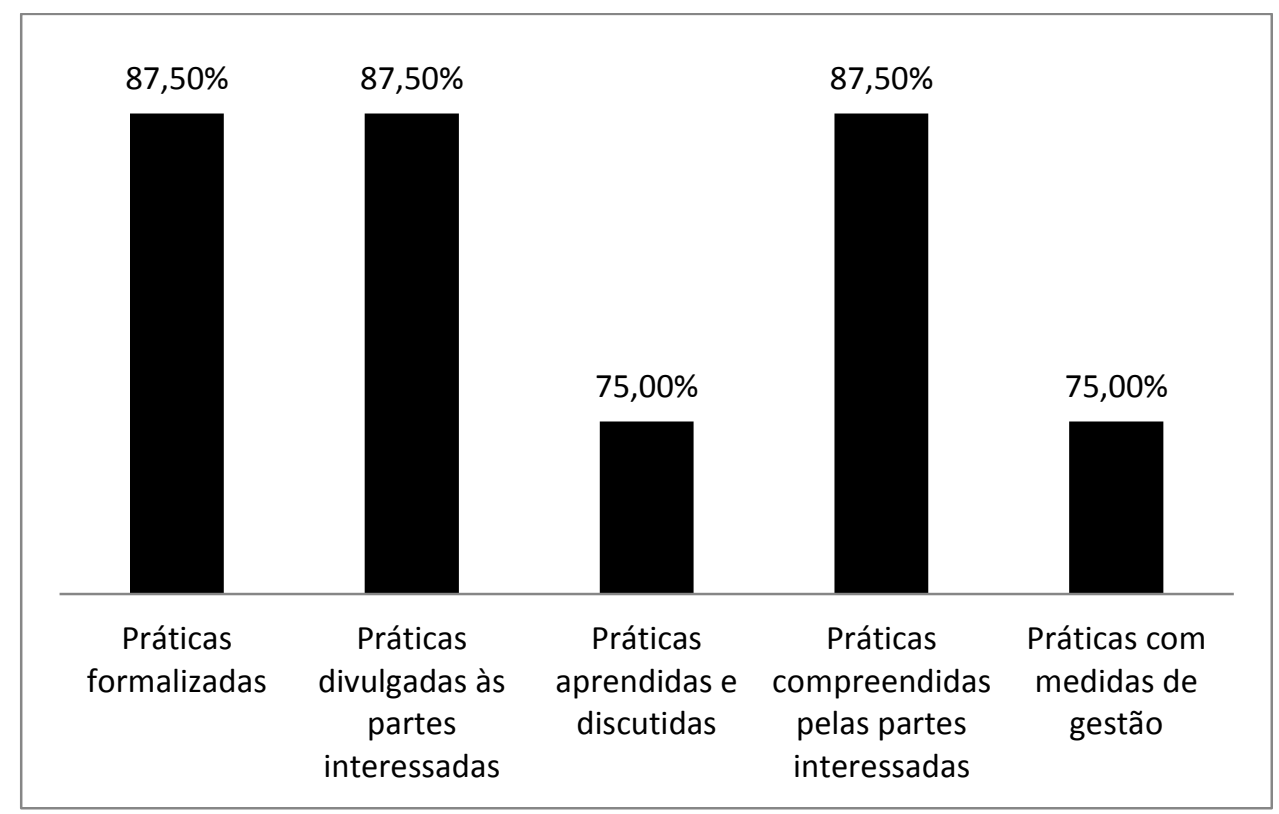

Figura 30 - Maturidade da priorização de projetos de TI Fonte: Dados da Pesquisa

\section{FCS da Categoria Controle de GTI}

O Quadro 40, referente à categoria Controle de GTI apura quatro FCS. O FCS com mais citações pelos entrevistados é o FCS - Ingerência política pequena com autonomia de decisão da área de TI com 15,38\%. Durante as entrevistas, pode-se perceber que esse FCS é crítico para a APF. Conforme observado no Levantamento de GTI do TCU ano 2012, instituições pertencentes a um mesmo grupo e com as mesmas características, tais como: pessoal qualificado, infraestrutura própria e grandes orçamentos em TI, apresentam grandes diferenças em termos de desempenho de GTI. Conforme exposto pelos entrevistados, essa 
diferença é motivada principalmente pelo fator ingerência política. A separação entre governança e gestão, bem como a divisão entre gestão e interesses políticos, propicia o aumento do desempenho e da continuidade das boas práticas em GTI.

\section{O FCS - Gestão de riscos e o FCS - Gestão de conformidade, de procedimentos e} de sistemas foram citados cada um por dois entrevistados. A questão da transparência foi mencionada por um entrevistado como sendo um FCS. É válido lembrar que nesta análise os FCS não foram julgados pelos entrevistados e sim coletados. Por exemplo, não foi apurado se as instituições consideram ou não a transparência como relevante. Neste caso, deliberadamente, a instituição informou que possui como FCS - Transparência.

Quadro 40 - FCS do controle de GTI

\begin{tabular}{|l|l|c|c|}
\hline Código & Categoria: Controle de GTI & Freq. & Porcentual \\
\hline Dneg0404 & Ingerência política pequena com autonomia de decisão da área de TI & 4 & $15,38 \%$ \\
\hline Dneg0402 & Gestão de riscos & 2 & $7,69 \%$ \\
\hline Dneg0401 & Gestão de conformidade, de procedimentos e de sistemas & 2 & $7,69 \%$ \\
\hline Dneg0403 & Transparência & 1 & $3,85 \%$ \\
\hline
\end{tabular}

Fonte: Dados da pesquisa

O Quadro 41 revela a maturidade dos FCS do Controle de GTI. Totalizando, foram nove respostas para essa categoria. O FCS sobre ingerência política, dois respondentes informaram que o FCS não está formalizado, embora em duas instituições exista a formalização desse tema, bem como a discussão, divulgação e compreensão das partes interessadas.

Quadro 41 - Maturidade dos FCS do controle de GTI

\begin{tabular}{|l|l|c|c|c|c|c|c|}
\hline Código & Categoria: Controle de GTI & Freq. & $\mathbf{1}$ & $\mathbf{2}$ & $\mathbf{3}$ & $\mathbf{4}$ & $\mathbf{5}$ \\
\hline Dneg0401 & Gestão de conformidade, de procedimentos e de sistemas & 2 & 2 & 2 & 2 & 2 & 2 \\
\hline Dneg0402 & Gestão de riscos & 2 & 2 & 2 & 2 & 2 & 1 \\
\hline Dneg0403 & Transparência & 1 & 1 & 1 & 1 & 1 & 1 \\
\hline Dneg0404 & $\begin{array}{l}\text { Ingerência política pequena com autonomia de decisão da área } \\
\text { de TI }\end{array}$ & 4 & 2 & 2 & 2 & 1 & 0 \\
\hline Total & $\mathbf{9}$ & $\mathbf{7}$ & $\mathbf{7}$ & $\mathbf{7}$ & $\mathbf{6}$ & $\mathbf{4}$ \\
\hline
\end{tabular}

Fonte: Dados da pesquisa

Na Figura 31 é apresentada a maturidade dessa categoria. Verifica-se que as práticas que representam essas categorias são primeiramente formalizadas, divulgadas, aprendidas e discutidas com o porcentual de $77,78 \%$, sendo que $44,44 \%$ dos entrevistados informaram que as práticas são medidas. 


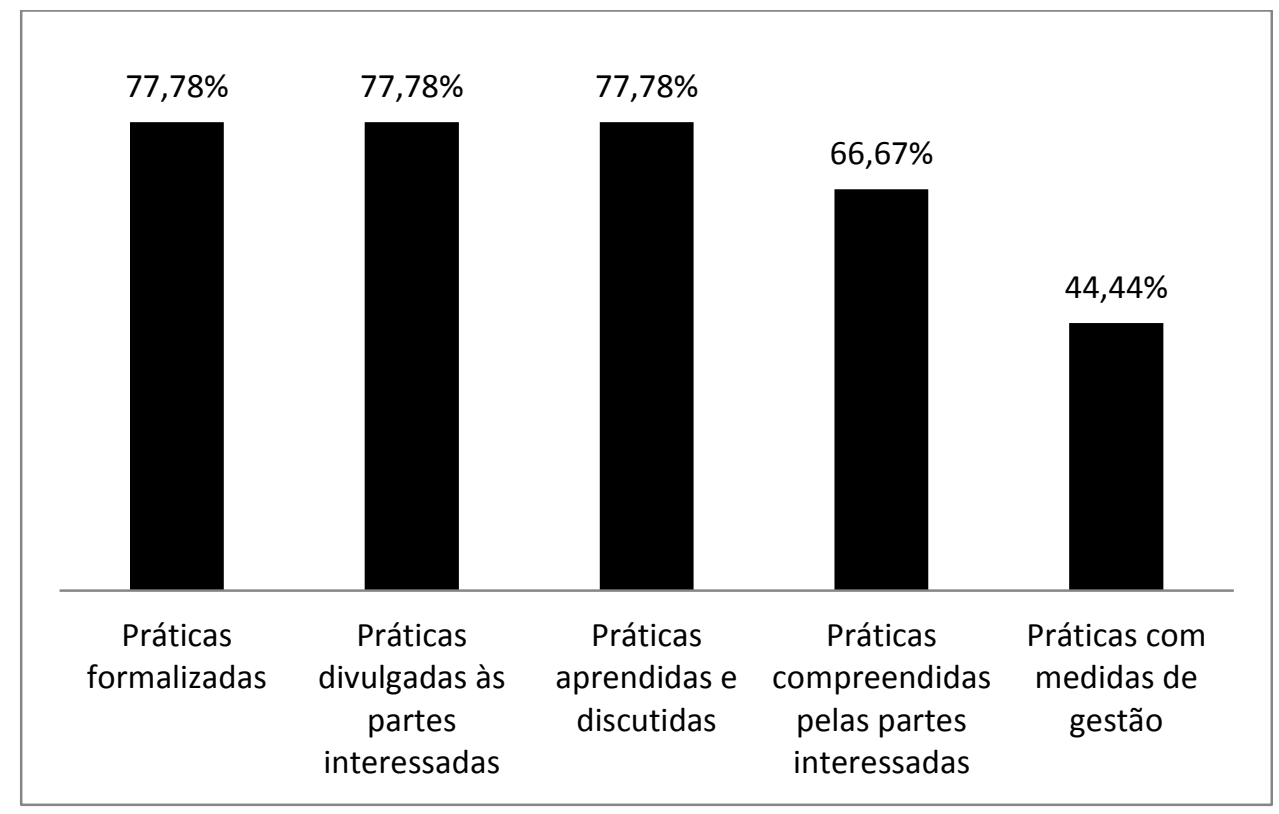

Figura 31 - Maturidade do controle de GTI

Fonte: Dados da Pesquisa

\section{FCS em Direcionadores de Estratégia de TI}

O Quadro 42, referente à categoria Direcionadores de estratégia de TI, tem cinco FCS. O FCS com mais citações pelos entrevistados é Entregas de valor com 11,54\%. Em seguida o FCS Demonstração de valor agregado de TI ao negócio conta com 7,69\%. Especialmente, sobre esses dois fatores, aparentemente são semelhantes, contudo o primeiro foca na percepção do valor da entrega de novos serviços ou soluções ao cliente ou ao usuário. Já o segundo fator objetiva melhorar a percepção da TI para o negócio. Considerando características únicas de suas instituições, dois FCS foram citados: Negócio único sem referenciais comparativos e Obrigação moral para servir de exemplo.

Quadro 42 - FCS dos direcionadores de estratégia de TI

\begin{tabular}{|l|l|c|c|}
\hline Código & Categoria: Direcionadores de estratégia de TI & Freq. & Porcentual \\
\hline Dneg0502 & Entregas de valor & 3 & $11,54 \%$ \\
\hline Dneg0501 & Demonstração de valor agregado de TI ao negócio & 2 & $7,69 \%$ \\
\hline Dneg0503 & Negócio único sem referenciais comparativos & 1 & $3,85 \%$ \\
\hline Dneg0504 & Obrigação moral para servir de exemplo & 1 & $3,85 \%$ \\
\hline
\end{tabular}

Fonte: Dados da pesquisa

O Quadro 43 mostra a maturidade dos FCS dos Direcionadores de estratégia de TI. Totalizando, foram sete respostas para essa categoria. Quatro instituições possuem FCS com práticas não formalizadas. 
Quadro 43 - Maturidade dos FCS dos direcionadores de estratégia de TI

\begin{tabular}{|l|l|c|c|c|c|c|c|}
\hline Código & Categoria: Direcionadores de estratégia de TI & Freq. & $\mathbf{1}$ & $\mathbf{2}$ & $\mathbf{3}$ & $\mathbf{4}$ & $\mathbf{5}$ \\
\hline Dneg0501 & Demonstração de valor agregado de TI ao negócio & 2 & 2 & 2 & 2 & 1 & 1 \\
\hline Dneg0502 & Entregas de valor & 3 & 2 & 2 & 3 & 2 & 2 \\
\hline Dneg0503 & Negócio único sem referenciais comparativos & 1 & 1 & 0 & 1 & 1 & 0 \\
\hline Dneg0504 & Obrigação moral para servir de exemplo & 1 & 0 & 1 & 1 & 0 & 0 \\
\hline Total & 7 & 5 & 5 & 7 & 4 & 3 \\
\hline
\end{tabular}

Fonte: Dados da pesquisa

Na Figura 32 é apresentada a maturidade dessa categoria. Verifica-se que as práticas $100 \%$ das práticas relacionadas aos FCS são aprendidas e discutidas. Depois as práticas são formalizadas com $71,43 \%$. Por último essas práticas possuem medidas de gestão com 41 , $86 \%$.

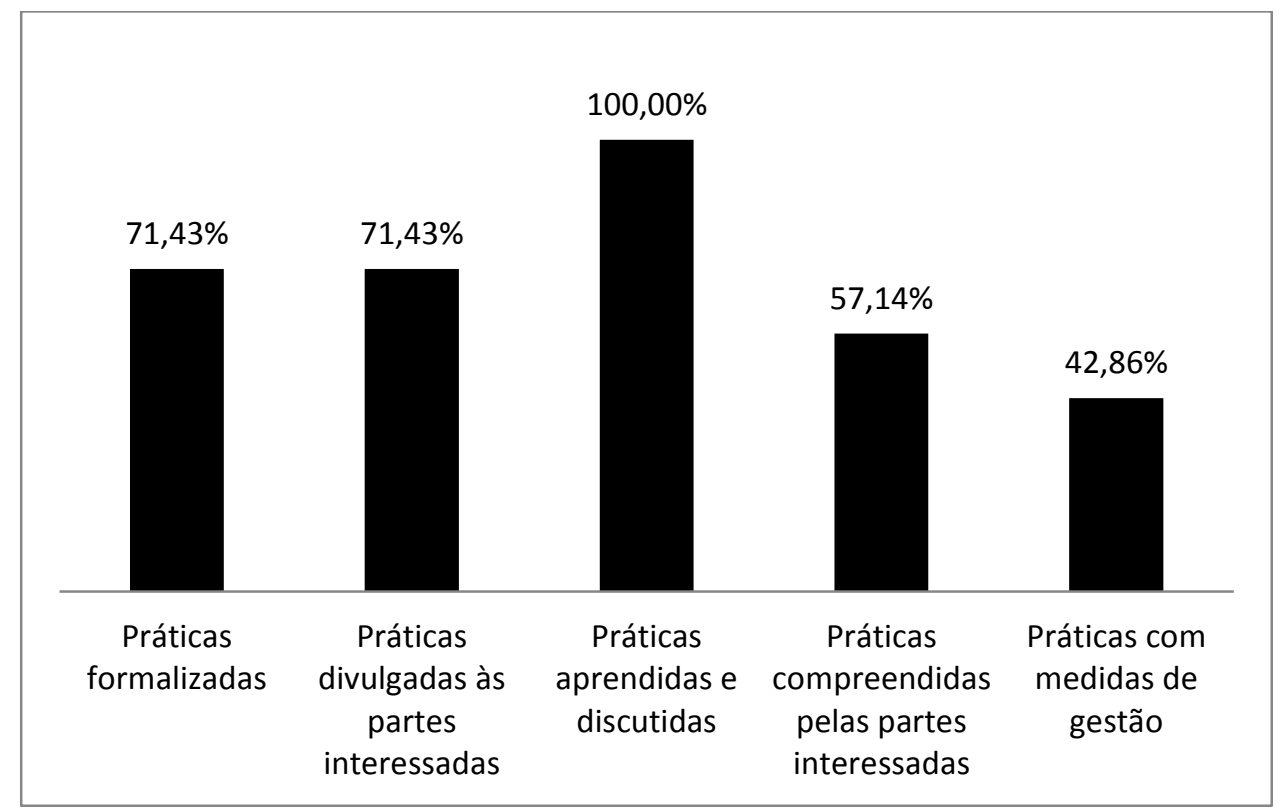

Figura 32 - Maturidade dos direcionadores de estratégia de TI Fonte: Dados da Pesquisa

\section{FCS da Categoria Formulação e Planejamento de Estratégia de TI}

O Quadro 44 referente à categoria Formulação e planejamento de estratégia de TI possui 13 FCS. O FCS com mais citações pelos entrevistados é Participação das áreas fins no desenvolvimento do PETI com 30,77\% (8 entrevistados). No geral, o Comitê de TI das instituições públicas é formado pelos dirigentes das áreas de negócio da instituição. Sendo assim, a participação das áreas fins no PETI é uma consequência da composição do Comitê de TI. Em seguida o FCS Patrocínio da alta administração na GTI conta com 19,23\% (5 entrevistados). Depois o FCS Participação da alta administração nas decisões de GTI aparece 
com 15,38\% (4 entrevistados). Verifica-se que os FCS apontados pelos entrevistados estão em conformidade com os conceitos do Subcapítulo 2.2, em que a governança deve apresentar as políticas e diretrizes para a formulação e planejamento da estratégia de TI.

Quadro 44 - FCS da formulação e planejamento de estratégia de TI

\begin{tabular}{|l|l|c|c|}
\hline Código & Categoria: Formulação e planejamento de estratégia de TI & Freq. & Porcentual \\
\hline Dneg0605 & Participação das áreas fins no desenvolvimento do PETI & 8 & $30,77 \%$ \\
\hline Dneg0601 & PETI & 2 & $7,69 \%$ \\
\hline Dneg0602 & $\begin{array}{l}\text { PETI com compreensão das necessidades dos clientes internos e } \\
\text { externos }\end{array}$ & 1 & $3,85 \%$ \\
\hline Dneg0603 & PETI com identificação de tecnologias emergentes & 1 & $3,85 \%$ \\
\hline Dneg0604 & Divulgação do PETI às partes interessadas & 1 & $3,85 \%$ \\
\hline Dneg0606 & Monitoração dos objetivos estratégicos & 1 & $3,85 \%$ \\
\hline Dneg0607 & $\begin{array}{l}\text { Relações de causa e efeito entre as necessidades organizacionais e as } \\
\text { ações estratégicas adotadas para alcança-las }\end{array}$ & 1 & $3,85 \%$ \\
\hline Dneg0608 & Prospecção de tendências & 1 & $3,85 \%$ \\
\hline Dneg0609 & PETI baseado em plano de metas e ações & 1 & $3,85 \%$ \\
\hline Dneg0610 & Cultura de planejamento estratégico, tático e operacional & 1 & $3,85 \%$ \\
\hline Dneg0611 & Definição de indicadores & 1 & $3,85 \%$ \\
\hline Dneg0612 & Indicadores que busquem resultados & 1 & $3,85 \%$ \\
\hline Dneg0613 & Fluidez na comunicação entre nível estratégico e nível tático & $3,85 \%$ \\
\hline
\end{tabular}

Fonte: Dados da pesquisa

O Quadro 45 mostra a maturidade dos FCS do Alinhamento entre TI e o negócio. Totalizando, foram 21 respostas para essa categoria.

Quadro 45 - Maturidade dos FCS da formulação e planejamento de estratégia de TI

\begin{tabular}{|l|l|c|c|c|c|c|c|}
\hline Código & Categoria: Formulação e planejamento de estratégia de TI & Freq. & $\mathbf{1}$ & $\mathbf{2}$ & $\mathbf{3}$ & $\mathbf{4}$ & $\mathbf{5}$ \\
\hline Dneg0601 & PETI & 2 & 2 & 1 & 1 & 0 & 1 \\
\hline Dneg0602 & $\begin{array}{l}\text { PETI com compreensão das necessidades dos clientes internos } \\
\text { e externos }\end{array}$ & 1 & 1 & 1 & 1 & 1 & 1 \\
\hline Dneg0603 & PETI com identificação de tecnologias emergentes & 1 & 1 & 1 & 1 & 1 & 0 \\
\hline Dneg0604 & Divulgação do PETI às partes interessadas & 1 & 1 & 1 & 1 & 1 & 0 \\
\hline Dneg0605 & Participação das áreas fins no desenvolvimento do PETI & 8 & 6 & 6 & 5 & 4 & 2 \\
\hline Dneg0606 & Monitoração dos objetivos estratégicos & 1 & 1 & 1 & 1 & 1 & 1 \\
\hline & $\begin{array}{l}\text { Relações de causa e efeito entre as necessidades } \\
\text { organizacionais e as ações estratégicas adotadas para alcança- } \\
\text { las }\end{array}$ & 1 & 0 & 0 & 0 & 0 & 0 \\
\hline Dneg060608 & Prospecção de tendências & 1 & 0 & 0 & 1 & 0 & 0 \\
\hline Dneg0609 & PETI baseado em plano de metas e ações & 1 & 1 & 1 & 1 & 1 & 1 \\
\hline Dneg0610 & Cultura de planejamento estratégico, tático e operacional & 1 & 1 & 1 & 1 & 1 & 1 \\
\hline Dneg0611 & Definição de indicadores & 1 & 1 & 1 & 0 & 1 & 1 \\
\hline Dneg0612 & Indicadores que busquem resultados & 1 & 0 & 0 & 0 & 0 & 0 \\
\hline Dneg0613 & Fluidez na comunicação entre nível estratégico e nível tático. & 1 & 0 & 0 & 0 & 0 & 0 \\
\hline Total & & $\mathbf{2 1}$ & $\mathbf{1 5}$ & $\mathbf{1 4}$ & $\mathbf{1 3}$ & $\mathbf{1 1}$ & $\mathbf{8}$ \\
\hline
\end{tabular}

Fonte: Dados da pesquisa

Na Figura 33 é exposta a maturidade da categoria Formulação e planejamento de estratégia de TI. A maioria das práticas é formalizada com 71,43\%, em seguida são divulgadas com $66,67 \%$, são aprendidas e discutidas com $61,90 \%$ e são compreendidas pelas 
partes interessadas com 52,38\%. Sobre a mensuração desses fatores, apenas 38,10\% são mensurados e 28,57\% não estão formalizadas. Esses últimos índices, ascendem uma preocupação sobre a continuidade de boas práticas de gestão, muitas vezes, centralizadas em conhecimento implícito que coloca em risco o desempenho da TI.

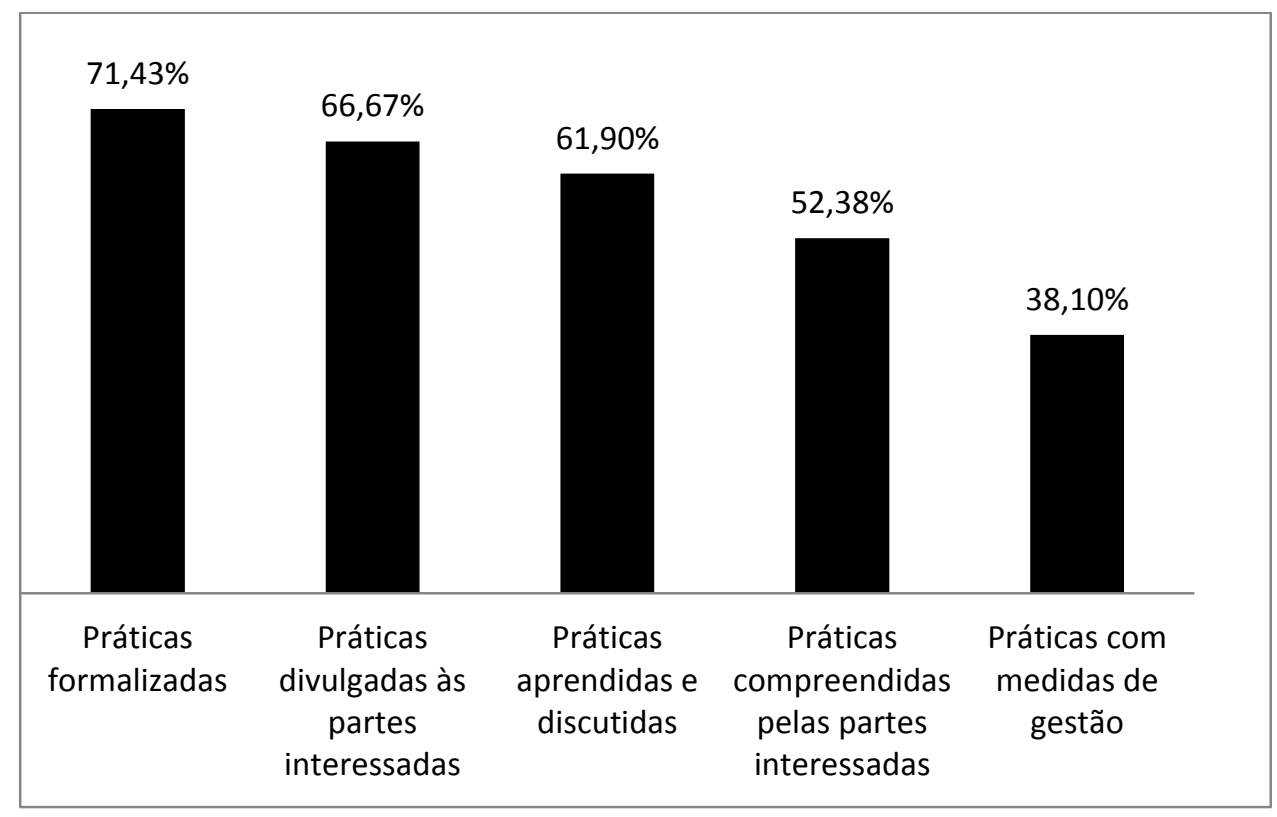

Figura 33 - Maturidade da formulação e planejamento de estratégia de TI Fonte: Dados da Pesquisa

\section{FCS da Categoria Modelo de Gestão de Negócio de TI}

O Quadro 46 referente à categoria Modelo de gestão de negócio de TI tem cinco FCS. Nessa categoria cada um dos cinco FCS teve apenas uma citação que corresponde a 3,85\% dos entrevistados. Verifica-se que nessa categoria são abordados temas sobre controle de TI, não devendo ser confundido com controle em GTI, categoria apresentada anteriormente.

Quadro 46 - FCS do modelo de gestão de negócio de TI

\begin{tabular}{|l|l|c|c|}
\hline Código & Categoria: Modelo de gestão de negócio de TI & Freq. & Porcentual \\
\hline Dneg0701 & Gestão baseada em planejamento, controle e correção & 1 & $3,85 \%$ \\
\hline Dneg0702 & $\begin{array}{l}\text { Tomada de decisões da alta administração baseada na estratégica } \\
\text { estabelecida }\end{array}$ & 1 & $3,85 \%$ \\
\hline Dneg0703 & Processo decisório efetivo com base no tratamento de demandas & 1 & $3,85 \%$ \\
\hline Dneg0704 & Apoio hierárquico no cumprimento das práticas de controle. & 1 & $3,85 \%$ \\
\hline Dneg0705 & Relatórios gerenciais & 1 & $3,85 \%$ \\
\hline
\end{tabular}

Fonte: Dados da pesquisa 
O Quadro 47 mostra a maturidade dos FCS do Alinhamento entre TI e o negócio. Totalizando, foram cinco respostas para essa categoria, sendo que duas respostas a não formalização das práticas relacionadas aos FCS.

Quadro 47 - Maturidade dos FCS do Modelo de gestão de negócio de TI

\begin{tabular}{|l|l|c|c|c|c|c|c|}
\hline Código & Categoria: Modelo de gestão de negócio de TI & Freq. & $\mathbf{1}$ & $\mathbf{2}$ & $\mathbf{3}$ & $\mathbf{4}$ & $\mathbf{5}$ \\
\hline Dneg0701 & Gestão baseada em planejamento, controle e correção & 1 & 0 & 1 & 1 & 0 & 0 \\
\hline Dneg0702 & $\begin{array}{l}\text { Tomada de decisões da alta administração baseada na } \\
\text { estratégica estabelecida }\end{array}$ & 1 & 1 & 1 & 1 & 1 & 0 \\
\hline Dneg0703 & $\begin{array}{l}\text { Processo decisório efetivo com base no tratamento de } \\
\text { demandas }\end{array}$ & 1 & 1 & 1 & 1 & 1 & 1 \\
\hline Dneg0704 & Apoio hierárquico no cumprimento das práticas de controle. & 1 & 0 & 0 & 1 & 0 & 0 \\
\hline Dneg0705 & Relatórios gerenciais & 1 & 1 & 1 & 1 & 1 & 1 \\
\hline Total & 5 & 3 & 4 & 5 & 3 & 2 \\
\hline
\end{tabular}

Fonte: Dados da pesquisa

Na Figura 34 é apresentada a maturidade dessa categoria. Verifica-se que $100 \%$ dos FCS são aprendidos e discutidos. Depois os FCS são divulgados com 80\%. Com porcentual de $60 \%$ os FCS são formalizados e compreendidos pelas partes interessadas. Nessa categoria, $40 \%$ dos FCS não estão formalizados e possuem medidas de gestão. Verifica-se que esses FCS se relacionam a práticas que podem ser disseminadas na organização fazendo parte da cultura gerencial, sem necessariamente serem medidas para demonstrar sua eficácia.

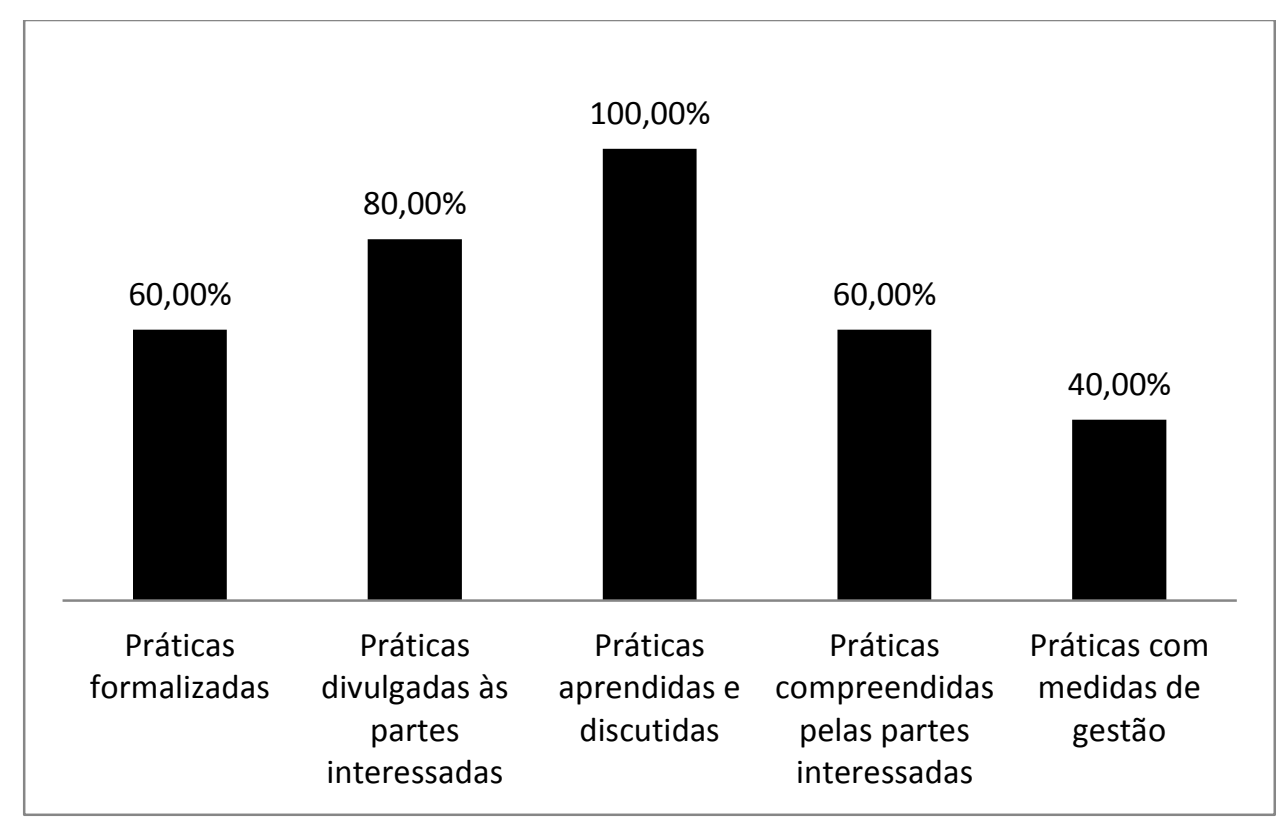

Figura 34 - Maturidade do modelo de gestão de negócio de TI Fonte: Dados da Pesquisa 


\section{FCS da Categoria Utilização de Boas práticas}

O Quadro 48 referente à categoria Utilização de boas práticas possui cinco FCS. Nesta categoria o FCS - Customização de boas práticas e o FCS - Implementação gradual de ITIL, cada um, com duas menções $(7,69 \%)$, são os FCS que mais se destacam. Nessa categoria, são abordadas as boas práticas ITIL e COBIT. Conforme pode ser observado, existe a preocupação em não se implementar essas práticas como um todo, evitando a adoção de objetivos de controle e indicadores desnecessários para a instituição.

Quadro 48 - FCS da utilização de boas práticas

\begin{tabular}{|l|l|c|c|}
\hline Código & Categoria: Utilização de boas práticas & Freq. & Porcentual \\
\hline Dneg0801 & Customização de boas práticas & 2 & $7,69 \%$ \\
\hline Dneg0805 & Implementação gradual de ITIL & 2 & $7,69 \%$ \\
\hline Dneg0802 & Implementação gradual de COBIT & 1 & $3,85 \%$ \\
\hline Dneg0803 & Priorização de aspectos fundamentais COBIT 5. & 1 & $3,85 \%$ \\
\hline Dneg0804 & Implementação de elementos ITIL & 1 & $3,85 \%$ \\
\hline
\end{tabular}

Fonte: Dados da pesquisa

O Quadro 49 mostra a maturidade dos FCS da Utilização de boas práticas. No total, foram sete respostas para essa categoria. Apenas dois FCS correspondem a práticas não formalizadas.

Quadro 49 - Maturidade dos FCS da utilização de boas práticas

\begin{tabular}{|l|l|r|c|c|c|c|c|}
\hline Código & Categoria: Utilização de boas práticas & Freq. & $\mathbf{1}$ & $\mathbf{2}$ & $\mathbf{3}$ & $\mathbf{4}$ & $\mathbf{5}$ \\
\hline Dneg0801 & Customização de boas práticas & 2 & 2 & 2 & 2 & 2 & 2 \\
\hline Dneg0802 & Implementação gradual de COBIT & 1 & 1 & 1 & 1 & 1 & 1 \\
\hline Dneg0803 & Priorização de aspectos fundamentais COBIT 5. & 1 & 0 & 1 & 0 & 1 & 0 \\
\hline Dneg0804 & Implementação de elementos ITIL & 1 & 1 & 1 & 1 & 1 & 1 \\
\hline Dneg0805 & Implementação gradual de ITIL & 2 & 1 & 1 & 2 & 2 & 1 \\
\hline Total & $\mathbf{7}$ & $\mathbf{5}$ & $\mathbf{6}$ & $\mathbf{6}$ & $\mathbf{7}$ & $\mathbf{5}$ \\
\hline
\end{tabular}

Fonte: Dados da pesquisa

Na Figura 35 é apresentada a maturidade dessa categoria. Verifica-se que $100 \%$ as práticas dos FCS são compreendidos pelas partes interessadas, depois são divulgadas, e aprendidas e discutidas por $85,71 \%$. Dentre as categorias a variável medidas de gestão possui um dos maiores índices com 71,43\%. 


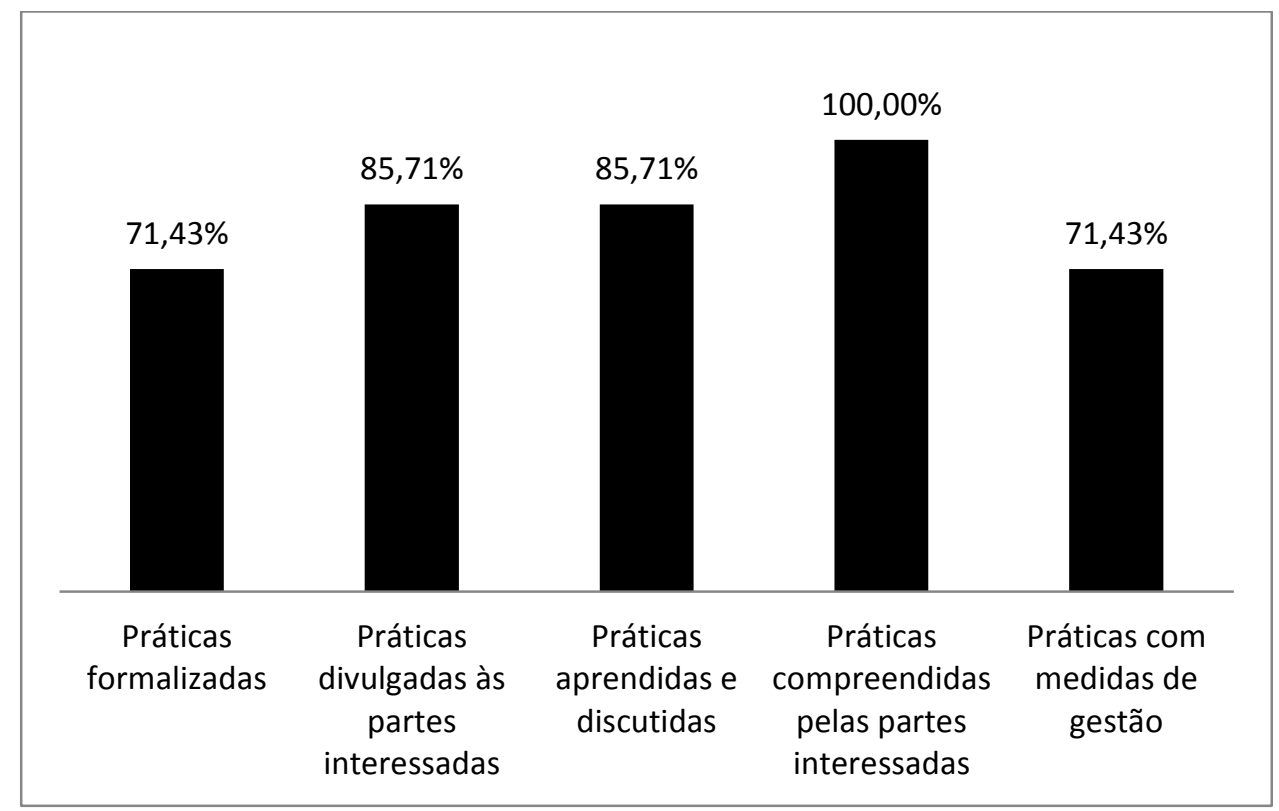

Figura 35 - Maturidade da utilização de boas práticas Fonte: Dados da Pesquisa

\section{FCS da Categoria Gestão de Processos de TI}

O Quadro 50 referente à categoria Gestão de processos de TI possui dois FCS. São os FCS: Processos definidos da gestão de TI e Avaliação e auditoria dos processos de TI, cada um, com apenas uma citação. Essa categoria se refere apenas ao mapeamento dos processos da TI.

Quadro 50 - FCS da gestão de processos de TI

\begin{tabular}{|l|l|c|c|}
\hline Código & Categoria: Gestão de processos de TI & Freq. & Porcentual \\
\hline Dneg0901 & Processos definidos da gestão de TI & 1 & $3,85 \%$ \\
\hline Dneg0902 & Avaliação e auditoria dos processos de TI & 1 & $3,85 \%$ \\
\hline
\end{tabular}

Fonte: Dados da pesquisa

O Quadro 51 mostra a maturidade das práticas relacionadas aos FCS da Gestão de processos de TI. Ambas as práticas são formalizadas e mensuradas.

Quadro 51 - Maturidade dos FCS da gestão de processos de TI

\begin{tabular}{|l|l|c|c|c|c|c|c|}
\hline Código & Categoria: Alinhamento entre TI e o negócio & Freq. & $\mathbf{1}$ & $\mathbf{2}$ & $\mathbf{3}$ & $\mathbf{4}$ & $\mathbf{5}$ \\
\hline Dneg0901 & Processos definidos da gestão de TI & 1 & 1 & 0 & 0 & 0 & 1 \\
\hline Dneg0902 & Avaliação e auditoria dos processos de TI & 1 & 1 & 0 & 0 & 0 & 1 \\
\hline Total & & $\mathbf{2}$ & $\mathbf{2}$ & $\mathbf{0}$ & $\mathbf{0}$ & $\mathbf{0}$ & $\mathbf{2}$ \\
\hline
\end{tabular}

Fonte: Dados da pesquisa

A Figura 36 mostra a representação gráfica dos valores totais apresentados no Quadro 51. 


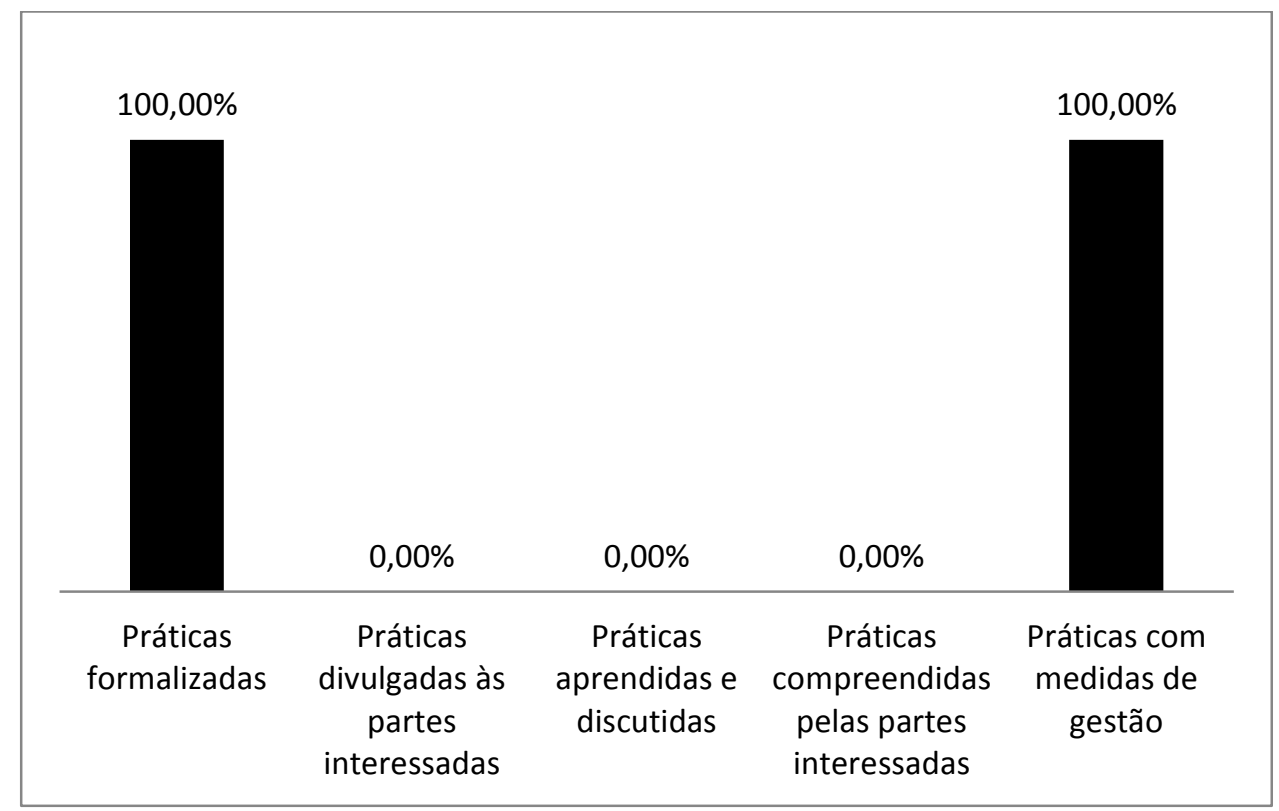

Figura 36 - Maturidade da gestão de processos de TI

Fonte: Dados da Pesquisa

\section{FCS da Categoria Estrutura Organizacional de TI}

O Quadro 52 referente à categoria Estrutura organizacional de TI possui sete FCS. O FCS com mais citações pelos entrevistados é Estrutura organizacional de TI com status de Diretoria ou área executiva com 7,69\% (2 entrevistados). Segundo os entrevistados, a área de TI como diretoria ou área executiva possibilita maior autonomia de decisão e novos investimentos. Além disso, aumenta a percepção de valor da TI para o negócio. Uma instituição citou o FCS - Estrutura pequena que se enquadra a realidade da mesma. Todavia, algumas estruturas de TI pesquisadas correspondem ao tamanho (em pessoal) de estruturas organizacionais inteiras. Também foram citadas divisões relacionadas às atividades estratégicas, táticas e operacionais (Dneg 1006 e Dneg 1007).

Quadro 52 - FCS da estrutura organizacional de TI

\begin{tabular}{|l|l|c|c|}
\hline Código & Categoria: Estrutura organizacional de TI & Freq. & Porcentual \\
\hline Dneg1004 & $\begin{array}{l}\text { Estrutura organizacional de TI com status de Diretoria ou área } \\
\text { executiva }\end{array}$ & 2 & $7,69 \%$ \\
\hline Dneg1001 & Normas claras sobre as responsabilidades das áreas de TI & 1 & $3,85 \%$ \\
\hline Dneg1002 & Definição de uma estrutura organizacional apropriada. & 1 & $3,85 \%$ \\
\hline Dneg1003 & Estruturas específicas de gestão e desenvolvimento de projeto & 1 & $3,85 \%$ \\
\hline Dneg1005 & Estrutura pequena & 1 & $3,85 \%$ \\
\hline Dneg1006 & Comissão técnica de TI & 1 & $3,85 \%$ \\
\hline Dneg1007 & $\begin{array}{l}\text { Separação dos comitês de definição estratégica da TI e de } \\
\text { priorização de demandas para TI }\end{array}$ & 1 & $3,85 \%$ \\
\hline
\end{tabular}

Fonte: Dados da pesquisa 
O Quadro 53 mostra a maturidade das práticas relacionados aos FCS da categoria Estrutura organizacional de TI. Totalizando, foram oito respostas para essa categoria. Apenas três FCS possuem práticas não formalizadas: Normas claras sobre as responsabilidades das áreas de TI; Estruturas específicas de gestão e desenvolvimento de projeto; e Estrutura pequena.

Quadro 53 - Maturidade dos FCS da estrutura organizacional de TI

\begin{tabular}{|l|l|c|c|c|c|c|c|}
\hline Código & Categoria: Estrutura organizacional de TI & Freq. & $\mathbf{1}$ & $\mathbf{2}$ & $\mathbf{3}$ & $\mathbf{4}$ & $\mathbf{5}$ \\
\hline Dneg1001 & Normas claras sobre as responsabilidades das áreas de TI & 1 & 0 & 1 & 1 & 1 & 0 \\
\hline Dneg1002 & Definição de uma estrutura organizacional apropriada. & 1 & 1 & 0 & 1 & 0 & 0 \\
\hline Dneg1003 & Estruturas específicas de gestão e desenvolvimento de projeto. & 1 & 0 & 0 & 0 & 0 & 0 \\
\hline Dneg1004 & $\begin{array}{l}\text { Estrutura organizacional de TI com status de Diretoria ou área } \\
\text { executiva }\end{array}$ & 2 & 2 & 1 & 2 & 2 & 1 \\
\hline Dneg1005 & Estrutura pequena & 1 & 0 & 0 & 0 & 0 & 0 \\
\hline Dneg1006 & Comissão técnica de TI & 1 & 1 & 0 & 0 & 0 & 1 \\
\hline Dneg1007 & $\begin{array}{l}\text { Separação dos comitês de definição estratégica da TI e de } \\
\text { priorização de demandas para TI }\end{array}$ & 1 & 1 & 1 & 1 & 1 & 1 \\
\hline Total & & $\mathbf{8}$ & $\mathbf{5}$ & $\mathbf{3}$ & $\mathbf{5}$ & $\mathbf{4}$ & $\mathbf{3}$ \\
\hline
\end{tabular}

Fonte: Dados da pesquisa

Na Figura 37 é apresentada a maturidade dessa categoria. Verifica-se que as práticas que representam essas categorias são primeiramente formalizadas, e aprendidas e discutidas $(62,50 \%)$. Com $37,50 \%$ essas práticas divulgadas às partes interessadas e possuem medidas de gestão.

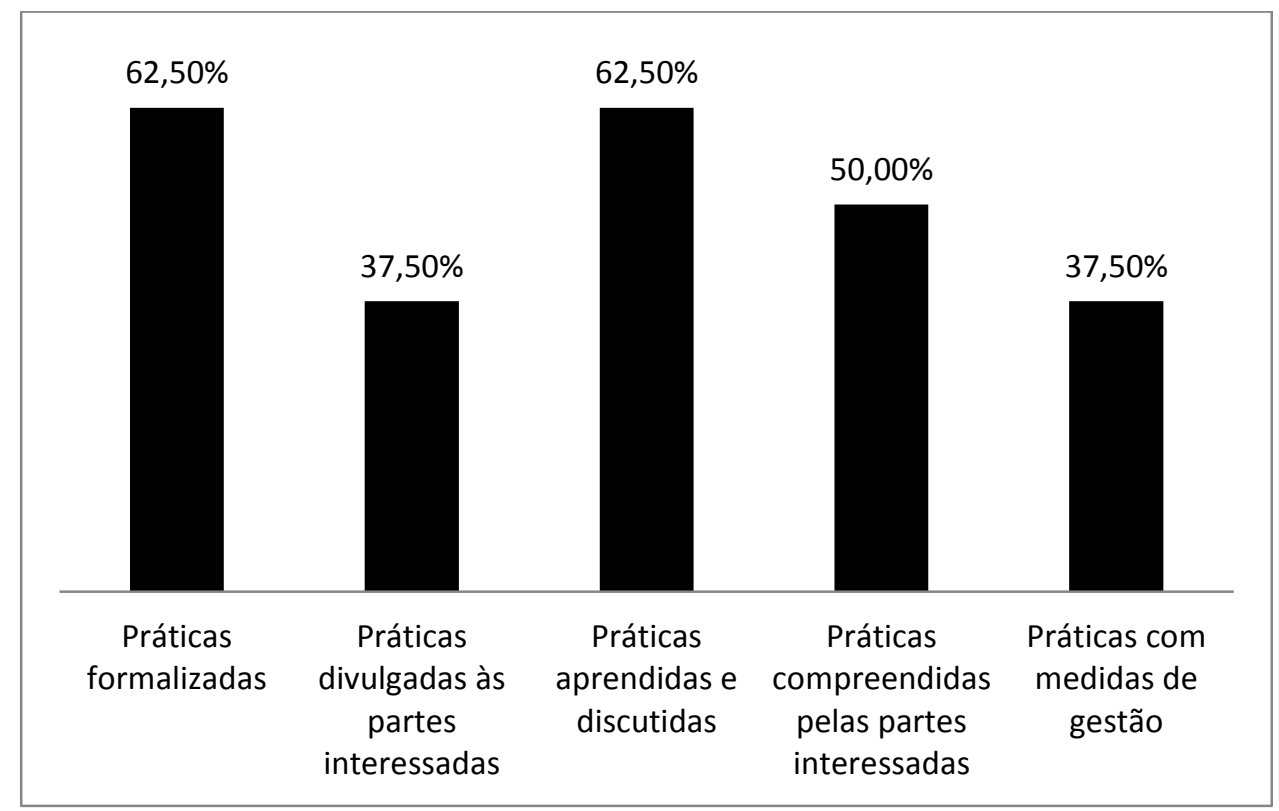

Figura 37 - Maturidade da estrutura organizacional de TI Fonte: Dados da Pesquisa 


\section{FCS da Categoria Gestão do Usuário de TI}

O Quadro 54 referente à categoria Gestão do usuário de TI possui oito FCS. Os FCS dessa categoria fazem parte do processo de desenvolvimento de soluções, mas também do processo de gestão de demandas. Além disso, contribuem para a percepção de valor da TI para o negócio, sendo esta categoria estratégica para a TI. Verificou-se durante a pesquisa que essa é uma boa prática executada nas áreas de TI, sendo, geralmente, definidas e monitoradas pela GTI.

Quadro 54 - FCS da gestão do usuário de TI

\begin{tabular}{|l|l|c|c|}
\hline Código & Categoria: Gestão do usuário de TI & Freq. & Porcentual \\
\hline Dneg1101 & Envolvimento dos usuários/cliente nos projetos & 2 & $7,69 \%$ \\
\hline Dneg1104 & $\begin{array}{l}\text { Comunicação efetiva com o usuário por meio de participações em } \\
\text { reuniões de desenvolvimento }\end{array}$ & 2 & $7,69 \%$ \\
\hline Dneg1102 & $\begin{array}{l}\text { Alta participação da área de negócio no planejamento e na execução } \\
\text { de projetos realizados em equipes matriciais }\end{array}$ & 1 & $3,85 \%$ \\
\hline Dneg1103 & Comprometimento dos usuários/unidades & 1 & $3,85 \%$ \\
\hline Dneg1105 & Participação da TI na construção de projetos das áreas finalísticas & 1 & $3,85 \%$ \\
\hline Dneg1106 & Análise de requisitos com envolvimento do usuário & 1 & $3,85 \%$ \\
\hline Dneg1107 & $\begin{array}{l}\text { Conhecimento do processo de negócio por parte do usuário e saber } \\
\text { comunica-lo }\end{array}$ & 1 & $3,85 \%$ \\
\hline Dneg1108 & Comunicação efetiva com o usuário & 1 & $3,85 \%$ \\
\hline
\end{tabular}

Fonte: Dados da pesquisa

O Quadro 55 mostra a maturidade das práticas associadas aos FCS da Gestão do usuário de TI. Totalizando, foram dez respostas para essa categoria. Apenas duas respostas indicam práticas não formalizadas, embora a maioria das respostas mostram práticas formalizadas.

Quadro 55 - Maturidade dos FCS da gestão do usuário de TI

\begin{tabular}{|l|l|c|c|c|c|c|c|}
\hline Código & Categoria: Gestão do usuário de TI & Freq. & $\mathbf{1}$ & $\mathbf{2}$ & $\mathbf{3}$ & $\mathbf{4}$ & $\mathbf{5}$ \\
\hline Dneg1101 & Envolvimento dos usuários/cliente nos projetos & 2 & 1 & 1 & 2 & 1 & 1 \\
\hline Dneg1102 & $\begin{array}{l}\text { Alta participação da área de negócio no planejamento e na } \\
\text { execução de projetos realizados em equipes matriciais. }\end{array}$ & 1 & 1 & 1 & 1 & 1 & 0 \\
\hline Dneg1103 & Comprometimento dos usuários/unidades & 1 & 1 & 0 & 1 & 0 & 0 \\
\hline Dneg1104 & $\begin{array}{l}\text { Comunicação efetiva com o usuário por meio de participações } \\
\text { em reuniões de desenvolvimento }\end{array}$ & 2 & 2 & 2 & 2 & 2 & 0 \\
\hline Dneg1105 & $\begin{array}{l}\text { Participação da TI na construção de projetos das áreas } \\
\text { finalísticas }\end{array}$ & 1 & 1 & 1 & 1 & 1 & 0 \\
\hline Dneg1106 & Análise de requisitos com envolvimento do usuário & 1 & 0 & 0 & 0 & 0 & 0 \\
\hline Dneg1107 & $\begin{array}{l}\text { Conhecimento do processo de negócio por parte do usuário e } \\
\text { saber comunica-lo }\end{array}$ & 1 & 1 & 1 & 1 & 0 & 0 \\
\hline Dneg1108 & Comunicação efetiva com o usuário & 1 & 1 & 1 & 1 & 1 & 1 \\
\hline Total & & $\mathbf{1 0}$ & $\mathbf{8}$ & $\mathbf{7}$ & $\mathbf{9}$ & $\mathbf{6}$ & $\mathbf{2}$ \\
\hline
\end{tabular}

Fonte: Dados da pesquisa 
Na Figura 38 é apresentada a maturidade dessa categoria. Verifica-se que as práticas que representam essas categorias são primeiramente aprendidas e discutidas (90\%), em seguida estão formalizadas (80\%), estão divulgadas às partes interessadas (79\%), são compreendidas pelas partes interessadas $(60 \%)$ e por último possuem medidas de gestão $(20 \%)$.

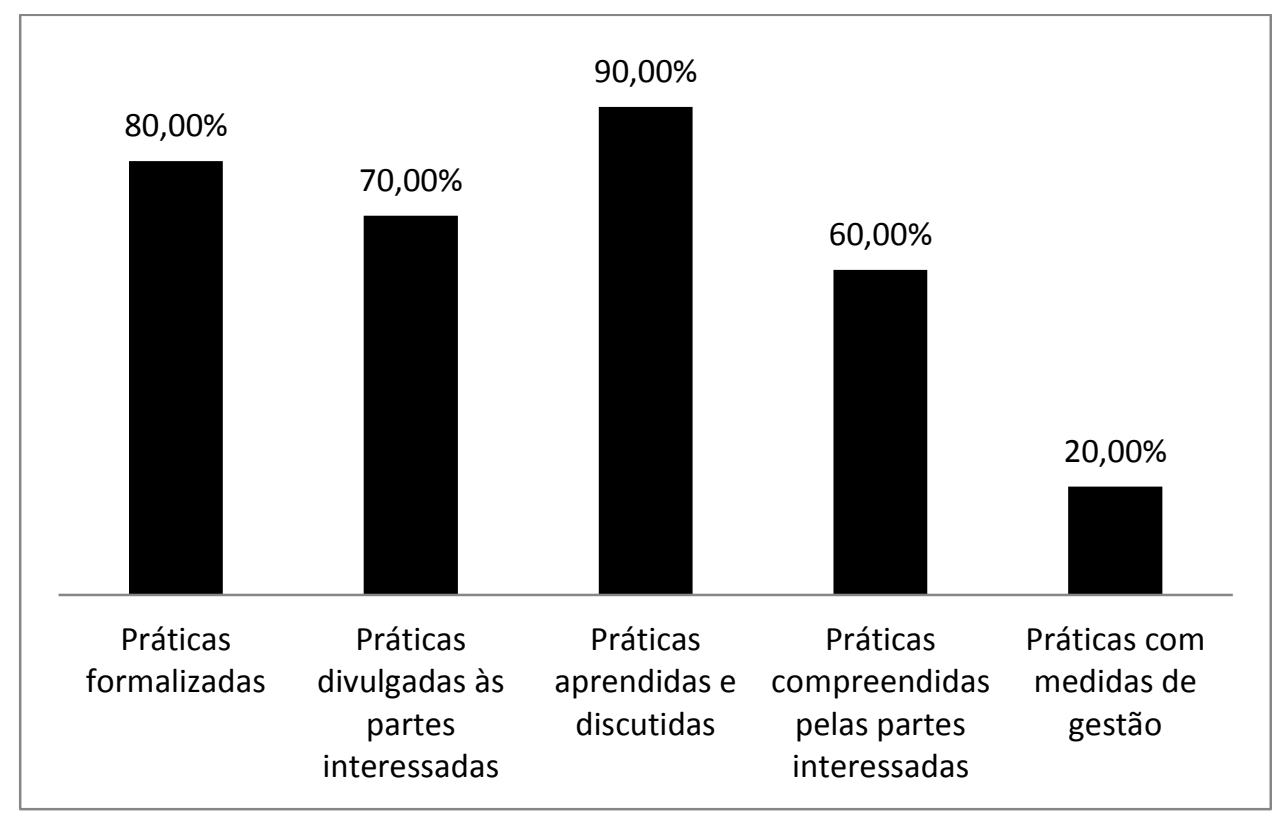

Figura 38 - Maturidade da gestão do usuário de TI Fonte: Dados da Pesquisa

\section{FCS da Categoria Gestão de Demandas}

O Quadro 56 referente à categoria Gestão de demandas tem onze FCS. Essa categoria é a base fundamental do subsistema de Direcionamento. Os FCS principais dessa categoria são Gestão de demandas e Gestão de portfólio.

Nessa categoria, o FCS - Demandas intempestivas - mencionado por três entrevistados, expõe as demandas que não são analisadas nem pela governança e nem pelo PEI, sendo fruto de decisões personalísticas. Embora esse FCS possua $100 \%$ de monitoramento, coloca em dúvida a divisão entre governança, gestão e demais interesses.

Outros dois FCS são apresentados na Figura dos gerentes de relacionamentos/consultores de negócio, conhecidos no mercado como analistas de negócio. Segundos os entrevistados, esses profissionais possuem conhecimento sobre o negócio e sobre a TI. Sua função é auxiliar as áreas de negócio no desenvolvimento de propostas de demanda. 
Em algumas instituições, dependendo do porte, esse analista da área de TI é posicionado em uma área de negócio ou pode ser uma unidade de relacionamento de TI dentro de uma área de negócio.

Quadro 56 - FCS da gestão de demandas

\begin{tabular}{|l|l|c|c|}
\hline Código & Categoria: Gestão de demandas & Freq. & Porcentual \\
\hline Dneg1206 & Demandas intempestivas & 3 & $11,54 \%$ \\
\hline Dneg1201 & Gestão de demandas & 1 & $3,85 \%$ \\
\hline Dneg1202 & Gestão de portfólio & 1 & $3,85 \%$ \\
\hline Dneg1203 & Implementação do processo de gestão de demandas & 1 & $3,85 \%$ \\
\hline Dneg1204 & Quantidade de solicitações & 1 & $3,85 \%$ \\
\hline Dneg1205 & Definição do objeto & 1 & $3,85 \%$ \\
\hline Dneg1207 & Lista de necessidades formalizada para priorização no Comitê de TI & $3,85 \%$ \\
\hline Dneg1208 & $\begin{array}{l}\text { Divisão de relacionamento com o negócio para identificação de } \\
\text { necessidades das áreas finalísticas }\end{array}$ & 1 & $3,85 \%$ \\
\hline Dneg1209 & Gerentes de relacionamentos & 1 & $3,85 \%$ \\
\hline Dneg1210 & Consultores de negócio conhece as demandas das áreas & 1 & $3,85 \%$ \\
\hline Dneg1211 & Grupos de trabalho com representantes de TI & 1 & $3,85 \%$ \\
\hline
\end{tabular}

Fonte: Dados da pesquisa

O Quadro 57 mostra a maturidade das práticas relacionadas aos FCS da Gestão de demandas. Totalizando, foram 13 respostas para essa categoria. Apenas o FCS - Demandas intempestivas - indica uma prática não formalizada.

Quadro 57 - Maturidade dos FCS da gestão de demandas

\begin{tabular}{|l|l|c|c|c|c|c|c|}
\hline Código & Categoria: Gestão de demandas & Freq. & $\mathbf{1}$ & $\mathbf{2}$ & $\mathbf{3}$ & $\mathbf{4}$ & $\mathbf{5}$ \\
\hline Dneg1201 & Gestão de demandas & 1 & 1 & 1 & 0 & 1 & 1 \\
\hline Dneg1202 & Gestão de portfólio & 1 & 1 & 1 & 1 & 1 & 0 \\
\hline Dneg1203 & Implementação do processo de gestão de demandas & 1 & 1 & 1 & 1 & 1 & 1 \\
\hline Dneg1204 & Quantidade de solicitações & 1 & 1 & 0 & 0 & 0 & 0 \\
\hline Dneg1205 & Definição do objeto & 1 & 1 & 1 & 1 & 1 & 1 \\
\hline Dneg1206 & Demandas intempestivas & 3 & 2 & 1 & 3 & 1 & 3 \\
\hline Dneg1207 & $\begin{array}{l}\text { Lista de necessidades formalizada para priorização no Comitê } \\
\text { de TI }\end{array}$ & 1 & 1 & 1 & 1 & 1 & 1 \\
\hline Dneg1208 & $\begin{array}{l}\text { Divisão de relacionamento com o negócio para identificação } \\
\text { de necessidades das áreas finalísticas }\end{array}$ & 1 & 1 & 1 & 1 & 1 & 1 \\
\hline Dneg1209 & Gerentes de relacionamentos & 1 & 1 & 1 & 1 & 1 & 1 \\
\hline Dneg1210 & Consultores de negócio conhece as demandas das áreas & 1 & 1 & 1 & 1 & 1 & 0 \\
\hline Dneg1211 & Grupos de trabalho com representantes de TI & 1 & 1 & 0 & 0 & 0 & 1 \\
\hline Total & & $\mathbf{1 3}$ & $\mathbf{1 2}$ & $\mathbf{9}$ & $\mathbf{1 0}$ & $\mathbf{9}$ & $\mathbf{1 0}$ \\
\hline
\end{tabular}

Fonte: Dados da pesquisa

Na Figura 39 é apresentada a maturidade dessa categoria. Verifica-se que as práticas que representam essas categorias são primeiramente formalizadas (92,31\%). Depois com $76,92 \%$ as práticas são aprendidas e discutidas. Em seguida são divulgadas às partes interessadas e possuem medidas de gestão, cada uma com 69,23\%. 


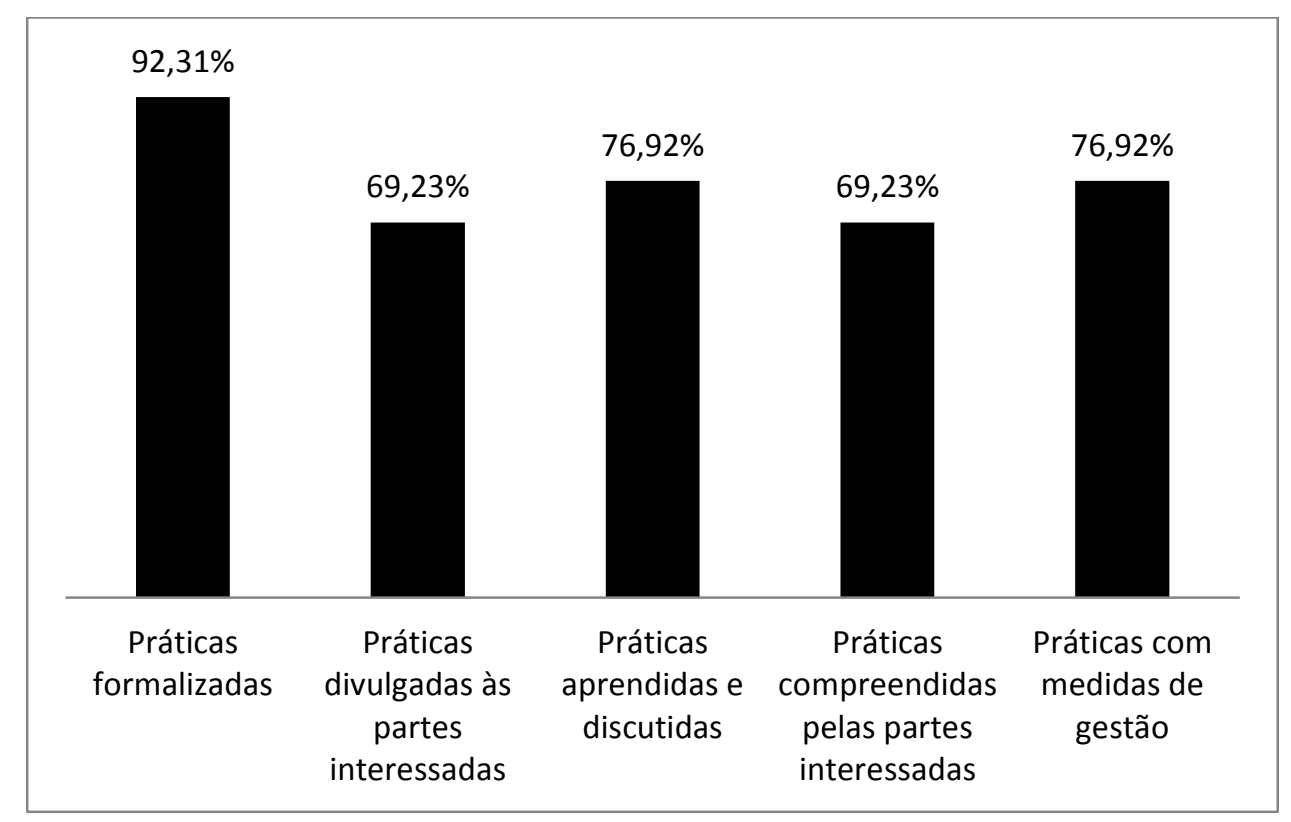

Figura 39 - Maturidade da gestão de demandas Fonte: Dados da Pesquisa

\section{FCS da Categoria Definição de Arquiteturas}

O Quadro 58 referente à categoria Definição de Arquiteturas possui dois FCS: $i$ ) Definição de arquitetura dominada e convergente, e ii) Meta arquitetura corporativa de TIC, cada um com apenas uma citação. Frisa-se que a definição sobre arquitetura é uma das atribuições da GTI.

Quadro 58 - FCS da definição de arquiteturas

\begin{tabular}{|l|l|c|c|}
\hline Código & Categoria: Definição de arquiteturas & Freq. & Porcentual \\
\hline Dneg1301 & Definição de arquitetura dominada e convergente & 1 & $3,85 \%$ \\
\hline Dneg1302 & Meta arquitetura corporativa de TIC & 1 & $3,85 \%$ \\
\hline
\end{tabular}

Fonte: Dados da pesquisa

O Quadro 59 mostra a maturidade dos FCS da Definição de Arquiteturas. Os dois FCS possuem bom nível de maturidade, todos formalizados.

Quadro 59 - Maturidade dos FCS da definição de arquiteturas

\begin{tabular}{|l|l|c|c|c|c|c|c|}
\hline Código & Categoria: Definição de arquiteturas & Freq. & $\mathbf{1}$ & $\mathbf{2}$ & $\mathbf{3}$ & $\mathbf{4}$ & $\mathbf{5}$ \\
\hline Dneg1301 & Definição de arquitetura dominada e convergente & 1 & 1 & 1 & 1 & 1 & 0 \\
\hline Dneg1302 & Meta arquitetura corporativa de TIC & 1 & 1 & 1 & 1 & 1 & 1 \\
\hline Total & & $\mathbf{2}$ & $\mathbf{2}$ & $\mathbf{2}$ & $\mathbf{2}$ & $\mathbf{2}$ & $\mathbf{1}$ \\
\hline
\end{tabular}

Fonte: Dados da pesquisa 
Na Figura 40 mostra que esses FCS são 100\% divulgados às partes interessadas, são aprendidos e discutidos, compreendidos pelas partes interessadas e parcialmente monitorados com $50 \%$.

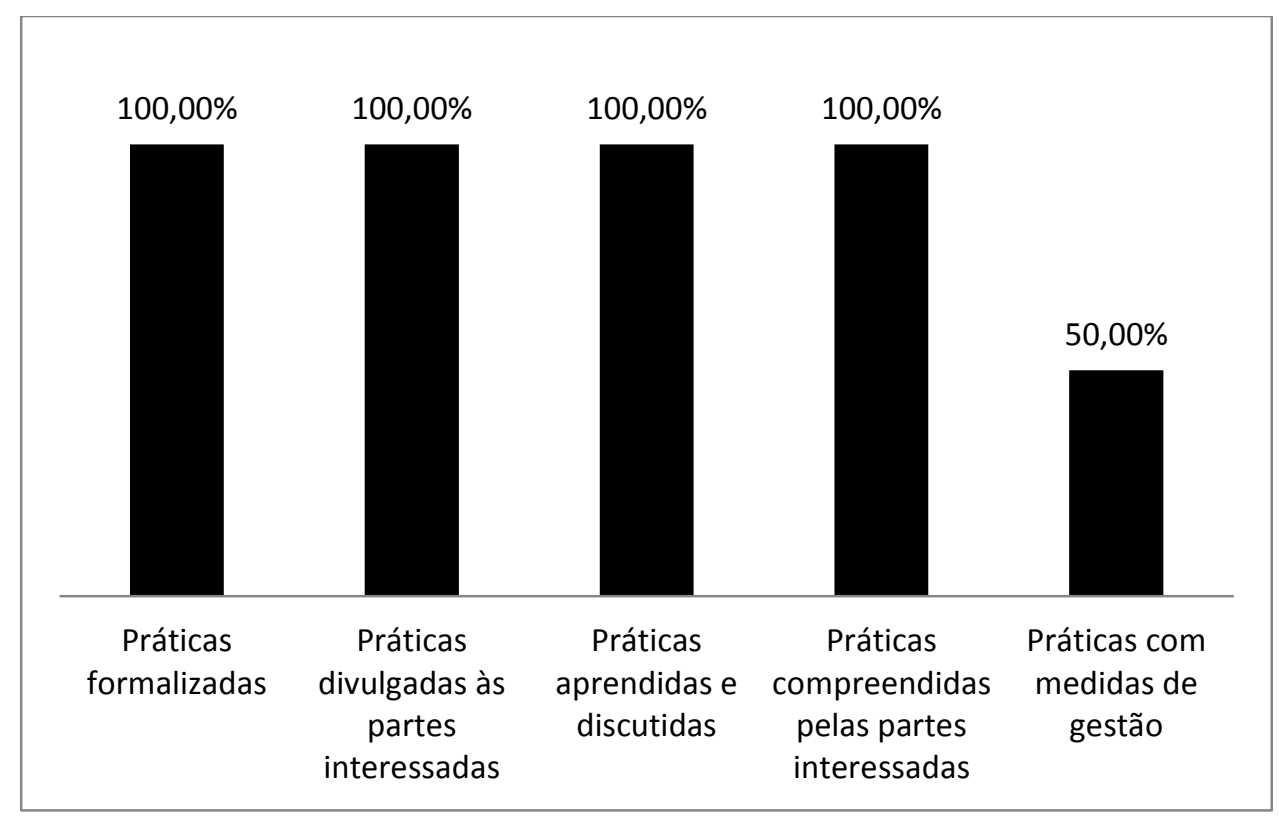

Figura 40 - Maturidade da definição de arquiteturas Fonte: Dados da Pesquisa

\section{FCS da Categoria Políticas e diretrizes de GTI}

O Quadro 60 se refere à categoria Políticas e diretrizes de GTI com três FCS. O FCS com mais citações pelos entrevistados é Definição, formalização, padronização das normas, procedimentos e protocolos de GTI com 15,38\%. Em seguida com duas citações Política de segurança da informação.

Quadro 60 - FCS das Políticas e diretrizes de GTI

\begin{tabular}{|l|l|c|c|}
\hline Código & Categoria: Políticas e diretrizes de GTI & Freq. & Porcentual \\
\hline Dneg1401 & $\begin{array}{l}\text { Definição, formalização, padronização das normas, procedimentos e } \\
\text { protocolos de GTI }\end{array}$ & 4 & $15,38 \%$ \\
\hline Dneg1402 & Política de segurança da informação & 2 & $7,69 \%$ \\
\hline Dneg1403 & Política de disponibilidade & 1 & $3,85 \%$ \\
\hline
\end{tabular}

Fonte: Dados da pesquisa

O Quadro 61 mostra a maturidade dos FCS das Políticas e diretrizes de GTI. Totalizando, foram sete respostas para essa categoria, sendo que todas as práticas referentes ao tema são formalizadas. 
Quadro 61 - Maturidade dos FCS das Políticas e diretrizes de GTI

\begin{tabular}{|c|c|c|c|c|c|c|c|}
\hline Código & Categoria: Políticas e diretrizes de GTI & Freq. & 1 & 2 & 3 & 4 & 5 \\
\hline Dneg1401 & \begin{tabular}{|l}
$\begin{array}{l}\text { Definição, formalização, padronização das } \\
\text { procedimentos e protocolos de GTI }\end{array}$ \\
\end{tabular} & 4 & 4 & 3 & 3 & 3 & 3 \\
\hline Dneg1403 & Política de segurança da informação & 2 & 2 & 1 & 0 & 1 & 0 \\
\hline Dneg1404 & Política de disponibilidade & 1 & 1 & 0 & 0 & 0 & 0 \\
\hline \multicolumn{2}{|l|}{ Total } & 7 & 7 & 4 & 3 & 4 & 3 \\
\hline
\end{tabular}

Fonte: Dados da pesquisa

Na Figura 41 é apresentada a maturidade dessa categoria. Verifica-se que as práticas que representam essas categorias são primeiramente $100 \%$ formalizadas. Em seguida estão divulgadas e compreendidas pelas partes interessadas. Depois são aprendidas e discutidas, e possuem medidas, cada uma com $42,86 \%$.

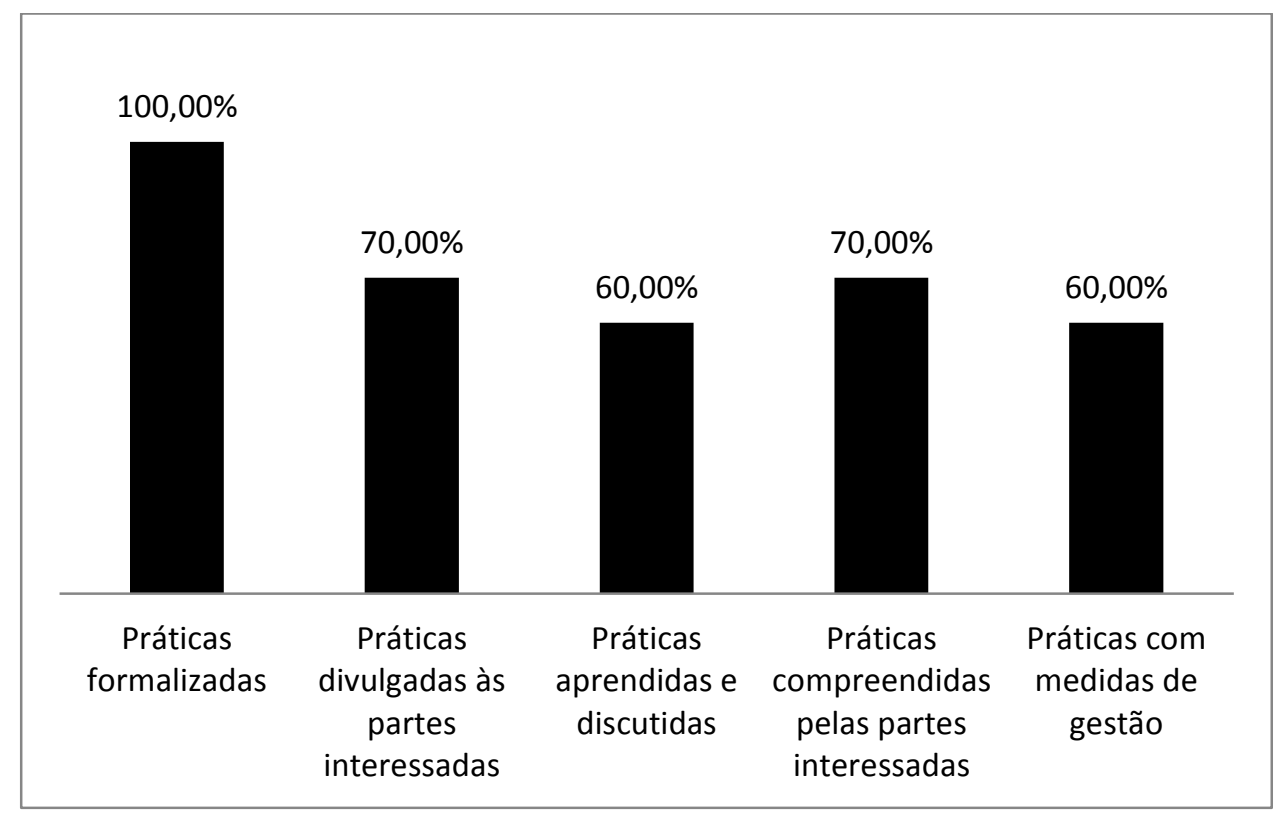

Figura 41 - Maturidade das Políticas e diretrizes de GTI Fonte: Dados da Pesquisa

\section{FCS da Categoria Plano Diretor de Tecnologia da Informação}

O Quadro 62 referente à categoria Plano diretor de tecnologia da informação possui seis FCS. O FCS com mais citações pelos entrevistados é Plano diretor de tecnologia da informação (PDTI) com 19,23\%. Em seguida, o FCS Alinhamento entre as metas do PEI e o PDTI. Depois, o FCS Alinhamento entre PDTI e PETI. Esses três FCS focam na coerência do PDTI com a estratégia de TI e com a estratégia institucional. 
Quadro 62 - FCS do PDTI

\begin{tabular}{|l|l|c|c|}
\hline Código & Categoria: Plano diretor de tecnologia da informação & Freq. & Porcentual \\
\hline Dneg1501 & PDTI & 5 & $19,23 \%$ \\
\hline Dneg1502 & Alinhamento entre as metas do PEI e o PDTI & 3 & $11,54 \%$ \\
\hline Dneg1505 & Alinhamento entre PDTI e PETI & 2 & $3,85 \%$ \\
\hline Dneg1503 & Áreas finalistas se identificam no PDTI & 1 & $3,85 \%$ \\
\hline Dneg1504 & $\begin{array}{l}\text { Acompanhamento das metas de execução do PDTI acordado com a } \\
\text { Diretoria. }\end{array}$ & 1 & $3,85 \%$ \\
\hline Dneg1506 & Lista de necessidades no PDTI & 1 & $3,85 \%$ \\
\hline
\end{tabular}

Fonte: Dados da pesquisa

O Quadro 63 mostra a maturidade dos FCS do Plano Diretor de Tecnologia da Informação, em que $100 \%$ dos entrevistados possuem práticas relacionadas aos FCS formalizadas.

Quadro 63 - Maturidade dos FCS do PDTI

\begin{tabular}{|l|l|c|c|c|c|c|c|}
\hline Código & Categoria: Plano diretor de tecnologia da informação & Freq. & $\mathbf{1}$ & $\mathbf{2}$ & $\mathbf{3}$ & $\mathbf{4}$ & $\mathbf{5}$ \\
\hline Dneg1501 & PDTI & 5 & 5 & 4 & 4 & 3 & 4 \\
\hline Dneg1502 & Alinhamento entre as metas do PEI e o PDTI & 3 & 3 & 3 & 3 & 3 & 3 \\
\hline Dneg1503 & Áreas finalistas se identificam no PDTI & 1 & 1 & 1 & 1 & 1 & 0 \\
\hline Dneg1504 & $\begin{array}{l}\text { Acompanhamento das metas de execução do PDTI acordado } \\
\text { com a Diretoria. }\end{array}$ & 1 & 1 & 1 & 1 & 0 & 1 \\
\hline Dneg1505 & Alinhamento entre PDTI e PETI & 2 & 2 & 2 & 2 & 2 & 1 \\
\hline Dneg1506 & Lista de necessidades no PDTI & 1 & 1 & 1 & 1 & 1 & 0 \\
\hline Total & $\mathbf{1 3}$ & $\mathbf{1 3}$ & $\mathbf{1 2}$ & $\mathbf{1 2}$ & $\mathbf{1 0}$ & $\mathbf{9}$ \\
\hline
\end{tabular}

Fonte: Dados da pesquisa

Na Figura 42 é apresentada a maturidade dessa categoria. Verifica-se que as práticas que representam essas categorias, depois de formalizadas são primeiramente divulgadas, e aprendidas e discutidas às partes interessadas (92,31\%), em seguida estão compreendidas $(76,92 \%)$ e por último possuem medidas de gestão $(69,23 \%)$. 


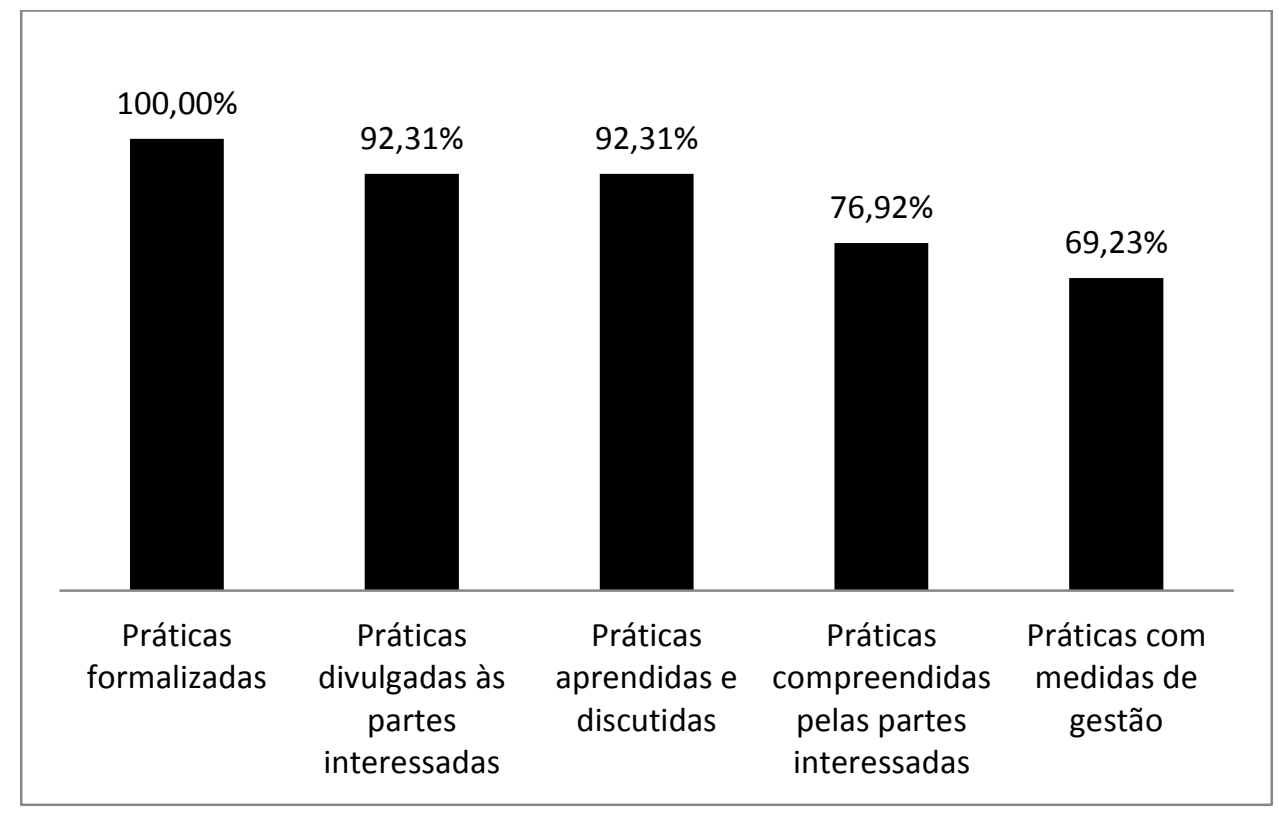

Figura 42 - Maturidade do PDTI

Fonte: Dados da Pesquisa

\section{FCS da Categoria Comunicação com as Partes Interessadas}

O Quadro 64 referente à categoria Comunicação com as Partes Interessadas possui quatro FCS. Verifica-se que todos os quatro FCS possuem apenas uma citação. Cada um desses FCS mobilizam as partes interessadas para a discussão sobre a GTI. Os FCS dessa categoria contribuem para o FCS Demonstração de valor agregado de TI ao negócio.

Quadro 64 - FCS da comunicação com as partes interessadas

\begin{tabular}{|l|l|c|c|}
\hline Código & Categoria: Comunicação com as partes interessadas & Freq. & Porcentual \\
\hline Dneg1601 & Conscientização da GTI para com todos os colaboradores. & 1 & $3,85 \%$ \\
\hline Dneg1602 & $\begin{array}{l}\text { Fórum de discussão sobre os principais sistemas do órgão com a } \\
\text { participação das partes interessadas }\end{array}$ & 1 & $3,85 \%$ \\
\hline Dneg1603 & Grupos de trabalho para discussão de temas e apoio à GTI & 1 & $3,85 \%$ \\
\hline Dneg1604 & $\begin{array}{l}\text { Grupos de governança, de arquitetura e de processos para discussão } \\
\text { de temas afins. }\end{array}$ & 1 & $3,85 \%$ \\
\hline
\end{tabular}

Fonte: Dados da pesquisa

O Quadro 65 mostra a maturidade dos FCS da Comunicação com as Partes Interessadas. Totalizando, foram quatro respostas para essa categoria, em que $100 \%$ dos FCS são formalizados. 
Quadro 65 - Maturidade dos FCS da comunicação com as partes interessadas

\begin{tabular}{|l|l|c|c|c|c|c|c|}
\hline Código & Categoria: Comunicação com as partes interessadas & Freq. & $\mathbf{1}$ & $\mathbf{2}$ & $\mathbf{3}$ & $\mathbf{4}$ & $\mathbf{5}$ \\
\hline Dneg1601 & Conscientização da GTI para com todos os colaboradores. & 1 & 1 & 1 & 1 & 1 & 0 \\
\hline Dneg1602 & $\begin{array}{l}\text { Fórum de discussão sobre os principais sistemas do órgão com } \\
\text { a participação das partes interessadas }\end{array}$ & 1 & 1 & 1 & 1 & 1 & 1 \\
\hline Dneg1603 & Grupos de trabalho para discussão de temas e apoio à GTI & 1 & 1 & 1 & 1 & 1 & 1 \\
\hline Dneg1604 & $\begin{array}{l}\text { Grupos de governança, de arquitetura e de processos para } \\
\text { discussão de temas afins. }\end{array}$ & 1 & 1 & 1 & 1 & 1 & 1 \\
\hline Total & 4 & 4 & 4 & 4 & 4 & 3 \\
\hline
\end{tabular}

Fonte: Dados da pesquisa

Na Figura 43 é apresentada a maturidade dessa categoria. Verifica-se que esta é uma das categorias com maior maturidade em GTI, em que $100 \%$ das práticas são formalizadas, são divulgadas às partes interessadas, são aprendidas e discutidas, são compreendidas pelas partes interessadas. Sobre as medidas de gestão, 75\% das práticas são mensuradas.

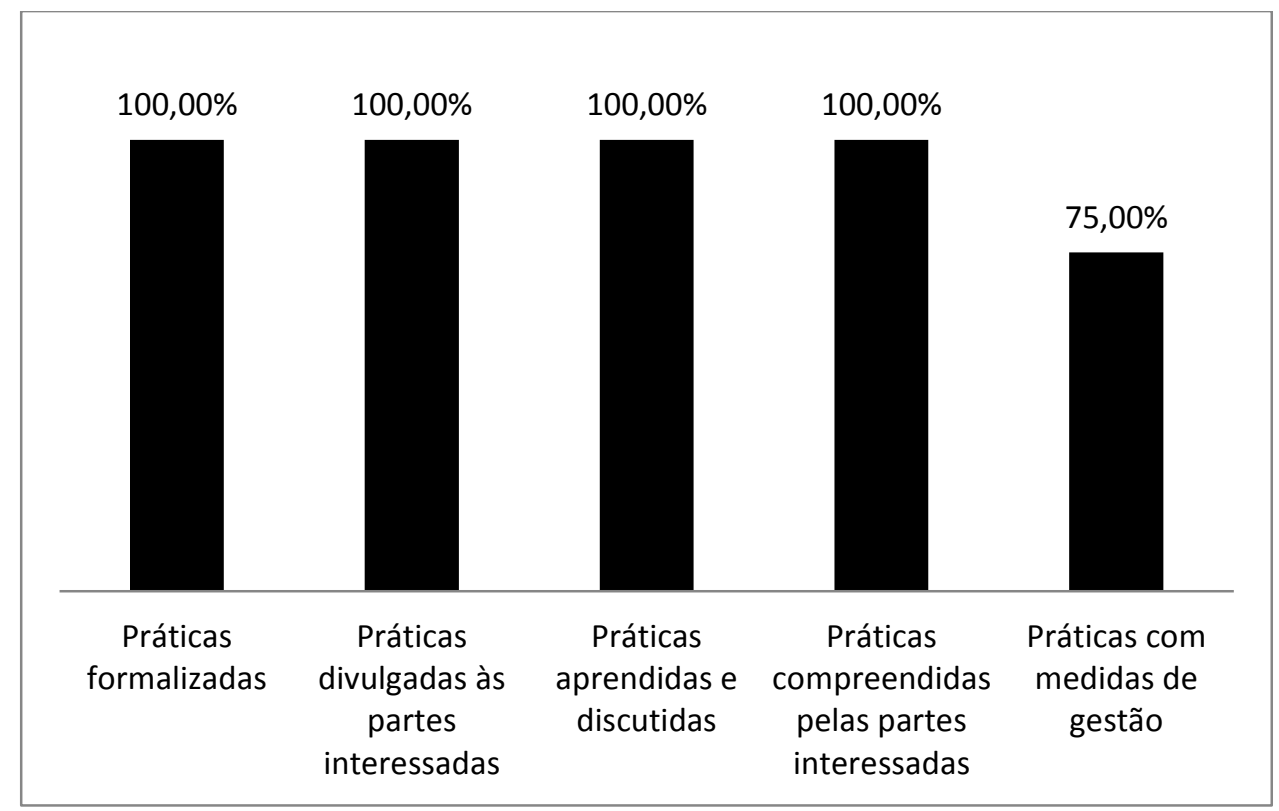

Figura 43 - Maturidade da comunicação com as partes interessadas Fonte: Dados da Pesquisa

\section{FCS da Categoria Normas e diretrizes para GTI}

O Quadro 66 se refere à categoria Normas e diretrizes para GTI com três FCS. Todos os FCS possuem apenas uma citação. 
Quadro 66 - FCS das Normas e diretrizes para GTI

\begin{tabular}{|l|l|c|c|}
\hline Código & Categoria: Políticas e diretrizes de GTI & Freq. & Porcentual \\
\hline Dneg1701 & Clareza de propósito da GTI & 1 & $3,85 \%$ \\
\hline Dneg1702 & Instruções do Tribunal de Contas da União (TCU) para GTI & 1 & $3,85 \%$ \\
\hline Dneg1703 & Igovti para processos internos & 1 & $3,85 \%$ \\
\hline
\end{tabular}

Fonte: Dados da pesquisa

O Quadro 67 mostra a maturidade dos FCS das Normas e diretrizes para GTI. Totalizando, foram três respostas para essa categoria, sendo que todas as práticas referentes ao tema são formalizadas.

Quadro 67 - Maturidade dos FCS das Normas e diretrizes para GTI

\begin{tabular}{|l|l|c|c|c|c|c|c|}
\hline Código & Categoria: Políticas e diretrizes de GTI & Freq. & $\mathbf{1}$ & $\mathbf{2}$ & $\mathbf{3}$ & $\mathbf{4}$ & $\mathbf{5}$ \\
\hline Dneg1701 & Clareza de propósito da GTI & 1 & 1 & 1 & 1 & 1 & 1 \\
\hline Dneg1702 & Instruções do Tribunal de Contas da União (TCU) para GTI & 1 & 1 & 1 & 1 & 1 & 1 \\
\hline Dneg1703 & Igovti para processos internos & 1 & 1 & 1 & 1 & 1 & 1 \\
\hline Total & $\mathbf{3}$ & $\mathbf{3}$ & $\mathbf{3}$ & $\mathbf{3}$ & $\mathbf{3}$ & $\mathbf{3}$ \\
\hline
\end{tabular}

Fonte: Dados da pesquisa

Na Figura 44 é apresentada a maturidade dessa categoria. Verifica-se que as práticas que representam essa categoria possuem de maturidade em todos os quesitos.

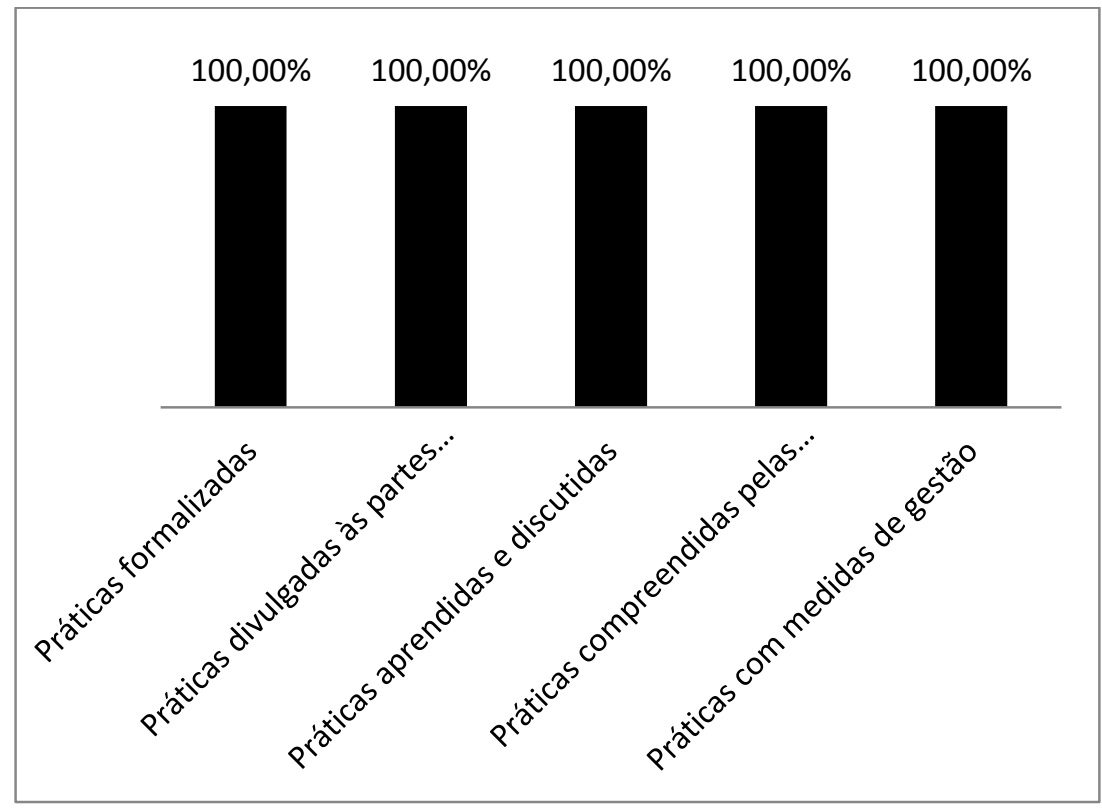

Figura 44 - Maturidade das Normas e diretrizes para GTI Fonte: Dados da Pesquisa 


\subsubsection{Análise dos FCS em GTI da APF - Subsistema Direcionamento em Gestão de TI}

Neste subcapítulo serão apresentados os FCS em gestão de TI. O foco em gestão de TI se refere aos recursos necessários para o desenvolvimento de soluções.

\section{FCS da Categoria Gestão de Fornecedores}

O Quadro 68 referente à categoria Gestão de Fornecedores possui 13 FCS. Nessa categoria, todos os FCS tiveram apenas uma citação. Os FCS se caracterizam por definirem a divisão entre os trabalhos para desenvolvimento interno e externo. A tomada de decisão sobre o ambiente de desenvolvimento varia pela criticidade ou pela função do sistema junto à instituição.

No cenário da APF, as empresas estatais possuem mais opções para o ambiente de desenvolvimento de software, enquanto as demais instituições públicas possuem poucas alternativas para o desenvolvimento. Dentre essas alternativas, os entrevistados citaram o Serpro e destacaram projetos são onerosos e atrasos frequentes. Entretanto, observou-se que as instituições que possuem projetos bem sucedidos com o Serpro, apresentam controles bem definidos explicitados no contrato, e controlados durante o planejamento e o desenvolvimento da solução.

Quadro 68 - FCS da gestão de fornecedores

\begin{tabular}{|l|l|c|c|}
\hline Código & Categoria: Alinhamento entre TI e o negócio & Freq. & Porcentual \\
\hline Dges0101 & Segregação do ambiente de produção de software & 1 & $3,85 \%$ \\
\hline Dges0102 & $\begin{array}{l}\text { Distribuição de projetos entre servidores e fábricas direcionados pela } \\
\text { criticidade }\end{array}$ & 1 & $3,85 \%$ \\
\hline Dges0103 & Divisão plena dos processos de projeto e de demanda do dia-a-dia & 1 & $3,85 \%$ \\
\hline Dges0104 & $\begin{array}{l}\text { Apenas sistemas relacionados a missão final são desenvolvidos e } \\
\text { mantidos pela área de TI }\end{array}$ & 1 & $3,85 \%$ \\
\hline Dges0105 & Sistemas críticos desenvolvidos internamente & 1 & $3,85 \%$ \\
\hline Dges0106 & Foco em soluções e não em desenvolvimento & 1 & $3,85 \%$ \\
\hline Dges0107 & $\begin{array}{l}\text { Empresas de desenvolvimento com atuações distintas, mas } \\
\text { complementares no desenvolvimento de soluções }\end{array}$ & 1 & $3,85 \%$ \\
\hline Dges0108 & Fábrica de software externa com entregas de qualidade & 1 & $3,85 \%$ \\
\hline Dges0109 & Parceria com Serpro e empresas públicas que prestam serviços & $3,85 \%$ \\
\hline Dges0110 & $\begin{array}{l}\text { Integração das empresas de desenvolvimento na construção da } \\
\text { solução }\end{array}$ & 1 & $3,85 \%$ \\
\hline Dges0111 & Controle rigoroso com fábrica de software & 1 & $3,85 \%$ \\
\hline Dges0112 & $\begin{array}{l}\text { Parceria estratégica de TI com empresa privada para } \\
\text { desenvolvimento de demandas do projeto (gestão de fornecedores) }\end{array}$ & 1 & $3,85 \%$ \\
\hline Dges0113 & Terceirização quando se está muito bem estruturado & 1 & 1 \\
\hline
\end{tabular}

Fonte: Dados da pesquisa 
O Quadro 69 mostra a maturidade dos FCS da Gestão de Fornecedores. Totalizam 13 respostas para essa categoria, sendo que apenas um FCS não possui prática formalizada.

Quadro 69 - Maturidade dos FCS da gestão de fornecedores

\begin{tabular}{|l|l|c|c|c|c|c|c|}
\hline Código & Categoria: Gestão de fornecedores & Freq. & $\mathbf{1}$ & $\mathbf{2}$ & $\mathbf{3}$ & $\mathbf{4}$ & $\mathbf{5}$ \\
\hline Dges0101 & Segregação do ambiente de produção de software & 1 & 1 & 1 & 1 & 1 & 1 \\
\hline Dges0102 & $\begin{array}{l}\text { Distribuição de projetos entre servidores e fábricas } \\
\text { direcionados pela criticidade }\end{array}$ & 1 & 0 & 0 & 1 & 0 & 0 \\
\hline Dges0103 & $\begin{array}{l}\text { Divisão plena dos processos de projeto e de demanda do dia-a- } \\
\text { dia }\end{array}$ & 1 & 1 & 1 & 1 & 0 & 1 \\
\hline Dges0104 & $\begin{array}{l}\text { Apenas sistemas relacionados à missão final são desenvolvidos } \\
\text { e mantidos pela área de TI }\end{array}$ & 1 & 1 & 1 & 1 & 1 & 0 \\
\hline Dges0105 & Sistemas críticos desenvolvidos internamente & 1 & 1 & 1 & 1 & 1 & 0 \\
\hline Dges0106 & Foco em soluções e não em desenvolvimento & 1 & 1 & 1 & 1 & 1 & 1 \\
\hline Dges0107 & $\begin{array}{l}\text { Empresas de desenvolvimento com atuações distintas, mas } \\
\text { complementares no desenvolvimento de soluções }\end{array}$ & 1 & 1 & 1 & 1 & 1 & 1 \\
\hline Dges0108 & Fábrica de software externa com entregas de qualidade & 1 & 1 & 1 & 1 & 0 & 0 \\
\hline Dges0109 & Parceria com Serpro e empresas públicas que prestam serviços & 1 & 1 & 1 & 1 & 1 & 1 \\
\hline Dges0110 & $\begin{array}{l}\text { Integração das empresas de desenvolvimento na construção da } \\
\text { solução }\end{array}$ & 1 & 1 & 1 & 1 & 1 & 1 \\
\hline Dges0111 & Controle rigoroso com fábrica de software & 1 & 1 & 1 & 1 & 1 & 1 \\
\hline Dges0112 & $\begin{array}{l}\text { Parceria estratégica de TI com empresa privada para } \\
\text { desenvolvimento de demandas do projeto. }\end{array}$ & 1 & 1 & 1 & 1 & 1 & 1 \\
\hline Dges0113 & Terceirização apenas quando se esta muito bem estruturado & 1 & 1 & 1 & 1 & 1 & 0 \\
\hline Total & & $\mathbf{1 3}$ & $\mathbf{1 2}$ & $\mathbf{1 2}$ & $\mathbf{1 3}$ & $\mathbf{1 0}$ & $\mathbf{8}$ \\
\hline
\end{tabular}

Fonte: Dados da pesquisa

Na Figura 45, é apresentada a maturidade dessa categoria.

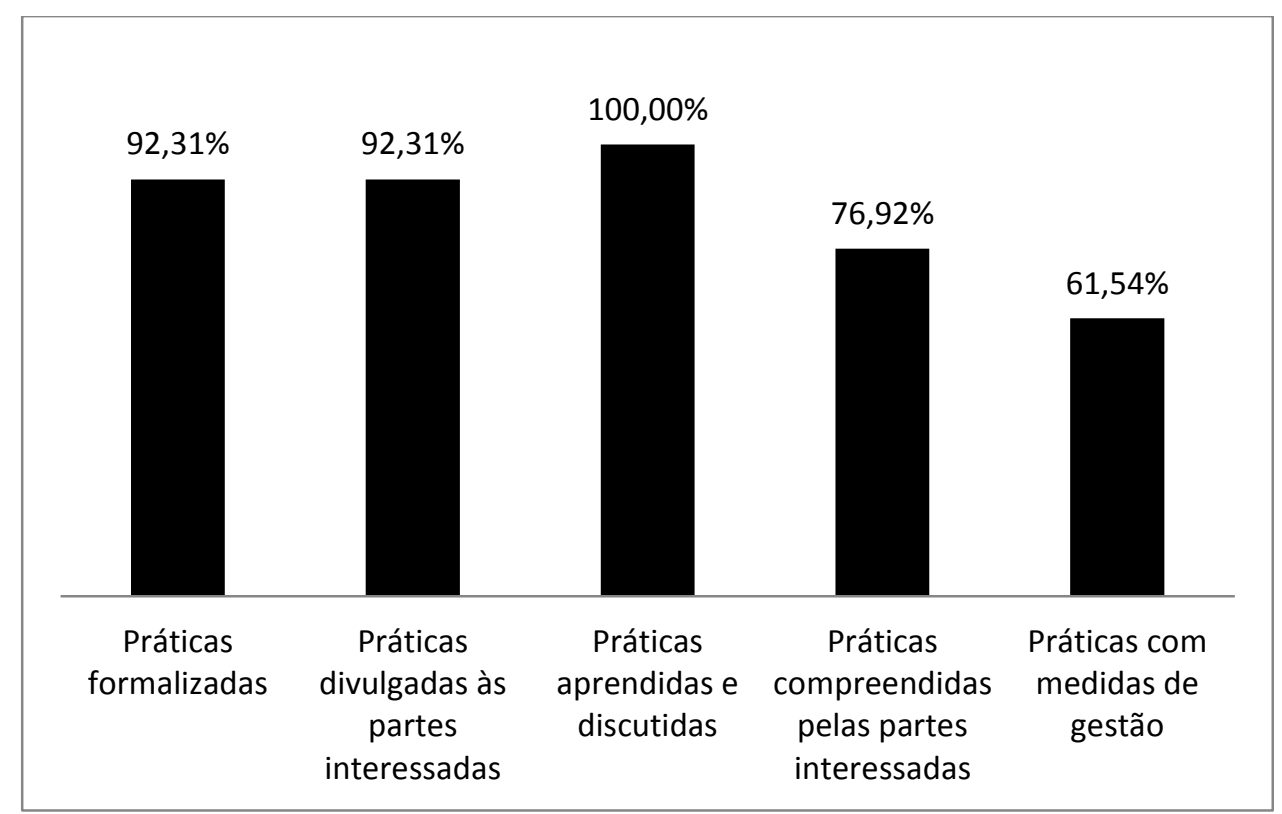

Figura 45 - Maturidade da gestão de fornecedores Fonte: Dados da Pesquisa 
Verifica-se que as práticas que representam essas categorias são primeiramente aprendidas e discutidas (100\%). Em seguida, estão formalizadas e divulgadas às partes interessadas. Depois, são compreendidas pelas partes interessadas $(76,92 \%)$ e por último possuem medidas de gestão $(61,54 \%)$.

\section{FCS da Categoria Gestão do pessoal de TI}

O Quadro 70 referente à categoria Gestão do pessoal de TI possui $28 \mathrm{FCS}$, a maior categoria desta pesquisa. Nessa categoria, o FCS com mais citações pelos entrevistados é

\section{Servidores de TI com competência em TI - Direcionamento.}

Quadro 70 - FCS da gestão do pessoal de TI

\begin{tabular}{|c|c|c|c|}
\hline Código & Categoria: Gestão do pessoal de TI & Freq. & Porcentual \\
\hline Dges0203 & Servidores de TI com competência em TI - Direcionamento & 7 & $26,92 \%$ \\
\hline Dges0210 & Servidores qualificados na TI - Desenvolvimento & 4 & $15,38 \%$ \\
\hline Dges0220 & Rotatividade de TI - Desenvolvimento & 4 & $15,38 \%$ \\
\hline Dges0202 & $\begin{array}{l}\text { Treinamento/desenvolvimento de } \\
\text { colaboradores) em Direcionamento }\end{array}$ & 3 & $11,54 \%$ \\
\hline Dges0208 & 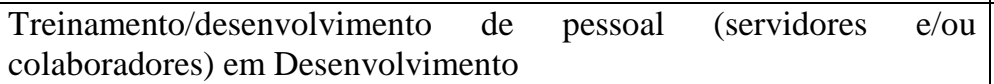 & 3 & $11,54 \%$ \\
\hline Dges0211 & Contratação de pessoas capacitadas - Desenvolvimento & 2 & $7,69 \%$ \\
\hline Dges0218 & Servidores permanentes & 2 & $7,69 \%$ \\
\hline Dges0219 & Rotatividade geral em TI & 2 & $7,69 \%$ \\
\hline Dges0221 & Rotatividade de TI - Entrega & 2 & $7,69 \%$ \\
\hline Dges0224 & Quantidade de servidores suficiente & 2 & $7,69 \%$ \\
\hline Dges0201 & Executivo de TI altamente qualificado - Direcionamento & 1 & $3,85 \%$ \\
\hline Dges0204 & Contratação de pessoas capacitadas - Direcionamento & 1 & $3,85 \%$ \\
\hline Dges0205 & $\begin{array}{l}\text { Analistas de TI com formação na área fim do órgão - } \\
\text { Direcionamento }\end{array}$ & 1 & $3,85 \%$ \\
\hline Dges0206 & $\begin{array}{l}\begin{array}{l}\text { Servidores com domínio padrões e métodos (COBIT) - } \\
\text { Direcionamento }\end{array} \\
\end{array}$ & 1 & $3,85 \%$ \\
\hline Dges0207 & $\begin{array}{l}\text { Executivo de TI insistentes na negociação com fornecedores - } \\
\text { Desenvolvimento }\end{array}$ & 1 & $3,85 \%$ \\
\hline Dges0209 & Equipe capacitada em projetos de TI - Desenvolvimento & 1 & $3,85 \%$ \\
\hline Dges0212 & $\begin{array}{l}\text { Profissionais (servidores e contratados) certificados } \\
\text { Desenvolvimento }\end{array}$ & 1 & $3,85 \%$ \\
\hline Dges0213 & Profissionais (contratados) a disposição do órgão - Desenvolvimento & 1 & $3,85 \%$ \\
\hline Dges0214 & Servidores qualificados na TI - Entrega & 1 & $3,85 \%$ \\
\hline Dges0215 & $\begin{array}{l}\begin{array}{l}\text { Treinamento/desenvolvimento } \\
\text { colaboradores) em Entrega }\end{array} \\
\end{array}$ & 1 & $3,85 \%$ \\
\hline Dges0216 & Pessoas com domínio padrões e métodos (ITIL) - Entrega & 1 & $3,85 \%$ \\
\hline Dges0217 & Clima organizacional & 1 & $3,85 \%$ \\
\hline Dges0222 & Rotatividade das áreas usuárias & 1 & $3,85 \%$ \\
\hline Dges0223 & Retenção de talentos & 1 & $3,85 \%$ \\
\hline Dges0225 & Carreiras estruturas e analistas de TI & 1 & $3,85 \%$ \\
\hline Dges0226 & Servidores comprometidos & 1 & $3,85 \%$ \\
\hline Dges0227 & Metas anuais de desempenho dos colaboradores. & 1 & $3,85 \%$ \\
\hline Dges0228 & $\begin{array}{l}\text { Relacionamento entre servidores de infraestrutura de redes e } \\
\text { terceirizados }\end{array}$ & 1 & $3,85 \%$ \\
\hline
\end{tabular}

Fonte: Dados da pesquisa 
Ainda no Quadro 70 foram citados fatores sobre treinamento e desenvolvimento de pessoal, sendo também referenciado o conhecimento em COBIT e ITIL. A questão sobre clima organizacional apresenta temática relevante nesta categoria, uma vez que reúne fatores como retenção de pessoal, rotatividade, relacionamento entre colaboradores e clima organizacional propriamente dito.

O Quadro 71 mostra a maturidade dos FCS da Gestão do pessoal de TI. Ao total foram 49 respostas para essa categoria. Apenas nove entrevistados informaram práticas não formalizadas.

Quadro 71 - Maturidade dos FCS da gestão do pessoal de TI

\begin{tabular}{|c|c|c|c|c|c|c|c|}
\hline Código & Categoria: Gestão do pessoal de TI & Freq. & 1 & 2 & 3 & 4 & 5 \\
\hline Dges0201 & Executivo de TI altamente qualificado - Direcionamento & 1 & 1 & 1 & 1 & 1 & 1 \\
\hline Dges0202 & $\begin{array}{l}\text { Treinamento/desenvolvimento de pessoal (servidores e/ou } \\
\text { colaboradores) em Direcionamento }\end{array}$ & 3 & 2 & 1 & 2 & 1 & 1 \\
\hline Dges0203 & Servidores de TI com competência em TI - Direcionamento & 7 & 6 & 5 & 7 & 6 & 4 \\
\hline Dges0204 & Contratação de pessoas capacitadas - Direcionamento & 1 & 1 & 1 & 1 & 1 & 1 \\
\hline Dges0205 & $\begin{array}{l}\text { Analistas de TI com formação na área fim do órgão - } \\
\text { Direcionamento }\end{array}$ & 1 & 1 & 1 & 1 & 1 & 0 \\
\hline Dges0206 & $\begin{array}{l}\text { Servidores com domínio padrões e métodos (COBIT) - } \\
\text { Direcionamento }\end{array}$ & 1 & 1 & 0 & 1 & 1 & 0 \\
\hline Dges0207 & $\begin{array}{l}\text { Executivo de TI insistentes na negociação com fornecedores - } \\
\text { Desenvolvimento }\end{array}$ & 1 & 1 & 1 & 1 & 1 & 1 \\
\hline Dges0208 & $\begin{array}{l}\text { Treinamento/desenvolvimento de pessoal (servidores e/ou } \\
\text { colaboradores) em Desenvolvimento }\end{array}$ & 3 & 3 & 2 & 2 & 2 & 2 \\
\hline Dges0209 & Equipe capacitada em projetos de TI - Desenvolvimento & 1 & 1 & 1 & 1 & 1 & 1 \\
\hline Dges0210 & Servidores qualificados na TI - Desenvolvimento & 4 & 3 & 3 & 4 & 3 & 3 \\
\hline Dges0211 & Contratação de pessoas capacitadas - Desenvolvimento & 2 & 2 & 1 & 2 & 1 & 0 \\
\hline Dges0212 & \begin{tabular}{|l}
$\begin{array}{l}\text { Profissionais (servidores e contratados) certificados - } \\
\text { Desenvolvimento }\end{array}$ \\
\end{tabular} & 1 & 1 & 1 & 1 & 0 & 0 \\
\hline Dges0213 & \begin{tabular}{|llllll}
$\begin{array}{l}\text { Profissionais (contratados) } \\
\text { Desenvolvimento }\end{array}$ & a disposição & do órgão - & & \\
\end{tabular} & 1 & 1 & 0 & 0 & 0 & 1 \\
\hline Dges0214 & Servidores qualificados na TI - Entrega & 1 & 0 & 1 & 1 & 1 & 0 \\
\hline Dges0215 & $\begin{array}{l}\text { Treinamento/desenvolvimento de pessoal (servidores e/ou } \\
\text { colaboradores) em Entrega }\end{array}$ & 1 & 1 & 1 & 1 & 1 & 1 \\
\hline Dges0216 & Pessoas com domínio padrões e métodos (ITIL) - Entrega & 1 & 1 & 0 & 1 & 1 & 0 \\
\hline Dges0217 & Clima organizacional & 1 & 1 & 1 & 1 & 1 & 1 \\
\hline Dges0218 & Servidores permanentes & 2 & 0 & 1 & 2 & 1 & 0 \\
\hline Dges0219 & Rotatividade geral em TI & 2 & 1 & 1 & 1 & 1 & 1 \\
\hline Dges0220 & Rotatividade de TI - Desenvolvimento & 4 & 3 & 1 & 3 & 1 & 0 \\
\hline Dges0221 & Rotatividade de TI - Entrega & 2 & 1 & 2 & 2 & 2 & 1 \\
\hline Dges0222 & Rotatividade das áreas usuárias & 1 & 1 & 1 & 1 & 1 & 0 \\
\hline Dges0223 & Retenção de talentos & 1 & 1 & 0 & 1 & 0 & 0 \\
\hline Dges0224 & Quantidade de servidores suficiente & 2 & 2 & 1 & 2 & 1 & 1 \\
\hline Dges0225 & Carreiras estruturas e analistas de TI & 1 & 1 & 1 & 1 & 1 & 1 \\
\hline Dges0226 & Servidores comprometidos & 1 & 1 & 1 & 1 & 1 & 1 \\
\hline Dges0227 & Metas anuais de desempenho dos colaboradores. & 1 & 1 & 1 & 1 & 1 & 1 \\
\hline Dges0228 & $\begin{array}{l}\text { Relacionamento entre servidores de infraestrutura de redes e } \\
\text { terceirizados }\end{array}$ & 1 & 1 & 0 & 1 & 0 & 0 \\
\hline \multicolumn{2}{|l|}{ Total } & 49 & 40 & 31 & 44 & 33 & 23 \\
\hline
\end{tabular}

Fonte: Dados da pesquisa 
$\mathrm{Na}$ Figura 46 é apresentada a maturidade dessa categoria. Verifica-se que primeiramente são aprendidas e discutidas. Em seguida são formalizadas. Depois são compreendidas pelas partes interessadas. Logo são compreendidas pelas partes interessadas. Por último, possuem medidas de gestão.

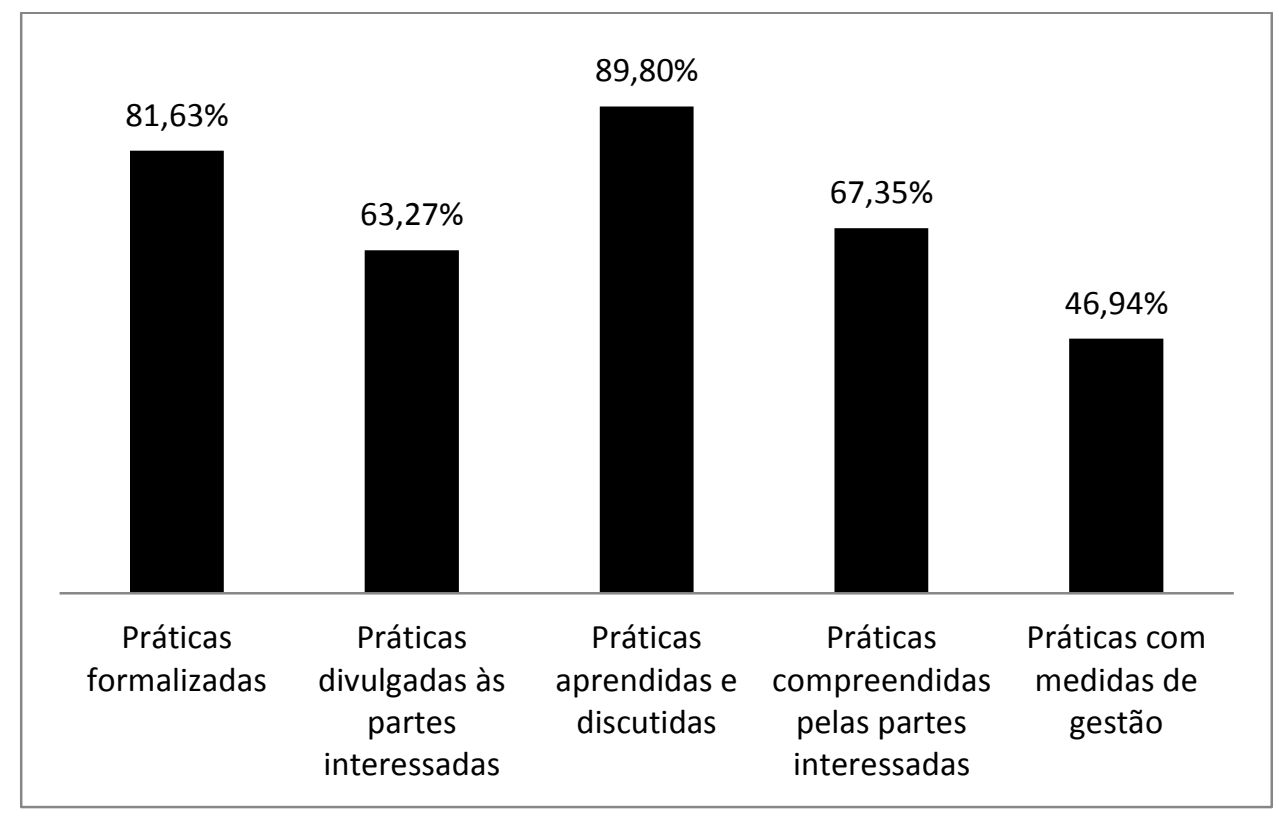

Figura 46 - Maturidade da gestão do pessoal de TI Fonte: Dados da Pesquisa

\section{FCS da Categoria Gestão de Recursos Financeiros e Orçamentários}

O Quadro 72 referente à categoria Gestão de recursos financeiros e orçamentários possui nove FCS. O FCS com mais citações pelos entrevistados é Recursos financeiros suficientes. Os entrevistados que responderam sobre esse fator ou a GTI dispõem de recursos financeiros parcos e de recursos financeiros maiores.

Quadro 72 - FCS da gestão de recursos financeiros e orçamentários

\begin{tabular}{|l|l|c|c|}
\hline Código & Categoria: Gestão de recursos financeiros e orçamentários & Freq. & Porcentual \\
\hline Dges0301 & Recursos financeiros suficientes. & 4 & $15,38 \%$ \\
\hline Dges0302 & Recursos financeiros favoráveis para aquisição e investimentos. & 2 & $7,69 \%$ \\
\hline Dges0309 & $\begin{array}{l}\text { Entendimento de que as necessidades da organização se acomodam } \\
\text { com o ciclo de orçamentação }\end{array}$ & 2 & $7,69 \%$ \\
\hline Dges0303 & Investimentos constantes em infraestrutura tecnológica & 1 & $3,85 \%$ \\
\hline Dges0304 & Questão orçamentária & 1 & $3,85 \%$ \\
\hline Dges0305 & Metodologia de gestão orçamentária & 1 & $3,85 \%$ \\
\hline Dges0306 & Priorização de investimentos entre demandas de TI e projetos & 1 & $3,85 \%$ \\
\hline Dges0307 & Autonomia na execução de investimentos & 1 & $3,85 \%$ \\
\hline Dges0308 & Planejamento de custos & 1 & $3,85 \%$ \\
\hline
\end{tabular}

Fonte: Dados da pesquisa 
O Quadro 73 mostra a maturidade desses FCS com apenas uma resposta informando sobre prática não formalizada.

Quadro 73 - Maturidade dos FCS da gestão de recursos financeiros e orçamentários

\begin{tabular}{|l|l|r|c|c|c|c|c|}
\hline Código & Categoria: Gestão de recursos financeiros e orçamentários & Freq. & $\mathbf{1}$ & $\mathbf{2}$ & $\mathbf{3}$ & $\mathbf{4}$ & $\mathbf{5}$ \\
\hline Dges0301 & Recursos financeiros suficientes. & 4 & 4 & 3 & 4 & 3 & 3 \\
\hline Dges0302 & $\begin{array}{l}\text { Recursos financeiros favoráveis para aquisição e } \\
\text { investimentos. }\end{array}$ & 2 & 1 & 1 & 1 & 1 & 0 \\
\hline Dges0303 & Investimentos constantes em infraestrutura tecnológica & 1 & 1 & 1 & 1 & 1 & 1 \\
\hline Dges0304 & Questão orçamentária & 1 & 1 & 0 & 0 & 0 & 0 \\
\hline Dges0305 & Metodologia de gestão orçamentária & 1 & 1 & 0 & 1 & 0 & 0 \\
\hline Dges0306 & Priorização de investimentos entre demandas de TI e projetos & 1 & 1 & 1 & 1 & 1 & 1 \\
\hline Dges0307 & Autonomia na elecução de investimentos & 1 & 1 & 1 & 1 & 1 & 1 \\
\hline Dges0308 & Planejamento de custos qu organização se & 1 & 1 & 1 & 1 & 1 & 1 \\
\hline Dges0309 & $\begin{array}{l}\text { Entendimento de que as necessidades da } \\
\text { acomodam com o ciclo de orçamentação }\end{array}$ & 2 & 2 & 2 & 2 & 2 \\
\hline Total & & $\mathbf{1 4}$ & $\mathbf{1 3}$ & $\mathbf{1 0}$ & $\mathbf{1 2}$ & $\mathbf{1 0}$ & $\mathbf{9}$ \\
\hline
\end{tabular}

Fonte: Dados da pesquisa

Na Figura 47 é apresentada a maturidade dessa categoria. Primeiramente as práticas são formalizadas $(92,86 \%)$. Em seguida são aprendidas e discutidas. Depois são divulgadas e compreendidas pelas partes interessadas, cada uma com 71,43\%. Por último são medidas.

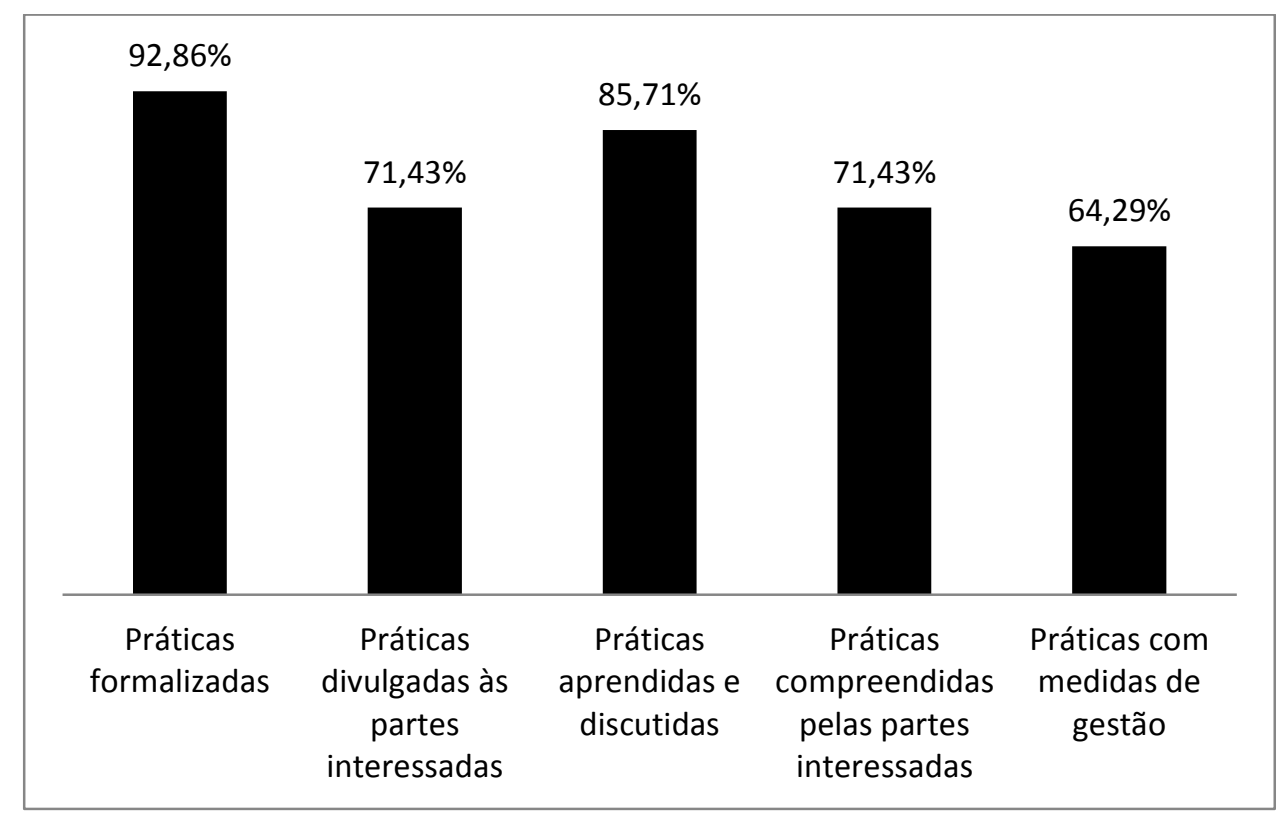

Figura 47 - Maturidade da gestão de recursos financeiros e orçamentários Fonte: Dados da Pesquisa

\section{FCS da Categoria Gestão de contratos}

O Quadro 74 referente à categoria Gestão de contratos possui 11 FCS. Apresentando a maioria das respostas dos entrevistados temos o FCS - Gestão de contratos eficientes. 
Depois aparece o FCS - Atuação diferenciada de serviços prestados por contratadas. Esse fator significa que para cada um dos seguintes serviços: de manutenção/relacionamento com usuário, de desenvolvimento de projetos de administração, de dados ou de business intelligence; um contrato é firmado.

Quadro 74 - FCS da gestão de contratos

\begin{tabular}{|l|l|c|c|}
\hline Código & Categoria: Gestão de contratos & Freq. & Porcentual \\
\hline Dges0401 & Gestão dos contratos eficiente & 3 & $11,54 \%$ \\
\hline Dges0403 & Atuação diferenciada de serviços prestados por contratadas & 2 & $7,69 \%$ \\
\hline Dges0402 & Padrões de aceite bem definidos para a contratada & 1 & $3,85 \%$ \\
\hline Dges0404 & Contrato por objetivos alinhado ao PDTI & 1 & $3,85 \%$ \\
\hline Dges0405 & Contrato com boa caracterização dos serviços & 1 & $3,85 \%$ \\
\hline Dges0406 & $\begin{array}{l}\text { Gestão de contratos com controles eficientes e responsabilidades } \\
\text { distribuídas em diferentes áreas. }\end{array}$ & 1 & $3,85 \%$ \\
\hline Dges0407 & Processo de compras centralizado & 1 & $3,85 \%$ \\
\hline Dges0408 & Contratos baseados em ponto de função (medidas de controle) & 1 & $3,85 \%$ \\
\hline Dges0409 & Processo de contratação bem definido baseada em ITIL & 1 & $3,85 \%$ \\
\hline Dges0410 & Relacionamento com sindicato das empresas de TI & 1 & $3,85 \%$ \\
\hline Dges0411 & Gestão das métricas e ponto de função & 1 & $3,85 \%$ \\
\hline
\end{tabular}

$$
\text { Fonte: Dados da pesquisa }
$$

O Quadro 75 mostra a maturidade desses FCS que totalizam 14 respostas para essa categoria. Apenas uma resposta conta como prática não formalizada.

Quadro 75 - Maturidade dos FCS da gestão de contratos

\begin{tabular}{|l|l|c|c|c|c|c|c|}
\hline Código & Categoria: Gestão de contratos & Freq. & $\mathbf{1}$ & $\mathbf{2}$ & $\mathbf{3}$ & $\mathbf{4}$ & $\mathbf{5}$ \\
\hline Dges0401 & Gestão dos contratos eficiente & 3 & 3 & 2 & 3 & 2 & 1 \\
\hline Dges0402 & Padrões de aceite bem definidos para a contratada & 1 & 1 & 1 & 1 & 1 & 1 \\
\hline Dges0403 & Atuação diferenciada de serviços prestados por contratadas & 2 & 2 & 2 & 2 & 2 & 1 \\
\hline Dges0404 & Contrato por objetivos alinhado ao PDTI & 1 & 1 & 1 & 1 & 1 & 0 \\
\hline Dges0405 & Contrato com boa caracterização dos serviços & 1 & 1 & 1 & 1 & 1 & 0 \\
\hline Dges0406 & $\begin{array}{l}\text { Gestão de contratos com controles eficientes } \\
\text { responsabilidades distribuídas em diferentes áreas. }\end{array}$ & 1 & 1 & 1 & 1 & 1 & 0 \\
\hline Dges0407 & Processo de compras centralizado & 1 & 1 & 1 & 1 & 1 & 1 \\
\hline Dges0408 & Contratos baseados em ponto de função (medidas de controle) & 1 & 1 & 1 & 1 & 1 & 1 \\
\hline Dges0409 & Processo de contratação bem definido baseada em ITIL & 1 & 1 & 1 & 1 & 1 & 1 \\
\hline Dges0410 & Relacionamento com sindicato das empresas de TI & 1 & 0 & 0 & 0 & 0 & 0 \\
\hline Dges0411 & Gestão das métricas e ponto de função & 1 & 1 & 1 & 1 & 1 & 1 \\
\hline Total & & $\mathbf{1 4}$ & $\mathbf{1 3}$ & $\mathbf{1 2}$ & $\mathbf{1 3}$ & $\mathbf{1 2}$ & $\mathbf{7}$ \\
\hline
\end{tabular}

Fonte: Dados da pesquisa

Na Figura 48 é apresentada a maturidade dessa categoria. Primeiramente, com 92,86\% esse "núcleo de sentido" é aprendido e discutido, e formalizado. Depois com as práticas são divulgadas e compreendidas pelas partes interessadas. Por último, possuem medidas de gestão. 


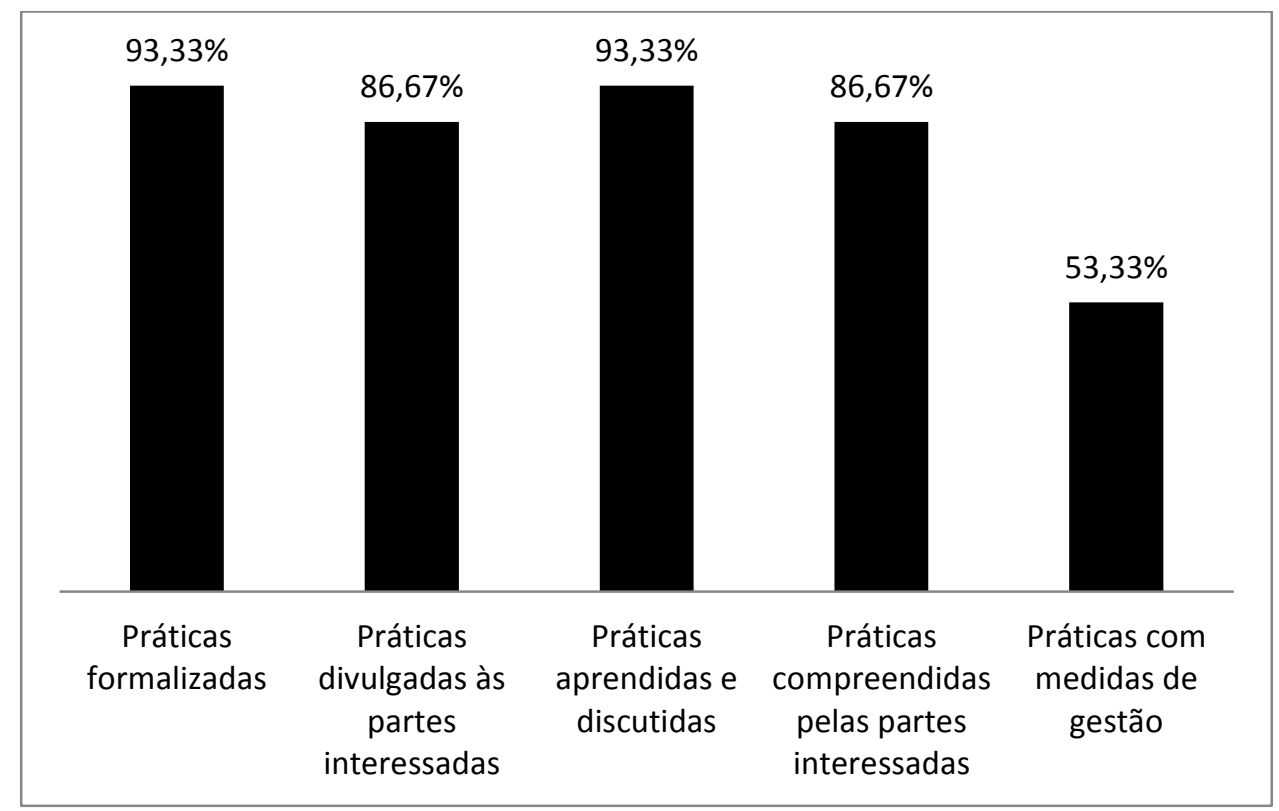

Figura 48 - Maturidade da gestão de contratos

Fonte: Dados da Pesquisa

\section{FCS da Categoria Gestão do conhecimento}

O Quadro 76 referente à categoria Gestão do conhecimento possui três FCS. Cada fator conta com apenas uma citação.

Quadro 76 - FCS da Gestão do conhecimento

\begin{tabular}{|l|l|c|c|}
\hline Código & Categoria: Gestão do conhecimento & Freq. & Porcentual \\
\hline Dges0501 & Gestão do conhecimento & 1 & $3,85 \%$ \\
\hline Dges0502 & Retenção de conhecimento & 1 & $3,85 \%$ \\
\hline Dges0503 & $\begin{array}{l}\text { Disseminação do conhecimento das regras de negócio que foram } \\
\text { implementadas. }\end{array}$ & 1 & $3,85 \%$ \\
\hline
\end{tabular}

Fonte: Dados da pesquisa

O Quadro 77 mostra a maturidade desses FCS. Verifica-se que esta categoria possui a menor maturidade desta pesquisa. A Figura 49 mostra que $100 \%$ desses FCS não estão formalizados, não são divulgados, não são compreendidos e não são medidos.

Quadro 77 - Maturidade dos FCS da gestão do conhecimento

\begin{tabular}{|l|l|r|c|c|c|c|c|}
\hline Código & Categoria: Gestão do conhecimento & Freq. & $\mathbf{1}$ & $\mathbf{2}$ & $\mathbf{3}$ & $\mathbf{4}$ & $\mathbf{5}$ \\
\hline Dges0501 & Gestão do conhecimento & 1 & 0 & 0 & 0 & 0 & 0 \\
\hline Dges0502 & Retenção de conhecimento & 1 & 0 & 0 & 1 & 0 & 0 \\
\hline Dges0503 & $\begin{array}{l}\text { Disseminação do conhecimento das regras de negócio que } \\
\text { foram implementadas. }\end{array}$ & 1 & 0 & 0 & 1 & 0 & 0 \\
\hline Total & & $\mathbf{3}$ & $\mathbf{0}$ & $\mathbf{0}$ & $\mathbf{2}$ & $\mathbf{0}$ & $\mathbf{0}$ \\
\hline
\end{tabular}

Fonte: Dados da pesquisa 


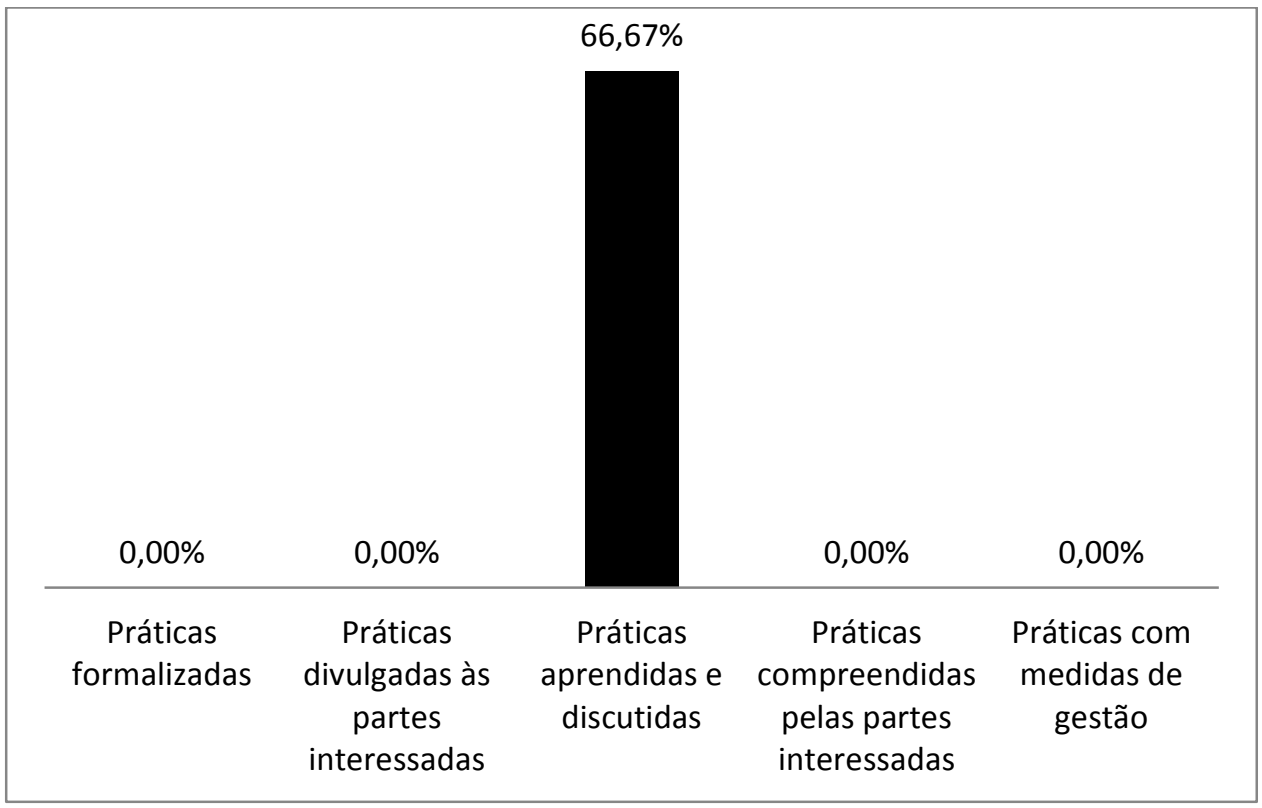

Figura 49 - Maturidade da gestão do conhecimento Fonte: Dados da Pesquisa

\subsubsection{Análise dos FCS em GTI da APF - Subsistema Desenvolvimento}

Neste Subcapítulo são mostrados os FCS de cada uma das três categorias no subsistema Desenvolvimento.

\section{FCS da Categoria Gestão de Processos para Desenvolvimento de Soluções}

O Quadro 78 referente à categoria Gestão de processos para desenvolvimento de soluções possui quatro FCS. O FCS com a maior quantidade de respostas é o Mapeamento de processos que segundo os entrevistados deve ter nível de detalhamento útil para o desenvolvimento de sistemas e o mapeamento deve ser executado. Além disso, segue o FCS Gestão de/por processos que é consequência do mapeamento.

Quadro 78 - FCS da gestão de processos para desenvolvimento de soluções

\begin{tabular}{|l|l|c|c|}
\hline Código & $\begin{array}{l}\text { Categoria: Gestão de processos para desenvolvimento de } \\
\text { soluções }\end{array}$ & Freq. & Porcentual \\
\hline Dese0102 & Mapeamento de processos & 8 & $30,77 \%$ \\
\hline Dese0101 & Gestão de/por processos & 3 & $11,54 \%$ \\
\hline Dese0103 & Gestão de processos em união com o desenvolvimento. & 1 & $3,85 \%$ \\
\hline Dese0104 & Cadeia de Valor & 1 & $3,85 \%$ \\
\hline
\end{tabular}

Fonte: Dados da pesquisa 
O Quadro 79 mostra a maturidade desses FCS, em que apenas um fator não está formalizado.

Quadro 79 - Maturidade dos FCS da gestão de processos para desenvolvimento de soluções

\begin{tabular}{|l|l|r|c|c|c|c|c|}
\hline Código & $\begin{array}{l}\text { Categoria: Gestão de processos para desenvolvimento de } \\
\text { soluções }\end{array}$ & Freq. & $\mathbf{1}$ & $\mathbf{2}$ & $\mathbf{3}$ & $\mathbf{4}$ & $\mathbf{5}$ \\
\hline Dese0101 & Gestão de/por processos & 3 & 3 & 3 & 3 & 3 & 3 \\
\hline Dese0102 & Mapeamento de processos & 8 & 7 & 8 & 7 & 6 & 6 \\
\hline Dese0103 & Gestão de processos em união com o desenvolvimento. & 1 & 1 & 1 & 1 & 1 & 0 \\
\hline Dese0104 & Cadeia de Valor & 1 & 1 & 1 & 1 & 1 & 1 \\
\hline Total & $\mathbf{1 3}$ & $\mathbf{1 2}$ & $\mathbf{1 3}$ & $\mathbf{1 2}$ & $\mathbf{1 1}$ & $\mathbf{1 0}$ \\
\hline
\end{tabular}

Fonte: Dados da pesquisa

$\mathrm{Na}$ Figura 50 é apresentada a maturidade dessa categoria. Primeiramente, essa categoria é $100 \%$ divulgada às partes interessadas. Depois, é formalizada, e aprendida e discutida com $92,31 \%$. Em seguida é compreendida pelas partes interessadas. Por último possuem medidas de gestão.

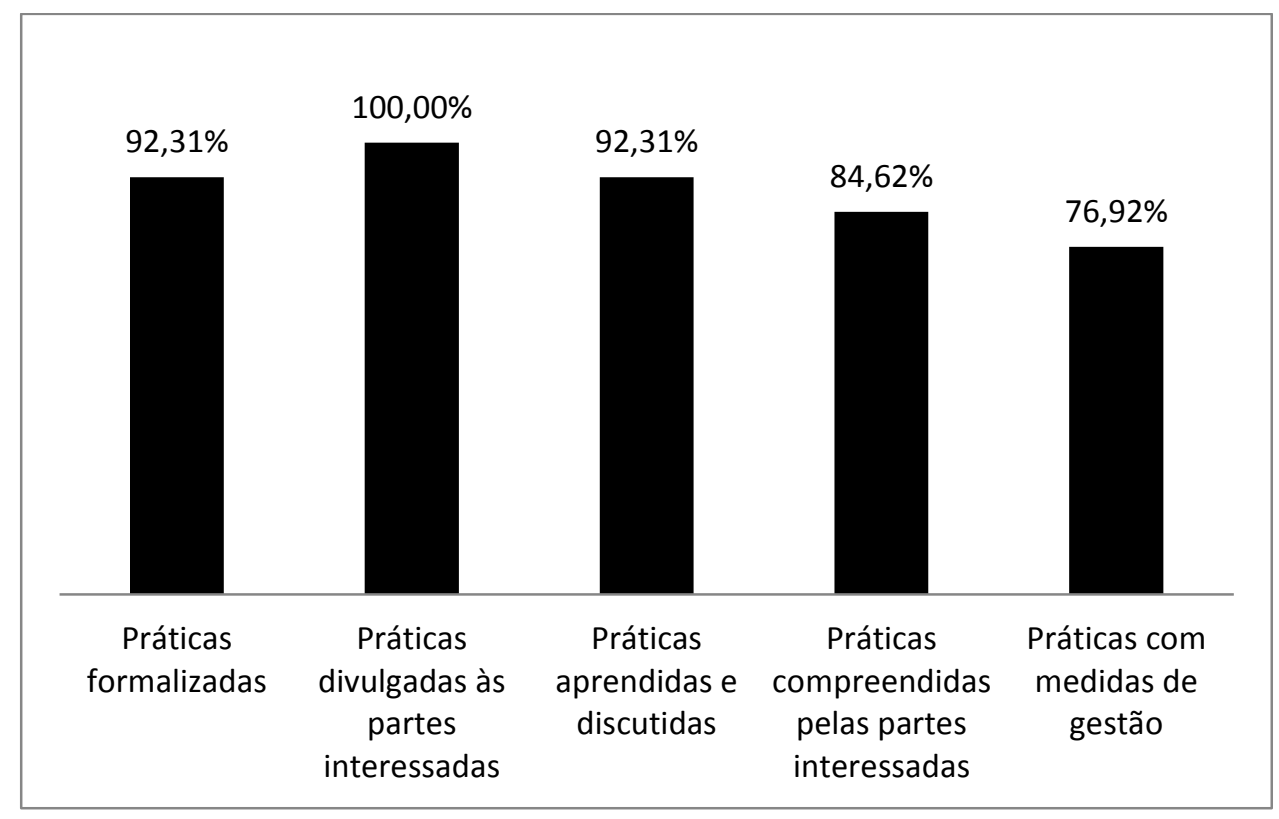

Figura 50 - Maturidade da gestão de processos para desenvolvimento de soluções Fonte: Dados da Pesquisa

FCS da Categoria Gestão de Projetos de TI

O Quadro 80 referente à categoria Gestão de projetos de TI possui 19 FCS. Destacamse o FCS - Gestão de projetos de TI e o FCS - Projetos ágeis, cada um com $15,38 \%$. Os FCS dessa categoria abordam os aspectos essenciais da disciplina da gestão de projetos, tais 
como: planejamento, controle, comunicação e gestão de riscos. Além disso, um aspecto estratégico revelado é a gerencia dos projetos liderado por servidores.

Quadro 80 - FCS da gestão de projetos de TI

\begin{tabular}{|l|l|c|c|}
\hline Código & Categoria: Gestão de projetos de TI & Freq. & Porcentual \\
\hline Dese0201 & Gestão de projetos de TI & 4 & $15,38 \%$ \\
\hline Dese0205 & Projetos ágeis & 4 & $15,38 \%$ \\
\hline Dese0202 & Metodologia de desenvolvimento de projetos detalhada & 2 & $7,69 \%$ \\
\hline Dese0203 & Customização de metodologia de gestão de projetos & 2 & $7,69 \%$ \\
\hline Dese0204 & Busca de metodologias mais adequadas para soluções & 1 & $3,85 \%$ \\
\hline Dese0206 & Foco em simplificação & 1 & $3,85 \%$ \\
\hline Dese0207 & Avaliação de projetos para assegurar a efetividade da solução & 1 & $3,85 \%$ \\
\hline Dese0208 & Cultura de gerenciamento de projetos & 1 & $3,85 \%$ \\
\hline Dese0209 & Planejamento do projeto & 1 & $3,85 \%$ \\
\hline Dese0210 & Gestão de riscos em projetos & 1 & $3,85 \%$ \\
\hline Dese0211 & Gestão da comunicação em projetos & 1 & $3,85 \%$ \\
\hline Dese0212 & Cronograma com prazo limitado para o desenvolvimento & 1 & $3,85 \%$ \\
\hline Dese0213 & Monitoramento e controle do desenvolvimento do projeto & 1 & $3,85 \%$ \\
\hline Dese0214 & Ferramenta para planejamento e controle do portfólio de projetos & 1 & $3,85 \%$ \\
\hline Dese0215 & Acompanhamento da evolução dos projetos & 1 & $3,85 \%$ \\
\hline Dese0216 & Escritório de projetos de TI informando sobre o status dos projetos & 1 & $3,85 \%$ \\
\hline Dese0217 & $\begin{array}{l}\text { Gerente de projetos de TI (acompanhando) participando junto com a a } \\
\text { terceirizada na construção da solução }\end{array}$ & 1 & $3,85 \%$ \\
\hline Dese0218 & Projetos gerenciados por servidores & 1 & $3,85 \%$ \\
\hline Dese0219 & Uso de ferramentas adequadas & 1 & $3,85 \%$ \\
\hline
\end{tabular}

Fonte: Dados da pesquisa

O Quadro 81 mostra a maturidade dos FCS. Apenas duas respostas mostraram práticas não formalizadas num total de 27 respostas.

Quadro 81 - Maturidade dos FCS da gestão de projetos de TI

\begin{tabular}{|l|l|c|c|c|c|c|c|}
\hline Código & Categoria: Gestão de projetos de TI & Freq. & $\mathbf{1}$ & $\mathbf{2}$ & $\mathbf{3}$ & $\mathbf{4}$ & $\mathbf{5}$ \\
\hline Dese0201 & Gestão de projetos de TI & 4 & 4 & 2 & 4 & 3 & 2 \\
\hline Dese0202 & Metodologia de desenvolvimento de projetos detalhada & 2 & 1 & 1 & 2 & 0 & 1 \\
\hline Dese0203 & Customização de metodologia de gestão de projetos & 2 & 2 & 1 & 2 & 1 & 0 \\
\hline Dese0204 & Busca de metodologias mais adequadas para soluções & 1 & 1 & 1 & 1 & 0 & 0 \\
\hline Dese0205 & Projetos ágeis & 4 & 4 & 4 & 4 & 2 & 2 \\
\hline Dese0206 & Foco em simplificação & 1 & 1 & 1 & 1 & 1 & 0 \\
\hline Dese0207 & Avaliação de projetos para assegurar a efetividade da solução & 1 & 0 & 0 & 0 & 0 & 0 \\
\hline Dese0208 & Cultura de gerenciamento de projetos & 1 & 1 & 1 & 1 & 1 & 1 \\
\hline Dese0209 & Planejamento do projeto & 1 & 1 & 0 & 1 & 0 & 0 \\
\hline Dese0210 & Gestão de riscos em projetos & 1 & 1 & 0 & 1 & 0 & 0 \\
\hline Dese0211 & Gestão da comunicação em projetos & 1 & 1 & 0 & 1 & 0 & 0 \\
\hline Dese0212 & Cronograma com prazo limitado para o desenvolvimento & 1 & 1 & 1 & 1 & 1 & 1 \\
\hline Dese0213 & Monitoramento e controle do desenvolvimento do projeto & 1 & 1 & 1 & 1 & 1 & 1 \\
\hline Dese0214 & Ferramenta para planejamento e controle do portfólio de projetos & 1 & 1 & 0 & 1 & 0 & 0 \\
\hline Dese0215 & Acompanhamento da evolução dos projetos & 1 & 1 & 1 & 1 & 1 & 1 \\
\hline Dese0216 & $\begin{array}{l}\text { Escritório de projetos de TI informando sobre o status dos } \\
\text { projetos }\end{array}$ & 1 & 1 & 1 & 1 & 1 & 1 \\
\hline Dese0217 & $\begin{array}{l}\text { Gerente de projetos de TI (acompanhando) participando junto } \\
\text { com a terceirizada na construção da solução }\end{array}$ & 1 & 1 & 1 & 1 & 1 & 1 \\
\hline Dese0218 & Projetos gerenciados por servidores & 1 & 1 & 1 & 1 & 1 & 1 \\
\hline Dese0219 & Uso de ferramentas adequadas & $\mathbf{2 7}$ & $\mathbf{2 5}$ & $\mathbf{1 8}$ & $\mathbf{2 6}$ & $\mathbf{1 5}$ & $\mathbf{1 2}$ \\
\hline Total & & & & 1 \\
\hline
\end{tabular}


Na Figura 51 é apresentada a maturidade geral dessa categoria. Verifica-se a que categoria é primeiramente aprendida e discutida (96,43\%). Em seguida é formalizada. Depois é divulgada às partes interessadas. Logo é compreendida pelas partes interessadas. Por fim, possui medidas de gestão $(46,43 \%)$.

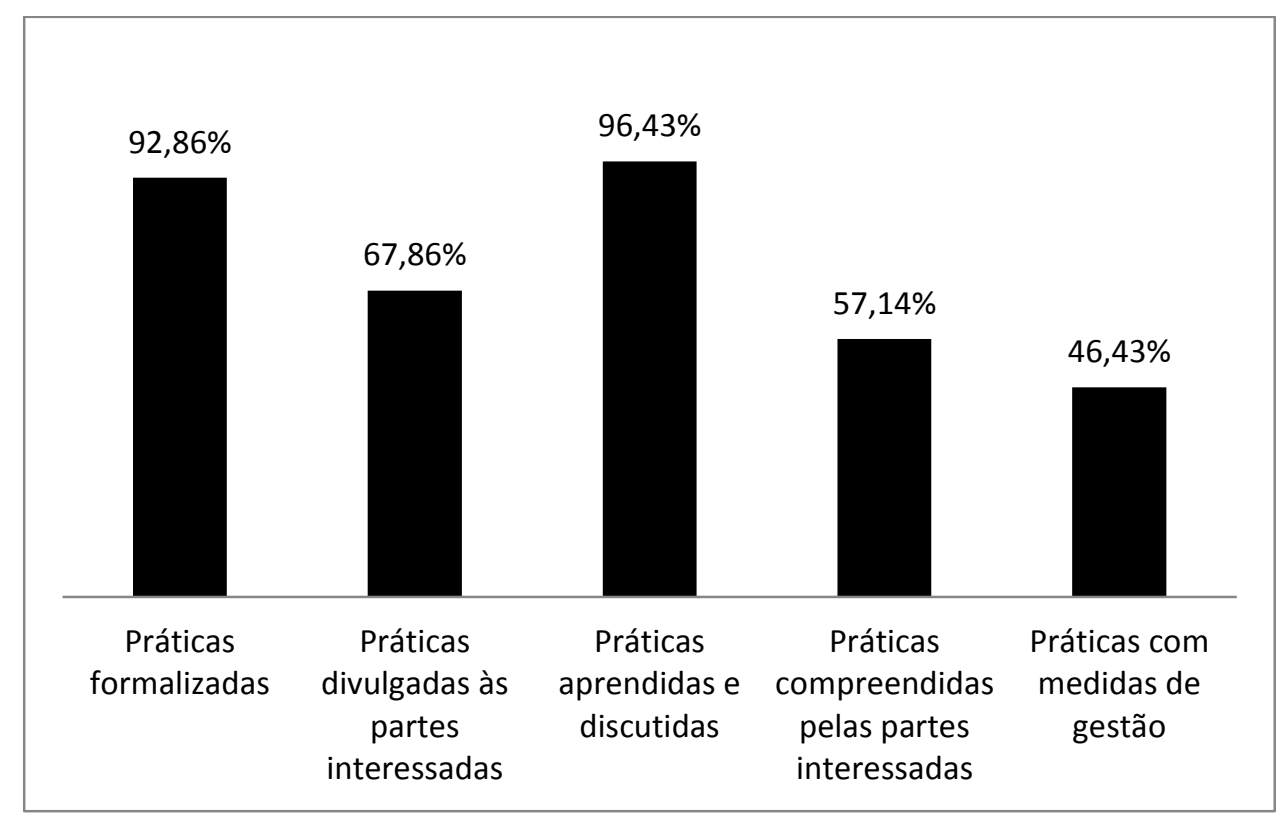

Figura 51 - Maturidade da gestão de projetos de TI Fonte: Dados da pesquisa

\section{FCS da Categoria Princípios para o desenvolvimento de soluções}

O Quadro 82 referente à categoria Princípios para o desenvolvimento de soluções possui 14 FCS. O FCS com mais citações pelos entrevistados é a Padronização da metodologia de desenvolvimento de sistemas. Frisa-se que dois FCS (Dese 0312 e Dese 0313) se relacionam com a categoria Gestão de Demandas e com a categoria Priorização de Projetos de TI. Inicialmente, as demandas são desenhadas por meio da pré-especificação em que o gerente de relacionamento ou analista de negócio auxilia nesse processo. Caso a demanda seja priorizada, o projeto é especificado. 
Quadro 82 - FCS dos princípios para o desenvolvimento de soluções

\begin{tabular}{|l|l|c|c|}
\hline Código & Categoria: Princípios para o desenvolvimento de soluções & Freq. & Porcentual \\
\hline Dese0301 & Padronização da metodologia de desenvolvimento de sistemas & 4 & $15,38 \%$ \\
\hline Dese0302 & Padrões e métodos definidos e praticados & 1 & $3,85 \%$ \\
\hline Dese0303 & Instruções Normativas da Diretoria Especializada & 1 & $3,85 \%$ \\
\hline Dese0304 & Boletins Técnicos da Diretoria Especializada & 1 & $3,85 \%$ \\
\hline Dese0305 & Prova de Conceito & 1 & $3,85 \%$ \\
\hline Dese0306 & $\begin{array}{l}\text { Centralização de informações com o objetivo de diminuir a } \\
\text { quantidade de sistemas }\end{array}$ & 1 & $3,85 \%$ \\
\hline Dese0307 & Integração de sistemas em nível estratégico, tático e operacional & 1 & $3,85 \%$ \\
\hline Dese0308 & Integração dos dados & 1 & $3,85 \%$ \\
\hline Dese0309 & Framework adequado de desenvolvimento & 1 & $3,85 \%$ \\
\hline Dese0310 & Carteira de projetos com padronização & 1 & $3,85 \%$ \\
\hline Dese0311 & $\begin{array}{l}\text { Reuniões de integração das áreas de desenvolvimento, processos e } \\
\text { redes para definição de planos de ação. }\end{array}$ & 1 & $3,85 \%$ \\
\hline Dese0312 & $\begin{array}{l}\text { Pré-especificação de demandas baseada em modelo de negócio e no } \\
\text { processo de trabalho }\end{array}$ & 1 & $3,85 \%$ \\
\hline Dese0313 & Especificação do projeto com detalhamento em caso de uso & 1 & $3,85 \%$ \\
\hline Dese0314 & Gestão da capacidade de TIC para realização de projetos & 1 \\
\hline
\end{tabular}

Fonte: Dados da pesquisa

O Quadro 83 mostra a maturidade desses FCS. Apenas duas de 17 respostas revelam FCS sem formalização.

Quadro 83 - Princípios para o desenvolvimento de soluções

\begin{tabular}{|l|l|c|c|c|c|c|c|}
\hline Código & Categoria: Princípios para o desenvolvimento de soluções & Freq. & $\mathbf{1}$ & $\mathbf{2}$ & $\mathbf{3}$ & $\mathbf{4}$ & $\mathbf{5}$ \\
\hline Dese0301 & Padronização da metodologia de desenvolvimento de sistemas & 4 & 4 & 3 & 4 & 3 & 3 \\
\hline Dese0302 & Padrões e métodos definidos e praticados & 1 & 1 & 1 & 1 & 0 & 0 \\
\hline Dese0303 & Instruções Normativas da Diretoria Especializada & 1 & 1 & 0 & 0 & 0 & 1 \\
\hline Dese0304 & Boletins Técnicos da Diretoria Especializada & 1 & 1 & 0 & 0 & 0 & 1 \\
\hline Dese0305 & Prova de Conceito & 1 & 1 & 1 & 1 & 1 & 1 \\
\hline Dese0306 & $\begin{array}{l}\text { Centralização de informações com o objetivo de diminuir a } \\
\text { quantidade de sistemas }\end{array}$ & 1 & 0 & 0 & 1 & 0 & 0 \\
\hline Dese0307 & $\begin{array}{l}\text { Integração de sistemas em nível estratégico, tático e } \\
\text { operacional }\end{array}$ & 1 & 1 & 1 & 1 & 1 & 0 \\
\hline Dese0308 & Integração dos dados & 1 & 1 & 1 & 1 & 1 & 0 \\
\hline Dese0309 & Framework adequado de desenvolvimento & 1 & 1 & 1 & 1 & 1 & 1 \\
\hline Dese0310 & Carteira de projetos com padronização & 1 & 0 & 0 & 1 & 0 & 0 \\
\hline Dese0311 & $\begin{array}{l}\text { Reuniões de integração das áreas de desenvolvimento, } \\
\text { processos e redes para definição de planos de ação. }\end{array}$ & 1 & 1 & 1 & 0 \\
\hline Dese0312 & $\begin{array}{l}\text { Pré-especificação de demandas baseada em modelo de negócio } \\
\text { e no processo de trabalho }\end{array}$ & 1 & 1 & 1 & 1 & 1 & 1 \\
\hline Dese0313 & Especificação do projeto com detalhamento em caso de uso & 1 & 1 & 1 & 1 & 1 & 1 \\
\hline Dese0314 & Gestão da capacidade de TIC para realização de projetos & 1 & 1 & 1 & 1 & 1 & 1 \\
\hline Total & & $\mathbf{1 7}$ & $\mathbf{1 5}$ & $\mathbf{1 2}$ & $\mathbf{1 5}$ & $\mathbf{1 1}$ & $\mathbf{1 0}$ \\
\hline
\end{tabular}

Fonte: Dados da pesquisa

Na Figura 52 é apresentada a maturidade da categoria. Verifica-se que as práticas que representam essa categoria são primeiramente formalizadas, e aprendidas e discutidas. Em seguida são divulgadas às partes interessadas. Depois são compreendidas pelas partes interessadas. Por último, têm medidas de gestão. 


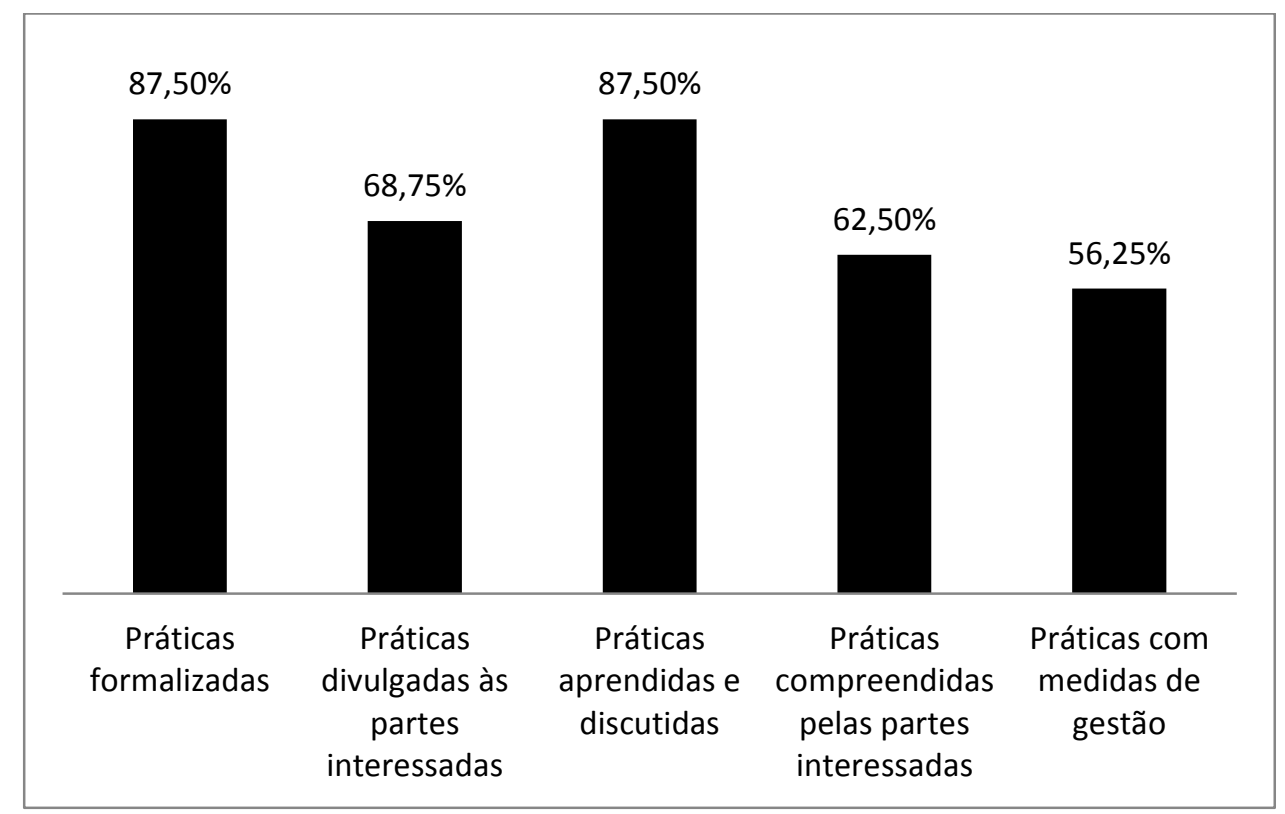

Figura 52 - Maturidade dos princípios para o desenvolvimento de soluções Fonte: Dados da Pesquisa

\subsubsection{Análise dos FCS em GTI da APF - Subsistema Entrega}

Neste Subcapítulo são apresentados os FCS do subsistema Entrega.

\section{FCS da Categoria Gestão de Entregas}

O Quadro 84 referente à categoria Gestão de Entregas possui nove FCS. O FCS com mais citações pelos entrevistados é a Padronização do Fluxo de Entrega. Especificamente dois FCS (Enet0105 e Enet 0106), são altamente relacionados à agregação de valor da TI para o negócio, que é representada pela categoria Direcionadores da Estratégia de TI.

Quadro 84 - FCS da gestão de entregas

\begin{tabular}{|l|l|c|c|}
\hline Código & Categoria: Gestão de entregas & Freq. & Porcentual \\
\hline Enet0108 & Padronização do fluxo de entrega & 2 & $7,69 \%$ \\
\hline Enet0101 & Gestão de Entregas & 1 & $3,85 \%$ \\
\hline Enet0102 & Possibilidade de realizar entregas & 1 & $3,85 \%$ \\
\hline Enet0103 & Velocidade nas entregas & 1 & $3,85 \%$ \\
\hline Enet0104 & Pequenos pacotes de entregáveis & 1 & $3,85 \%$ \\
\hline Enet0105 & Auferição da satisfação com os entregáveis & 1 & $3,85 \%$ \\
\hline Enet0106 & Avaliação dos benefícios das soluções & 1 & $3,85 \%$ \\
\hline Enet0107 & Dar a garantia do que foi solicitado ser entregue com homologação & 1 & $3,85 \%$ \\
\hline Enet0109 & Monitoramento dos entregáveis da produção & 1 & $3,85 \%$ \\
\hline
\end{tabular}

Fonte: Dados da pesquisa 
O Quadro 85 mostra a maturidade dessa categoria. No total, foram dez respostas e apenas duas respostas revelam FCS não formalizados, quais sejam: i) Avaliação dos benefícios das soluções; e ii) Dar a garantia do que foi solicitado ser entregue com homologação. Frisa-se que segundo os entrevistados, esses FCS estão sendo discutidos para serem formalizados na estratégia de TI.

Quadro 85 - Maturidade dos FCS da gestão de entregas

\begin{tabular}{|l|l|r|c|c|c|c|c|}
\hline Código & Categoria: Gestão de entregas & Freq. & $\mathbf{1}$ & $\mathbf{2}$ & $\mathbf{3}$ & $\mathbf{4}$ & $\mathbf{5}$ \\
\hline Enet0101 & Gestão de Entregas & 1 & 1 & 1 & 1 & 1 & 1 \\
\hline Enet0102 & Possibilidade de realizar entregas & 1 & 1 & 0 & 1 & 0 & 0 \\
\hline Enet0103 & Velocidade nas entregas & 1 & 1 & 1 & 1 & 1 & 1 \\
\hline Enet0104 & Pequenos pacotes de entregáveis & 1 & 1 & 0 & 1 & 1 & 0 \\
\hline Enet0105 & Auferição da satisfação com os entregáveis & 1 & 1 & 1 & 1 & 1 & 1 \\
\hline Enet0106 & Avaliação dos benefícios das soluções & 1 & 0 & 1 & 1 & 0 & 0 \\
\hline Enet0107 & $\begin{array}{l}\text { Dar a garantia do que foi solicitado ser entregue com } \\
\text { homologação }\end{array}$ & 1 & 0 & 0 & 1 & 1 & 0 \\
\hline Enet0108 & Padronização do fluxo de entrega & 2 & 2 & 2 & 2 & 2 & 2 \\
\hline Enet0109 & Monitoramento dos entregáveis da produção & 1 & 1 & 1 & 1 & 1 & 1 \\
\hline Total & & $\mathbf{1 0}$ & $\mathbf{8}$ & $\mathbf{7}$ & $\mathbf{1 0}$ & $\mathbf{8}$ & $\mathbf{6}$ \\
\hline
\end{tabular}

Fonte: Dados da pesquisa

Na Figura 53 é apresentada a maturidade dessa categoria. Verifica-se que $100 \%$ da categoria é aprendida e discutida. Em seguida é formalizada e compreendida pelas partes interessadas. Depois é divulgada às partes interessadas. Por último, é mensurada.

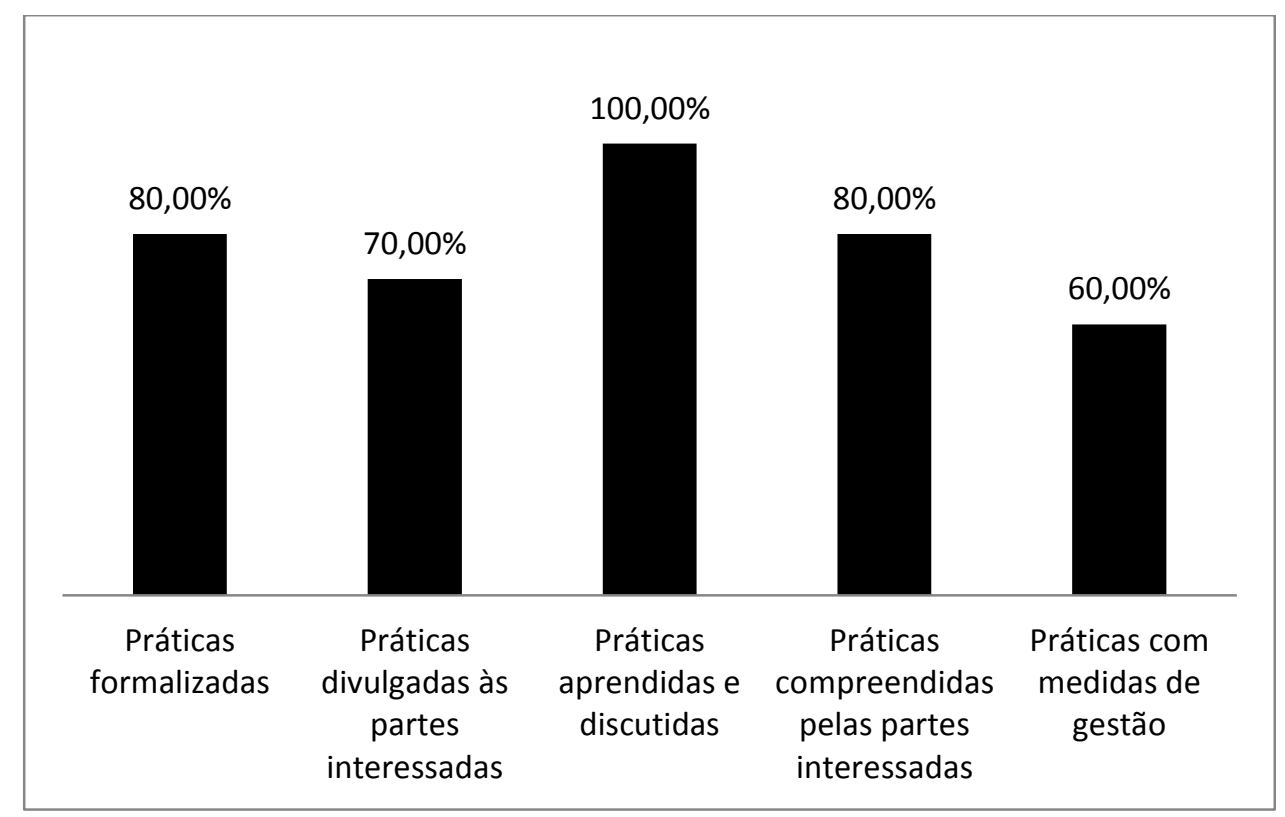

Figura 53 - Maturidade da gestão de entregas

Fonte: Dados da Pesquisa 


\section{FCS da Categoria Gestão de Infraestrutura}

O Quadro 86 referente à categoria Gestão de infraestrutura possui oito FCS. Os FCS com mais citações pelos entrevistados são Renovação periódica de equipamentos e Padronização de infraestutura. Os FCS dessa categoria visam a diminuição de custos para a TI, por meio da renovação, padronização e otimização da infraestrtutura.

Quadro 86 - FCS da gestão de infraestrutura

\begin{tabular}{|l|l|c|c|}
\hline Código & Categoria: Gestão de Infraestrutura & Freq. & Porcentual \\
\hline Enet0204 & Renovação periódica de equipamentos & 2 & $7,69 \%$ \\
\hline Enet0205 & Padronização de infraestutura & 2 & $7,69 \%$ \\
\hline Enet0201 & Infraestrutura tecnológica adequada & 1 & $3,85 \%$ \\
\hline Enet0202 & Infraestrutura própria & 1 & $3,85 \%$ \\
\hline Enet0203 & Tratamento corporativo e integrado de infraestrutura & 1 & $3,85 \%$ \\
\hline Enet0206 & Centro Local de TI & 1 & $3,85 \%$ \\
\hline Enet0207 & Centro de Tecnologia da Informação & 1 & $3,85 \%$ \\
\hline Enet0208 & Diversidade baixa de tecnologia dos sistemas & 1 & $3,85 \%$ \\
\hline
\end{tabular}

Fonte: Dados da pesquisa

O Quadro 87 mostra a maturidade dessa categoria. Nota-se que $100 \%$ dos FCS são formalizados. Depois, $90 \%$ é compreendida e possui medidas de gestão, conforme apresentado na Figura 54. Esse cenário é atípico nesta pesquisa, uma vez que a variável medidas de gestão, geralmente, têm menor porcentual, abaixo apenas dos FCS não formalizados.

Quadro 87 - Maturidade dos FCS da gestão de infraestrutura

\begin{tabular}{|l|l|c|c|c|c|c|c|}
\hline Código & Categoria: Gestão de Infraestrutura & Freq. & $\mathbf{1}$ & $\mathbf{2}$ & $\mathbf{3}$ & $\mathbf{4}$ & $\mathbf{5}$ \\
\hline Enet0201 & Infraestrutura tecnológica adequada & 1 & 1 & 1 & 1 & 1 & 1 \\
\hline Enet0202 & Infraestrutura própria & 1 & 1 & 1 & 1 & 1 & 1 \\
\hline Enet0203 & Tratamento corporativo e integrado de infraestrutura & 1 & 1 & 1 & 1 & 1 & 1 \\
\hline Enet0204 & Renovação periódica de equipamentos & 2 & 2 & 2 & 2 & 2 & 2 \\
\hline Enet0205 & Padronização de infraestutura & 2 & 2 & 2 & 2 & 2 & 2 \\
\hline Enet0206 & Centro Local de TI & 1 & 1 & 0 & 0 & 1 & 0 \\
\hline Enet0207 & Centro de Tecnologia da Informação & 1 & 1 & 0 & 0 & 0 & 1 \\
\hline Enet0208 & Diversidade bai1a de tecnologia dos sistemas & 1 & 1 & 1 & 1 & 1 & 1 \\
\hline Enet0201 & Infraestrutura tecnológica adequada & 1 & 1 & 1 & 1 & 1 & 1 \\
\hline Enet0202 & Infraestrutura própria & 1 & 1 & 1 & 1 & 1 & 1 \\
\hline Enet0203 & Tratamento corporativo e integrado de infraestrutura & 2 & 1 & 1 & 1 & 1 & 1 \\
\hline Enet0204 & Renovação periódica de equipamentos & 2 & 2 & 2 & 2 & 2 \\
\hline Enet0205 & Padronização de infraestutura & 2 & 2 & 2 & 2 & 2 \\
\hline Enet0206 & Centro Local de TI & 1 & 1 & 0 & 0 & 1 & 0 \\
\hline Enet0207 & Centro de Tecnologia da Informação & 1 & 0 & 0 & 0 & 1 \\
\hline Enet0208 & Diversidade bai1a de tecnologia dos sistemas & $\mathbf{1 0}$ & $\mathbf{1 0}$ & $\mathbf{8}$ & $\mathbf{8}$ & $\mathbf{9}$ & $\mathbf{9}$ \\
\hline Total & & & & \\
\hline
\end{tabular}

Fonte: Dados da pesquisa 


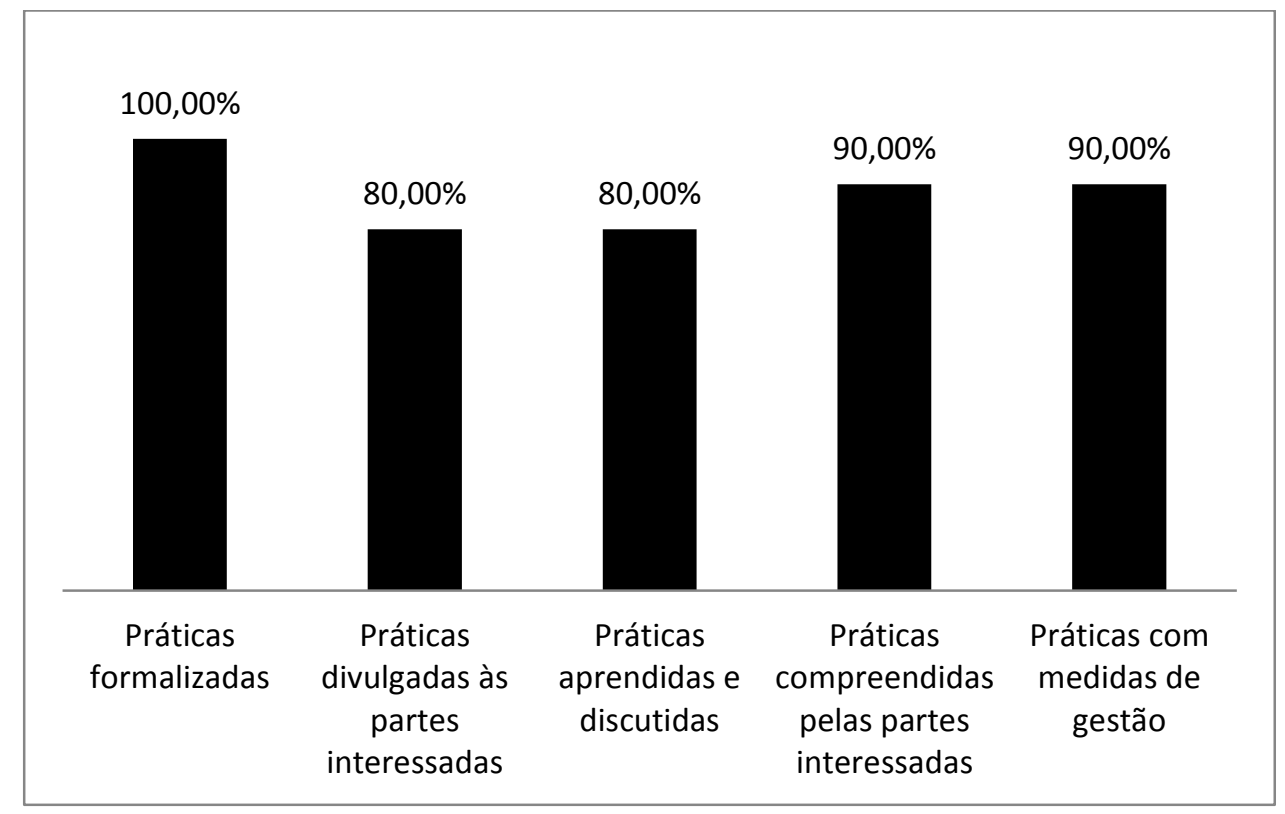

Figura 54 - Maturidade da gestão de infraestrutura Fonte: Dados da Pesquisa

\section{FCS da Categoria Processos de Gestão de Serviços de TI em Desenho do Serviço}

O Quadro 88 referente à categoria Processos de gestão de serviços de TI em desenho do serviço possui nove FCS. Para melhor compreensão, nessa categoria os FCS foram subgrupados em dois: Gerenciamento do nível de serviço e Gestão da segurança da informação. No primeiro grupo constam seis FCS, sendo que Catálogo de serviço possui três citações. No segundo grupo constam três FCS, sendo que Segurança da Informação conta com três citações.

Quadro 88 - FCS dos processos de gestão de serviços de TI em desenho do serviço

\begin{tabular}{|l|l|c|c|}
\hline Código & $\begin{array}{l}\text { Categoria: Processos de gestão de serviços de } \\
\text { TI em desenho do serviço }\end{array}$ & Freq. & Porcentual \\
\hline Enet0310 & Planos de continuidade & 1 & $3,85 \%$ \\
\hline Gerenciamento do nível de serviço & 2 & $7,69 \%$ \\
\hline Enet0301 & $\begin{array}{l}\text { Acordo de nível de serviço (service level } \\
\text { agreement) }\end{array}$ & 1 & $3,85 \%$ \\
\hline Enet0302 & Gestão da ordem de serviço & 1 & $3,85 \%$ \\
\hline Enet0303 & $\begin{array}{l}\text { Níveis de serviço existem e são claros, mas não } \\
\text { são formalizados em acordos de níveis de serviço. }\end{array}$ & 1 & $3,85 \%$ \\
\hline Enet0304 & Priorização no atendimento por hierarquia & 1 & $3,85 \%$ \\
\hline Enet0305 & $\begin{array}{l}\text { Disponibilidade dos serviços e performance tempo } \\
\text { de resposta }\end{array}$ & 3 & $11,54 \%$ \\
\hline Enet0306 & Catálogo de serviço (bem definido) & 3 & $11,54 \%$ \\
\hline Gestão da segurança da informação & 1 & $3,85 \%$ \\
\hline Enet0307 & Segurança da informação & 1 & $3,85 \%$ \\
\hline Enet0308 & Gestão de segurança de sistemas e infraestrutura & \\
\hline Enet0309 & Backup externo & & \\
\hline
\end{tabular}

Fonte: Dados da pesquisa 
O Quadro 89 mostra a maturidade dessa categoria. No total, foram 15 respostas, em que apenas três FCS não são formalizadas.

Quadro 89 - Maturidade dos FCS dos processos de gestão de serviços de TI em desenho do serviço

\begin{tabular}{|c|c|c|c|c|c|c|c|}
\hline Código & $\begin{array}{l}\text { Categoria: Processos de gestão de serviços de TI em } \\
\text { desenho do serviço }\end{array}$ & Freq. & 1 & 2 & 3 & 4 & 5 \\
\hline Enet0310 & Planos de continuidade & 1 & 1 & 1 & 0 & 0 & 1 \\
\hline \multicolumn{8}{|c|}{ Gerenciamento do nível de serviço } \\
\hline Enet0301 & Acordo de Nível de Serviço (service level agreement) & 2 & 1 & 0 & 2 & 1 & 1 \\
\hline Enet0302 & Gestão da ordem de serviço & 1 & 1 & 1 & 1 & 1 & 1 \\
\hline Enet0303 & $\begin{array}{l}\text { Níveis de serviço elistem e são claros, mas não são } \\
\text { formalizados em acordos de níveis de serviço. }\end{array}$ & 1 & 0 & 1 & 1 & 0 & 0 \\
\hline Enet0304 & Priorização no atendimento por hierarquia & 1 & 1 & 1 & 1 & 1 & 1 \\
\hline Enet0305 & Disponibilidade dos serviços e performance tempo de resposta & 1 & 1 & 1 & 1 & 1 & 0 \\
\hline Enet0306 & Catálogo de serviço (bem definido) & 3 & 3 & 1 & 1 & 1 & 1 \\
\hline \multicolumn{8}{|c|}{ Gestão da segurança da informação } \\
\hline Enet0307 & Segurança da informação & 3 & 3 & 2 & 2 & 3 & 3 \\
\hline Enet0308 & Gestão de segurança de sistemas e infraestrutura & 1 & 0 & 0 & 1 & 1 & 0 \\
\hline Enet0309 & Backup externo & 1 & 1 & 1 & 1 & 1 & 1 \\
\hline \multicolumn{2}{|l|}{ Total } & 15 & 12 & 9 & 11 & 10 & 9 \\
\hline
\end{tabular}

Fonte: Dados da pesquisa

Na Figura 55, verifica-se que primeiramente a categoria é formalizada. Em seguida é aprendida e discutida. Depois é compreendida pelas partes interessadas. Por último, possui medidas de gestão.

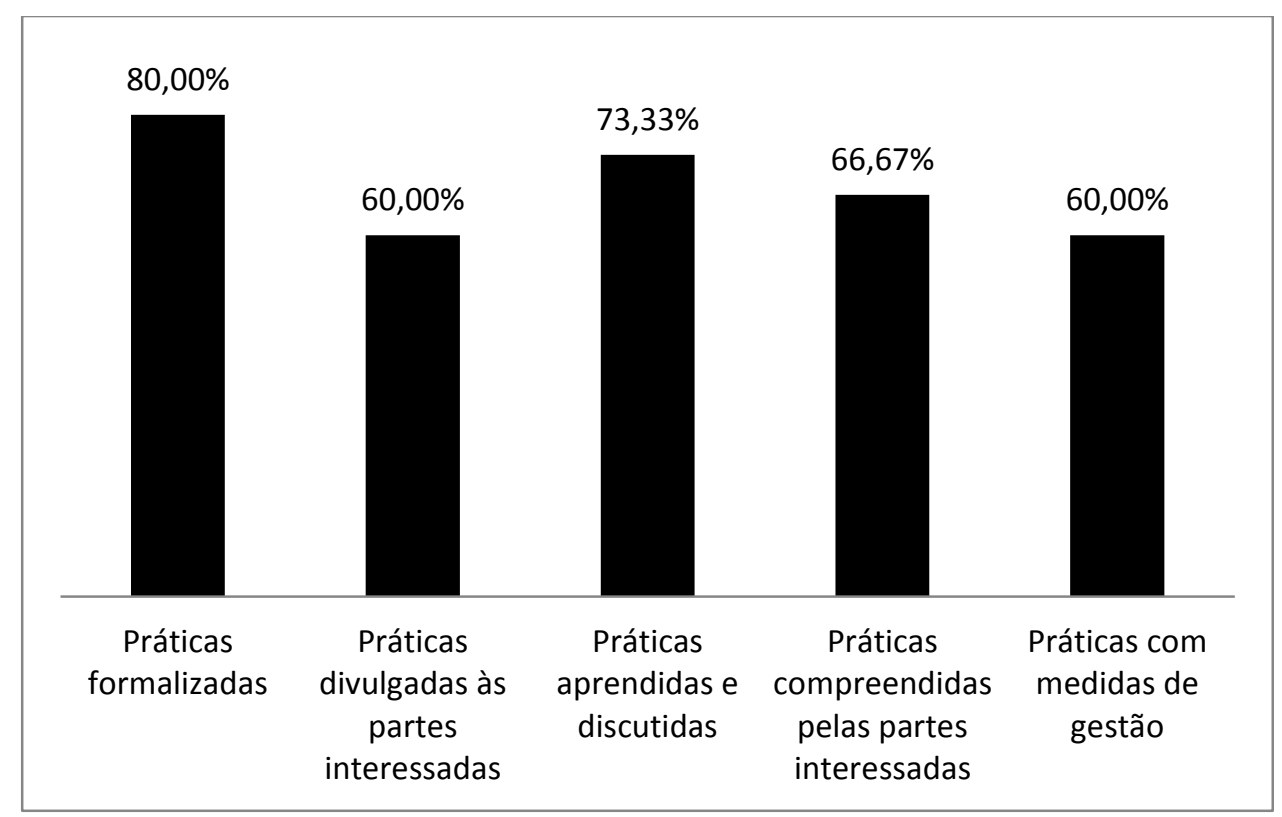

Figura 55 - Maturidade dos processos de gestão de serviços de TI em desenho do serviço Fonte: Dados da Pesquisa 


\section{FCS da Categoria Processos de Gestão de Serviços de TI em Transição de Serviços}

O Quadro 90 referente à categoria Processos de gestão de serviços de TI em transição de serviços possui dois FCS, quais sejam: Gestão de Mudança e Gestão de Configuração. Sendo que Gestão da Mudança teve a maioria nas citações.

Quadro 90 - FCS dos processos de gestão de serviços de TI em transição de serviços

\begin{tabular}{|l|l|c|c|}
\hline Código & $\begin{array}{l}\text { Categoria: Processos de gestão de serviços de TI em transição de } \\
\text { serviços }\end{array}$ & Freq. & Porcentual \\
\hline Enet0501 & Gestão de mudança & 5 & $19,23 \%$ \\
\hline Enet0502 & Gestão de configuração & 3 & $11,54 \%$ \\
\hline
\end{tabular}

Fonte: Dados da pesquisa

O Quadro 91 mostra a maturidade dessa categoria, em que apenas um FCS teve uma citação informando conteúdo não formalizado.

Quadro 91 - Maturidade dos FCS dos processos de gestão de serviços de TI em transição de serviços

\begin{tabular}{|l|l|r|r|r|r|r|r|}
\hline Código & $\begin{array}{l}\text { Categoria: Processos de gestão de serviços de TI em } \\
\text { transição de serviços }\end{array}$ & Freq. & $\mathbf{1}$ & $\mathbf{2}$ & $\mathbf{3}$ & $\mathbf{4}$ & $\mathbf{5}$ \\
\hline Enet0501 & Gestão de mudança & 5 & 4 & 4 & 4 & 4 & 4 \\
\hline Enet0502 & Gestão de configuração & 3 & 3 & 2 & 2 & 3 & 2 \\
\hline Total & $\mathbf{8}$ & $\mathbf{7}$ & $\mathbf{6}$ & $\mathbf{6}$ & $\mathbf{7}$ & $\mathbf{6}$ \\
\hline
\end{tabular}

Fonte: Dados da pesquisa

A Figura 56 apresenta a maturidade dessa categoria.

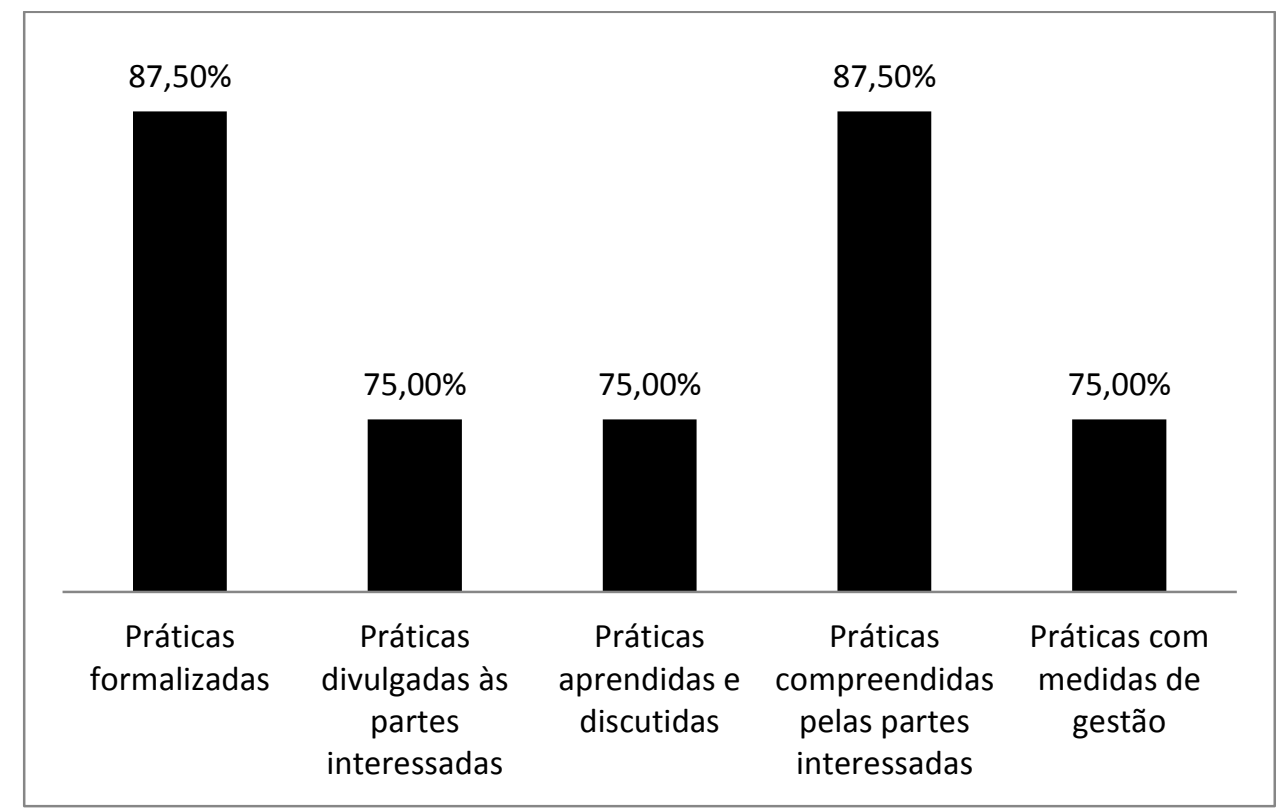

Figura 56 - Maturidade dos processos de gestão de serviços de TI em transição de serviços Fonte: Dados da Pesquisa 
Verifica-se a categoria é primeiramente formalizada e compreendida pelas partes interessadas (87,50\%). Depois é divulgada, mensurada, e aprendida e discutida (75\%).

\section{FCS da Categoria Processos de Gestão de Serviços de TI em Operação do Serviço}

O Quadro 92 referente à categoria Processos de gestão de serviços de TI em operação do serviço possui nove FCS. O FCS com mais citações pelos entrevistados é a Gestão de incidentes. Para melhor compreensão, nessa categoria os FCS foram subgrupados em dois: $i$ ) Gestão de incidentes; e ii) Gestão do cumprimento de requisições de serviços.

Quadro 92 - FCS dos processos de gestão de serviços de TI em operação do serviço

\begin{tabular}{|l|l|c|c|}
\hline Código & $\begin{array}{l}\text { Categoria: Processos de gestão de serviços de TI em operação do } \\
\text { serviço }\end{array}$ & Freq. & Porcentual \\
\hline Enet0404 & Gestão de problemas & 1 & $3,85 \%$ \\
\hline Gestão de incidentes & 4 & $15,38 \%$ \\
\hline Enet0401 & Gestão de incidentes & 1 & $3,85 \%$ \\
\hline Enet0402 & $\begin{array}{l}\text { Processo de gestão de incidentes atendidos juntamente com o service } \\
\text { desk. Todos com alto nível de problema. }\end{array}$ & 1 & $3,85 \%$ \\
\hline Enet0403 & $\begin{array}{l}\text { Monitoramento dos serviços e equipamentos sendo proativos na } \\
\text { identificação dos incidentes. }\end{array}$ & \multirow{2}{|c|}{1} \\
\hline Gestão do cumprimento de requisições de serviços & 3 & $11,54 \%$ \\
\hline Enet0405 & $\begin{array}{l}\text { Gestão da qualidade das entregas de tangíveis e módulos de sistemas } \\
\text { funcionais }\end{array}$ & 1 & $3,85 \%$ \\
\hline Enet0406 & Validação da entrega & 1 & $3,85 \%$ \\
\hline Enet0407 & $\begin{array}{l}\text { Fornecimento de serviços de TI na quantidade e na performance } \\
\text { exigida pelo Órgão. }\end{array}$ & 1 & $3,85 \%$ \\
\hline Enet0408 & Testes das soluções de TI & 1 & $3,85 \%$ \\
\hline Enet0409 & Tempestividade quanto à qualidade da especificação & \\
\hline
\end{tabular}

Fonte: Dados da pesquisa

O Quadro 93 mostra a maturidade dessa categoria, que teve um total de 14 respostas. Nenhuma das respostas sinalizou FCS não formalizados. 
Quadro 93 - Maturidade dos FCS dos processos de gestão de serviços de TI em operação do serviço

\begin{tabular}{|c|c|c|c|c|c|c|c|}
\hline Código & $\begin{array}{l}\text { Categoria: Processos de gestão de serviços de TI em } \\
\text { operação do serviço }\end{array}$ & Freq. & 1 & 2 & 3 & 4 & 5 \\
\hline Enet0404 & Gestão de problemas & 1 & 1 & 1 & 1 & 1 & 1 \\
\hline \multicolumn{8}{|c|}{ Gestão de incidentes } \\
\hline Enet0401 & Gestão de incidentes & 4 & 4 & 3 & 2 & 4 & 3 \\
\hline Enet0402 & $\begin{array}{l}\text { Processo de gestão de incidentes atendidos juntamente com o } \\
\text { service desk. Todos com alto nível de problema. }\end{array}$ & 1 & 1 & 1 & 1 & 1 & 1 \\
\hline Enet0403 & $\begin{array}{l}\text { Monitoramento dos serviços e equipamentos sendo proativos } \\
\text { na identificação dos incidentes. }\end{array}$ & 1 & 1 & 1 & 1 & 1 & 1 \\
\hline \multicolumn{8}{|c|}{ Gestão do cumprimento de requisições de serviços } \\
\hline Enet0405 & $\begin{array}{l}\text { Gestão da qualidade das entregas de tangíveis e módulos de } \\
\text { sistemas funcionais }\end{array}$ & 3 & 3 & 2 & 3 & 2 & 1 \\
\hline Enet0406 & Validação da entrega & 1 & 1 & 1 & 1 & 1 & 1 \\
\hline Enet0407 & $\begin{array}{l}\text { Fornecimento de serviços de TI na quantidade e na } \\
\text { performance exigida pelo Órgão. }\end{array}$ & 1 & 1 & 1 & 1 & 1 & 1 \\
\hline Enet0408 & Testes das soluções de TI & 1 & 1 & 0 & 1 & 1 & 0 \\
\hline Enet0409 & Tempestividade quanto a qualidade da especificação & 1 & 1 & 1 & 1 & 1 & 1 \\
\hline \multicolumn{2}{|l|}{ Total } & 14 & 14 & 11 & 12 & 13 & 10 \\
\hline
\end{tabular}

Fonte: Dados da pesquisa

A Figura 57 mostra a maturidade da categoria. Verifica-se que depois de formalizadas, as práticas referentes aos são compreendidas pelas partes interessadas (92,86\%). Em seguida são aprendidas e discutidas $(85,71 \%)$. Logo, são divulgadas às partes interessadas $(78,13 \%)$. Por último, possui medidas de gestão $(71,43 \%)$.

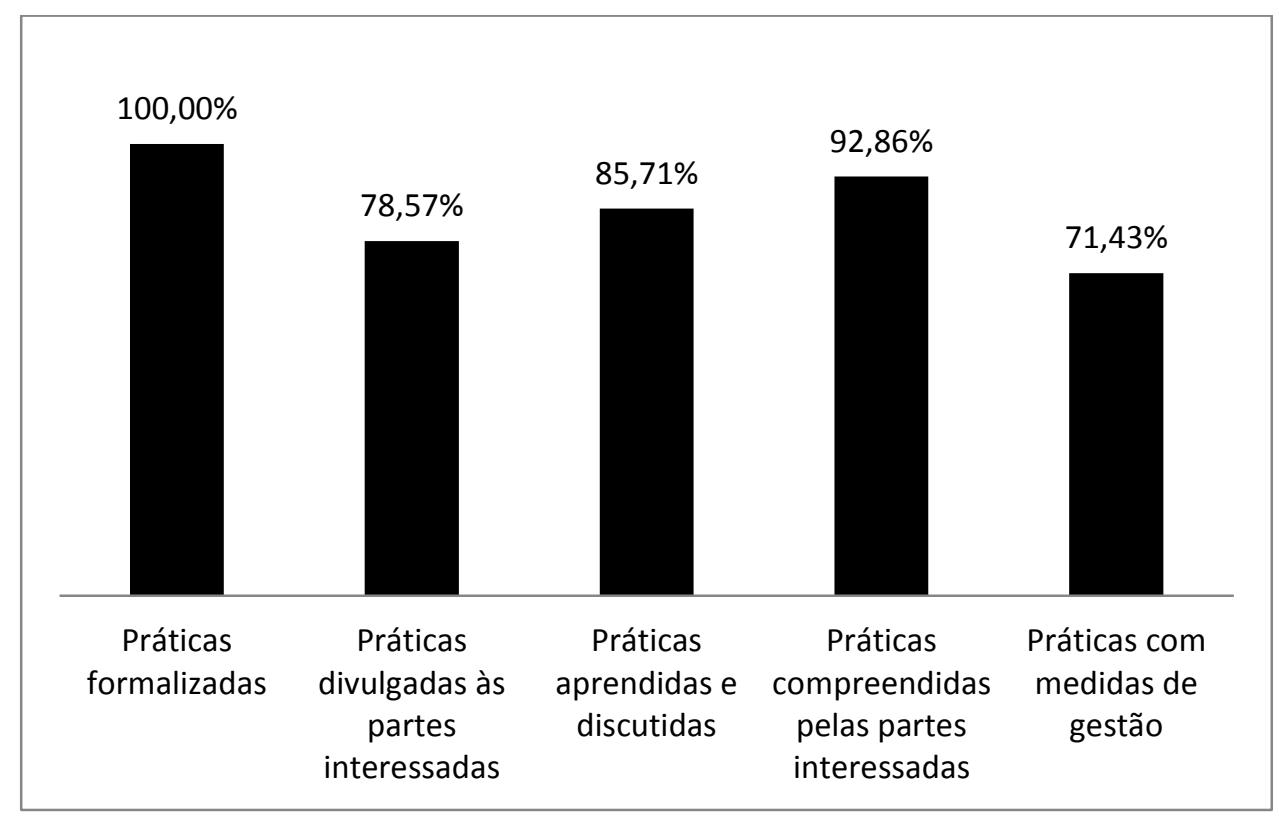

Figura 57 - Maturidade dos processos de gestão de serviços de TI em operação do serviço Fonte: Dados da Pesquisa 


\section{FCS da Categoria Gestão de Serviços}

O Quadro 94 referente à categoria Gestão de serviços possui doze FCS. Todos os FCS possuem apenas uma citação. Os temas monitoração e controle têm parte relevante na formação desses FCS.

Quadro 94 - FCS da gestão de serviços

\begin{tabular}{|l|l|c|c|}
\hline Código & Categoria: Gestão de serviços & Freq. & Porcentual \\
\hline Enet0601 & $\begin{array}{l}\text { Gestão de serviços (baseada em métricas, correção de problemas, } \\
\text { incentivo ao fornecedor para melhores serviços) }\end{array}$ & 1 & $3,85 \%$ \\
\hline Enet0602 & Processo de subida hot deploy & 1 & $3,85 \%$ \\
\hline Enet0603 & Estabelecimento de níveis de desempenho dos serviços de TI & 1 & $3,85 \%$ \\
\hline Enet0604 & Monitoramento do desempenho dos serviços de TI & 1 & $3,85 \%$ \\
\hline Enet0605 & Conhecimento dos serviços que são geridos & 1 & $3,85 \%$ \\
\hline Enet0606 & $\begin{array}{l}\text { Acompanhamento e controle de uso dos softwares das áreas } \\
\text { finalísticas }\end{array}$ & 1 & $3,85 \%$ \\
\hline Enet0607 & Monitoração constante & 1 & $3,85 \%$ \\
\hline Enet0608 & Controles de softwares por meio de sistemas (gestão de riscos) & 1 & $3,85 \%$ \\
\hline Enet0609 & Manutenção dos sistemas corporativos desenvolvidos pela TI & 1 & $3,85 \%$ \\
\hline Enet0610 & Gerência de serviços & 1 & $3,85 \%$ \\
\hline Enet0611 & Divisão de apoio (usabilidade e acessibilidade) & 1 & $3,85 \%$ \\
\hline Enet0612 & Setores de TI das unidades de negócio & $35 \%$ \\
\hline
\end{tabular}

Fonte: Dados da pesquisa

O Quadro 95 mostra a maturidade dessa categoria. No total, foram 12 respostas, em que apenas três FCS se mostraram com práticas não formalizadas.

Quadro 95 - Maturidade dos FCS da gestão de serviços

\begin{tabular}{|l|l|r|c|c|c|c|c|}
\hline Código & Categoria: Gestão de serviços & Freq. & $\mathbf{1}$ & $\mathbf{2}$ & $\mathbf{3}$ & $\mathbf{4}$ & $\mathbf{5}$ \\
\hline Enet0601 & $\begin{array}{l}\text { Gestão de serviços (baseada em métricas, correção de } \\
\text { problemas, incentivo ao fornecedor para melhores serviços) }\end{array}$ & 1 & 1 & 1 & 1 & 1 & 1 \\
\hline Enet0602 & Processo de subida hot deploy & 1 & 1 & 1 & 1 & 1 & 1 \\
\hline Enet0603 & Estabelecimento de níveis de desempenho dos serviços de TI & 1 & 0 & 0 & 0 & 0 & 0 \\
\hline Enet0604 & Monitoramento do desempenho dos serviços de TI & 1 & 1 & 1 & 1 & 1 & 1 \\
\hline Enet0605 & Conhecimento dos serviços que são geridos & 1 & 1 & 0 & 0 & 0 & 0 \\
\hline Enet0606 & $\begin{array}{l}\text { Acompanhamento e controle de uso dos softwares das áreas } \\
\text { finalísticas }\end{array}$ & 1 & 1 & 1 & 1 & 1 & 1 \\
\hline Enet0607 & Monitoração constante & 1 & 1 & 1 & 0 & 1 & 0 \\
\hline Enet0608 & Controles de softwares por meio de sistemas (gestão de riscos) & 1 & 0 & 1 & 1 & 1 & 1 \\
\hline Enet0609 & Manutenção dos sistemas corporativos desenvolvidos pela TI & 1 & 1 & 1 & 1 & 1 & 1 \\
\hline Enet0610 & Gerência de serviços & 1 & 0 & 0 & 0 & 0 & 0 \\
\hline Enet0611 & Divisão de apoio (usabilidade e acessibilidade) & 1 & 1 & 1 & 1 & 1 & 1 \\
\hline Enet0612 & Setores de TI das unidades de negócio & 1 & 1 & 0 & 0 & 1 & 0 \\
\hline Total & & $\mathbf{1 2}$ & $\mathbf{9}$ & $\mathbf{8}$ & $\mathbf{7}$ & $\mathbf{9}$ & $\mathbf{7}$ \\
\hline
\end{tabular}

Fonte: Dados da pesquisa

Na Figura 58 é apresentada a maturidade da categoria. Verifica-se que as práticas que representam essa categoria são formalizadas e compreendidas pelas partes interessadas $(75 \%)$. 
Em seguida estão divulgadas às partes interessadas. Depois são compreendidas aprendidas e discutidas, e possuem medidas de gestão $(58,33 \%)$.

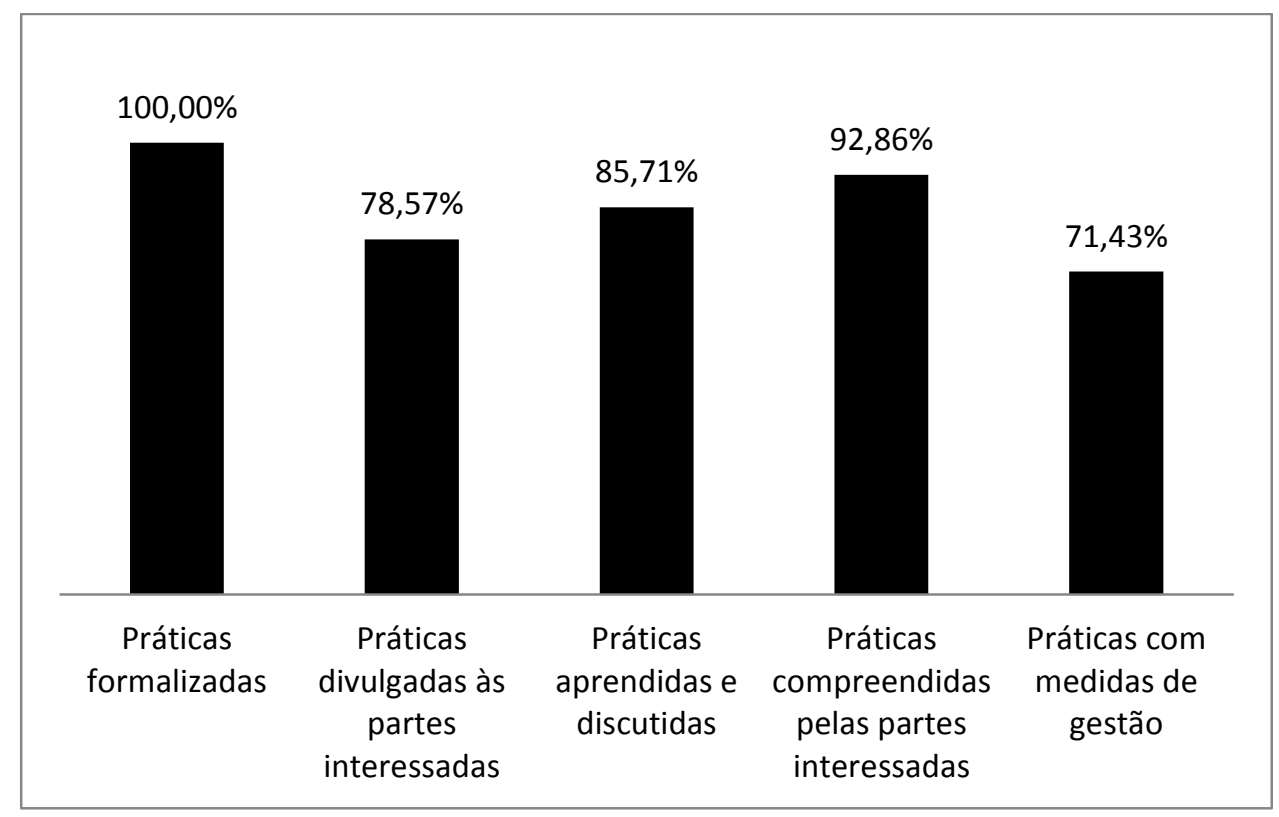

Figura 58 - Maturidade da gestão de serviços

Fonte: Dados da Pesquisa

\section{FCS da Categoria Central de Serviços}

O Quadro 96 referente à categoria Central de Serviços possui quatro FCS. O FCS com mais citações pelos entrevistados é a Central de serviço unificada. Os temas desses FCS focam em help desk e no service desk, em que o service desk teve o maior número de citações, evidenciando certa maturidade na Central de Serviços.

Quadro 96 - FCS da central de serviços

\begin{tabular}{|l|l|c|c|}
\hline Código & Categoria: Central de serviços & Freq. & Porcentual \\
\hline Enet0701 & Central de serviços unificada & 3 & $11,54 \%$ \\
\hline Enet0702 & Service desk & 2 & $7,69 \%$ \\
\hline Enet0703 & $\begin{array}{l}\text { Função service desk do ITIL com suporte de ferramentas para } \\
\text { gerenciar os incidentes }\end{array}$ & 1 & $3,85 \%$ \\
\hline Enet0704 & Conhecimento do processo de tratamento de incidentes (help desk) & 1 & $3,85 \%$ \\
\hline
\end{tabular}
Fonte: Dados da pesquisa

O Quadro 97 mostra a maturidade dos FCS. No total, foram sete respostas sobre os FCS, em que apenas um FCS se mostrou com prática não formalizada. 
Quadro 97 - Maturidade dos FCS da central de serviços

\begin{tabular}{|l|l|c|c|c|c|c|c|}
\hline Código & Categoria: Central de Serviços & Freq. & $\mathbf{1}$ & $\mathbf{2}$ & $\mathbf{3}$ & $\mathbf{4}$ & $\mathbf{5}$ \\
\hline Enet0701 & Central de serviços unificada & 3 & 3 & 2 & 2 & 2 & 3 \\
\hline Enet0702 & Service desk & 2 & 1 & 2 & 1 & 2 & 2 \\
\hline Enet0703 & $\begin{array}{l}\text { Função service desk do ITIL com suporte de ferramentas para } \\
\text { gerenciar os incidentes }\end{array}$ & 1 & 1 & 1 & 1 & 1 & 1 \\
\hline Enet0704 & $\begin{array}{l}\text { Conhecimento do processo de tratamento de incidentes (help } \\
\text { desk) }\end{array}$ & 1 & 1 & 1 & 1 & 1 & 1 \\
\hline Total & $\mathbf{7}$ & $\mathbf{6}$ & $\mathbf{6}$ & $\mathbf{5}$ & $\mathbf{6}$ & $\mathbf{7}$ \\
\hline
\end{tabular}

Fonte: Dados da pesquisa

Na Figura 59 é apresentada a maturidade da categoria. Essa é a única categoria em que a medida de gestão consta em 100\% das práticas associadas aos FCS. Depois essas práticas são formalizadas, e divulgadas e compreendidas $(85,71 \%)$. Por último são aprendidas e discutidas.

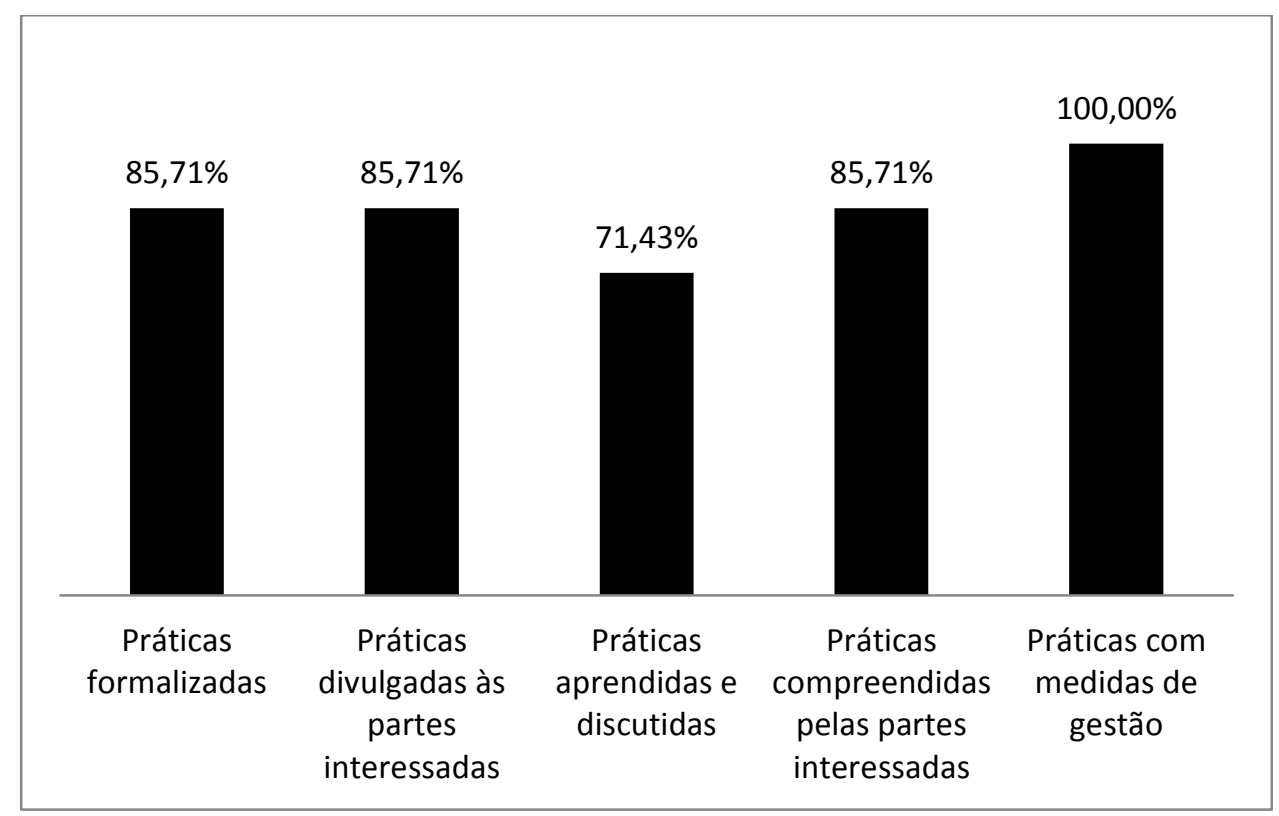

Figura 59 - Maturidade da central de serviços

Fonte: Dados da Pesquisa

\subsection{VERIFICAÇÃO DOS FCS EM GTI DA APF COM O LEVANTAMENTO DE GTI DO} ANO 2012 DO TCU

Neste subcapítulo são verificadas as questões do Levantamento de GTI do ano 2012 do TCU que possuem temática similar aos FCS e respectivamente às categorias do Subcapítulo 4.3. Esse Levantamento resulta em um banco de dados com 274 questões. Dentre essas questões, 60 foram associadas aos FCS e às respectivas categorias no Quadro 98. 
O Quadro 98 possui quatro colunas. A primeira coluna mostra o código da categoria, o mesmo utilizado no Subcapítulo 4.3. Na segunda coluna constam as categorias. Na terceira coluna estão os códigos das questões do TCU, que é sequencial numérico, por exemplo, o item 1.1 (Em relação à estrutura de governança corporativa, a alta administração da instituição) tem 12 questões, sendo que a primeira é denotada de Q11a. Finalmente, na quarta coluna mostra o total numérico de questões da terceira coluna.

Quadro 98 - Maturidade dos FCS da central de serviços

\begin{tabular}{|c|c|c|c|}
\hline Código & Categorias & Questões do TCU & Freq. \\
\hline Dneg0100 & Alinhamento entre TI e o negócio & Q11a, Q12a2, Q12e; Q21* & 4 \\
\hline Dneg0200 & Estrutura organizacional de GTI & Q12b; Q12c; Q23e & 3 \\
\hline Dneg0300 & Priorização de projetos de TI & Q24* & 1 \\
\hline Dneg0400 & Controle de GTI & Q12a8; Q12a3 & 2 \\
\hline Dneg0500 & Direcionadores de estratégia de TI & - & 0 \\
\hline Dneg0600 & Formulação e planejamento de estratégia de TI & $\mathrm{Q} 22 *$ & 1 \\
\hline Dneg0700 & Modelo de gestão de negócio de TI & Q13b, Q13c, Q13d & 3 \\
\hline Dneg0800 & Utilização de boas práticas & - & 0 \\
\hline Dneg0900 & Gestão de processos de TI & Q15f & 1 \\
\hline Dneg1000 & Estrutura organizacional de TI & Q12a1 & 1 \\
\hline Dneg1100 & Gestão do usuário de TI & - & 0 \\
\hline Dneg1200 & Gestão de demandas & Q12a7; Q51a; Q51b & 3 \\
\hline Dneg1300 & Definição de arquiteturas & - & 0 \\
\hline Dneg1400 & Políticas e diretrizes gerais de GTI & $\begin{array}{c}\text { Q12a; Q12a4; Q12a10; Q53e; } \\
\text { Q51f }\end{array}$ & 5 \\
\hline Dneg1500 & Plano diretor de tecnologia da informação (PDTI) & Q23b; Q23f; Q23h; Q23k & 4 \\
\hline Dneg1600 & Comunicação com as partes interessadas & - & 0 \\
\hline Dneg1700 & Normas e diretrizes para GTI & - & 0 \\
\hline Dges0100 & Gestão de fornecedores & - & 0 \\
\hline Dges0200 & Gestão do pessoal de TI & $\begin{array}{c}\text { Q12a11; Q12a13; Q14b; Q42b; } \\
\text { Q42i; Q44*; Q45b }\end{array}$ & 7 \\
\hline Dges0300 & Gestão de recursos financeiros e orçamentários & Q12a7; Q51c; Q23j & 3 \\
\hline Dges0400 & Gestão de contratos & Q12a5; Q57c; Q57h; Q59* & 4 \\
\hline Dges0500 & Gestão do conhecimento & Q12a9; Q51n & 2 \\
\hline Dese0100 & Gestão de processos para desenvolvimento de soluções & $\mathrm{Q} 31 \mathrm{a}$ & 1 \\
\hline Dese0200 & Gestão de projetos de TI & Q51i; Q55* & 2 \\
\hline Dese0300 & Princípios para o desenvolvimento de soluções & Q51h; Q54* & 2 \\
\hline Enet0100 & Gestão de entregas & - & 0 \\
\hline Enet0200 & Gestão de infraestrutura & - & 0 \\
\hline Enet0300 & Proc. de gestão de serviços de TI em desenho do serviço & Q51d; Q51e, Q51g; Q51j1; Q52* & 5 \\
\hline Enet0500 & Proc. de gestão de serviços de TI em transição de serviços & Q51k; Q511 & 2 \\
\hline Enet0400 & Proc. de gestão de serviços de TI em operação do serviço & Q51o; Q51p; Q51r & 3 \\
\hline Enet0600 & Gestão de serviços & Q12a6; Q31d & 2 \\
\hline Enet0700 & Central de serviços & - & 0 \\
\hline \multicolumn{2}{|c|}{$\begin{array}{ll} & \text { Total } \\
\end{array}$} & - & 60 \\
\hline
\end{tabular}

Fonte: Dados da Pesquisa

Conforme o Quadro 98, a categoria com a maior associação de questões do TCU é Gestão do pessoal de TI possui sete questões. Constata-se também que as categorias abarcam questões de itens diferentes, como as questões sobre política de segurança apresentadas no Item 1.2 (Em relação à estrutura de governança de TI, a alta administração da instituição) e no 
Item 2.3. Além disso, esse Item 1.2 reúne aspectos de estruturas de GTI, bem como de atribuições de GTI. Para nós, o termo estrutura de GTI, refere-se aos conjuntos de unidades funcionais verticais organizadas, que reúnem as funções da GTI, para atingir o objetivo planejado, sendo aqui discutida na categoria Estrutura organizacional de GTI. Já as atribuições gerais da GTI foram tratadas na categoria Políticas e diretrizes de GTI. Além disso, não consideramos a alta administração como estrutura legítima de governança.

Já o Quadro 99 apresenta todos os itens do Levantamento de GTI do TCU e as respectivas questões do TCU consideradas FCS. Ressalta-se que essas questões são as mesmas apresentadas na coluna Questões do TCU do Quadro 98. A descrição dessas questões consta no Anexo V. Verifica-se que 21,90\% das 274 questões do TCU equivalem aos FCS identificados na pesquisa qualitativa deste trabalho.

Os itens com a maior quantidade de questões associadas aos FCS são: i) 1.2 Em relação à estrutura de governança de TI, a alta administração da instituição, e ii) 5.1 A instituição implementou os processos de gestão de serviços de TI abaixo relacionados? 
Quadro 99 - Maturidade dos FCS da central de serviços

\begin{tabular}{|c|c|c|c|c|}
\hline $\begin{array}{l}\text { Cod. } \\
\text { TCU }\end{array}$ & Itens do Levantamento de Governança de TI ano 2012 & $\begin{array}{l}\text { Freq. } \\
\text { Questões } \\
\text { TCU }\end{array}$ & $\begin{array}{l}\text { Questões Correlatas com } \\
\text { FCS }\end{array}$ & $\begin{array}{l}\text { Freq. } \\
\text { Questões } \\
\text { Corr. c/ } \\
\text { FCS }\end{array}$ \\
\hline 1.1 & $\begin{array}{l}\text { Em relação à estrutura de governança corporativa, a alta administração da } \\
\text { instituição. }\end{array}$ & 12 & Q11a & 1 \\
\hline 1.2 & Em relação à estrutura de governança de TI, a alta administração da instituição & 22 & $\begin{array}{c}\text { Q12a, Q12a1, Q12a2, Q12a3; } \\
\text { Q12a4; Q12a5, Q12a6, Q12a7, } \\
\text { Q12a8, Q12a9, Q12a10; } \\
\text { Q12a11; Q12a13, Q12b, Q12c, } \\
\text { Q12e }\end{array}$ & 16 \\
\hline 1.3 & $\begin{array}{l}\text { Em relação ao desempenho institucional da gestão e de uso corporativos de } \\
\text { TI, a Alta Administração da instituição: }\end{array}$ & 8 & Q13b, Q13c, Q13d & 3 \\
\hline 1.4 & $\begin{array}{l}\text { Em relação ao desenvolvimento interno dos gestores de TI, a Alta } \\
\text { Administração: }\end{array}$ & 3 & Q14b & 1 \\
\hline 1.5 & $\begin{array}{l}\text { Em } 2010 \text { ou 2011, foi realizada auditoria formal, por iniciativa da própria } \\
\text { instituição, em algum dos temas indicados a seguir? }\end{array}$ & 7 & Q15f & 1 \\
\hline 1.6 & $\begin{array}{l}\text { A Alta administração utilizou informações fornecidas pela auditoria interna } \\
\text { (ou instância equivalente) como subsídio: }\end{array}$ & 9 & - & 0 \\
\hline 2.1 & $\begin{array}{l}\text { Em relação ao processo de planejamento estratégico institucional, marque a } \\
\text { opção que melhor descreve a sua instituição: }\end{array}$ & 7 & Q21* & 1 \\
\hline 2.2 & $\begin{array}{l}\text { Em relação ao processo de planejamento estratégico de TI, marque a opção } \\
\text { que melhor descreve a sua instituição: }\end{array}$ & 6 & Q22* & 1 \\
\hline 2.3 & $\begin{array}{l}\text { Em relação ao PDTIC (Plano Diretor de Tecnologia da Informação e } \\
\text { Comunicação): }\end{array}$ & 11 & $\begin{array}{l}\text { Q23b, Q23e, Q23f, Q23h, } \\
\text { Q23j, Q23k }\end{array}$ & 6 \\
\hline 2.4 & $\begin{array}{l}\text { Em relação ao processo decisório de priorização das ações e gastos de TI, } \\
\text { assinale a opção que descreve o comportamento majoritário da instituição: }\end{array}$ & 5 & Q24* & 1 \\
\hline 3.1 & Em relação à gestão de informação e conhecimento para o negócio: & 5 & Q31a, Q31d & 2 \\
\hline 4.1 & Qual o quantitativo de funções comissionadas voltadas à gestão de TI? & 5 & - & 0 \\
\hline 4.2 & Qual o quantitativo de pessoas que compõem a força de trabalho em TI? & 13 & Q42b; Q42i & 2 \\
\hline 4.3 & $\begin{array}{l}\text { Para membros do SISP, em relação à composição da força de trabalho } \\
\text { alocada: }\end{array}$ & 10 & - & 0 \\
\hline 4.4 & $\begin{array}{l}\text { Em relação ao plano de capacitação de pessoal para gestão de TI, assinale a } \\
\text { opção que melhor descreve sua instituição: }\end{array}$ & 5 & Q44* & 1 \\
\hline 4.5 & $\begin{array}{l}\text { Em relação à qualificação do atual principal dirigente responsável pela gestão } \\
\text { de TI na instituição,quais dos elementos abaixo ele possui: }\end{array}$ & 12 & Q45b & 1 \\
\hline 5.1 & $\begin{array}{l}\text { A instituição implementou os processos de gestão de serviços de TI abaixo } \\
\text { relacionados? }\end{array}$ & 24 & $\begin{array}{l}\text { Q51a, Q51b, Q51c, Q51d, } \\
\text { Q51e, Q51f, Q51g, Q51h, } \\
\text { Q51i, Q51j1, Q51k, Q511, } \\
\text { Q51n, Q51o, Q51p, Q51r }\end{array}$ & 16 \\
\hline 5.2 & Em relação à gestão de nível de serviço de TI: & 6 & Q52* & 1 \\
\hline 5.3 & Em relação à gestão da segurança da informação, a instituição: & 11 & Q53e & 1 \\
\hline 5.4 & Em que nível de capacidade melhor se enquadra o seu processo de software? & 6 & Q54* & 1 \\
\hline 5.5 & Em relação ao processo de gerenciamento de projetos: & 5 & Q55* & 1 \\
\hline 5.7 & Em relação às contratações de serviços de TI & 11 & Q57c, Q57h & 2 \\
\hline 5.8 & $\begin{array}{l}\text { Em relação à fase de planejamento da contratação em TI, em qual das } \\
\text { descrições abaixo a instituição se encaixa melhor? }\end{array}$ & 5 & - & 0 \\
\hline 5.9 & $\begin{array}{l}\text { Em relação à fase de gestão dos contratos de TI, em qual das descrições } \\
\text { abaixo a instituição se encaixa melhor? }\end{array}$ & 5 & Q59* & 1 \\
\hline 5.10 & $\begin{array}{l}\text { Em relação aos papéis "gestor de contrato(s)" e "fiscal de contrato(s)" de } \\
\text { serviços de TI: }\end{array}$ & 12 & - & 0 \\
\hline 6.2 & Em relação aos resultados de TI: & 8 & - & 0 \\
\hline 6.3 & $\begin{array}{l}\text { Informe as quantidades de contratos/aquisições de bens ou serviços } \\
\text { celebrados em } 2011 \text { e os seus valores totais: }\end{array}$ & 11 & - & 0 \\
\hline 6.4 & $\begin{array}{l}\text { Em relação às licitações de TI (bens ou serviços) publicadas em } 2011 \text { (mesmo } \\
\text { que não concluídas), informe as quantidades e valores solicitados: }\end{array}$ & 6 & - & 0 \\
\hline 7.1 & Em relação à Carta de Serviços ao Cidadão (Decreto 6.932/2009): & 6 & - & 0 \\
\hline 7.2 & Em relação ao atendimento ao cidadão: & 5 & - & 0 \\
\hline 7.3 & $\begin{array}{l}\text { Dos serviços disponíveis ao cidadão, qual o percentual provido também por e- } \\
\text { Gov? }\end{array}$ & 4 & - & 0 \\
\hline 8.3 & Em relação ao atendimento dos interesses difusos da sociedade, a instituição: & 9 & - & 0 \\
\hline \multicolumn{2}{|c|}{ Total } & 274 & & 60 \\
\hline
\end{tabular}

Fonte: Dados da Pesquisa 


\subsection{ANÁLISE DAS COMPONENTES PRINCIPAIS VERSUS FCS}

Considerando a relevância qualitativa das 60 variáveis apresentadas no Quadro 99, elaboraram-se as seguintes hipóteses:

- Hipótese 1: as 60 variáveis correspondentes a FCS são consideradas variáveis de maior relevância pela análise ACP;

- Hipótese 2: as 60 variáveis correspondentes a FCS são determinantes para o bom posicionamento no ranking das instituições avaliada.

A Figura 60 representa uma classificação das componentes em FCS ou não FCS. Desta forma, os autovalores de cada uma das variáveis foram classificadas como 1 (é um FCS) ou -1 (não é um FCS). Os resultados mostraram que não existe um distanciamento muito significativo entre os autovalores, ou seja, não há um grupo de poucos autovalores que representam um alto percentual da variância total, que é obtido por meio dos autovalores. Como comparação, utilizou-se a classificação de FCS feita anteriormente, a partir dos dados colhidos em entrevistas.

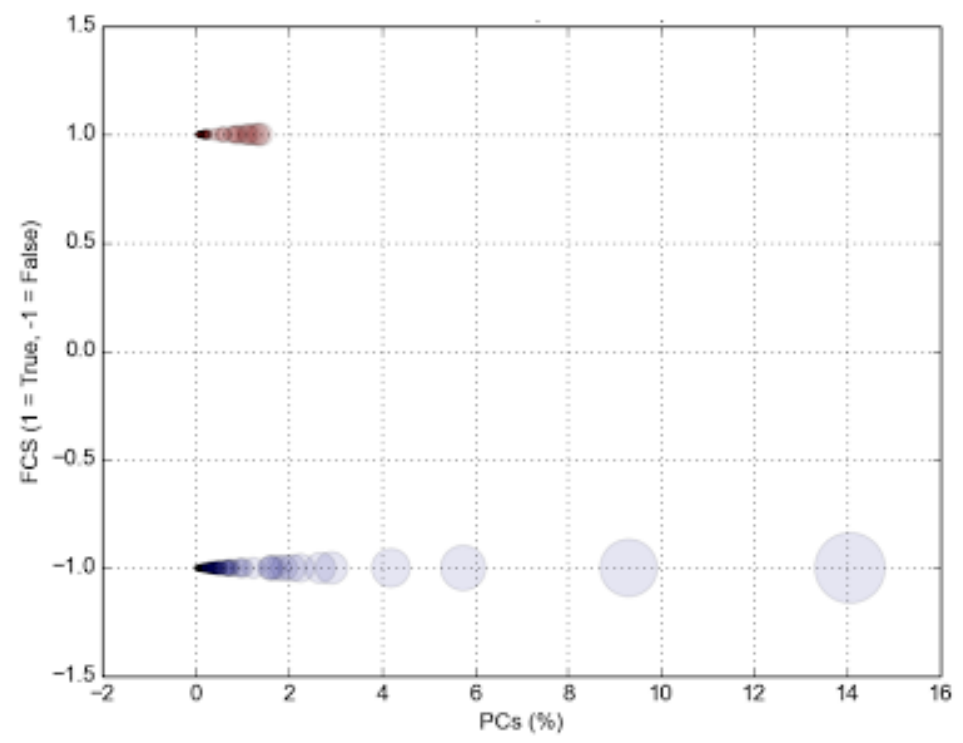

Figura 60 - PCs versus FCS

Fonte: Dados da pesquisa

Além disto, para se identificar os maiores autovalores, cada ponto da Figura 60 tem o tamanho proporcional ao tamanho do seu autovalor. Desta forma os maiores círculos representam os maiores autovalores. 
A Figura 60 mostra que as variáveis de maiores autovalores foram classificadas como não sendo FCS, em comparação com os FCS obtidos por meio da pesquisa qualitativa.

\subsection{ANÁLISE DAS COMPONENTES PRINCIPAIS}

Para a análise eficiente da matriz original $\mathrm{X}_{349}$ × 201 é relevante separar as informações úteis das redundantes. Segundo Johnson e Wichern (1992), há vários instrumentos para essa finalidade, mas a ACP é a que melhor desempenha este papel.

Uma vez calculados os autovalores da matriz original, temos um resultado que mostra que aproximadamente $70 \%$ da variabilidade dos dados é explicado por 51 componentes principais. O critério para a escolha desses fatores foi o de identificar os autovalores que possuem variância acumulada em torno de 70\% (MARDIA, 1979). Tal valor também será utilizado nesta pesquisa (Quadro 100). 
Quadro 100 - Autovalores

\begin{tabular}{|c|c|c|c|c|}
\hline $\begin{array}{l}\text { Ordem dos } \\
\text { autovalores }\end{array}$ & Autovalores & $\begin{array}{c}\text { Porcentagem da } \\
\text { variância explicada }\end{array}$ & $\begin{array}{l}\text { Autovalores } \\
\text { acumulados }\end{array}$ & $\begin{array}{c}\text { Porcentagem da } \\
\text { variância explicada } \\
\text { acumulada } \\
\end{array}$ \\
\hline 1. & 24,88966 & 12,38292 & 24,8897 & 12,3829 \\
\hline 2. & 10,33305 & 5,14082 & 35,2227 & 17,5237 \\
\hline 3. & 7,49873 & 3,73071 & 42,7214 & 21,2545 \\
\hline 4. & 5,27875 & 2,62625 & 48,0002 & 23,8807 \\
\hline 5. & 4,78008 & 2,37815 & 52,7803 & 26,2588 \\
\hline 6. & 4,49112 & 2,23439 & 57,2714 & 28,4932 \\
\hline 7. & 3,73598 & 1,85870 & 61,0074 & 30,3519 \\
\hline 8. & 3,59164 & 1,78689 & 64,5990 & 32,1388 \\
\hline 9. & 3,19618 & 1,59014 & 67,7952 & 33,7290 \\
\hline 10. & 3,11010 & 1,54731 & 70,9053 & 35,2763 \\
\hline 11. & 2,66175 & 1,32426 & 73,5671 & 36,6005 \\
\hline 12. & 2,54482 & 1,26608 & 76,1119 & 37,8666 \\
\hline 13. & 2,51698 & 1,25223 & 78,6289 & 39,1188 \\
\hline 14. & 2,40926 & 1,19864 & 81,0381 & 40,3175 \\
\hline 15. & 2,35614 & 1,17221 & 83,3943 & 41,4897 \\
\hline 16. & 2,30653 & 1,14753 & 85,7008 & 42,6372 \\
\hline 17. & 2,25284 & 1,12081 & 87,9536 & 43,7580 \\
\hline 18. & 2,11772 & 1,05359 & 90,0714 & 44,8116 \\
\hline 19. & 2,06312 & 1,02643 & 92,1345 & 45,8380 \\
\hline 20. & 2,01891 & 1,00443 & 94,1534 & 46,8425 \\
\hline 21. & 1,99258 & 0,99133 & 96,1460 & 47,8338 \\
\hline 22. & 1,97266 & 0,98142 & 98,1186 & 48,8152 \\
\hline 23. & 1,95377 & 0,97203 & 100,0724 & 49,7873 \\
\hline 24. & 1,86320 & 0,92696 & 101,9356 & 50,7142 \\
\hline 25. & 1,83124 & 0,91107 & 103,7668 & 51,6253 \\
\hline 26. & 1,80163 & 0,89633 & 105,5685 & 52,5216 \\
\hline 27. & 1,76688 & 0,87905 & 107,3354 & 53,4007 \\
\hline 28. & 1,70876 & 0,85013 & 109,0441 & 54,2508 \\
\hline 29. & 1,69776 & 0,84465 & 110,7419 & 55,0955 \\
\hline 30. & 1,66091 & 0,82633 & 112,4028 & 55,9218 \\
\hline 31. & 1,62693 & 0,80942 & 114,0297 & 56,7312 \\
\hline 32. & 1,60039 & 0,79621 & 115,6301 & 57,5274 \\
\hline 33. & 1,54662 & 0,76946 & 117,1767 & 58,2969 \\
\hline 34. & 1,51306 & 0,75277 & 118,6898 & 59,0496 \\
\hline 35. & 1,51005 & 0,75127 & 120,1998 & 59,8009 \\
\hline 36. & 1,47437 & 0,73352 & 121,6742 & 60,5344 \\
\hline 37. & 1,43597 & 0,71441 & 123,1102 & 61,2488 \\
\hline 38. & 1,42247 & 0,70770 & 124,5326 & 61,9565 \\
\hline 39. & 1,40464 & 0,69882 & 125,9373 & 62,6554 \\
\hline 40. & 1,35176 & 0,67252 & 127,2890 & 63,3279 \\
\hline 41. & 1,33162 & 0,66250 & 128,6207 & 63,9904 \\
\hline 42. & 1,32118 & 0,65731 & 129,9418 & 64,6477 \\
\hline 43. & 1,29010 & 0,64184 & 131,2320 & 65,2895 \\
\hline 44. & 1,26013 & 0,62693 & 132,4921 & 65,9165 \\
\hline 45. & 1,25589 & 0,62482 & 133,7480 & 66,5413 \\
\hline 46. & 1,22165 & 0,60779 & 134,9696 & 67,1491 \\
\hline 47. & 1,20095 & 0,59749 & 136,1706 & 67,7466 \\
\hline 48. & 1,18070 & 0,58741 & 137,3513 & 68,3340 \\
\hline 49. & 1,17744 & 0,58579 & 138,5287 & 68,9198 \\
\hline 50. & 1,16657 & 0,58038 & 139,6953 & 69,5001 \\
\hline 51. & 1,14340 & 0,56886 & 140,8387 & 70,0690 \\
\hline
\end{tabular}

Fonte: Dados da Pesquisa

Depois da extração dos autovalores e percentual da variância explicada, é decidida a quantidade de fatores a serem retirados para análise. Para isso, a Figura $61 \mathrm{em}$ que o total de autovalores está no eixo das ordenadas e os autovalores no eixo das abscissas, auxilia na identificação. Essa Figura consiste no ranking dos autovalores (eixo x), relacionado com o valor de cada autovalor (eixo y). Verifica-se que uma queda menos acentuada ocorreu entre o 
quarto e o quinto autovalor e analisando-se os autovalores superiores a 2, observa-se que pode-se considerar até o vigésimo valor já que a partir daí os valores dos autovalores sucessivos são praticamente constantes.

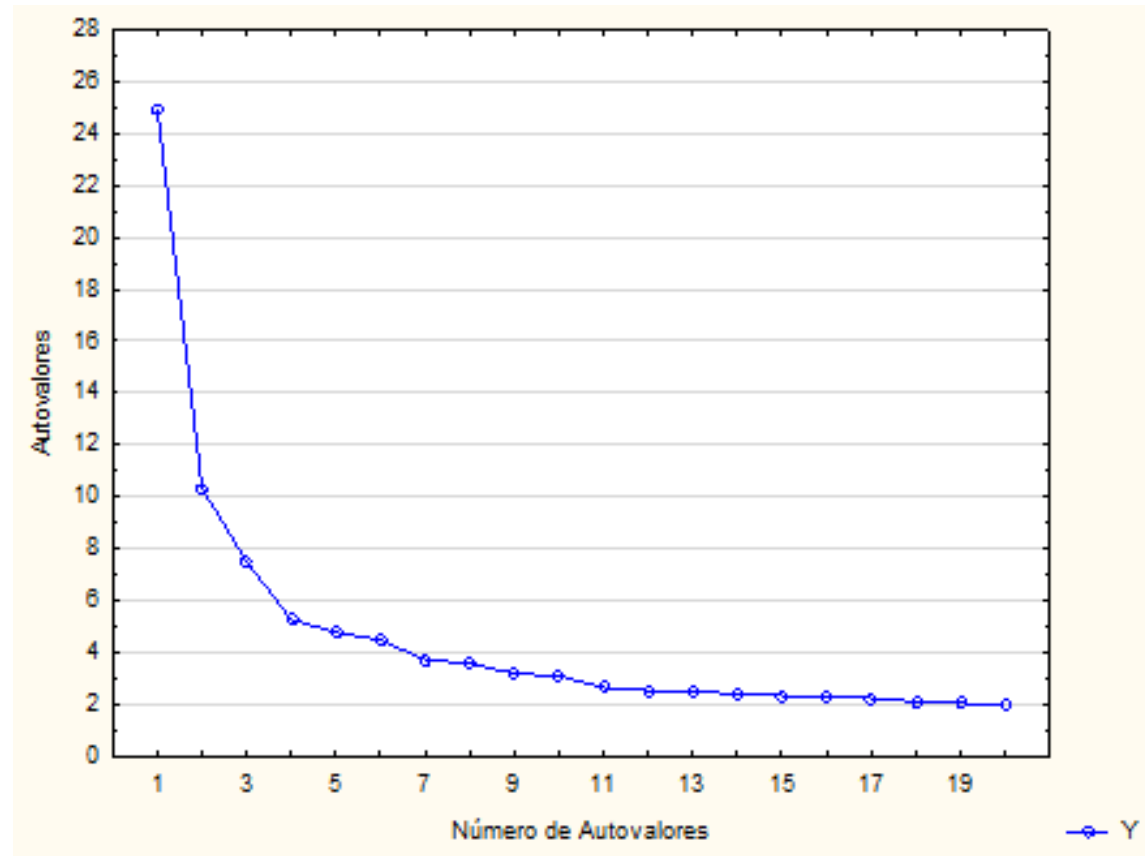

Figura 61-Ranking dos autovalores

Fonte: Dados da pesquisa

Visando encontrar os planos fatoriais, realizou-se uma rotação dos eixos, onde as cargas fatoriais mais elevadas são as responsáveis pelas denominações das componentes e são estatisticamente significativas. As rotações de eixos melhor expressam a dispersão de dados. No modelo fatorial final, as variáveis das medidas estão maximizadas e as relações entre dimensões suavizadas (VICINI, 2005).

Para esta análise, buscam-se valores que possuem variância maior que 0,7, mostrando que a correlação entre as variáveis está de moderada a forte (VICINI, 2005). Essa identificação não seria possível sem a rotação dos eixos, possibilitando assim a melhor visualização das variáveis mais significativas em cada componente. Tal rotação mantem os eixos perpendiculares entre si, ou seja, ortogonais e a variabilidade do sistema não é alterada, apenas as coordenadas dos eixos são rotacionadas e a inércia do sistema fica inalterada.

A partir dos valores obtidos pela rotação das componentes principais, podem-se obter valores com variância maior que 0,7 . Logo, foi possível a identificação das variáveis significantes de cada componente principal.

Para visualização desses fatores, foi utilizada a Figura de dispersão (Figura 62). A Figura 62 mostra a caixa de seleção de variáveis e comandos para ACP em que se utilizam os 
fatores 1 e 2, eixo x e eixo y respectivamente. O objetivo da Figura 62 é fazer os planos principais com a nuvem de pontos dos indivíduos, no caso as 349 instituições, destacando o posicionamento das respostas das instituições classificadas pelo iGovTI. Tal Figura se baseia

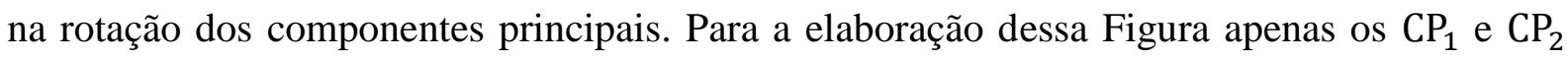
foram utilizados.

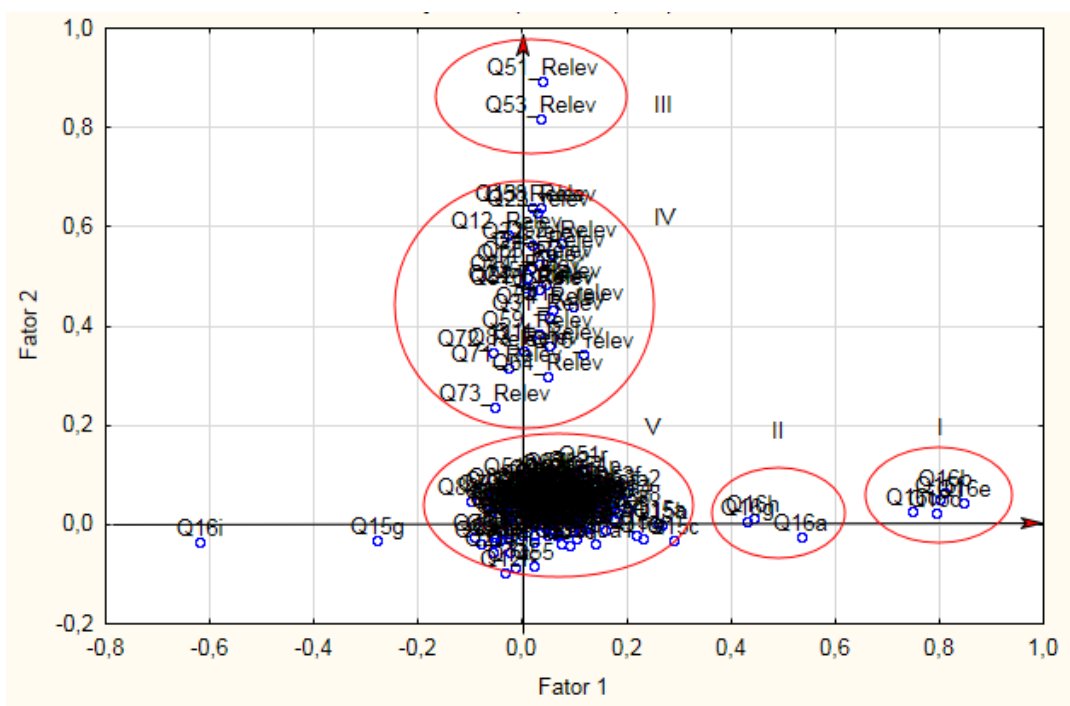

Figura 62- Relação entre os $\mathrm{CP}_{1}$ e $\mathrm{CP}_{2}$

Fonte: Dados da pesquisa

Na Figura 62, projetam-se as variáveis sobre o eixo da $\mathrm{CP}_{1} \mathrm{e}$ se tem três grupos (I, II e V). O grupo I é o grupo com maior variância da $\mathrm{CP}_{1}$, nesse tomam-se as variáveis Q16d, Q16e e Q16f que são descorrelacionadas. Já no grupo II, segundo grupo de variáveis com maior variância, a questão Q16g é questão selecionada para representá-lo. Tanto o grupo I quanto o grupo II não apresentam FCS. Além disso, verifica-se que ambos os grupos possuem variáveis denotadas Q16, que se referem à Subdimensão 1.6 (A Alta Administração Utilizou Informações Fornecidas pela Auditoria Interna), que significa a participação de auditoria interna no preenchimento do questionário.

$\mathrm{O}$ mesmo processo se aplica a analise da $\mathrm{CP}_{2}$. Assim, observam-se três grupos (III, IV e V). Para cada grupo se seleciona apenas uma variável representativa, o restante é desconsiderado, uma vez que cada grupo significa correlação.

$\mathrm{O}$ grupo III é o grupo com maior variância da $\mathrm{CP}_{2}$ e não tem FCS. Nesse grupo a variável Q53_Relev é a selecionada. Tal variável expõe sobre a relevância do item Q53, cujo tema é segurança da informação. O grupo IV, segundo grupo de variáveis com maior variância nessa componente, também não apresenta FCS e a questão Q12_Relev é questão 
selecionada para representá-lo. Vale frisar que ambos os grupos concentram variáveis que tratam sobre relevância das variáveis.

Finalmente, pela análise $\mathrm{ACP}$, o grupo $\mathrm{V}$ mostra as questões que não são representadas pelas $\mathrm{CP}_{1}$ e $\mathrm{CP}_{2}$, sendo esse o grupo que contem os FCS.

Depois, buscou-se por meio da análise das $\mathrm{CP}_{3}, \mathrm{CP}_{4}$ e $\mathrm{CP}_{5}$ a identificação de FCS (Figura 63).

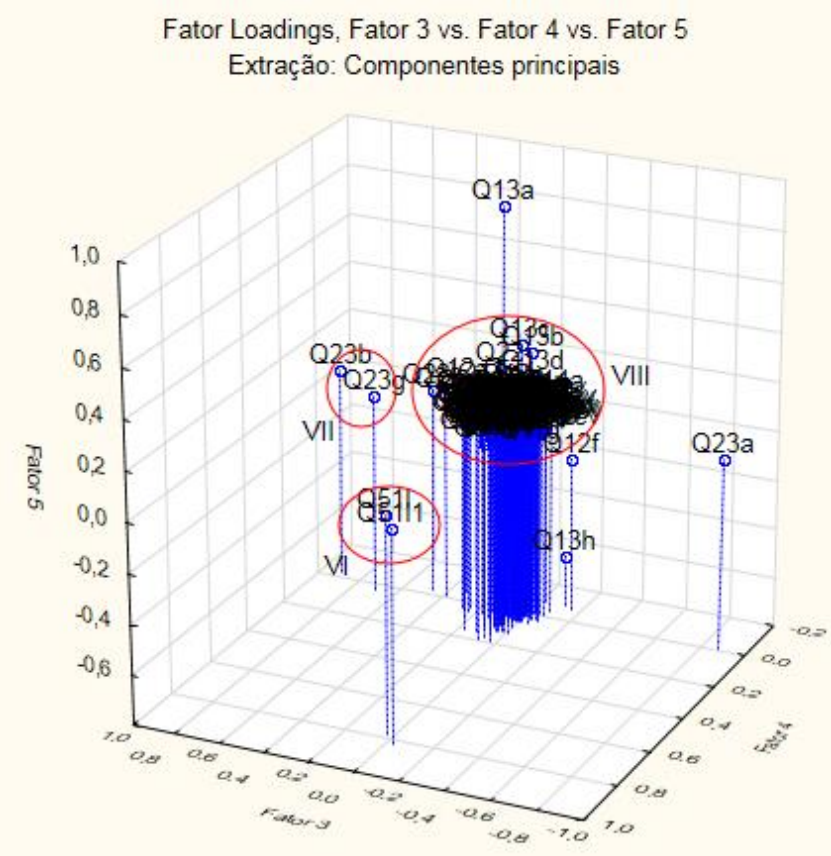

Figura 63- Relação entre os $\mathrm{CP}_{3}, \mathrm{CP}_{4}$ e $\mathrm{CP}_{5}$ Fonte: Dados da pesquisa

A Figura 63 mostra a análise dessas componentes principais que revela a existência de três grupos (VI, VII e VIII). O grupo VI contém a variável Q511 que corresponde a um FCS e o grupo VII também consta um FCS, a variável Q23b.

Na identificação das variáveis significativas das primeiras 20 componentes principais, com os autovalores superiores a 1, as questões que mais contribuem são Q16b (para responder às questões do grupo 2. Estratégias e planos), Q16c (para responder às questões do grupo 3. Informação e conhecimento), Q16d (para responder às questões do grupo 4. Pessoas), Q16e (para responder às questões do grupo 5. Processos) e Q16f (para responder às questões do grupo 6. Resultados da gestão), todas da dimensão “Governança corporativa e de TI, a alta administração utilizou informações fornecidas pela auditoria interna (ou instância equivalente)". Nota-se que as variáveis Q16, citadas anteriormente, fazem parte do grupo I da Figura 62. Ao total foram identificadas 29 variáveis das 20 primeiras componentes principais 
(autovalores maiores que 1) das variáveis com variância maior que 0,7. O Quadro 101 mostra quais são essas variáveis significativas.

Quadro 101- Variáveis com alta variância CP1 a CP20

\begin{tabular}{|c|c|c|c|c|c|c|}
\hline CP & Dimensão & Var.1 & Sig. & Var. 2 & Sig. & FCS \\
\hline CP 01 & DI1 & Q16b & 0,8108 & Q16c & 0,7496 & Não \\
\hline CP 01 & DI1 & Q16d & 0,7923 & Q16e & 0,8469 & Não \\
\hline CP 01 & DI1 & Q16f & 0,7998 & 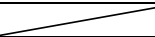 & 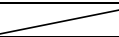 & Não \\
\hline CP 02 & D5 & Q51_Relev & 0,8941 & Q53_Relev & 0,8176 & Não \\
\hline CP 03 & D2 & Q23a & $-0,8833$ & Q23b & 0,9009 & não/sim \\
\hline CP 04 & D5 & Q511 & 0,7925 & Q5111 & 0,8254 & sim/não \\
\hline CP 05 & DI1 & Q13a & 0,8842 & $\infty$ & $\infty$ & Não \\
\hline CP 06 & D5 & Q57h & 0,8285 & W & \% & Sim \\
\hline CP 07 & DI1 & Q11f2 & 0,8362 & 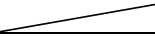 & $\longrightarrow$ & Não \\
\hline CP 08 & D5 & Q53e & 0,8684 & $\longrightarrow$ & 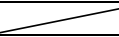 & Sim \\
\hline CP 09 & D7 & Q71 & 0,9111 & 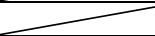 & 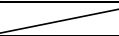 & não \\
\hline CP 10 & D4 & Q45b & $-0,8960$ & 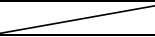 & 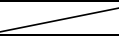 & Sim \\
\hline CP 11 & DI1 & Q14c & $-0,8605$ & 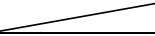 & 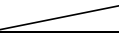 & não \\
\hline CP 12 & D5 & Q510d2 & 0,8322 & $\infty$ & $\infty$ & não \\
\hline CP 13 & D6 & Q64h & 0,9240 & 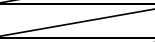 & $\longrightarrow$ & não \\
\hline CP 14 & D8 & Q83a & 0,8822 & 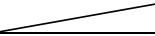 & $\longrightarrow$ & não \\
\hline CP 15 & DI1 & Q15d & 0,8738 & Q15g & $-0,7003$ & não \\
\hline CP 16 & D3 & Q31b & 0,9098 & Q31e & $-0,9070$ & não \\
\hline CP 17 & D2 & Q23i & 0,9286 & W & 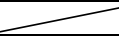 & não \\
\hline CP 18 & DI1 & Q11c1 & 0,9204 & 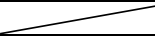 & 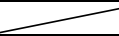 & não \\
\hline CP 19 & D5 & Q510e1 & 0,9362 & $=$ & $\longrightarrow$ & não \\
\hline CP 20 & D4 & Q45j & 0,9536 & 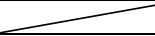 & 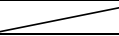 & não \\
\hline \multicolumn{2}{|c|}{ Total } & \multicolumn{4}{|c|}{29} & 5 \\
\hline
\end{tabular}

Fonte: Dados da pesquisa

Ainda no Quadro 101, verificaram-se as variáveis que são FCS, de acordo com resultado da pesquisa apresentada na Subcapítulo 4.1. Das 29 questões apenas cinco são FCS, de acordo com classificação obtida por meio de pesquisa qualitativa, quais sejam: Q12c (designou representantes de todas as áreas relevantes para o negócio institucional para compor o Comitê de TI); Q23b (a instituição aprovou e publicou PDTI interna e externamente); Q511 (gestão de configuração de ativos); Q53e (formalizou a política corporativa de segurança da informação); Q57h (os pagamentos são feitos em função da mensuração objetiva dos resultados entregues e aceitos).

Ainda no Quadro 101, chamam atenção as $\mathrm{CP}_{3}, \mathrm{CP}_{15}$ e $\mathrm{CP}_{16}$. Nelas constam variáveis com valor positivo ou negativo. Tal fato significa que quanto maior for a resposta de uma questão menor será a da outra. Frisa-se que isto só vale para questões que estejam em uma mesma variável ACP. Caso as questões tenham sinais diferentes (i.e. os elementos dos autovetores), mas em ACP diferentes o sinal positivo e negativo não importa.

A análise das categorias relacionadas às variáveis revela: Q53e referente à Categoria Processos de Gestão de Serviços de TI em Desenho do Serviço que mostrou Porcentual igual a 53,85\%; Q57h se liga à Categoria Gestão de Contratos que teve Porcentual de 34,62\%; 
Q23b se vincula à Categoria PDTI que teve 38,46\%. A variável Q511 se relaciona à Categoria Processos de Gestão de Serviços de TI em Transição de Serviços com 19,23\%.

Devido ao baixo percentual de 16,66\% de identificação de FCS do Quadro 101, realizou-se a análise das variáveis que completam as 51 componentes principais, referentes aos 51 autovalores do Quadro 102. Nesta identificação, levantaram-se 33 variáveis, sendo que nove são FCS (Quadro 102). Somando os totais obtidos pelo Quadro 101 e pelo Quadro 102 se tem $20,96 \%$ de variáveis que são FCS.

Quadro 102- Variáveis com alta variância CP 21 a CP 51

\begin{tabular}{|c|c|c|c|c|c|c|}
\hline $\mathbf{C P}$ & Dimensão & Var.1 & Sig. & Var. 2 & Sig. & FCS \\
\hline CP 21 & DI1 & Q12e & 0,7210 & Q12e1 & 0,8314 & $\operatorname{sim} /$ não \\
\hline CP 22 & D5 & Q55a & 0,8256 & 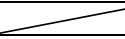 & $\infty$ & não \\
\hline CP 23 & D8 & Q83b2 & 0,8816 & 2 & 2 & não \\
\hline CP 24 & D7 & Q72a3 & 0,9220 & $\longrightarrow$ & $\infty$ & não \\
\hline CP 25 & D4 & Q45g & $-0,9334$ & 2 & $\infty$ & não \\
\hline CP 26 & D5 & Q510b1 & 0,8942 & $\infty$ & 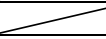 & não \\
\hline CP 27 & DI1 & Q12e3 & 0,9294 & 2 & 2 & não \\
\hline CP 28 & DI1 & Q12b & 0,8415 & Q12c & 0,8934 & sim/sim \\
\hline CP 29 & DI1 & Q12e2 & 0,9621 & $\infty$ & 2 & não \\
\hline CP 30 & DI1 & Q11_Relev & 0,8400 & 2 & 1 & não \\
\hline CP 31 & D2 & Q24 & 0,9425 & 2 & $\infty$ & sim \\
\hline CP 32 & D5 & Q510b2 & 0,9024 & 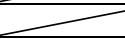 & 1 & não \\
\hline CP 33 & D5 & Q53a1 & 0,8840 & 2 & $\infty$ & não \\
\hline CP 34 & DI1 & Q13e & 0,8986 & 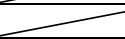 & 1 & não \\
\hline CP 35 & D4 & $\mathrm{Q} 45 \mathrm{~d}$ & 0,9487 & 2 & 2 & não \\
\hline CP 36 & DI1 & Q16_relev & 0,8364 & 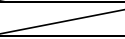 & 2 & não \\
\hline CP 37 & D5 & Q51h & 0,8175 & 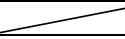 & & sim \\
\hline CP 38 & D5 & Q53d & 0,8864 & 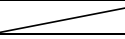 & $<$ & não \\
\hline CP 39 & DI1 & Q11c2 & 0,9258 & 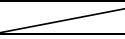 & 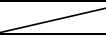 & não \\
\hline CP 40 & DI1 & Q11a & 0,8674 & 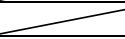 & 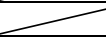 & sim \\
\hline CP 41 & DI1 & Q15f & 0,9201 & 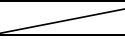 & 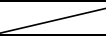 & não \\
\hline CP 42 & D4 & Q45f & 0,9450 & 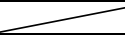 & $\Gamma$ & não \\
\hline CP 43 & D5 & Q53f & 0,7871 & 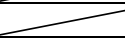 & 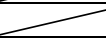 & não \\
\hline CP 44 & D4 & Q45h & $-0,9612$ & 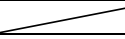 & $\longrightarrow$ & não \\
\hline CP 45 & D7 & Q72a4 & 0,9401 & 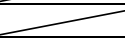 & 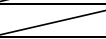 & não \\
\hline CP 46 & D3 & Q31d & 0,8714 & & $\sim$ & sim \\
\hline CP 47 & D4 & Q45i & 0,9462 & 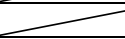 & 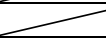 & não \\
\hline CP 48 & D5 & Q51e & 0,8432 & 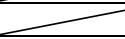 & 2 & sim \\
\hline CP 49 & D4 & $\mathrm{Q} 45 \mathrm{e}$ & 0,9406 & $\quad$ & 1 & não \\
\hline CP 50 & DI1 & Q12a1 & 0,8635 & 4 & 2 & sim \\
\hline CP 51 & D8 & Q83b5 & 0,9237 & $\infty$ & $\infty$ & não \\
\hline \multicolumn{2}{|c|}{ Total } & \multicolumn{4}{|c|}{33} & 9 \\
\hline
\end{tabular}

Fonte: Dados da pesquisa

Já a Figura 64 apresenta a disposição das 349 instituições avaliadas pelo TCU nos dois planos principais $\left(\mathrm{CP}_{1}\right.$ e $\left.\mathrm{CP}_{2}\right)$. Cada uma dessas instituições é anonimizada por uma numeração atribuída pelo TCU. 


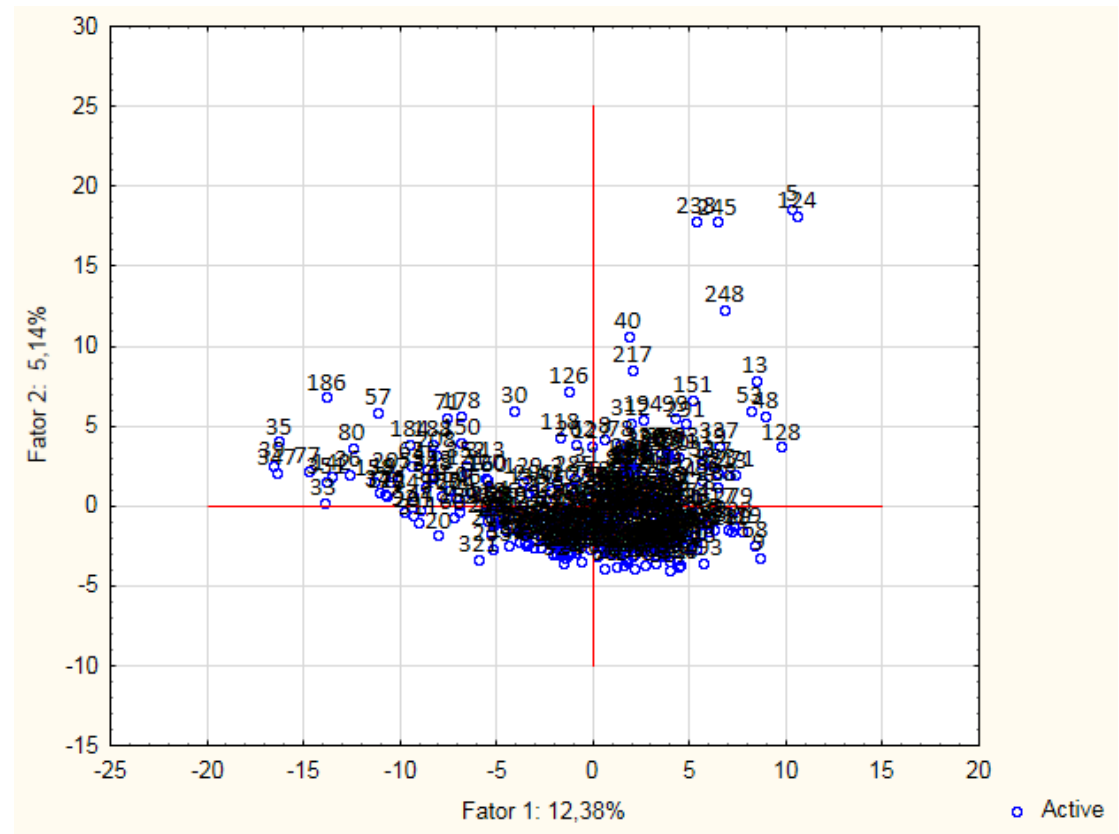

Figura 64- Dados brutos da pesquisa

Fonte: Dados da pesquisa

A partir do resultado apresentado na Figura 64 é possível identificar um padrão na disposição das instituições, conforme o índice iGovTI. Esse padrão ocorre principalmente com as intituições com maior iGovTI, embora ainda não seja possível obter uma separação clara entre os resultados. Para melhor observação dos resultados, amplia-se a Figura 64, destacando a esquerda do ponto $(-8,8,0)$. Assim, 23 instituições podem ser visualizadas na Figura 65.

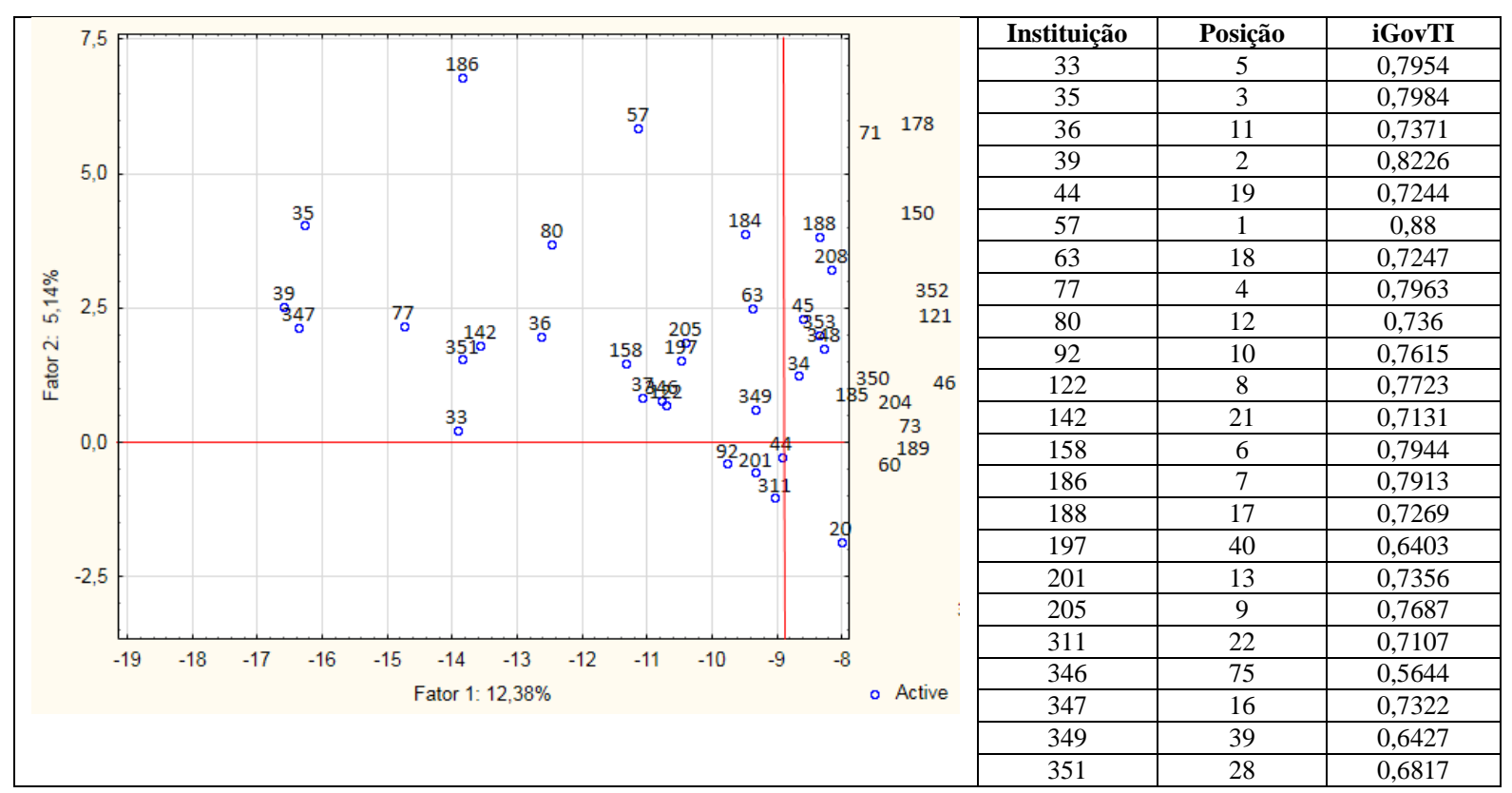

Figura 65- Destaque de corte nas instituições

Fonte: Dados da pesquisa 
Dessas instituições, 22, são consideradas pelo TCU como aprimoradas, ou seja, 95,65\%. Apenas a instituição 346 é avaliada como intermediária.

Após a análise ACP, verifica-se que a mesma não confirma a Hipótese 1, apesar de contribuir com dados sobre a classificação das instituições conforme o iGovTI. Já para a validação da Hipótese 2, são executados os algoritmos de classificação SVC e depois o ERV.

\subsection{MÁQUINAS DE VETORES DE SUPORTE}

Para prever a classificação de uma instituição de acordo com suas respostas para as questões do questionário iGovTI, foram avaliados algoritmos de classificação que pudessem apresentar acurácia para a classificação de organizações de acordo com o iGovTI. Uma vez encontrado um algoritmo capaz desta classificação, é possível utilizar o algoritmo selecionado em conjunto com técnicas de feature selection para identificar as questões mais relevantes para a classificação da instituição de acordo com o iGovTI.

Assim, para a definição do algoritmo de classificação foram realizados testes em 21 algoritmos, a seguir é apresentada no Quadro 103 a lista dos algoritmos avaliados e a taxa de acerto de classificação obtida.

Quadro 103 - Algoritmos de Classificação Avaliados

\begin{tabular}{|c|c|}
\hline Algoritmos de Classificação & Porcentual \\
\hline KNN & $71,4286 \%$ \\
\hline ElasticNet & $15,5336 \%$ \\
\hline ElasticNetCV & $83,1531 \%$ \\
\hline LassoCV & $82,7440 \%$ \\
\hline LassoLarsIC & $71,3763 \%$ \\
\hline LinearRegression & $36,0878 \%$ \\
\hline LogisticRegression & $77,1429 \%$ \\
\hline OrthogonalMatchingPursuit & $76,9630 \%$ \\
\hline PassiveAggressiveClassifier & $80,0000 \%$ \\
\hline PassiveAggressiveRegressor & $85,2184 \%$ \\
\hline Perceptron & $80,0000 \%$ \\
\hline Ridge & $52,9922 \%$ \\
\hline RidgeClassifier & $65,7143 \%$ \\
\hline RidgeClassifierCV & $74,2857 \%$ \\
\hline RidgeCV & $75,0149 \%$ \\
\hline SGDClassifier & $82,8571 \%$ \\
\hline MultinomialNB & $74,2857 \%$ \\
\hline lda.LDA & $62,8571 \%$ \\
\hline SVM.SVR & $82,6885 \%$ \\
\hline SVM.SVC & $91,4286 \%$ \\
\hline SVM.LinearSVC & $71,4286 \%$ \\
\hline
\end{tabular}

Fonte: Dados da pesquisa 
O algoritmo que obteve maior sucesso para classificação foi o SVC, que é uma implementação de Máquina de Vetores de Suporte (MVS) aplicado para a classificação. SVC apresentou uma taxa de acerto de 91,4\%. Para a avaliação dos algoritmos, utilizamos uma metodologia que divide os dados dos questionários pelo iGovTI entre questões que serão utilizadas para aprendizado do algoritmo e questões que serão utilizadas para comparativo de predições. Para treinar o algoritmo, utilizou-se $90 \%$ dos dados e os $10 \%$ restantes foram utilizados para avaliar a eficiência de classificação dos algoritmos, comparando a taxa de acerto entre as predições feitas e os valores reais de classificações de organizações pelo iGovTI.

Uma vez identificado um algoritmo capaz de efetuar a classificação desejada, o próximo passo é identificar as variáveis mais relevantes para esta classificação. Para isso, será utilizado o algoritmo ERV.

\subsection{ELIMINAÇÃO RECURSIVA DE VARIÁVEIS}

A ERV pode usar vários algoritmos de classificação como critério de seleção das variáveis mais importantes. Escolhemos o algoritmo SVC por ele ter apresentado maior acurácia entre os algoritmos de classificação avaliados. Ainda é necessário definir o quantitativo de variáveis mais importantes a serem selecionadas. A partir da pesquisa de identificação por meio de entrevistas na APF, identificou-se 60 variáveis consideradas FCS, este critério foi utilizado para determinar o quantitativo de variáveis mais importantes para a classificação.

Assim, aplicaram-se o algoritmo ERV (GUYON, 2002), utilizando o SVC como critério para a seleção das variáveis mais importantes para a classificação, selecionando as 60 variáveis que correspondem aos FCS levantados nas entrevistas com os executivos de TI. Os resultados mostraram que $66,66 \%$ das variáveis foram classificadas da mesma forma que os FCS identificados anteriormente por meio de pesquisa qualitativa. Para se chegar a esse porcentual, soma-se a quantidade de questões que são FCS das variáveis identificadas pelo ERV com a quantidade de questões que não são FCS e não fazem da amostra final do ERV.

Especificamente sobre as questões tidas como FCS, foram identificadas 22 questões, que contribuíram para a classificação do SVC, sendo descritas no Quadro 104. No Quadro 104 também consta o ranking com a relevância das questões para a classificação do SVC. 
Denominamos essas questões de FCS de alto impacto, sendo comprovadas por pesquisa qualitativa e quantitativa.

Quadro 104 - Fatores críticos de sucesso de alto impacto

\begin{tabular}{|c|c|c|c|}
\hline $\begin{array}{l}\text { Ranking } \\
\text { do ERV }\end{array}$ & Questão & $\begin{array}{c}\text { Tema da Questão do Levantamento do } \\
\text { TCU ano } 2012\end{array}$ & $\begin{array}{c}\text { Categoria da Pesquisa } \\
\text { Qualitativa Correspondente }\end{array}$ \\
\hline 1 & Q13d & Gestão de TI & Modelo de gestão de negócio de TI \\
\hline 2 & Q12c & Estrutura de GTI & Estrutura organizacional de GTI \\
\hline 5 & $\mathrm{Q} 23 \mathrm{~b}$ & PDTI & PDTI \\
\hline 7 & Q44 & $\begin{array}{c}\text { Plano de capacitação de pessoal para gestão } \\
\text { de TI }\end{array}$ & Gestão do pessoal de TI \\
\hline 9 & Q31c & Gestão da informação & $\begin{array}{c}\text { Gestão de processos para } \\
\text { desenvolvimento de soluções }\end{array}$ \\
\hline 11 & $* \mathrm{Q} 21$ & Planejamento estratégico institucional & Alinhamento entre TI e o negócio \\
\hline 13 & Q51j1 & $\begin{array}{l}\text { Tem plano de continuidade de negócio em } \\
\text { vigor }\end{array}$ & $\begin{array}{l}\text { Proc. de gestão de serviços de TI } \\
\text { em desenho do serviço }\end{array}$ \\
\hline 15 & Q14b & Desenvolvimento interno de gestores de TI & Gestão do pessoal de TI \\
\hline 23 & Q23k & PDTI & PDTI \\
\hline 24 & Q31a & $\begin{array}{l}\text { Os principais processos de negócio da } \\
\text { instituição foram identificados e mapeados }\end{array}$ & $\begin{array}{c}\text { Gestão de processos para } \\
\text { desenvolvimento de soluções }\end{array}$ \\
\hline 26 & Q12a11 & Estrutura de GTI & Gestão do pessoal de TI \\
\hline 29 & Q12b & Estrutura de GTI & Estrutura organizacional de GTI \\
\hline 30 & *Q24 & $\begin{array}{l}\text { Processo decisório de priorização das ações e } \\
\text { gastos de TI }\end{array}$ & Priorização de projetos de TI \\
\hline 32 & Q51r & Processos de gestão de serviços de TI & $\begin{array}{l}\text { Proc. de gestão de serviços de TI } \\
\text { em operação do serviço }\end{array}$ \\
\hline 34 & Q57h & Contratações de serviços de TI & Gestão de contratos \\
\hline 39 & Q13c & Gestão de TI & Modelo de gestão de negócio de TI \\
\hline 42 & $* \mathrm{Q} 22$ & Processo de planejamento estratégico de TI & $\begin{array}{c}\text { Formulação e planejamento de } \\
\text { estratégia de TI }\end{array}$ \\
\hline 46 & Q12a5 & Estrutura de GTI & Gestão de contratos \\
\hline 47 & Q12e & Estrutura de GTI & Gestão de contratos \\
\hline 49 & Q51h & Gestão de fornecedores & Alinhamento entre TI e o negócio \\
\hline 51 & Q23f & PDTI & $\begin{array}{c}\text { Princípios para o desenvolvimento } \\
\text { de soluções }\end{array}$ \\
\hline 53 & Q12a7 & Estrutura de GTI & PDTI \\
\hline
\end{tabular}

Fonte: Dados da pesquisa

Já o Quaro 104 mostra o restante das 54 variáveis identificadas pelo algoritmo ERV. Nessa tabela o tema com a maior frequência é Governança Corporativa. Assim, interpreta-se que as instituições que responderam positivamente sobre essas questões tiveram melhor posição na classificação. Além disso, pondera-se que Empresas Públicas e Sociedades de Economia Mista são beneficiadas quanto à Governança Corporativa, uma vez que possuem mais instrumentos de controle interno e são mais auditadas externamente sobre o assunto. 
Quadro 105 - Questões relevantes para a classificação e não correlacionadas aos FCS

\begin{tabular}{|c|c|c|}
\hline $\begin{array}{l}\text { Ranking } \\
\text { do ERV }\end{array}$ & Questão & $\begin{array}{c}\text { Tema da Questão do Levantamento do TCU } \\
\text { ano } 2012\end{array}$ \\
\hline 3 & Q15a & Auditoria \\
\hline 4 & Q14a & Desenvolvimento interno de gestores de TI \\
\hline 6 & Q13g & Gestão de TI \\
\hline 8 & Q11d & Governança Corporativa \\
\hline 9 & Q31c & Gestão da informação \\
\hline 10 & Q83b2 & Atendimento aos interesses da sociedade \\
\hline 12 & Q13a & Gestão de TI \\
\hline 14 & Q15c & Auditoria \\
\hline 16 & Q72a1 & Atendimento ao cidadão \\
\hline 17 & Q11c & Governança Corporativa \\
\hline 18 & Q45a & Qualificação do principal gestor de TI \\
\hline 19 & Q53c & Gestão de Segurança da Informação \\
\hline 20 & Q58 & Planejamento da contratação de serviços de TI \\
\hline 21 & Q12e1 & Estrutura de GTI \\
\hline 22 & Q72a4 & Atendimento ao cidadão \\
\hline 25 & Q83a & Atendimento aos interesses da sociedade \\
\hline 27 & Q53f & Gestão de Segurança da Informação \\
\hline 28 & Q53d & Gestão de Segurança da Informação \\
\hline 33 & Q5111 & Processos de gestão de serviços de TI \\
\hline 35 & Q11g & Governança Corporativa \\
\hline 36 & Q54 & Nível de capacidade processo de software \\
\hline 37 & Q12d & Estrutura de GTI \\
\hline 41 & Q57d & Contratações de serviços de TI \\
\hline 43 & Q11f & Governança Corporativa \\
\hline 45 & Q83b1 & Atendimento aos interesses da sociedade \\
\hline 48 & Q510d2 & Papéis gestor de contratos e fiscal de contratos \\
\hline 50 & Q11e & Governança Corporativa \\
\hline 52 & Q16c & Informações de Auditoria interna \\
\hline 54 & Q73 & Atendimento ao cidadão \\
\hline
\end{tabular}

Fonte: Dados da pesquisa

Para a análise ACP foram utilizados dados brutos, ao invés dos dados normalizados. A análise dos dados brutos mostrou resultados mais significativos do algoritmo de classificação, com $91,4 \%$, enquanto os dados normalizados $85 \%$.

\subsection{SÍNTESE CRÍTICA}

Nesta pesquisa, os FCS em GTI identificados na APF foram analisados tanto diretamente como por meio de categorias. 


\subsubsection{Síntese da pesquisa qualitativa}

$\mathrm{Na}$ análise das categorias, é verificado o total de FCS que fazem parte de determinada categoria. Para não ter o risco de uma instituição influenciar o resultado dessa análise, relatando um número maior de FCS, conta-se apenas a participação da instituição na categoria. Nessa análise se destaca a Gestão de pessoal de TI com 76,92\%. Contribui para esse resultado, o agrupamento que originou essa categoria. Para isso, os FCS de gestão de pessoal dos quatro subsistemas de TI foram reunidos, haja vista que a análise das arquiteturas das instituições pesquisadas tem a gestão de pessoal de TI centralizada na gestão da TI. Em seguida, temos o Alinhamento entre TI e negócio com 69,23\% que teve reunidos todos os FCS que visam os seguintes alinhamentos: GTI com GC; PETI com PEI; alta administração com TI e conselho de administração com comitê de TI. Depois, a terceira categoria com maior frequência é partilhada entre as categorias Gestão de projetos de TI e Processos de gestão de serviços de TI em desenho do serviço, cada uma com 53,85\%. Cada uma dessas quatro categorias faz parte de um subsistema específico (Quadro 106).

Quadro 106 - Categorias com maior porcentual

\begin{tabular}{|l|l|c|c|}
\hline \multicolumn{1}{|c|}{ Código } & \multicolumn{1}{|c|}{ Categoria } & Frequência & Porcentual \\
\hline Dges0200 & Gestão do pessoal de TI & 20 & $76,92 \%$ \\
\hline Dneg0100 & Alinhamento entre TI e o negócio & 18 & $69,23 \%$ \\
\hline Dese0200 & Gestão de projetos de TI & 14 & $53,85 \%$ \\
\hline Enet0300 & $\begin{array}{l}\text { Processos de gestão de serviços de TI em desenho do } \\
\text { serviço }\end{array}$ & 14 & $53,85 \%$ \\
\hline Dneg0600 & Formulação e planejamento de estratégia de TI & 13 & $50,00 \%$ \\
\hline Dneg1200 & Gestão de demandas & 11 & $42,31 \%$ \\
\hline Dges0300 & Gestão de recursos financeiros e orçamentários & 11 & $42,31 \%$ \\
\hline Dese0300 & Princípios para o desenvolvimento de soluções & 11 & $42,31 \%$ \\
\hline Enet0600 & Gestão de serviços & & $42,31 \%$ \\
\hline
\end{tabular}

Fonte: Dados da pesquisa

Já o Quadro 107 mostra os FCS com maior frequência entre os entrevistados. Nessa análise a frequência determina a quantidade de instituições que citaram o FCS. Dos FCS com a maior frequência, listam-se três: Alinhamento entre PETI e PEI, Participação das áreas fins no desenvolvimento do PETI e Mapeamento de processos, cada um com oito referências. Conforme o modelo de Henserson e Venkatraman (1990), apresentado no Subcapítulo 2.2.1, o alinhamento de negócio e TI é conquistado a partir da sintonia entre estratégia institucional e estratégia de TI. Já o FCS Mapeamento de processos se refere ao 
uso do mapeamento de processos para o desenvolvimento de soluções. As instituições que responderam sobre este FCS descataram que esse mapeamento é um dos critérios para a priorização de projetos, ou seja, a unidade organizacional deve ter mapeado o processo que deseja automatizar. Além disso, é indispensável que o mapeamento tenha o nível de detalhamento que auxilie no desenvolvimento de soluções.

Quadro 107- FCS com maior porcentual

\begin{tabular}{|l|l|c|c|}
\hline \multicolumn{1}{|c|}{ Código } & \multicolumn{1}{|c|}{ Categoria } & Frequência & Porcentual \\
\hline Dneg0105 & Alinhamento entre PETI e o PEI & 8 & $30,77 \%$ \\
\hline Dneg0605 & Participação das áreas fins no desenvolvimento do PETI & 8 & $30,77 \%$ \\
\hline Dese0102 & Mapeamento de processos & 8 & $30,77 \%$ \\
\hline Dneg0301 & Priorização de projetos de TI & 7 & $26,92 \%$ \\
\hline Dges0203 & $\begin{array}{l}\text { Servidores de TI com competência em TI - } \\
\text { Direcionamento }\end{array}$ & 7 & $26,92 \%$ \\
\hline Dneg0109 & Patrocínio da alta administração na GTI & 5 & $19,23 \%$ \\
\hline Dneg0201 & Comitê de TI & 5 & $19,23 \%$ \\
\hline Dneg1501 & PDTI & 5 & $19,23 \%$ \\
\hline Enet0501 & Gestão de mudança & & $19,23 \%$ \\
\hline
\end{tabular}

Fonte: Dados da pesquisa

Além das informações verificadas na análise categorial temática, descatam-se outras lacunas existentes na GTI da APF quando comparadas a outras GTI públicas internacionais. As considerações do Subcapítulo 4.1 mostram que internacionalmente a GTI é altamente vinculada à $\mathrm{AC}$, ao governo eletrônico e à interoperabilidade, tal como descreve Schekkerman (2004).

A relevância da AC para GTI é servir como mapa para organizar as estruturas, os processos, os controles, as tecnologias e as pessoas, mas também para informar às partes interessadas sobre o que fundamenta a tomada de decisão do gestor público. Essa visão permite o controle social sobre a gestão pública, em que o controle é exercido pelo acesso às entradas, às saídas, mas também aos processos, e para isso, é necessário o governo eletrônico.

Por fim, a partir dos resultados deste trabalho, algumas premissas de GTI podem ser reforçadas no âmbito federal, são elas:

- A GTI aproxima a organização da tomada de decisão em TI;

- GTI é eficiente em seus propósitos se a gestão estiver bem administrada (planejada, organizada, dirigida e controlada);

- A GTI controla e dirige a gestão de TI. Logo, conforme o princípio de controle interno, os membros da GTI não devem pertencer à gestão de TI. Por isso, é 
importante a educação dos membros do Comitê em TI ou que o mesmo conte com uma assessoria consultiva em TI.

- As partes interessadas, direta ou indiretamente, à GTI e à gestão de TI não podem ser beneficiadas em aquisições de TI, devendo ser declarado conflito de interesse.

- A GTI é parte da GC. Existindo a GC na organização, essa deve funcionar por meio do Conselho de Administração que se subdivide em comitês, sendo um deles o Comitê de TI. Sem GC, a estrutura da GTI deve ser denominada de Conselho de TI. Tal fato é relevante para destacar a inexistência da GC na organização. A classificação em conselho de TI não deve ser visto como fragilidade da organização, mas como modelo de gestão transparente em busca pela maturidade.

- A gestão de TI realiza a gestão e a elaboração de contratos de TI e a GTI os fiscaliza.

- A estratégia de TI é responsabilidade da gestão de TI. Nesse interim, a GTI é responsável por definir políticas e diretrizes da estratégia de TI, verificando e garantindo o alinhamento da TI com o negócio.

- Separam-se GTI, negócio de TI e gestão de TI. Governança de TI inclui priorização de projetos de TI, alinhamento de TI com o negócio e as demais atividades de integração de TI com o negócio. Negócio de TI especifica a atividade fim da TI. Gestão de TI administra os recursos humanos, financeiros e orçamentários, e materiais que servirão às atividades fins da TI.

\subsubsection{Síntese da pesquisa quantitativa}

Após a apresentação dos resultados, comparam-se as hipóteses de pesquisa utilizadas para a abordagem quantitativa, visando determinar se essas foram confirmadas ou rejeitadas. O Quadro 108 apresenta as hipóteses de pesquisa e os resultados.

Quadro 108 - Hipóteses e resultados

\begin{tabular}{|l|c|}
\hline \multicolumn{1}{|c|}{ Hipótese } & Resultado \\
\hline $\begin{array}{l}\text { As } 60 \text { variáveis correspondentes a FCS são consideradas variáveis de } \\
\text { maior relevância pela análise ACP }\end{array}$ & Não \\
\hline $\begin{array}{l}\text { As } 60 \text { variáveis correspondentes a FCS são determinantes para o bom } \\
\text { posicionamento no ranking das instituições avaliada }\end{array}$ & Sim \\
\hline
\end{tabular}

$$
\text { Fonte: Dados da pesquisa }
$$


Sobre a análise da ACP, embora forneça um indicativo de quais variáveis são as mais relevantes de forma abrangente, esperava-se que por meio dela pudessem ser identificadas variáveis significativas definidas como FCS. Entretanto, as variáveis não possuem variância significativa nas $\mathrm{CP}$ apuradas.

Contudo, para o objetivo específico de classificar as instituições conforme o iGovTI, é necessário um complemento que é dado por técnicas que possam identificar quais variáveis são as mais importantes para classificação das instituições de acordo com o iGovTI.

Em outras palavras, é importante selecionar um algoritmo que seja mais eficiente na classificação das instituições de acordo com o resultado do iGovTI, a partir de suas respostas ao questionário. Este algoritmo foi utilizado para a identificação das variáveis mais importantes para a classificação. Para isso, utilizou-se dos algoritmos SVC e ERV.

O Quadro 109 apresenta as dez questões mais relevantes segundo o algoritmo ERV. Verifica-se que cinco são FCS apontados pela pesquisa qualitativa. Além disso, o primeiro e segundo lugar do ranking do ERV são FCS.

Quadro 109 - Questões relevantes para a classificação e não correlacionadas aos FCS

\begin{tabular}{|c|c|c|c|}
\hline $\begin{array}{c}\text { Ranking } \\
\text { do } \boldsymbol{E} \boldsymbol{V} \boldsymbol{V}\end{array}$ & $\begin{array}{c}\text { Questão do } \\
\text { TCU }\end{array}$ & $\begin{array}{c}\text { Tema da Questão do Levantamento do } \\
\text { TCU ano 2012 }\end{array}$ & $\begin{array}{c}\text { Questão representa FCS } \\
\text { da pesquisa qualitativa }\end{array}$ \\
\hline 1 & Q13d & Gestão de TI & Sim \\
\hline 2 & Q12c & Estrutura de GTI & Sim \\
\hline 3 & Q15a & Auditoria & Não \\
\hline 4 & Q14a & $\begin{array}{c}\text { Desenvolvimento interno de gestores de } \\
\text { TI }\end{array}$ & Sim \\
\hline 5 & Q23b & PDTI & Não \\
\hline 6 & Q13g & Gestão de TI & Sim \\
\hline 7 & Q44 & Plano de capacitação de pessoal para \\
gestão de TI & Não \\
\hline 8 & Q11d & Governança Corporativa & Sim \\
\hline 9 & Q31c & Gestão da informação & Não \\
\hline 10 & Q83b2 & Atendimento aos interesses da sociedade & \\
\hline
\end{tabular}

Fonte: Dados da pesquisa

Feitas tais considerações, em suma, considera-se quatro contribuições dessa análise: $i$ ) identificaram-se FCS em GTI de instituições públicas consideradas com desempenho "Aprimorado"; $i$ ) identificou-se um algoritmo que pode classificar com 91,4\% de acerto um órgão em relação ao iGovTI, sem a necessidade de se conhecer o cálculo para composição do iGovTI; iii) o levantamento qualitativo por meio de entrevistas teve comprovação quantitativa por meio dos algoritmos SVC (KNERR; PERSONNAZ; DREYFUS, 1990) e ERV (GUYON, 2002) de 66,66\%; e iv) identificaram-se FCS comuns que possam ser considerados como fatores de altíssimo impacto. 


\section{CONCLUSÕES}

A evolução da GTI no âmbito governamental nos últimos anos deve muito às fiscalizações dos órgãos de controle externo da APF. O interesse dessa fiscalização se deve principalmente, aos respectivos altos gastos em TI, em média mais de três bilhões por ano. Assim, em particular, desde 2007, o TCU lidera os levantamentos e consequentes diagnósticos da situação da GTI nas instituições públicas federais de todos os poderes da República. O instrumento de tais levantamentos é um questionário com mais de 100 questões para avaliação contemplando variáveis que representam práticas tanto de gestão quanto de governança de TI. Além disso, conforme os ciclos de levantamento, de dois em dois anos, verifica-se que uma parte das variáveis é substituída, dificultando o acompanhamento e adaptação das instituições públicas, principalmente daquelas que dispõem de pouco orçamento. Segundo os entrevistados desse trabalho, essas fiscalizações contribuem com a maturidade dos órgãos, embora considerem que as instruções advindas dessas fiscalizações podem levar ao aumento da burocracia e mesmo à diminuição do desempenho dos órgãos.

De acordo com os pressupostos de McLane (2003), esta pesquisa assumiu que a customização da GTI é a ferramenta-chave para a determinação de controles e para a racionalização dos custos de TI na criação de valor para organização. Logo, para atingir essa customização, esta tese considerou como o objeto de pesquisa FCS em GTI da APF.

Inicialmente, a identificação dos FCS utilizou parcialmente as etapas sugeridas por Bullen e Rockart (1981), conforme consta no Capítulo 3. As adaptações a esse método se mostraram eficientes, uma vez que foram levantados fatores que, de fato, direcionam a tomada de decisão em GTI. Para isso, identificaram-se FCS oriundos da percepção de gestores de TI da APF, de órgãos públicos considerados com GTI “Aprimorada” pelo índice iGovTI de 2012.

Para a validação desses fatores, os entrevistados ainda analisaram o estágio de maturidade das práticas associadas aos FCS, por meio das seguintes variáveis: $i$ ) formalização; ii) divulgação às partes interessadas; iii) práticas aprendidas e discutidas; iv) compreensão pelas partes interessadas; e v) medidas de gestão. Essas variáveis não correspondem a uma escala, tendo sido analisadas individualmente. Para os executivos, tal modificação retratou melhor a realidade dos elementos avaliados, também possibilitou a identificação de tendências que com o uso da escala não seria permitida. 
Os FCS coletados forma objeto de uma análise categorial temática, em que os fatores foram agrupados em "núcleos de sentido", definidos por meio de análise bibliométrica. A bibliometria contribuiu para a identificação de categorias refinadas, oriundas de pesquisas relevantes que deram maior robustez à formação dos "núcleos de sentido". Além disso, as categorias foram organizadas conforme a meta arquitetura corporativa de TI do Subcapítulo 2.3.2, atualizada graças às arquiteturas de duas instituições, as primeiras do Levantamento de GTI do TCU ano 2012.

Assim, quatro subsistemas e 32 categorias organizam os 259 FCS identificados. Destacam-se três FCS com a maior frequência: $i$ ) Alinhamento entre PETI e PEI, ii) Participação das áreas fins no desenvolvimento do PETI, e iii) Mapeamento de processos.

A última etapa buscou FCS de alto impacto para APF. Durante esta pesquisa, percebeu-se que os fatores anteriormente coletados se alinhavam, em parte, às questões do Levantamento de GTI do TCU ano 2012, especificamente a 21,90\% delas. Devido à dimensão da base de dados desse levantamento corresponder a uma matriz $X_{349 \times 201}$, optou-se que a mesma fosse compreendida e interpretada por análise multivariada. Assim, primeiramente, usou-se a técnica ACP, para identificar componentes principais que correspondessem a FCS. Para isso, duas hipóteses foram testadas:

- Hipótese 1: 60 variáveis correspondentes a FCS são consideradas variáveis de maior relevância pela análise ACP;

- Hipótese 2: 60 variáveis correspondentes a FCS são determinantes para o bom posicionamento no ranking das instituições avaliada.

Entretanto, a ACP foi pouco conclusiva, não permitindo revelar a relevância dos FCS, embora se identificasse um grupo com as instituições com maior iGovTI. Assim, foi necessário definir um algoritmo para prever a classificação das instituições conforme suas respostas para as questões do questionário do TCU. Após, testar 21 algoritmos de classificação, o algoritmo SVC apresentou uma taxa de acerto de 91,4\%. Uma vez identificado esse algoritmo, o próximo passo identificou as variáveis mais relevantes para esta classificação. Para isso, aplicaram-se o algoritmo VER utilizando o SVC como critério para a seleção das variáveis mais importantes para a classificação, selecionando as 60 variáveis que correspondem aos FCS levantados nas entrevistas com os executivos de TI. Os resultados mostraram que $66,66 \%$ das variáveis foram classificadas da mesma forma que os FCS 
identificados anteriormente por meio de pesquisa qualitativa o que consideramos os FCS de alto impacto em GTI da APF.

\subsection{TRABALHOS FUTUROS}

A complexidade do setor público amplia o âmbito da GC até o poder legislativo. Durante o desenvolvimento deste trabalho, o Congresso Nacional foi visitado para verificação dos possíveis rumos para as governanças e gestões públicas. Entretanto, não houve atividades sobre esse assunto nas frentes parlamentares, principalmente a Frente Parlamentar Mista de Gestão Pública e sua divisão de tecnologia.

Em paralelo, desde 1996, foi aprovada no Congresso dos Estados Unidos da America (EUA) a Lei Clinger Cohen ou lei de Reforma no Gerenciamento da Tecnologia da Informação, como uma diretriz obrigatória para as áreas de tecnologia das organizações públicas, desde âmbito federal até o municipal. Essa lei federal guia as instituições para uma tomada de decisão que proporcione eficácia nos investimentos em TI. A Lei também atribui ao CIO (Chief Information Officers) a responsabilidade de desenvolver, manter e facilitar a implementação de uma Arquitetura de Tecnologia da Informação. A consideração sobre esse aspecto é relevante, uma vez que a ausência de leis sobre o tema conduz órgãos do controle externo e do executivo a atuarem não só como controladores, mas também como legisladores do tema. Além disso, conforme Cordeiro e De Sousa Jr (2011), além da questão federal, a gestão das TIC em municípios carence de mais estudos. Nesse interim, é interessante verificar também a aplicabilidade de indicadores de organismos internacionais, como Organização das Nações Unidas (ONU), para complemento ou substituto das boas práticas utilizadas para avaliação da governança.

Além dessa consideração, é válido destacar que os FCS foram levantados após os órgãos terem concluído o Levantamento de GTI do TCU ano 2014, todavia na época das entrevistas deste trabalho a base de dados do ano 2014, não estava disponibilizada, bem como o relatório de feedback. Portanto, torna-se interessante, uma nova pesquisa considerando os dados de 2014.

Outro aspecto importante é a redefinição da meta arquitetura corporativa de TI. Esta pesquisa mostrou a viabilidade de atualização em cinco subsistemas, quais sejam: $i$ ) 
governança de TI, ii) negócio de TI, iii) gestão de TI, iv) desenvolvimento e v) entrega. Além de outros ajustes que sintetizem estudos de caso de sucesso em AC na APF.

\subsection{PUBLICAÇÕES RELACIONADAS A ESTE TRABALHO}

RAMOS, K. H. C. , DE SOUSA JR, R. T. Bibliometric Analysis of Enterprise Architecture in the Public Administration. Information (Yamaguchi), v. 18, n. 2, p. 501-520, 2015.

RAMOS, K. H. C., VIEIRA, T. P.; DA COSTA, J.P.C; DE SOUSA JR, R. T. Análise Multivariada de Fatores Críticos de Sucesso em Governança de TI na Administração Pública Federal à Luz dos Dados de Controle Externo. In: 12th International Conference on Information Systems and Technology Management CONTECSI, 2015, São Paulo. Anais... São Paulo: TECSI FEA USP, 2015. Trabalho aceito em 28 de fevereiro de 2015. 


\section{REFERÊNCIAS BIBLIOGRÁFICAS}

ABU-MUSA, A.A. Exploring information technology governance (ITG) in developing countries: an empirical study. International Journal of Digital Accounting Research, v. 7, n. 13-14, p. 71-120, 2007.

ALMEIDA, F.A.S.; KRUGLIANSKAS, I; SANTOS, S.A.; GUIMARÃES, A.T.R. Governança Corporativa em Empresa Pública e a Visão de suas Práticas pelos Grupos de interessados. XXXII Encontro da Anpad, Rio de Janeiro, jan de 2008.

ALVARES, E.; GIACOMETTI, C.; GUSSO, E. Governança corporativa: um modelo Brasileiro. Rio de Janeiro: Elsevier, 2008.

ALVES, C.A.M. As Contribuições das Ouvidorias para a Gestão e para a Governança Corporativa: Estudo em Instituições Bancárias Baseado na Regulação Brasileira. Tese de (Doutorado), Universidade de São Paulo, 2012.

ANAO - Australian National Audit Office. Public Sector Governance, v. 1 e 2: Better Practice Guide, Commonwealth of Australia, Canberra, 2003. Disponível em <http://www.anao.gov.au/uploads/documents/Public_Sector_Governance.zip>. Acesso em: 02 fev. 2014.

ANTAO, R.S. Improvement through Change and Access Control Integration. 2005. $86 \mathrm{f}$. Tese. (Master of Science In Information Security Technology and Management) - Carnegie Mellon University, 2005.

ANTHOPOULOS, L.G.; TSOUKALAS, I.A., The implementation model of a digital city: the case study of the digital city of Trikala, Greece: e-trikala, Journal of Information Technology \& Politics, v.2, n.2, p. 87-96, 2006.

ANTUNES, G.A.; GALDI, F.C.; AZEVEDO, F.B., MENDONÇA, M.M. Instrumentos Contábeis de Proteção aos Recursos Públicos Investidos nas Sociedades de Economia Mista: Uma investigação empírica. $8^{\circ}$ Congresso de Controladoria e Contabilidade da USP. $\mathrm{Jul} / 2008$.

ATTADIA, L.C.L.; MARTINS, R. A. Medição de desempenho como base para evolução da melhoria contínua. Revista Produção, v. 13 n. 2003.

BADRI, M.A.; DONALD, D.; DONNA, D. A study of measuring the critical factors of quality management. International Journal of Quality \& Reliability Management, v. 12, n. 2, p. 36-53, 1995.

BARBOSA, A.F. Governo Eletrônico: Dimensões da avaliação de desempenho na perspectiva do cidadão. 2008. 248 f. Tese (doutorado) - Escola de Administração de Empresas de São Paulo. São Paulo, 2008.

BARDIN, L. Análise de Conteúdo. Pinheiro, São Paulo, 2011.

BARRET, P. Achieving Better Practice Corporate Governance. AM Auditor General for Australia. 2005.

Disponível em 
http://www.anao.gov.au/uploads/documents/Achieving_Better_Practice_Corporate_Governan ce_in_the_Public_Sector1.pdf>.Acesso em: 15 dez. 2013.

BARTENS, Y.; DE HAES, S.; EGGERT, L.;HEILIG, L.; MAES, K.;SCHULTE, F; VOB, S. A. Visualization Approach for Reducing the Perceived Complexity of COBIT 5. In Advancing the Impact of Design Science: Moving from Theory to Practice. Springer International Publishing. p. 403-407, 2014. Disponível em <http://link.springer.com/chapter/10.1007/978-3-319-06701-8_34\#page-1>. Acesso em: 11 nov. 2014.

BECKER, J.; ALGERMISSEN, L.; NIEHAVES, B. A procedure model for process oriented e-Government projects. Business Process Management Journal, v.12, n.1, p. 61-75. 2006.

BENZI, D. M.; SOUSA JR, R. T. Medição da Confiança no Contexto dos Processos de Gestão da Tecnologia da Informação. Revista Militar de Ciência e Tecnologia, v. XXV, p. 4045, 2008.

BETZ, C. T. Architecture and patterns for IT service management, resource planning, and governance: making shoes for the Cobbler's children. USA: Morgan Kaufman Publishers, 2007.

BHATTACHARYA, H. Empirical Research. In: GIVEN, L. M. The SAGE Encyclopedia of Qualitative Research Methods. 1. ed. California: Sage Publications, v. 1 e 2, 2008.

BIDAN, M.; ROWE, F.; TRUEX, D. An empirical study of IS architectures in french SMES: integration approaches. European Journal of Information Systems, v.21, n.3, p.287-302, 2012

BIO, S. R. Sistemas de Informação: um enfoque gerencial. São Paulo: Atlas, 1996.

BOH, W.F.; YELLIN, D. Using enterprise architecture standards in managing information technology. Journal of Management Information Systems, v.23, n.3, p.163-207, 2007.

BOWEN, P.L.; CHEUNG, M.-Y.D.; ROHDE, F.H. Enhancing It Governance Practices: A Model and Case Study of an Organization's Efforts. International Journal of Accounting Information Systems, v.8, n.3, p. 191-221, 2007.

BRANCO, C.S.C.; CRUZ, C.S. A prática de governança corporativa no setor público federal. Revista do Tribunal de Contas da União, Brasília, DF, v. 45, n. 127, p. 20-27, maio/ago, 2013.

BULLEN, C.V; ROCKART, J.F. A primer on critical success factors. Center for Information Systems, Sloan School of Management. M.I.T, Cambridge Massachusetts, 1981.

CALDEIRA, M.; DHILLON, G. Are we really competent?: assessing organizational ability in delivering it benefits, Journal of Business Process Management, v. 16, p.5-28, 2010.

CARVALHO, A.G. Governança Corporativa no Brasil em Perspectiva. Revista Brasileira de Administração, São Paulo, v. 37, n. 3, p. 19-32, 2002.

CHONG, A. Y.; OOI, K.B.; DARMAWAN, N.; CHAN, F.T.S. Does employee alignment affect business-IT alignment? An empirical analysis. Journal of Computer Information Systems, v. 54, n. 3, p. 1207-1218, fev. 2013. 
CLAVER, E.; TARÍ, J.J.; MOLINA, J.F. Critical factors and results of quality management: an empirical study. Total Quality Management, v. 14, n. 1, p. 91-118, 2003.

COASE, R. The Nature of the Firm, 1. Origin, 2. Meaning, 3. Influence, 4 Journal of Law, Economics, and Organization, p. 3-47, 1988.

COLES, J. L.; DANIEL, N. D.; NAVEEN, L. Boards: Does one size fil all? Journal of Financial Economics. v. 87, p. 329-356, 2007. Disponível em: <http://ac.elscdn.com/S0304405X07001821/1-s2.0-S0304405X07001821-main.pdf?_tid=e4374208-a31f11e4-9312-00000aab0f02\&acdnat=1422031989_e25d29e686819f2fc86b32aad3a4588d >. Acesso em: 23 de jan. de 2015.

CORDEIRO, J. P. M. ; SOUSA JR, R. T. . As TICs a Serviço da Gestão para Resultados: um estudo comparado sobre a contribuição das Tecnologias da Informação e Comunicação para o desempenho dos municípios brasileiros. In: International Research Society For Public Management Regional Conference, 2011, Brasília. Anais do.. Conventry: IRSPM, 2011. v. 1. p. 11.1-11.19.

COSTA, G.G.O.; SOUZA, R.C.; GOUVEA, V.H.C. Um Procedimento Inferencial para Análise Fatorial Utilizando as Técnicas BOOTSTRAP e JACKKNIFE: Construção de Intervalos de Confiança e Testes de Hipótese. Rev. Univ. Rural. Sér. Ci. Exatas e da Terra, Seropédica, RJ, EDUR, vol. 26, n. 1-2, p. 33-44, 2007 jan-dez.

CREW, M. A.; TWIGHT, C. On the efficiency of law: A public choice perspective. Public

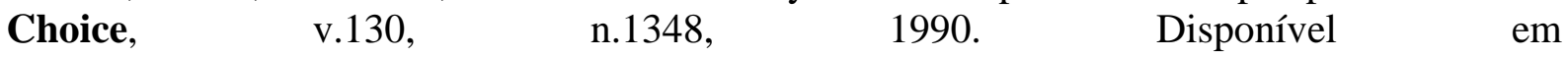
http://www.springerlink.com/index/mr523v1041v90622.pdf. Acesso em 8 de agosto, 2014

DE HAES, S.; VAN GREMBERGEN, W. IT governance structures, processes and relational mechanisms: achieving IT/business alignment in a major Belgian financial group, Hawaii International Conference on System Sciences. Proceedings of the 38th Hawaii International Conference on System Sciences, Hawaii, p.237, 2005.

DE HAES, S.; VAN GREMBERGEN, W. An exploratory study into IT governance implementations and its impact on business/IT alignment. Information Systems Management, v.26, n.2, p.123-137, 2009.

DE HAES, S.; VAN GREMBERGEN, W. COBIT 5 and Enterprise Governance of Information Technology: Building Blocks and Research Opportunities. Journal of Information Systems, v. 27, n.1, p. 307-324, 2013.

DE HAES, S.; VAN GREMBERGEN, W. An Exploratory Study into the Design of an It Governance Minimum Baseline through Delphi Research. Communications of AIS, n. 2, p. 443-458, 2008.

DHALIWAL, J.; ONITA, C.G.; POSTON, R.; ZHANG, X.P. Alignment within the software development unit: assessing structural and relational dimensions between developers and testers. The Journal of Strategic Information Systems, v.20, p.323-342, 2011

DIAS JUNIOR, F.J.; GUSSONI, R.; MUNIZ JUNIOR, J. Fatores críticos de sucesso (fcs) e desdobramento da função qualidade (qfd): aplicação em projeto de treinamento. V Congresso Nacional de Excelência em Gestão. Rio de Janeiro, 2009. 
DUNLEAVY, P.; MARGETTS, H.; BASTOW, S.; TINKLER J. New public management is dead-long live digital-era governance, Journal of Public Administration Research and Theory, v.16, n.3, p.467-494, 2006.

ELMIR, B.; BOUNABAT, B. Integrated public e-services interoperability assessment, International Journal of Information Science and Management, special issue, 1-12, 2012

FINKLER, T.F. Desenvolvimento de uma Ferramenta para Obtenção de Modelos Empíricos. Dissertação de Mestrado em Engenharia Química, Universidade Federal do Rio Grande do Sul, 2003.

FONTES FILHO, J.R. Governança organizacional aplicada ao setor público. In: III Congreso Internacional del CLAD sobre la Reforma del Estado y de la Administración Pública, Panamá, p. 28-31, 2003 out.

FOORTHUIS, R.; HOFMAN, F.; BRINKKEMPER, S.; BOS, R. Compliance assessments of projects adhering to Enterprise Architecture. Journal of Database Management, v.23, n.2, p. 44-71, 2012.

FOORTHUIS, R.M.; STEENBERGEN, M; MUSHKUDIANI, N.; BRULS, W.; BRINKKEMPER, S.; BOS, R. On Course, But Not There Yet: Enterprise Architecture Conformance and Benefits in Systems Development. In: Proceedings of the Thirty First International Conference on Information Systems (ICIS 2010), St. Louis, Missouri, USA. 2010

GHARAJEDAGUI, J. Systems Thinking: managing chaos and complexity: a platform for designing business architecture. 2. ed. Reino Unido: Elsevier, 2006.

GIDDENS, A. A constituição da sociedade. 3. edição. ed. São Paulo: Editora WMF Martins Fontes, 2009.

GREGOR, S.; JONES, D. The anatomy of a design theory. Journal of the Association for Information Systems, v.8, n.5, p.312-335, 2007.

GUARDA, G. F. ; OLIVEIRA, E. C.; DE SOUSA JÚNIOR, R. T. Analysis of Contracts of IT Outsourcing Services in TCU and the Legislation Governing these Contracts in the Federal Public Administration. In: 11th International Conference on Information Systems and Technology Management CONTECSI, 2014, São Paulo. Proceedings of.. São Paulo: TECSI FEA USP, 2014. v. 1. p. 4038-4065.

GUYON, I.; WESTON, J.; BARNHILL, S.; VAPNIK, V. Gene selection for cancer classification using support vector machines. Springer. Machine Learning, v.46, n.1-3, p.389-422, 2002.

HANNA, N.K.; QIANG, C.Z.W. China's emerging informatization strategy. Journal of the Knowledge Economy, v.1, n.2, p. 128-64, 2010.

HARDY, G. Using IT governance and COBIT to deliver value with IT and respond to legal, regulatory and compliance challenges. Information Security technical report, p.55-61, 2006

HARMON, Paul. Business Process Change: a guide for business managers and BPM and six sigma professionals. 2. ed. USA: Morgan Kaufman Publishers, 2007. 
HART, O. "Corporate Governance: Some Theory and Implications," The Economic Journal, v.105, n.430, p. 678-89, 1995.

HARZING, A. W. The Publish and Perish ${ }^{\mathrm{TM}}$ : Your Guide to Effective and Responsible Citation Analysis. Melbourne, Australia: Tarma Software Research Pty Ltd., 2010.

HARZING, A. W., van der Wal, R. A google scholar h-index for journals: an alternative metric to measure journal impact in economics \& business, Journal of the American Society for Information Science and Technology, v.60, n.1, p.41-46, 2008.

HAWORTH, D.; PIETRON, L. Sarbanes-Oxley: achieving compliance by starting with ISO17799. Information Systems Management, v.23, n.1, p. 73-87, 2006.

HAZEN, B.T.; KUNG, L.A.; CEGIELSKI, C.G.; JONES-FARMER, L. A. Performance expectancy and use of Enterprise Architecture: training as an intervention, Journal of Enterprise Information Management, v.27, n.2, p.180-196, 2014.

HENDERSON, J. C.; VENKATRAMAN, N. Strategic alignment: leveraging information, 1990.

HENDERSON, J. C.; VENKATRAMAN, N; OLDACH, S. Continuous strategic alignment: Exploiting information technology capabilities for competitive success. European Management Journal. v. 11, n. 2, p. 139-149, 1993.

HOOGERVORST, J. "Enterprise Architecture: Enabling Integration, Agility and Change." International Journal of Cooperative Information Systems, v.13, n.3, p. 213-233, 2004

HU, Q.; PLANT, R. An empirical study of the casual relationship between IT investment and firm performance. Information Resources Management Journal, v.14, n.3, p. 15-26, 2001

IBGC - Instituto Brasileiro De Governança Corporativa. Código das boas práticas de governança corporativa. 4a. ed., SP. 2009. Acesso em 14 de setembro, 2014, de http://www.ibgc.org.br.

IFAC - International Federation of Accountants. Governance in the public sector: a governing body perspective. In International public sector study $\mathrm{n}^{\circ}$ 13., 2001. Disponivel em: <http://www.ifac.org/sites/default/files/publications/files/study-13-governance-in-th.pdf >. Acesso em: 26 dez. 2013.

IM, J.J.H.; SEO, J.W. e-Government in South Korea: planning and implementation, Electronic Government, v.2, n.2, p.188-204, 2005

ISACA, Information Systems Audit and Control Association. COBIT 5: Framework, Rolling Meadows, 2014.

ISO/IEC/IEEE 42010:2011. Systems and software engineering - Architecture description, 2011.

IT GOVERNANCE INSTITUTE - ITGI. COBIT 4.0: control objectives, management guidelines, maturity models. Estados Unidos: IT Governance Institute, 2005.

ITAUDIT. Reaching Compliance Through Foundational IT Controls. Institute of Internal Auditors, v.10, 2007 
ITIL. Fundamentos em gerenciamento de serviços. [s. 1.]: ITIL, 2007.

ITPI. IT Controls Benchmarking Survey: quantifying the value, effectiveness, efficiency and security of IT controls (Formerly Known as "VEESC Survey"). [s.1]: ITPI, 2005. Disponível em:< http://www.itpi.org/docs/ITPI_Controls_Benchmarking_Survey_Initial_Findings_v0817.pdf> . Acesso em: 11 fev. 2012.

IYAMU, T.; MPHAHLELE, L. The impact of organisational structure on Enterprise Architecture deployment, Journal of Systems and Information Technology, v.16, n.1, p.219,2014

JAIN, R.; SHRIMALI, T. e-janraj-smart governance at municipal level. International Journal of Computer Science, v.3, n.2, p. 303-316, 2013.

JANSSEN, M.; CHARALABIBIS, Y.; KUK G.; CRESSWELL, T. Guest editors' introduction: e-Government interoperability, infrastructure and architecture: state-of-the-art and challenges. Journal of Theoretical and Applied Electronic Commerce Research, v.6, n.1, p.i-viii. 2011.

JANSSEN, M.; CRESSWELL, A. M. An enterprise application integration methodology for e-government. Journal of Enterprise Information Management, v.18, n.5, p.531-547, 2005.

JANSSEN, M.; HJORT-MADSEN, K. Analyzing Enterprise Architecture in National Governments: The cases of Denmark and the Netherlands. Proceedings of the 40th Hawaii International Conference on System Sciences. 2007.

JENSEN, M. C.; MECKLING, W. H. Theory of the firm: managerial behavior, agency costs and ownership structure. Journal of Financial Economics, v. 3, n. 4, p. 305-360, outubro. 1976.

JOHNSON, R.A.; WICHERN, D.W. Applied multivariate statistical analysis. 3a. ed. New Jersey: Prentice-Hall, 1992

KAISLER, S.H.; ARMOUR, F.; VALIVULLAH, M. "Enterprise Architecting: Critical Problems". Proceedings of the 38th Hawaii International Conference on System Sciences, HICSS'05. Hawaii, IEEE Computer Society, 2005.

KAPLAN, R.S., NORTON, D.P. A Estratégia em Ação: balanced scorecard. 13 ed. Rio de Janeiro: Campus, 1997.

KAPPLER, L.; LOVE, I. Corporate governance, investor protection, and performance in emerging markets. World Bank Policy Research Working Paper n. 2818, April, 2002.

KHANDELWAL, V. K. An empirical study of misalignment between Australian CEOs and IT managers. Journal of Strategic Information Systems, v. 10, p. 15-28, 2001.

KLISCHEWSKI, R. Architectures for tinkering?: contextual strategies towards interoperability in e-government, Journal of Theoretical and Applied Electronic Commerce Research, v.6, n.1, p.26-42, 2011 
KNERR, S.; PERSONNAZ, L.; DREYFUS, G. Single-layer learning revisited: a stepwise procedure for building and training a neural network. Neurocomputing, p. 41-50, 1990.

KORAC-KAKABADSE, N.; KAKABADSE, A. IS/IT governance: need for an integrated model. Corporate Governance, v.1, n.4, p.9-11, 2001.

KURTI, I.; BARROLLI, E.; SEVRANI, K. Effective IT Governance in the Albanian Public Sector-A Critical Success Factors Approach. Electronic Journal of Information Systems in Developing Countries, v.63, v.6 p. 1-22, 2014.

LAM, W. Investigating success factors in enterprise application integration: a case-driven analysis. European Journal of Information Systems, v. 2005, n.14, p. 175-187, 2005.

LANKHORST, Marc, et al. Enterprise architecture at work: modelling, communication, and analysis. Berlin: Springer, 2005.

LAURINDO, F. J. B.; SHIMIZU, T.; CARVALHO, M. M.; RABECHINI Jr., R. O papel da Tecnologia da Informação na estratégia das Organizações. Revista G\&P: Gestão e Produção, v.8, n.2, p.160-179, 2001.

LEVINA, N; ROSS, J.W. From the vendor's perspective: exploring the value proposition in information technology outsourcing. MIS Quarterly: Management Information Systems, v.27, n.1, p. 331-364, set 2003.

LIM, J.H.; TANG, S.Y. Urban e-Government initiatives and environmental decision performance in Korea. Journal of Public Administration Research and Theory, v.18, n.1, p.109-138, 2008.

LUFTMAN, J.; PAPP, R.; BRIER, T. Enablers and Inhibitors of Business-IT Alignment. Communications of Association for Information Systems, v. 1, 1999.

LUFTMAN, N. J. Measure Your Business-IT Alignment. Optimize. Business execution for CIOs Magazine. n. 26, 2003.

LUNARDI, G. Um Estudo Empírico e Analítico do Impacto da Governança de TI no Desempenho Organizacional. Tese de Doutorado em Administração. Universidade Federal do Rio Grande do Sul, 2008.

MADNICK, S.E.; WANG, R.Y.; LEE, Y.W.; ZHU, H. Overview and framework for data and information quality research, Journal of Data and Information Quality, v.1, n.1, article 2, 2009.

MALHOTRA, N. K. Pesquisa de marketing: uma orientação aplicada. Porto Alegre: Bookman, 2001

MARDIA, K.V.; KENT, J. T.; BIBBY, J. M. Multivariate analysis. London: Academic, 1979.

MARKUS, M.L.; BUI, Q.N. Going concerns: the governance of interorganizational coordination hubs, Journal of Management Information Systems, v. 28, n.4, p.163-198, 2012.

MARQUES, M. C. C. Aplicação dos Princípios da Governança Corporativa ao Setor Público. Revista da Administração Contemporânea, v. 11, n. 2, p. 11-26, abr./jun. 2007. 
MARTIN, N.; GREGOR, S. ICT governance: frameworks for managing Australian egovernment. Journal of Information Technology \& Politics, v.2, n.3, p.19-49, 2006.

MCLANE, G. IT governance and its impact on IT management (a literature review). Unpublished master dissertation, University of Technology Sydney, Sydney. 2003

MERRIAM, S. B. Qualitative research and case study application in education. San Francisco: Jossey Bass, 2002.

Ministério do Planejamento, Orçamento e Gestão (MPOG). Secretaria de Logística e Tecnologia da Informação - SLTI. Contratações Públicas de Bens e Serviços de Tecnologia da Informação, 2015.

MOSTAFA, M.M.; EL-MASRY, A.A., Citizens as consumers: profiling e-Government services' users in Egypt via data mining techniques. International Journal of Information Management, v.33, n.4, p. 627-641, 2013

NEELY, A.; ADAMS, C. Perspectives on performance: the performance prism. Working paper, Center for Business Performance, School of Management, Cranfield University, Cranfield, 2000.

NFUKA, E.N.; RUSU, L. The Effect of Critical Success Factors on It Governance Performance. Industrial Management and Data Systems, v.111, n.9, p.1418-1448, 2011.

ORGANISATION FOR ECONOMIC CO-OPERATION AND DEVELOPMENT - OECD. Principles of corporate governance. Paris, 2004. Disponível em : <http,oecd,org>. Acesso em : 15 de outubro de 2014.

PACHECO, A. L. F. Governança de TI: O desafio atual da Administração Pública. 39 Seminário Nacional TIC para Gestão Pública, Recife, 2011. Disponível em:<portal2.tcu.gov.br/portal/pls/portal/docs/2188949.PDF> Acesso em: 6 nov. 2013.

PANKOWSKA, M. National frameworks' survey on standardization of e-Government documents and processes for interoperability, Journal of Theoretical and Applied Electronic Commerce Research, v.3, n.3, p.64-82, 2008.

PAPAZOGLOU, M.P.; HEUVEL, W.J. Service oriented architectures: approaches, technologies and research issues. The VLDB Journal, v.16, n.3, p.389-415, 2007.

PEREIRA, M.I.; SANTOS, S. A. Modelo de gestão: uma análise conceitual. Brasil, Pioneira, 2001.

PERISTERAS, V.; LOUTAS, N.; GOUDOS, S.K.; TARABANIS, K. A conceptual analysis of semantic conflicts in pan-european e-Government services. Journal of Information Science, v.34, n.6, p.877-891, 2008.

PERISTERAS, V.; TARABANIS, K. Toward and Enterprise for Public Administration Using a Top-Down Approach. European Journal of Information systems, v. 9, p.252-260, dez. 2000.

PETERSON. R. R. Crafting Information Technology Governance. Information Systems Management, v.21, p.7, 2004. 
PEUTO, B. L. Architecture of a New Microprocessor, In Computer, v. 12, n. 2, fev, 1979. Disponível

em: $<$ http://ieeexplore.ieee.org/xpl/login.jsp?tp=\&arnumber=1658612\&url=http\%3A\%2F\%2Fieeex plore.ieee.org\%2Fxpls\%2Fabs_all.jsp\%3Farnumber\%3DI1658612 > Acesso em: 6 de março de 2013.

PLAZAOLA, L., et al. A metamodel for strategic bussiness and IT alignment assesment. Estocolmo: [s. e.], 2006.

POLLARD, C.; CATER-STEEL, A. Justifications, strategies, and critical success factors in successful ITIL implementations in U.S. and Australian companies: an exploratory study. Information Systems Management, v. 26, n. 2, p. 164-175, 2009. Disponível em:<http://dx.doi.org/10.1080/10580530902797540>. Acesso em: 10 dez. 2014.

PROCOPIUCK, M. Políticas Públicas e Fundamentos da Administração Pública: Análise e Avaliação: governança e redes de políticas, administração judiciária. São Paulo: Atlas, 2013.

RAMAGE, P. Factors impacting on the adoption and operation of corporate governance reform in Australian state government departments. Tese (Doutorado em Engenharia de Produção) -Victoria University, 2009.

RAMOS, K. H. C; MOLINARO, L. F. R.; ROCHA, A. S.; MARANHÃO, A.C.K., DEUS, F. E. Enterprise Architecture Applied Towards Sustainable IT Governance In: Corporate Environmental Management Information System.1 ed. : Igi Global, 2010, v.13.

RAMOS, K. H. C.; DE SOUSA JR, R. T. Bibliometric Analysis of Enterprise Architecture in the Public Administration. Information (Yamaguchi), v. 18, n. 2, p. 501-520, 2015

RAMOS, K. H. C. Governança e Gestão de Tecnologia da Informação: decompondo a Organização em componentes com base em arquitetura organizacional orientada a serviços. 2009, 203f. Dissertação (Mestrado em Engenharia). Universidade de Brasília. Departamento de Engenharia Elétrica, Brasília, 2009.

REICH, B.H; BENBASAT, I. Factors that influence the social dimension of alignment between business and information technology objectives. MIS Quartely, v.24, n.1, p.81-113, 2000 .

RINIA, E.J.; VAN LEEUWEN, T.N.; VAN VUREN H.G., Comparative analysis of a set of bibliometric indicators and central peer review criteria: Evaluation of condensed matter physics in the Netherlands. Research policy, v.7,v.1,p. 95-107. 1998.

ROCHA, H. M.; DELAMARO, M. C. Combinação de métodos não paramétricos na comparação de percepções sobre fatores críticos de sucesso na indústria automobilística Brasileira. Revista da Produção Online, Florianópolis, SC, v.13, n. 4, p. 1493-1516, out./dez. 2013. Disponível em:<http://producaoonline.org.br/rpo/article/view/1472/1090>. Acesso em: 02 mar. 2014.

ROCHA, H. M.; DELAMARO, M. C.; QUINTELlA, H. L. M. M.; AFFONSO, L. M. F. Fatores críticos de sucesso no processo de desenvolvimento de produtos na indústria automotiva Sul-Fluminense. In: VII Simpósio de Excelência em Gestão e Tecnologia, 2010, Resende. VII Simpósio de Excelência em Gestão e Tecnologia. Resende: AEDB, 2010. 
Disponível em: $<$ http://www.aedb.br/seget/artigos10/234_SEGeT_FCS_c_autores.pdf $>$. Acesso em: dez 2013.

ROCKART, J. F. A new approach to defining the chief executive's information needs. Working Paper no. 37. Center for Information Systems Research, Sloan School of Management. Massachusetts Institute of Technology. maio 1978.

Chief Executives Define Their Own Data Needs. Harvard Business Review, v.57, p.81-83, 1979.

.Critical success factors: a 2002 retrospective. CIRS Research Briefings 2002, v 2, Massachusettes. Institute of Technology, Sloan School of Management, 2002.

RODRIGUES, L.C.; MACCARI, E.A.; SIMÕES, S.A. O desenho da gestão da tecnologia da informação nas 100 maiores empresas na visão dos executivos de TI. JISTEM Journal of Information Systems and Technology Management (Online), v. 6, n. 3, 2009. Disponível em:http://www.scielo.br/scielo.php?script=sci_arttextepid=S1807-

$17752009000300006 \mathrm{elng}=$ enenrm=iso. Acesso em: dez 2013.

ROSS, J.; Beath, C., SUBRAMANI, M. Synchronizing IT Management Practices for Business Value. Center for Information Systems Research. MIT Sloan, July, 2002.

ROY, J., Electronic service delivery in a multi-channel public sector: an assessment of the government of Canada, International Journal of Information Technology and Management, v.6, n.2/3, p.148-169, 2007.

RUMMLER, G.; BRACHE, A.P. Melhores desempenhos das empresas. São Paulo: Makron Books, 1994.

SABIN, J.G; FERRÃO, M.F.; FURTADO, J.C. Análise multivariada aplicada na identificação de fármacos antidepressivos. Parte II: Análise por componentes principais (PCA) e o método de classificação SIMCA. Brazilian Journal of Pharmaceutical Sciences, v. 40, n. 3, jul./set., 2004.

SALEM, H. Organizational Performance Management and Measurement: The Lebanese Experience, Beirut. Economic and Social Council, 2003. Disponível em <http://unpan1.un.org/intradoc/groups/public/documents/unescwa/unpan010860.pdf>. Acesso em 04 de outubro de 2012.

SANTANA, M. A preliminary assessment of the development of e-Government in a local government in Peru, Journal of Asia-Pacific Studies, v.12, p.75-89, 2009.

SANTOS, M.F.N.; QUITAIROS, P.C.R.; OLIVEIRA, E.A.A.Q. Um estudo exploratório da produção acadêmica sobre a relação entre governança de ti e Governança Corporativa. The 4th International Congress University Industry and Cooperation, Taubate, SP, Brazil, December, 2012.

SANTOS, R.N.M.; KOBASHI, N.Y. Bibliometria, Cientometria, Infometria: conceitos e aplicações. Pesq. bras. Ci. Inf., Brasília, v.2, n.1, p.155-172, jan./dez. 2009

SAUL, L.A.; LÓPEZ-GONZÁLEZ, M.A.; MORENO-PULIDO, A.; CORBELLA, S.; COMPAÑ, V.; FEIXAS, G. Bibliometric review of the repertory grid technique: 1998-2007. Journal of Constructivist Psychology, v.25, n.2, p. 112-131, 2012. 
SCHEER, A.-W.: ARIS - Business Process Frameworks, 2nd ed. Berlin et al, 1998.

SCHEKKERMAN, J. How to survive in the jungle of enterprise architecture frameworks: creating or choosing an enterprise architecture framework. Canadá: TrafFord, 2004.

SCHNEIDER, J.W.; BORLUND P. Introduction to bibliometrics for construction and maintenance of thesauri. Journal of Documentation, v. 60, n. 5, p. 524-549, 2004.

SCOTT, G.M. Still not solved: the persistent problem of IT strategic planning. Communications of the Association for Information Systems, v.16, p.904-936, 2005.

SILVA, T. E. V.; SOUZA, T. I. A.; BARROS FILHO, F. F.; SANTOS, F. J.; GOMES, P. R. B.; RIBEIRO, G.; NUNES, A. O.; VASCONCELOS, F. H. L. Análise de Componentes Principais Aplicada a Avaliação Discente: Um Estudo de Caso em Ambientes Virtuais de Aprendizagem. Computer on the Beach. p. 71-80, 2012. Disponível em 28/12/2014, de https://www6.univali.br/seer/index.php/acotb/article/view/6552.

SILVEIRA, A. M. Governança corporativa e estrutura de propriedade : determinantes e relação com o desempenho das empresas no Brasil, 2004. 250 f. Tese (Doutorado) Universidade de São Paulo, 2004.

SIMONSSON, M.; EKSTEDT, M. Prioritizing IT governance: literature vs practice. [s.1.]: Earp Working Paper MS105, 2006.2 Disponível em:<http://whitepapers.zdnet.com/white.aspx?docid=167004>. Acesso em: 21 jan. 2008.

SOUSA JR, R. T. Gestão da Qualidade de Redes: Processos de Garantia, Controle da Qualidade e Qualimetria de Serviços de Rede. In: Congresso TELEXPO 95, 1995, São Paulo. Anais da TELEXPO 95, 1995.

SOUSA JR, R. T.; FELIX, R.; FELIX, P. P. Balanced Scorecard: adequação para a gestão estratégica nas organizações públicas. Revista do Serviço Público, v. 62, p. 51-74, 2011.

TAN, W.G.; CATER-STEEL, A; TOLEMAN, M. Implementing it service management: A case study focussing on critical success factors. Journal of Computer Information Systems, 2009 .

TARAFDAR, M.; GORDON, S.R. Understanding the influence of information systems competencies on process innovation: A resource-based view. Journal of Strategic Information Systems, v.16. p.353-392, 2007.

TARÍ, J.J. Components of successful total quality management. The TQM Magazine, v.17,:n.2, p. 182-194, 2005.

TEIXEIRA JÚNIOR, F. Alinhamento estratégico entre os negócios e a tecnologia da informação (TI): Estudo de Caso em uma Instituição Financeira. Dissertação (Mestrado em Administração de Empresas) - Universidade de Fortaleza, Fortaleza, 2003.

TORRES, J. A. S.; DEUS, F. E. G.; DE SOUSA JÚNIOR, RAFAEL TIMÓTEO. Diagnóstico do governo eletrônico brasileiro - uma análise com base no modelo de gerenciamento de identidades e no novo guia de serviços. In: XIV Simpósio Brasileiro em Segurança da Informação e de Sistemas Computacionais SBSeg 2014, Belo Horizonte. Anais do.. Porto Alegre: Sociedade Brasileira de Computação, v. 1. p. 490-499, 2014. 
TRIBUNAL DE CONTAS DA UNIÃO. Levantamento dos Gastos em TI na Administração Pública Federal. Brasília: Tribunal de Contas da União, Brasília: TCU, 2008a.

TRIBUNAL DE CONTAS DA UNIÃO. Acórdão 1603/2008-TCU-Plenário, Brasília: TCU. $2008 b$.

TRIBUNAL DE CONTAS DA UNIÃO. Acórdão 2471/2008-TCU-Plenário, Brasília: TCU. 2008c.

TRIBUNAL DE CONTAS DA UNIÃO. Aquisições em TI, IN 04/2008-SLTI e perspectivas futuras, Brasília: TCU, 2009.

TRIBUNAL DE CONTAS DA UNIÃO. Levantamento de governança de TI 2010 / Relator Ministro Aroldo Cedraz. Brasília: TCU, 2010a.

TRIBUNAL DE CONTAS DA UNIÃO. Acórdão 2308/2008-TCU-Plenário. 2010b.

TRIBUNAL DE CONTAS DA UNIÃO. Relatório de Levantamento TC 000.390/2010-0. 2010c.

TRIBUNAL DE CONTAS DA UNIÃO. Acórdão 1233/2012-TCU-Plenário, Brasília: TCU, 2012a.

TRIBUNAL DE CONTAS DA UNIÃO. Acórdão 2585/2012-TCU-Plenário, Brasília: TCU, $2012 b$.

TRIBUNAL DE CONTAS DA UNIÃO. Levantamento de Governança de TI 2012: resultado retornado para a instituição: Tribunal de Contas da União, Brasília: TCU, 2012c $\begin{array}{llllll}\text { Recuperado em } & 10 & \text { de } & \text { outubro } & 2014, & \text { de }\end{array}$ http://portal2.tcu.gov.br/portal/page/portal/TCU/comunidades/tecnologia_informacao/pesquis as_governanca.

TRIBUnAl DE CONTAS DA UNIÃO. Portaria-TCU No 175, de 9 de julho de 2013, Brasília: TCU, 2013a.

TRIBUNAL DE CONTAS DA UNIÃO. Acórdão 3117/2012-TCU-Plenário, Brasília: TCU, $2013 b$.

TRIBUNAL DE CONTAS DA UNIÃO. Levantamento de governança de TI 2012. Relator Ministro Walton Alencar Rodrigues. Brasília: TCU, Secretaria de Fiscalização de Tecnologia da Informação. 2013c.

TRIPATHI, R.; GUPTA M.P.; BHATTACHARYA J. Interoperability adoption among government and corporate portals in India: a study, Journal of Enterprise Information Management, v.25, n.2, p.98-122, 2012.

VAN DER RAADT, B.; SOETENDAL, J.; PERDECK, M.; VAN VLIET, H. Polyphony in Architecture. Proceedings of the 26th International Conference on Software Engineering, IEEE Computer Society, 2004.

VAN GREMBERGEN, W. Strategies for information technology governance. [Estados Unidos]: Idea Group Publishing, 2004. 
VERGARA, S.C. A resiliência de profissionais angolanos. Revista de Administração Pública, Rio de Janeiro, v.42, n.4, p.701-18, 2008 jul/ago.

VERHOEF, C. Quantifying the effects of IT-governance rules. Science of Computer Programming, v.67, n.2-3, p.247-277, 2007.

VICINI, L. Análise multivariada da teoria à prática. Especialização em Ciências Naturais da Universidade Federal de Santa, 2005.

VOGEL, T.; SCHMIDT, A.; LEMM, A.; ÖSTERLE, H. Service and document based interoperability for European e customs solutions, Journal of Theoretical and Applied Electronic Commerce Research, v.3, n.3, p.17-37, 2008.

WEILL, P. Don't just lead govern: how top-performing firms govern IT. MIS Quarterly Executive, v.3, n.1, p.1-17, 2004.

WEILL, P.; ROSS, J.W. It Governance: How Top Performers Manage It Decision Rights For Superior Results. Boston, Massachusetts: Harvard Business School Press. 2004.

WEILL, P.; ROSS, J. W. Governança de TI, Tecnologia da Informação. M. Books do Brasil, São Paulo, 2006.

WILLIAMSON, O. E. Markets and Hierarchies, New York: Free Press, 1975.

The Economic Institutions of Capitalism, New York: Free Press, 1985.

The mechanisms of governance. 1 ed. Oxford University Press, 1996.

YADAV, N.; YADAV H. An electronic government model based on case study approach, Electronic Government, v.6, n.4, p.421-432, 2009

YLIMÄKI, T. Potential critical success factors for enterprise architecture. Journal of Enterprise Architecture, v. 2, n. 4, p. 29-40, 2006. Disponível em:<http: https://jyx.jyu.fi/dspace/bitstream/handle/123456789/41369/Article_CSFs_for_EA.pdf?seque nce=1> Acesso em: 17 fev. 2014.

YOUNG, R; POON, S. Top management support—almost always necessary and sometimes sufficient for success: Findings from a fuzzy set analysis. International Journal of Project Management, v. 31, p.943-957, 2013.

YOUNG, R.; JORDAN, E. Top management support: Mantra or necessity? International Journal of Project Management, v. 2006, p.713-725, 2008.

ZACHMAN, John A. The framework for enterprise architecture: background, description and utility by John A. Zachman, published by Zachman Institute for Framework Advancement (ZIFA) Document ID 810-231-0531. 1996.

ZAVADSKAS, E.K.; KAKLAUSKAS, A.; BANAITISC, A. Application of e technologies for regional development: the case of Vilnius city. Journal of Business Economics and Management, v.11, n.3, p.415-427, 2010.

ZIKMUND, W.G. Exploring Marketing Research. Forth Worth. 6. ed. The Dryden Press, 1997. 


\section{ANEXO I}

\section{Universidade de Brasília}

Prezado (a) Profissional,

O Departamento de Engenharia Elétrica da Universidade de Brasília está desenvolvendo um estudo com o objetivo de identificar os "fatores críticos de sucesso em governança de TI na Administração Pública Federal".

Essa pesquisa está sendo realizada junto a Gestores da Administração Pública Federal que lideram os trabalhos de GTI e que chefiam áreas de trabalho que se encaixam nesse perfil. Dessa forma, V.Sa faz parte da amostra selecionada para a coleta de dados e por isso solicitamos sua colaboração no sentido de participar de uma entrevista individual sobre o tema.

Por se tratar de trabalho de natureza acadêmica, as informações serão utilizadas apenas para esta finalidade indicada. V.Sa não será identificada, já que as informações serão analisadas em termos globais.

Contando com vossa colaboração, desde já expressamos os mais sinceros agradecimentos e colocamonos à disposição para quaisquer esclarecimentos.

Cordialmente,

Karoll Haüssler Carneiro Ramos Doutoranda em Engenharia ElétricaFT/UnB
Rafael Timóteo de Sousa Jr. Professor Doutor em Engenharia ElétricaFT/UnB 


\section{Sobre o Questionário}

Este questionário trata da entidade responsável por prover todo o serviço de TI para as outras entidades da organização. Nesse questionário considera-se que a área de TI é uma entidade autônoma composta por três subsistemas: Direcionamento, Desenvolvimento e Entrega. Sendo assim, os fatores críticos de sucesso em governança de TI (FCS em GTI) serão analisados sob a ótica de cada um deles.

Direcionamento (do inglês Direct) envolve a formulação e planejamento de estratégias e arquiteturas, tem as funções: planejamento e controle em alto-nível; monitoramento das demandas; definição das prioridades no portfólio de serviços e produtos a serem desenvolvidos ou entregues por outros subsistemas.

Desenvolvimento (do inglês Develop) gere o desenvolvimento e construção de soluções, utiliza os processos de gestão de projetos que garantem a gestão da qualidade e da configuração para mitigar os riscos desse subsistema.

Entrega (do inglês Delivery) implementa os projetos desenvolvidos, gerencia o catálogo de serviços, executa todos os sistemas de informação, suporte e equipamentos para operações, assim como a gestão dos programas de manutenção para prover o suporte a esses sistemas e equipamentos.

Para cada um desses subsistemas considere também os aspectos organizacionais, processos, pessoas, tecnologia e outros que você considere relevantes para a Organização.

No aspecto organizacional (estratégico) são apresentadas as estratégias, a governança, a estrutura e arquiteturas corporativas e o emprego dos recursos, além dos instrumentos que auxiliam na compreensão da visão dos clientes, fornecedores e recursos humanos.

No aspecto processos (tático) as variáveis devem representar o fluxo de processos e procedimentos.

No aspecto pessoas (operacional) são verificadas as pessoas que colaboram com a governança de TI. Ao tratar das pessoas, refere-se às competências profissionais que contribuem para a realização dos objetivos do negócio e à gestão de recursos humanos.

No aspecto de tecnologia pessoas (operacional) são verificadas as tecnologias que viabilizam a execução das atividades de governança de TI. Ressalta-se que por meio dessa tecnologia podem-se construir as bases para automatização da governança de TI.

Frisa-se que Fatores Críticos de Sucesso (FCS) são motivados pelas necessidades de informações de gestores e em especial de diretores executivos que, geralmente, não estão claramente determinadas. Vislumbre os FCS em GTI como as questões que são essenciais para eficiência e eficácia da Governança de TI e que contribuem para o sucesso do desempenho da TI. 


\section{ANEXO II}

Perfil da Organização

Questão 1: Qual o perfil da entidade

1. Autarquia

2. Fundação pública

3. Empresa pública

4. Sociedade de economia mista

5. Agência reguladora

6. Agência executiva

7. Serviço social autônomo

8. Tribunal de Contas

9. Congresso Nacional

10. Presidência da República

11. Ministério

12. Tribunais

13. Secretaria

14. Organização Militar

15. Outros

Questão 2: Em quais anos o órgão participou no levantamento da governança de TI realizada pelo TCU/Sefti ?

1. Participação apenas ano 2007

2. Participação apenas ano 2010

3. Participação apenas ano 2012

4. Participação apenas nos anos 2007 e 2010

5. Participação apenas nos anos 2007 e 2012

6. Participação apenas nos anos 2010 e 2012

7. Participação em todos os três anos

Questão 3: Qual o resultado do $i G o v T I$ da organização no relatório da governança de TI realizada pelo TCU/Sefti ano 2012?

Questão 4: Qual a posição da organização no levantamento da governança de TI realizada pelo TCU/Sefti ano 2012?

Questão 5: Quantas pessoas fazem parte dos trabalhos em governança de TI na organização?

1. De 1 a 5 pessoas

2. De 5 a 10 pessoas

3. De 10 a 15 pessoas

4. De 15 a 20 pessoas

5. De 20 a 25 pessoas

6. Mais de 25 pessoas 
Perfil do Entrevistado

Questão 6: Qual o cargo do entrevistado?

1. Assessor;

2. Auditor;

3. Capitã de Corveta;

4. Chefe;

5. Coordenador Geral;

6. Diretor;

7. Especialista.

8. General;

9. Gerente Executivo;

10. Gerente;

11. Responsável de Área;

12. Secretário;

13. Subsecretário;

14. Superintendente;

15. Vice-Presidente.

16. Outros

Questão 7: A quanto tempo atua na governança de TI?

17. Menos de 1 ano

18. Entre 1 e 3 anos

19. Entre 3 e 5 anos

20. Entre 5 e 7 anos

21. Mais de 7 anos

Questão 8: Quais são suas atribuições na governança de TI?

Questão 9: Você recebeu algum curso/treinamento sobre governança de TI?

1. Não

2. Sim

Questão 10: Se sim para questão 9. Como foi o curso/treinamento?

1. Capacitação interna realizada pela equipe de projeto por meio de estudos.

2. Treinamento realizado por consultoria especializada.

3. Treinamento realizado por outros órgãos públicos.

4. Curso de pós-graduação.

5. Outros:

Questão 11: Se sim para questão 9. Somando-se todos os treinamentos recebidos em governança de TI, qual o tempo recebido em treinamento?

1. Menos de 10 horas

2. Entre 10 horas e 20 horas

3. Entre 20 horas e 60 horas semanas

4. Entre 60 horas e 100 horas

5. Entre 100 horas e 200 horas

6. Mais de 200 horas 


\section{Questionário dos Fatores Críticos de Sucesso em Governança de TI}

Como o seu órgão se destaca em governança de TI na Administração Pública Federal. Analise o que de fato é de grande importância para o sucesso da governança de TI do seu órgão.

Questão 12. Escreva os FCS em GTI em Direcionamento para a governança de TI do Órgão. Por favor, caso existam mais FCS em GTI além do espaço, inclua linha com o nome e a descrição.

\begin{tabular}{|l|l|l|}
\hline Código & Nome & Descrição \\
\hline DI01. & & \\
\hline DI02 & & \\
\hline DI03 & & \\
\hline DI04 & & \\
\hline DI05 & & \\
\hline
\end{tabular}

Questão 13. Escreva os FCS em GTI em Desenvolvimento para a governança de TI do Órgão. Por favor, caso existam mais FCS em GTI além do espaço, inclua linha com o nome e a descrição.

\begin{tabular}{|l|l|l|}
\hline Código & Nome & Descrição \\
\hline DE001. & & \\
\hline DE002 & & \\
\hline DE003 & & \\
\hline DE004 & & \\
\hline DE005 & & \\
\hline
\end{tabular}

Questão 14. Escreva os FCS em GTI em Entrega para a governança de TI do Órgão. Por favor, caso existam mais FCS em GTI além do espaço, inclua linha com o nome e a descrição.

\begin{tabular}{|l|l|l|}
\hline Código & Nome & Descrição \\
\hline E001. & & \\
\hline E002 & & \\
\hline E003 & & \\
\hline E004 & & \\
\hline E005 & & \\
\hline
\end{tabular}

Avalie os FCS em GTI atribuindo os valores de 1 a 5. Ressalta-se que um FCS em GTI pode receber mais de um valor. Atenção não é escala e sim múltiplas respostas.

- Assinale [1] se não possui as práticas formalizadas relacionadas ao FCSTI, com lacunas no seu entendimento pelas partes interessadas.

- Assinale [2] se divulga o conteúdo do FCS em GTI pelos meios de comunicação disponíveis (revistas, sites, emails, blogs e wikis) com o entendimento das partes interessadas.

- Assinale [3] se aprende e discute o conteúdo do FCS em GTI por meio de treinamentos, reuniões departamentais, palestras entre outros meios de aprendizado com uma boa compreensão.

- Assinale [4] se as partes interessadas possuem um bom entendimento e incentivam as práticas vinculadas aos FCS em GTI.

- Assinale [5] se existem medidas de gestão (formas de mensuração) que possibilitam o monitoramento do FCS em GTI buscando uma maior eficácia e eficiência de seus resultados.

Questão 15. Avaliação do Direcionamento

\begin{tabular}{|l|l|l|l|l|l|}
\hline Código & $\mathbf{1}$ & $\mathbf{2}$ & $\mathbf{3}$ & $\mathbf{4}$ & $\mathbf{5}$ \\
\hline DI01. & & & & & \\
\hline DI02 & & & & & \\
\hline DI03 & & & & & \\
\hline DI04 & & & & & \\
\hline DI05 & & & & & \\
\hline
\end{tabular}


Questão 16. Avaliação do Desenvolvimento

\begin{tabular}{|l|l|l|l|l|l|}
\hline Código & $\mathbf{1}$ & $\mathbf{2}$ & $\mathbf{3}$ & $\mathbf{4}$ & $\mathbf{5}$ \\
\hline DE001. & & & & & \\
\hline DE002 & & & & & \\
\hline DE003 & & & & & \\
\hline DE004 & & & & & \\
\hline DE005 & & & & & \\
\hline
\end{tabular}

Questão 17. Avaliação da Entrega

\begin{tabular}{|l|l|l|l|l|l|}
\hline Código & $\mathbf{1}$ & $\mathbf{2}$ & $\mathbf{3}$ & $\mathbf{4}$ & $\mathbf{5}$ \\
\hline E001. & & & & & \\
\hline E002 & & & & & \\
\hline E003 & & & & & \\
\hline E004 & & & & & \\
\hline E005 & & & & & \\
\hline
\end{tabular}

Questão 18. Os FCS em GTI são identificados e definidos na organização? Se sim, como é o processo de identificação e definição?

Questão 19. Qual esquema, modelo ou arquitetura que representa a governança de TI da organização?

Questão 20. Qual a estrutura organizacional (organograma) da área de TI da organização?

*Observações 


\section{ANEXO III}

Posição e iGovTI do ano 2012 de 349 instituições públicas. Quadro retirado do site gestaoti.org.br no dia 03/09/2014.

\begin{tabular}{|c|c|c|c|c|}
\hline $\begin{array}{c}\text { Ranking } \\
\text { Geral }\end{array}$ & Órgão & Poder & Tipo & $\begin{array}{l}\text { IGovTI } \\
2012\end{array}$ \\
\hline 1 & Banco central do brasil & Executivo & Seccional & 0,84 \\
\hline 2 & Petróleo brasileiro s.a. & Executivo & $\begin{array}{l}\text { Sociedade de Economia } \\
\text { Mista }\end{array}$ & 0,83 \\
\hline 4 & Marinha do brasil & Executivo & Seccional & 0,83 \\
\hline 3 & Caixa econômica federal & Executivo & Empresa Pública & 0,82 \\
\hline 5 & Departamento de polícia federal & Executivo & Seccional & 0,81 \\
\hline 6 & Tribunal de contas da união & Legislativo & N/A & 0,79 \\
\hline 7 & Hospital de clínicas de porto alegre & Executivo & Seccional & 0,78 \\
\hline 8 & Empresa gestora de ativos & Executivo & Empresa Pública & 0,78 \\
\hline 9 & $\begin{array}{l}\text { Instituto nacional de metrologia, } \\
\text { normalização e qualidade industrial }\end{array}$ & Executivo & Seccional & 0,74 \\
\hline 10 & $\begin{array}{l}\text { Banco nacional de desenvolvimento } \\
\text { ecônomico e social }\end{array}$ & Executivo & $\begin{array}{c}\text { Sociedade de Economia } \\
\text { Mista }\end{array}$ & 0,74 \\
\hline 11 & $\begin{array}{l}\text { Companhia hidroelétrica do são } \\
\text { francisco }\end{array}$ & Executivo & $\begin{array}{l}\text { Sociedade de Economia } \\
\text { Mista }\end{array}$ & 0,73 \\
\hline 12 & Secretaria da receita federal do brasil & Executivo & Correlata & 0,72 \\
\hline 13 & $\begin{array}{l}\text { Ministério da defesa / comando do } \\
\text { exército - dct }\end{array}$ & Executivo & Seccional & 0,71 \\
\hline 14 & $\begin{array}{l}\text { Ministério da defesa / comando do } \\
\text { exército - dgp }\end{array}$ & Executivo & Seccional & 0,71 \\
\hline 15 & Ministério da educação & Executivo & Setorial & 0,69 \\
\hline 17 & Tribunal superior eleitoral & Judiciário & N/A & 0,67 \\
\hline 16 & Tribunal superior do trabalho & Judiciário & N/A & 0,67 \\
\hline 18 & Agência nacional de energia elétrica & Executivo & Seccional & 0,65 \\
\hline 19 & $\begin{array}{l}\text { Universidade tecnológica federal do } \\
\text { paraná }\end{array}$ & Executivo & Seccional & 0,64 \\
\hline 20 & $\begin{array}{l}\text { Ministério da defesa / comando do } \\
\text { exército - decex }\end{array}$ & Executivo & Seccional & 0,64 \\
\hline 22 & $\begin{array}{l}\text { Tribunal regional do trabalho } 23 \mathrm{a} \\
\text { região/mt }\end{array}$ & Judiciário & N/A & 0,62 \\
\hline 21 & Instituto de pesquisa econômica aplicada & Executivo & Seccional & 0,62 \\
\hline 23 & $\begin{array}{c}\text { Instituto nacional da propriedade } \\
\text { industrial }\end{array}$ & Executivo & Seccional & 0,62 \\
\hline 24 & $\begin{array}{l}\text { Tribunal regional do trabalho } 13 \mathrm{a} \\
\text { região/pb }\end{array}$ & Judiciário & N/A & 0,62 \\
\hline 25 & $\begin{array}{l}\text { Secretaria-geral da presidência da } \\
\text { república }\end{array}$ & Executivo & Setorial & 0,62 \\
\hline 26 & $\begin{array}{l}\text { Tribunal regional do trabalho } 4 \mathrm{a} \\
\text { região/rs }\end{array}$ & Judiciário & N/A & 0,62 \\
\hline 27 & Tribunal regional federal 4a região & Judiciário & N/A & 0,61 \\
\hline 28 & $\begin{array}{c}\text { Empresa brasileira de pesquisa } \\
\text { agropecuária }\end{array}$ & Executivo & Empresa Pública & 0,61 \\
\hline 29 & Agência nacional de aviação civil & Executivo & Seccional & 0,61 \\
\hline 30 & Tribunal regional eleitoral/to & Judiciário & N/A & 0,61 \\
\hline 31 & Tribunal regional eleitoral/rs & Judiciário & N/A & 0,61 \\
\hline 32 & Eletrosul centrais eletricas s.a. & Executivo & $\begin{array}{l}\text { Sociedade de Economia } \\
\text { Mista }\end{array}$ & 0,6 \\
\hline 33 & Fundação universidade federal de & Executivo & Seccional & 0,6 \\
\hline
\end{tabular}




\begin{tabular}{|c|c|c|c|c|}
\hline & uberlândia & & & \\
\hline 35 & $\begin{array}{l}\text { Empresa brasileira de correios e } \\
\text { telégrafos }\end{array}$ & Executivo & Empresa Pública & 0,6 \\
\hline 34 & Superior tribunal de justiça & Judiciário & N/A & 0,6 \\
\hline 36 & Grupo hospitalar conceição & Executivo & $\begin{array}{l}\text { Sociedade de Economia } \\
\text { Mista }\end{array}$ & 0,59 \\
\hline 37 & Tribunal regional eleitoral/es & Judiciário & N/A & 0,59 \\
\hline 38 & Ministério das minas e energia & Executivo & Setorial & 0,59 \\
\hline 40 & $\begin{array}{l}\text { Agência nacional de transportes } \\
\text { terrestres }\end{array}$ & Executivo & Seccional & 0,58 \\
\hline 39 & Furnas centrais elétricas s.a. & Executivo & $\begin{array}{l}\text { Sociedade de Economia } \\
\text { Mista }\end{array}$ & 0,58 \\
\hline 41 & Banco da amazônia s.a. & Executivo & $\begin{array}{c}\text { Sociedade de Economia } \\
\text { Mista }\end{array}$ & 0,57 \\
\hline 42 & Agência nacional de saúde suplementar & Executivo & Seccional & 0,57 \\
\hline 43 & Universidade federal fluminense & Executivo & Seccional & 0,57 \\
\hline 44 & Companhia nacional de abastecimento & Executivo & Empresa Pública & 0,57 \\
\hline 46 & Força aérea brasileira & Executivo & Seccional & 0,57 \\
\hline 45 & $\begin{array}{l}\text { Fundação universidade federal do } \\
\text { tocantins }\end{array}$ & Executivo & Seccional & 0,57 \\
\hline 47 & $\begin{array}{l}\text { Ministério da defesa / comando do } \\
\text { exército - eme }\end{array}$ & Executivo & Seccional & 0,57 \\
\hline 48 & Ministério da previdência social & Executivo & Setorial & 0,56 \\
\hline 49 & Universidade federal de viçosa & Executivo & Seccional & 0,56 \\
\hline 50 & Ministério da integração nacional & Executivo & Setorial & 0,55 \\
\hline 51 & $\begin{array}{c}\text { Conselho nacional de desenvolvimento } \\
\text { científico e tecnológico }\end{array}$ & Executivo & Seccional & 0,55 \\
\hline 53 & $\begin{array}{c}\text { Fundação universidade federal de mato } \\
\text { grosso }\end{array}$ & Executivo & Seccional & 0,55 \\
\hline 52 & $\begin{array}{c}\text { Instituto brasileiro de informação em } \\
\text { ciência e tecnologia }\end{array}$ & Executivo & Seccional & 0,55 \\
\hline 54 & $\begin{array}{l}\text { Ministério da defesa / comando do } \\
\text { exército - colog }\end{array}$ & Executivo & Seccional & 0,54 \\
\hline 55 & Câmara dos deputados & Legislativo & N/A & 0,54 \\
\hline 56 & $\begin{array}{l}\text { Fundo nacional de desenvolvimento da } \\
\text { educação }\end{array}$ & Executivo & Seccional & 0,54 \\
\hline 57 & Tribunal regional eleitoral/pi & Judiciário & N/A & 0,53 \\
\hline 58 & Agência nacional de vigilância sanitária & Executivo & Seccional & 0,53 \\
\hline 59 & Ministério da ciência e tecnologia & Executivo & Setorial & 0,53 \\
\hline 61 & Superintendência de seguros privados & Executivo & Seccional & 0,52 \\
\hline 60 & $\begin{array}{l}\text { Coordenação de aperfeiçoamento de } \\
\text { pessoal de nível superior }\end{array}$ & Executivo & Seccional & 0,52 \\
\hline 62 & $\begin{array}{l}\text { Ministério da defesa / comando do } \\
\text { exército - dec }\end{array}$ & Executivo & Seccional & 0,52 \\
\hline 63 & Ministério do trabalho e emprego & Executivo & Setorial & 0,51 \\
\hline 64 & $\begin{array}{l}\text { Instituto nacional de pesquisas da } \\
\text { amazônia }\end{array}$ & Executivo & Seccional & 0,51 \\
\hline 65 & Universidade federal do abc & Executivo & Seccional & 0,51 \\
\hline 66 & $\begin{array}{l}\text { Tribunal regional do trabalho 10a } \\
\text { região/df }\end{array}$ & Judiciário & N/A & 0,51 \\
\hline 67 & $\begin{array}{l}\text { Ministério do desenvolvimento, indústria } \\
\text { e comércio }\end{array}$ & Executivo & Setorial & 0,51 \\
\hline 68 & Imprensa nacional & Executivo & Seccional & 0,5 \\
\hline 69 & Conselho nacional do ministério público & $\begin{array}{l}\text { Ministério } \\
\text { Público }\end{array}$ & N/A & 0,5 \\
\hline 70 & $\begin{array}{l}\text { Ministério da defesa / comando do } \\
\text { exército - coter }\end{array}$ & Executivo & Seccional & 0,5 \\
\hline 71 & Universidade federal do rio grande do & Executivo & Seccional & 0,5 \\
\hline
\end{tabular}




\begin{tabular}{|c|c|c|c|c|}
\hline & norte & & & \\
\hline 72 & Ministério das comunicações & Executivo & Setorial & 0,5 \\
\hline 73 & $\begin{array}{l}\text { Ministério da agricultura, pecuária e } \\
\text { abastecimento }\end{array}$ & Executivo & Setorial & 0,5 \\
\hline 75 & Amazonas distribuidora de energia s/a & Executivo & $\begin{array}{c}\text { Sociedade de Economia } \\
\text { Mista }\end{array}$ & 0,5 \\
\hline 74 & Indústria de material bélico do brasil & Executivo & Empresa Pública & 0,5 \\
\hline 76 & Universidade federal da bahia & Executivo & Seccional & 0,49 \\
\hline 77 & Controladoria-geral da união & Executivo & Seccional & 0,49 \\
\hline 78 & Companhia docas do espírito santo s.a. & Executivo & $\begin{array}{l}\text { Sociedade de Economia } \\
\text { Mista }\end{array}$ & 0,49 \\
\hline 79 & $\begin{array}{l}\text { Ministério da defesa / comando do } \\
\text { exército - sef }\end{array}$ & Executivo & Seccional & 0,49 \\
\hline $\mathbf{8 0}$ & Agência espacial brasileira & Executivo & Seccional & 0,48 \\
\hline 81 & Tribunal regional eleitoral/ba & Judiciário & N/A & 0,48 \\
\hline 82 & Universidade federal de goiás & Executivo & Seccional & 0,48 \\
\hline $\mathbf{8 3}$ & Ministério da saúde & Executivo & Setorial & 0,48 \\
\hline 84 & Tribunal regional eleitoral/sp & Judiciário & N/A & 0,47 \\
\hline 86 & Universidade federal do oeste do pará & Executivo & Seccional & 0,47 \\
\hline 85 & Fundação universidade federal de sergipe & Executivo & Seccional & 0,47 \\
\hline 87 & $\begin{array}{l}\text { Departamento nacional de obras contra } \\
\text { as secas }\end{array}$ & Executivo & Seccional & 0,47 \\
\hline 88 & $\begin{array}{l}\text { Instituto brasileiro do meio ambiente e } \\
\text { dos recursos naturais renováveis }\end{array}$ & Executivo & Seccional & 0,47 \\
\hline 89 & $\begin{array}{c}\text { Companhia de geração térmica de } \\
\text { energia elétrica }\end{array}$ & Executivo & $\begin{array}{c}\text { Sociedade de Economia } \\
\text { Mista }\end{array}$ & 0,47 \\
\hline 90 & Financiadora de estudos e projetos & Executivo & Seccional & 0,46 \\
\hline 91 & $\begin{array}{l}\text { Instituto nacional de colonização e } \\
\text { reforma agrária }\end{array}$ & Executivo & Seccional & 0,46 \\
\hline 92 & Fundação oswaldo cruz & Executivo & Seccional & 0,45 \\
\hline 94 & Instituto nacional de pesquisas espaciais & Executivo & Seccional & 0,45 \\
\hline 93 & $\begin{array}{l}\text { Empresa de trens urbanos de porto alegre } \\
\text { s.a. }\end{array}$ & Executivo & $\begin{array}{l}\text { Sociedade de Economia } \\
\text { Mista }\end{array}$ & 0,45 \\
\hline 95 & $\begin{array}{l}\text { Companhia de entrepostos e armazéns } \\
\text { gerais de são paulo }\end{array}$ & Executivo & $\begin{array}{c}\text { Sociedade de Economia } \\
\text { Mista }\end{array}$ & 0,45 \\
\hline 96 & $\begin{array}{l}\text { Superintendência nacional de } \\
\text { previdência complementar }\end{array}$ & Executivo & Seccional & 0,44 \\
\hline 97 & Ministério da defesa & Executivo & Setorial & 0,44 \\
\hline 98 & Universidade federal de pernambuco & Executivo & Seccional & 0,44 \\
\hline 100 & Empresa de pesquisa energética & Executivo & Empresa Pública & 0,43 \\
\hline 99 & Advocacia-geral da união & Executivo & Seccional & 0,43 \\
\hline 101 & Casa da moeda do brasil & Executivo & Empresa Pública & 0,43 \\
\hline 102 & Arquivo nacional & Executivo & Seccional & 0,43 \\
\hline 103 & Tribunal regional eleitoral/am & Judiciário & N/A & 0,43 \\
\hline 104 & Ministério do meio ambiente & Executivo & Setorial & 0,42 \\
\hline 107 & $\begin{array}{l}\text { Fundação universidade federal de ouro } \\
\text { preto }\end{array}$ & Executivo & Seccional & 0,42 \\
\hline 106 & Secretaria do tesouro nacional & Executivo & Correlata & 0,42 \\
\hline 105 & $\begin{array}{l}\text { Ministério público do distrito federal e } \\
\text { territórios }\end{array}$ & $\begin{array}{l}\text { Ministério } \\
\text { Público }\end{array}$ & N/A & 0,42 \\
\hline 108 & $\begin{array}{l}\text { Tribunal regional do trabalho 6a } \\
\text { região/pe }\end{array}$ & Judiciário & N/A & 0,42 \\
\hline 109 & $\begin{array}{l}\text { Tribunal regional do trabalho } 3 \mathrm{a} \\
\text { região/mg }\end{array}$ & Judiciário & N/A & 0,42 \\
\hline 110 & Ministério do turismo & Executivo & Setorial & 0,42 \\
\hline 111 & Tribunal regional eleitoral/pr & Judiciário & N/A & 0,42 \\
\hline 112 & Universidade federal da grande dourados & Executivo & Seccional & 0,42 \\
\hline 113 & Tribunal regional do trabalho 2a & Judiciário & N/A & 0,42 \\
\hline
\end{tabular}




\begin{tabular}{|c|c|c|c|c|}
\hline & região/sp & & & \\
\hline 114 & $\begin{array}{l}\text { Universidade federal do estado do rio de } \\
\text { janeiro }\end{array}$ & Executivo & Seccional & 0,41 \\
\hline 115 & Agência nacional do cinema & Executivo & Seccional & 0,41 \\
\hline 116 & $\begin{array}{l}\text { Superintendência de desenvolvimento da } \\
\text { amazônia }\end{array}$ & Executivo & Seccional & 0,41 \\
\hline 117 & Ministério da fazenda & Executivo & Setorial & 0,4 \\
\hline 118 & $\begin{array}{l}\text { Empresa de tecnologia e informações da } \\
\text { previdência social }\end{array}$ & Executivo & Empresa Pública & 0,4 \\
\hline 119 & Comissão de valores mobiliários & Executivo & Seccional & 0,4 \\
\hline 120 & $\begin{array}{l}\text { Tribunal regional do trabalho } 18 \mathrm{a} \\
\text { região/go }\end{array}$ & Judiciário & N/A & 0,4 \\
\hline 121 & Instituto brasileiro de turismo & Executivo & Seccional & 0,4 \\
\hline 122 & $\begin{array}{l}\text { Agência nacional do petróleo, gás natural } \\
\text { e biocombustíveis }\end{array}$ & Executivo & Seccional & 0,4 \\
\hline 123 & Universidade federal de lavras & Executivo & Seccional & 0,39 \\
\hline 125 & Senado federal & Legislativo & N/A & 0,39 \\
\hline 124 & Universidade federal do pampa & Executivo & Seccional & 0,39 \\
\hline 126 & Tribunal regional eleitoral/ce & Judiciário & N/A & 0,39 \\
\hline 127 & Ministério dos transportes & Executivo & Setorial & 0,39 \\
\hline 128 & $\begin{array}{c}\text { Empresa brasileira de infra-estrutura } \\
\text { aeroportuária }\end{array}$ & Executivo & Empresa Pública & 0,39 \\
\hline 129 & $\begin{array}{l}\text { Companhia docas do estado de são paulo } \\
\text { s.a. }\end{array}$ & Executivo & $\begin{array}{l}\text { Sociedade de Economia } \\
\text { Mista }\end{array}$ & 0,38 \\
\hline 130 & Ministério da pesca e aquicultura & Executivo & Setorial & 0,38 \\
\hline 131 & Universidade federal de são paulo & Executivo & Seccional & 0,37 \\
\hline 132 & Universidade federal do paraná & Executivo & Seccional & 0,37 \\
\hline 133 & Agência brasileira de inteligência & Executivo & Seccional & 0,37 \\
\hline 134 & Ministério do esporte & Executivo & Setorial & 0,37 \\
\hline 135 & $\begin{array}{l}\text { Agência nacional de transportes } \\
\text { aquaviários }\end{array}$ & Executivo & Seccional & 0,37 \\
\hline 136 & $\begin{array}{c}\text { Departamento nacional de produção } \\
\text { mineral }\end{array}$ & Executivo & Seccional & 0,36 \\
\hline 138 & Eletrobrás termonuclear s.a. & Executivo & $\begin{array}{c}\text { Sociedade de Economia } \\
\text { Mista }\end{array}$ & 0,36 \\
\hline 137 & Conselho superior da justiça do trabalho & Judiciário & N/A & 0,36 \\
\hline 139 & $\begin{array}{l}\text { Tribunal regional do trabalho } 9 \mathrm{a} \\
\text { região/pr }\end{array}$ & Judiciário & N/A & 0,36 \\
\hline 140 & Ministério do desenvolvimento agrário & Executivo & Setorial & 0,36 \\
\hline 142 & Tribunal regional eleitoral/ms & Judiciário & N/A & 0,36 \\
\hline 141 & $\begin{array}{l}\text { Superintendência de desenvolvimento do } \\
\text { nordeste }\end{array}$ & Executivo & Seccional & 0,36 \\
\hline 143 & $\begin{array}{l}\text { Companhia de desenvolvimento dos } \\
\text { vales do são francisco e do parnaíba }\end{array}$ & Executivo & Empresa Pública & 0,35 \\
\hline 144 & $\begin{array}{l}\text { Instituto do patrimônio histórico e } \\
\text { artístico cultural }\end{array}$ & Executivo & Seccional & 0,35 \\
\hline 145 & Universidade federal do rio grande do sul & Executivo & Seccional & 0,35 \\
\hline 146 & Empresa gerencial de projetos navais & Executivo & Empresa Pública & 0,35 \\
\hline 147 & Universidade federal de alfenas & Executivo & Seccional & 0,34 \\
\hline 148 & $\begin{array}{l}\text { Fundação escola nacional de } \\
\text { administração pública }\end{array}$ & Executivo & Seccional & 0,34 \\
\hline 149 & Companhia docas do pará s.a. & Executivo & $\begin{array}{l}\text { Sociedade de Economia } \\
\text { Mista }\end{array}$ & 0,34 \\
\hline 150 & $\begin{array}{l}\text { Ministério do desenvolvimento social e } \\
\text { combate à fome }\end{array}$ & Executivo & Setorial & 0,34 \\
\hline 151 & Companhia docas do estado da bahia s.a. & Executivo & $\begin{array}{l}\text { Sociedade de Economia } \\
\text { Mista }\end{array}$ & 0,34 \\
\hline 152 & Instituto nacional de meteorologia & Executivo & Seccional & 0,34 \\
\hline
\end{tabular}




\begin{tabular}{|c|c|c|c|c|}
\hline 153 & $\begin{array}{l}\text { Valec engenharia, construções e } \\
\text { ferrovias s.a. }\end{array}$ & Executivo & $\begin{array}{l}\text { Sociedade de Economia } \\
\text { Mista }\end{array}$ & 0,33 \\
\hline 154 & Universidade federal do maranhão & Executivo & Seccional & 0,33 \\
\hline 155 & $\begin{array}{l}\text { Fundação universidade federal do } \\
\text { amazonas }\end{array}$ & Executivo & Seccional & 0,33 \\
\hline 157 & Tribunal regional eleitoral/sc & Judiciário & N/A & 0,32 \\
\hline 156 & $\begin{array}{c}\text { Departamento de polícia rodoviária } \\
\text { federal }\end{array}$ & Executivo & Correlata & 0,32 \\
\hline 158 & Universidade federal rural da amazônia & Executivo & Seccional & 0,32 \\
\hline 159 & Ministério da cultura & Executivo & Setorial & 0,32 \\
\hline 160 & Ministério das relações exteriores & Executivo & Setorial & 0,32 \\
\hline 161 & $\begin{array}{l}\text { Secretaria de acompanhamento } \\
\text { econômico }\end{array}$ & Executivo & Correlata & 0,31 \\
\hline 162 & $\begin{array}{l}\text { Instituto nacional de tecnologia da } \\
\text { informação }\end{array}$ & Executivo & Seccional & 0,31 \\
\hline 163 & Ministério da justiça & Executivo & Setorial & 0,3 \\
\hline 164 & Ministério das cidades & Executivo & Setorial & 0,3 \\
\hline 166 & Universidade federal de roraima & Executivo & Seccional & 0,3 \\
\hline 165 & Fundação universidade de brasília & Executivo & Seccional & 0,3 \\
\hline 167 & $\begin{array}{l}\text { Companhia de pesquisa de recursos } \\
\text { minerais }\end{array}$ & Executivo & Seccional & 0,29 \\
\hline 168 & Departamento nacional de trânsito & Executivo & Seccional & 0,27 \\
\hline 169 & Defensoria pública da união & Executivo & Seccional & 0,25 \\
\hline 170 & Fundação casa de rui barbosa & Executivo & Seccional & 0,25 \\
\hline 171 & Universidade federal rural do semi-árido & Executivo & Seccional & 0,24 \\
\hline 173 & $\begin{array}{l}\text { Universidade federal rural de } \\
\text { pernambuco }\end{array}$ & Executivo & Seccional & 0,24 \\
\hline 172 & Fundação cultural palmares & Executivo & Seccional & 0,24 \\
\hline 174 & Universidade federal do ceará & Executivo & Seccional & 0,24 \\
\hline 175 & Escola de administração fazendária & Executivo & Seccional & 0,23 \\
\hline 176 & $\begin{array}{l}\text { Fundação universidade federal do vale } \\
\text { do são francisco }\end{array}$ & Executivo & Seccional & 0,22 \\
\hline 177 & Companhia brasileira de trens urbanos & Executivo & $\begin{array}{l}\text { Sociedade de Economia } \\
\text { Mista }\end{array}$ & 0,21 \\
\hline 178 & Agência nacional de telecomunicações & Executivo & Seccional & 0,2 \\
\hline 179 & Secretaria de políticas para as mulheres & Executivo & Setorial & 0,19 \\
\hline 180 & $\begin{array}{l}\text { Fundação jorge duprat figueiredo de seg. } \\
\text { E medicina do trabalho }\end{array}$ & Executivo & Seccional & 0,18 \\
\hline 181 & $\begin{array}{l}\text { Secretaria de políticas de promoção da } \\
\text { igualdade racial }\end{array}$ & Executivo & Setorial & 0,16 \\
\hline 182 & $\begin{array}{l}\text { Companhia docas do rio grande do norte } \\
\text { s.a. }\end{array}$ & Executivo & $\begin{array}{c}\text { Sociedade de Economia } \\
\text { Mista }\end{array}$ & 0,16 \\
\hline 183 & Instituto nacional de educação de surdos & Executivo & Seccional & 0,14 \\
\hline 184 & Agência brasileira de cooperação & Executivo & Seccional & 0,08 \\
\hline 185 & $\begin{array}{l}\text { Departamento nacional de registro do } \\
\text { comércio }\end{array}$ & Executivo & Seccional & 0,08 \\
\hline 186 & Companhia docas do maranhão s.a. & Executivo & $\begin{array}{l}\text { Sociedade de Economia } \\
\text { Mista }\end{array}$ & 0,07 \\
\hline 187 & Agência nacional de águas & Executivo & Seccional & \\
\hline- & Banco do brasil s.a. & Executivo & $\begin{array}{l}\text { Sociedade de Economia } \\
\text { Mista }\end{array}$ & \\
\hline- & Banco do nordeste do brasil s.a. & Executivo & $\begin{array}{l}\text { Sociedade de Economia } \\
\text { Mista }\end{array}$ & \\
\hline- & Companhia docas do ceará s.a. & Executivo & $\begin{array}{c}\text { Sociedade de Economia } \\
\text { Mista }\end{array}$ & \\
\hline- & Companhia energetica do piaui & Executivo & $\begin{array}{l}\text { Sociedade de Economia } \\
\text { Mista }\end{array}$ & \\
\hline- & Centrais elétricas de rondônia s.a. & Executivo & Sociedade de Economia & \\
\hline
\end{tabular}




\begin{tabular}{|c|c|c|c|c|}
\hline & & & Mista & \\
\hline- & Conselho da justiça federal & Judiciário & N/A & \\
\hline- & Conselho nacional de justiça & Judiciário & N/A & \\
\hline- & Cobra tecnologia s.a. & Executivo & $\begin{array}{c}\text { Sociedade de Economia } \\
\text { Mista }\end{array}$ & \\
\hline - & Empresa brasileira de comunicacão s.a. & Executivo & $\begin{array}{c}\text { Sociedade de Economia } \\
\text { Mista }\end{array}$ & \\
\hline- & Centrais elétricas brasileiras s.a. & Executivo & $\begin{array}{l}\text { Sociedade de Economia } \\
\text { Mista }\end{array}$ & \\
\hline- & Centrais elétricas do norte do brasil s.a. & Executivo & $\begin{array}{c}\text { Sociedade de Economia } \\
\text { Mista }\end{array}$ & \\
\hline- & Fundação biblioteca nacional & Executivo & Seccional & \\
\hline- & Fundação osório & Executivo & Seccional & \\
\hline - & Fundação alexandre de gusmão & Executivo & Seccional & \\
\hline- & $\begin{array}{l}\text { Fundação universidade federal do rio } \\
\text { grande }\end{array}$ & Executivo & Seccional & \\
\hline- & Instituto benjamin constant & Executivo & Seccional & \\
\hline- & $\begin{array}{l}\text { Fundação instituto brasileiro de } \\
\text { geografia e estatística }\end{array}$ & Executivo & Seccional & \\
\hline- & Instituto evandro chagas & Executivo & Seccional & \\
\hline- & Indústrias nucleares do brasil s.a. & Executivo & $\begin{array}{c}\text { Sociedade de Economia } \\
\text { Mista }\end{array}$ & \\
\hline- & $\begin{array}{l}\text { Instituto nacional de cardiologia } \\
\text { laranjeiras/rj } \\
\end{array}$ & Executivo & Seccional & \\
\hline- & Instituto nacional do câncer & Executivo & Seccional & \\
\hline- & $\begin{array}{l}\text { Instituto de pesquisas jardim botânico do } \\
\text { rio de janeiro }\end{array}$ & Executivo & Seccional & \\
\hline- & $\begin{array}{l}\text { Secretaria de logística e tecnologia da } \\
\text { informação }\end{array}$ & Executivo & Setorial & \\
\hline- & Ministério público federal & $\begin{array}{l}\text { Ministério } \\
\text { Público }\end{array}$ & N/A & \\
\hline- & Ministério público militar & $\begin{array}{l}\text { Ministério } \\
\text { Público } \\
\end{array}$ & N/A & \\
\hline- & Ministério público do trabalho & $\begin{array}{l}\text { Ministério } \\
\text { Público } \\
\end{array}$ & N/A & \\
\hline- & $\begin{array}{l}\text { Associação brasileira de tecnologia de } \\
\text { luz síncrotron }\end{array}$ & Executivo & Seccional & \\
\hline- & Associação das pioneiras sociais & Executivo & Seccional & \\
\hline - & $\begin{array}{l}\text { Associação de comunicação educativa } \\
\text { roquette-pinto }\end{array}$ & Executivo & Seccional & \\
\hline- & $\begin{array}{l}\text { Comissão executiva do plano da lavoura } \\
\text { cacaueira }\end{array}$ & Executivo & Seccional & \\
\hline- & Fundação banco do brasil & Executivo & Seccional & \\
\hline- & Hospital dos servidores do estado/rj & Executivo & Seccional & \\
\hline- & Petrobras distribuidora s.a. & Executivo & $\begin{array}{l}\text { Sociedade de Economia } \\
\text { Mista }\end{array}$ & \\
\hline- & Rede nacional de ensino e pesquisa & Executivo & Seccional & \\
\hline- & Refinaria alberto pasqualini s.a. & Executivo & Seccional & \\
\hline- & Nuclebras equipamentos pesados s.a. & Executivo & $\begin{array}{l}\text { Sociedade de Economia } \\
\text { Mista }\end{array}$ & \\
\hline- & Procuradoria geral da fazenda nacional & Executivo & Seccional & \\
\hline- & Supremo tribunal federal & Judiciário & N/A & \\
\hline- & Superior tribunal militar & Judiciário & N/A & \\
\hline- & $\begin{array}{l}\text { Transportadora bras. Gasoduto bolívia- } \\
\text { brasil s.a. }\end{array}$ & Executivo & $\begin{array}{c}\text { Sociedade de Economia } \\
\text { Mista } \\
\end{array}$ & \\
\hline- & Petrobras transporte s.a. & Executivo & $\begin{array}{l}\text { Sociedade de Economia } \\
\text { Mista }\end{array}$ & \\
\hline- & Universidade federal do acre & Executivo & Seccional & \\
\hline
\end{tabular}




\begin{tabular}{|c|c|c|c|}
\hline- & $\begin{array}{l}\text { Fundação universidade federal de mato } \\
\text { grosso do sul }\end{array}$ & Executivo & Seccional \\
\hline- & Universidade federal do pará & Executivo & Seccional \\
\hline- & Universidade federal da paraíba & Executivo & Seccional \\
\hline- & Fundação universidade federal de pelotas & Executivo & Seccional \\
\hline- & Fundação universidade federal do piauí & Executivo & Seccional \\
\hline- & Universidade federal do rio de janeiro & Executivo & Seccional \\
\hline- & $\begin{array}{c}\text { Fundação universidade federal de } \\
\text { roraima }\end{array}$ & Executivo & Seccional \\
\hline- & Universidade federal de santa maria & Executivo & Seccional \\
\hline- & $\begin{array}{l}\text { Universidade federal dos vales do } \\
\text { jequitinhonha e mucuri }\end{array}$ & Executivo & Seccional \\
\hline- & $\begin{array}{l}\text { Fundação universidade federal de } \\
\text { rondônia }\end{array}$ & Executivo & Seccional \\
\hline- & $\begin{array}{c}\text { Instituto nacional de traumatologia e } \\
\text { ortopedia }\end{array}$ & Executivo & Seccional \\
\hline- & Irb-brasil resseguros s.a. & Executivo & Seccional \\
\hline- & $\begin{array}{l}\text { Tribunal regional do trabalho } 14 \mathrm{a} \\
\text { região/ac-ro }\end{array}$ & Judiciário & N/A \\
\hline- & $\begin{array}{l}\text { Tribunal regional do trabalho } 15 \text { a } \\
\text { região/campinas/sp }\end{array}$ & Judiciário & N/A \\
\hline- & $\begin{array}{l}\text { Tribunal regional do trabalho } 16 \mathrm{a} \\
\text { região/ma }\end{array}$ & Judiciário & N/A \\
\hline- & $\begin{array}{l}\text { Tribunal regional do trabalho } 17 \mathrm{a} \\
\text { região/es }\end{array}$ & Judiciário & N/A \\
\hline- & $\begin{array}{l}\text { Tribunal regional do trabalho } 19 \mathrm{a} \\
\text { região/al }\end{array}$ & Judiciário & N/A \\
\hline- & Tribunal regional do trabalho 1a região/rj & Judiciário & N/A \\
\hline- & $\begin{array}{l}\text { Tribunal regional do trabalho } 20 \mathrm{a} \\
\text { região/se }\end{array}$ & Judiciário & N/A \\
\hline- & $\begin{array}{l}\text { Tribunal regional do trabalho } 21 \mathrm{a} \\
\text { região/rn }\end{array}$ & Judiciário & N/A \\
\hline- & $\begin{array}{l}\text { Tribunal regional do trabalho } 22 \mathrm{a} \\
\text { região/pi }\end{array}$ & Judiciário & N/A \\
\hline- & $\begin{array}{l}\text { Tribunal regional do trabalho } 24 \mathrm{a} \\
\text { região/ms }\end{array}$ & Judiciário & N/A \\
\hline- & $\begin{array}{l}\text { Tribunal regional do trabalho 5a } \\
\text { região/ba }\end{array}$ & Judiciário & N/A \\
\hline- & $\begin{array}{l}\text { Tribunal regional do trabalho } 7 \mathrm{a} \\
\text { região/ce }\end{array}$ & Judiciário & N/A \\
\hline- & $\begin{array}{l}\text { Tribunal regional do trabalho 8a } \\
\text { região/pa }\end{array}$ & Judiciário & N/A \\
\hline- & Tribunal regional eleitoral/ac & Judiciário & N/A \\
\hline- & Tribunal regional eleitoral/al & Judiciário & N/A \\
\hline- & Tribunal regional eleitoral/ap & Judiciário & N/A \\
\hline- & Tribunal regional eleitoral/go & Judiciário & N/A \\
\hline- & Tribunal regional eleitoral/mg & Judiciário & N/A \\
\hline - & Tribunal regional eleitoral/mt & Judiciário & N/A \\
\hline- & Tribunal regional eleitoral/pa & Judiciário & N/A \\
\hline- & Tribunal regional eleitoral/pe & Judiciário & N/A \\
\hline- & Tribunal regional eleitoral/rj & Judiciário & N/A \\
\hline- & Tribunal regional eleitoral/rn & Judiciário & N/A \\
\hline- & Tribunal regional eleitoral/ro & Judiciário & N/A \\
\hline- & Tribunal regional eleitoral/rr & Judiciário & N/A \\
\hline- & Tribunal regional federal 1a região & Judiciário & N/A \\
\hline- & Tribunal regional federal 2a região & Judiciário & N/A \\
\hline- & Tribunal regional federal 3a região & Judiciário & N/A \\
\hline- & Tribunal regional federal 5a região & Judiciário & N/A \\
\hline
\end{tabular}




\begin{tabular}{|c|c|c|c|}
\hline- & $\begin{array}{l}\text { Departamento nacional de infraestrutura } \\
\text { de transportes }\end{array}$ & Executivo & Correlata \\
\hline- & Fundação nacional do índio & Executivo & Seccional \\
\hline- & Fundação nacional de artes & Executivo & Seccional \\
\hline- & Fundação nacional de saúde & Executivo & Seccional \\
\hline - & Instituto nacional de tecnologia & Executivo & Seccional \\
\hline- & $\begin{array}{l}\text { Superintendência da zona franca de } \\
\text { manaus }\end{array}$ & Executivo & Seccional \\
\hline- & $\begin{array}{l}\text { Tribunal de justiça do distrito federal e } \\
\text { territórios }\end{array}$ & Judiciário & N/A \\
\hline- & Universidade federal de minas gerais & Executivo & Seccional \\
\hline- & $\begin{array}{l}\text { Fundação universidade federal de são } \\
\text { joão del rei }\end{array}$ & Executivo & Seccional \\
\hline- & $\begin{array}{l}\text { Tribunal regional do trabalho } 12 \mathrm{a} \\
\text { região/sc }\end{array}$ & Judiciário & N/A \\
\hline- & $\begin{array}{l}\text { Tribunal regional do trabalho } 4 \mathrm{a} \\
\text { região/rs }\end{array}$ & Judiciário & N/A \\
\hline- & Tribunal regional eleitoral/ma & Judiciário & N/A \\
\hline- & Tribunal regional eleitoral/se & Judiciário & N/A \\
\hline
\end{tabular}


Instituições pesquisadas e informações sobre posição e iGovTI coligidos durante as entrevistas.

\begin{tabular}{|c|c|c|c|c|c|c|}
\hline \multirow[b]{2}{*}{ Órgão } & \multicolumn{6}{|c|}{ Levantamento de GTI em 2012} \\
\hline & Grupo & $\begin{array}{l}\text { Posição } \\
\text { no } \\
\text { Grupo }\end{array}$ & Segmento & $\begin{array}{l}\text { Posição no } \\
\text { Segmento }\end{array}$ & Geral & iGovTI \\
\hline Caixa Econômica Federal (CEF) & Banco & $\mathrm{n} / \mathrm{i}$ & Exe--Dest & $\mathrm{n} / \mathrm{i}$ & $02^{\circ}$ & $\mathrm{n} / \mathrm{i}$ \\
\hline Banco do Brasil (BB) & Banco & $2^{\circ}$ & Exe--Dest & $3^{\circ}$ & $03^{\circ}$ & 0,78 \\
\hline Marinha do Brasil (CMAR) & Órgãos militares & $1^{\circ}$ & Exe-Sisp & $1^{\circ}$ & $04^{\circ}$ & 0,78 \\
\hline $\begin{array}{l}\text { Petróleo Brasileiro S.A. } \\
\text { (PETROBRAS) }\end{array}$ & $\begin{array}{l}\text { Soc. econ. mista } \\
\text { ou empresa } \\
\text { pública }\end{array}$ & $\mathrm{n} / \mathrm{i}$ & Exe-Dest & $\mathrm{n} / \mathrm{i}$ & $05^{\circ}$ & 0,78 \\
\hline Banco Central do Brasil (BACEN) & Autarquia & $1^{\circ}$ & Exe-Sisp & $2^{\circ}$ & $06^{\circ}$ & 0,78 \\
\hline $\begin{array}{l}\text { Hospital de Cínicas de Porto Alegre } \\
\text { (HCPA) }\end{array}$ & $\begin{array}{l}\text { Soc. econ. mista } \\
\text { ou empresa } \\
\text { pública }\end{array}$ & $4^{\circ}$ & Exe-Dest & $6^{\circ}$ & $08^{\circ}$ & 0,76 \\
\hline Tribunal de Contas da União (TCU) & Tribunal & $1^{\circ}$ & Leg & $1^{\circ}$ & $10^{\circ}$ & 0,75 \\
\hline Empresa Gestora de Ativos (EMGEA) & $\begin{array}{l}\text { Soc. econ. mista } \\
\text { ou empresa } \\
\text { pública }\end{array}$ & $5^{\circ}$ & Exe-Dest & $8^{\circ}$ & $14^{\circ}$ & 0,72 \\
\hline $\begin{array}{l}\text { Departamento de Polícia Federal } \\
\text { (DPF) }\end{array}$ & $\begin{array}{l}\text { Órgão executivo } \\
\text { (Adm. Direta) }\end{array}$ & $1^{o}$ & Exe-Sisp & $5^{\circ}$ & $19^{\circ}$ & $\mathrm{n} / \mathrm{i}$ \\
\hline $\begin{array}{l}\text { Secretaria de Orçamento Federal } \\
\text { (SOF) }\end{array}$ & $\begin{array}{l}\text { Executivo - } \\
\text { APFD }\end{array}$ & $2^{\circ}$ & Exe-Sisp & $7^{\circ}$ & $23^{\circ}$ & 0,69 \\
\hline $\begin{array}{l}\text { Secretaria da Receita Federal do Brasil } \\
\text { (SRF) }\end{array}$ & $\begin{array}{l}\text { Executivo - } \\
\text { APFD }\end{array}$ & $3^{\circ}$ & Exe-Sisp & $8^{\circ}$ & $24^{\circ}$ & 0,69 \\
\hline $\begin{array}{c}\text { Ministério da Defesa / Comando do } \\
\text { Exército (DCT) } \\
\end{array}$ & Órgão militar & $3^{\circ}$ & Exe-Sisp & $11^{\circ}$ & $29^{\circ}$ & 0,66 \\
\hline Tribunal Superior do Trabalho (TST) & Tribunal & $9^{\circ}$ & Jud & $8^{\circ}$ & $36^{\circ}$ & 0,64 \\
\hline $\begin{array}{l}\text { Empresa Brasileira de Pesquisa } \\
\text { Agropecuária (EMBRAPA) }\end{array}$ & $\begin{array}{c}\text { Soc economia } \\
\text { mista ou empresa } \\
\text { publica }\end{array}$ & $11^{\circ}$ & Exe--DST & $15^{\circ}$ & $40^{\circ}$ & 0,63 \\
\hline $\begin{array}{c}\text { Agência Nacional de Transportes } \\
\text { Terrestres (ANTT) } \\
\end{array}$ & Agência & $1^{\circ}$ & Exe-Sisp & $15^{\circ}$ & $44^{\circ}$ & 0,62 \\
\hline $\begin{array}{c}\text { Agência Nacional de Energia Elétrica } \\
\text { (ANEEL) }\end{array}$ & Agência & $2^{\circ}$ & Exe-Sisp & $16^{\circ}$ & $47^{\circ}$ & 0,62 \\
\hline $\begin{array}{c}\text { Secretaria-Geral da Presidência da } \\
\text { República (SGPR) }\end{array}$ & Ministério & $2^{\circ}$ & Exe-Sisp & $17^{\circ}$ & $50^{\circ}$ & 0,62 \\
\hline $\begin{array}{c}\text { Empresa Brasileira de Correios e } \\
\text { Telégrafos (ECT) }\end{array}$ & $\begin{array}{l}\text { Soc.econ.mista } \\
\text { ou empresa } \\
\text { pública }\end{array}$ & $13^{\circ}$ & Exe--Dest & $17^{\circ}$ & $59^{\circ}$ & 0,48 \\
\hline $\begin{array}{c}\text { Instituto de Pesquisa Econômica } \\
\text { Aplicada (IPEA) } \\
\end{array}$ & Fundações & $3^{\circ}$ & Exe-Sisp & $24^{\circ}$ & $68^{\circ}$ & 0,57 \\
\hline Câmara dos Deputados (CD) & não classifica & $\begin{array}{c}\text { não } \\
\text { classifica }\end{array}$ & Leg & $2^{\circ}$ & $87^{\circ}$ & 0,54 \\
\hline Secretaria do Tesouro Nacional (STN) & $\begin{array}{l}\text { Executivo - } \\
\text { APFD }\end{array}$ & $11^{\circ}$ & Exe-Sisp & $92^{\circ}$ & $184^{\circ}$ & 0,43 \\
\hline $\begin{array}{l}\text { Agência Nacional de Aviação Civil } \\
\text { (ANAC) }\end{array}$ & Agência & $\mathrm{n} / \mathrm{i}$ & Exe-Sisp & $\mathrm{n} / \mathrm{i}$ & $\mathrm{n} / \mathrm{i}$ & $\mathrm{n} / \mathrm{i}$ \\
\hline Ministério da Educação (MEC) & Adm. Direta & $\mathrm{n} / \mathrm{i}$ & Exe-Sisp & $\mathrm{n} / \mathrm{i}$ & $\mathrm{n} / \mathrm{i}$ & $\mathrm{n} / \mathrm{i}$ \\
\hline Ministério da Fazenda (MF) & Adm. Direta & $\mathrm{n} / \mathrm{i}$ & Exe-Sisp & $\mathrm{n} / \mathrm{i}$ & $\mathrm{n} / \mathrm{i}$ & $\mathrm{n} / \mathrm{i}$ \\
\hline $\begin{array}{c}\text { Ministério das Minas e Energia } \\
\text { (MME) }\end{array}$ & Adm. Direta & $\mathrm{n} / \mathrm{i}$ & Exe-Sisp & $\mathrm{n} / \mathrm{i}$ & $\mathrm{n} / \mathrm{i}$ & $\mathrm{n} / \mathrm{i}$ \\
\hline $\begin{array}{c}\text { Ministério Público do Distrito Federal } \\
\text { e Territórios (MPDFT) } \\
\end{array}$ & $\begin{array}{l}\text { MPU e MP } \\
\text { Estaduais }\end{array}$ & $1^{\mathrm{o}}$ & Jud & $\mathrm{n} / \mathrm{i}$ & $\mathrm{n} / \mathrm{i}$ & $\mathrm{n} / \mathrm{i}$ \\
\hline
\end{tabular}

Fonte: Dados da Pesquisa 


\section{ANEXO V}

Itens e descrição das questões do questionário do Levantamento de GTI do TCU ano 2012.

\begin{tabular}{|c|c|}
\hline $\begin{array}{c}\text { Nome } \\
\text { Campo }\end{array}$ & PerguntaVinculada \\
\hline Q11a & $\begin{array}{l}\text { se responsabiliza pelo estabelecimento e pelo cumprimento das políticas de gestão e uso corporativos } \\
\text { de TI. }\end{array}$ \\
\hline Q11b & $\begin{array}{l}\text { designou formalmente um Comitê de TI para auxiliá-la nas decisões relativas à gestão e ao uso } \\
\text { corporativos de TI. }\end{array}$ \\
\hline Q11c & $\begin{array}{l}\text { designou representantes de todas as áreas relevantes para o negócio institucional para compor o } \\
\text { Comitê de TI. }\end{array}$ \\
\hline Q11d & monitora regularmente o funcionamento do Comitê de TI. \\
\hline Q11e & nenhuma das opções anteriores descreve a situação desta instituição. \\
\hline Q12a & estabeleceu objetivos (diretrizes) de desempenho de gestão e de uso corporativos de TI. \\
\hline Q12b & estabeleceu indicadores de desempenho de gestão e de uso corporativos de TI. \\
\hline Q12c & $\begin{array}{l}\text { recebe e avalia regularmente informações sobre o desempenho relativo à gestão e ao uso corporativos } \\
\text { de TI. }\end{array}$ \\
\hline Q12d & $\begin{array}{l}\text { acompanha os indicadores de benefício dos principais sistemas de informação e toma decisões a } \\
\text { respeito quando as metas de benefício não são atingidas. }\end{array}$ \\
\hline Q12e & nenhuma das opções anteriores descreve a situação desta instituição. \\
\hline Q13a & provê política de desenvolvimento de gestores de TI. \\
\hline Q13b & $\begin{array}{l}\text { prioriza (pelo menos 75\%) o preenchimento das funções gerenciais com pessoas do quadro efetivo } \\
\text { permanente da própria instituição. }\end{array}$ \\
\hline Q13c & implementa programa de acompanhamento de desempenho gerencial. \\
\hline Q13d & $\begin{array}{l}\text { escolhe os gestores de TI fundamentalmente com base em suas competências (p.ex. desempenho } \\
\text { profissional, experiência, formação acadêmica etc.) }\end{array}$ \\
\hline Q13e & nenhuma das opções anteriores descreve a situação desta instituição. \\
\hline Q14a & não foi realizada auditoria de TI de iniciativa da própria instituição nos últimos três anos. \\
\hline Q14b & auditoria de dados. \\
\hline Q14c & auditoria de segurança da informação. \\
\hline Q14d & auditoria de contratos de TI. \\
\hline Q14e & auditoria de sistemas de informação. \\
\hline Q14f & auditoria de governança de TI. \\
\hline Q14g & outra(s). \\
\hline Q23a & a instituição não aprovou e nem publicou PDTI interna ou externamente. \\
\hline Q23b & o PDTI vincula as ações de TI a indicadores e metas de negócio. \\
\hline Q23c & o PDTI vincula os custos de TI a atividades e projetos de TI. \\
\hline Q23d & o PDTI é publicado na internet para acesso livre. \\
\hline Q23e & o PDTI vincula as ações de TI a indicadores e metas de serviços ao cidadão. \\
\hline Q41a & $\begin{array}{l}\text { adota política formal de TI para conservação de recursos não renováveis, preservação dos } \\
\text { ecossistemas e a otimização do uso dos recursos renováveis (p. ex. economia de insumos físicos, de } \\
\text { energia elétrica etc.). }\end{array}$ \\
\hline Q64a & experiência em gestão de TI \\
\hline Q64b & curso superior (em qualquer área não relacionada à TI) \\
\hline Q64c & curso superior (em qualquer área relacionada à TI) \\
\hline Q64d & pós-graduação lato sensu (especialização) não relacionada à TI \\
\hline Q64e & pós-graduação lato sensu (especialização) em TI, exceto gestão ou governança de TI \\
\hline Q64f & pós-graduação lato sensu (especialização) em gestão ou governança de TI \\
\hline Q64g & pós-graduação stricto sensu (mestrado/doutorado/pós-doutorado) não relacionada à TI \\
\hline Q64h & $\begin{array}{l}\text { pós-graduação stricto sensu (mestrado/doutorado/pós-doutorado) em TI, exceto gestão ou governança } \\
\text { de TI }\end{array}$ \\
\hline
\end{tabular}




\begin{tabular}{|c|c|}
\hline Q64i & pós-graduação stricto sensu (mestrado/doutorado/pós-doutorado) em gestão ou governança de TI \\
\hline Q64j & certificados profissionais (CGEIT, CobiT, PMP, ITIL, CISM, CISA etc.) \\
\hline Q64k & outros elementos de qualificação considerados relevantes \\
\hline Q712a1 & Há norma interna que defina as atribuições do papel FISCAL? \\
\hline Q712a2 & Há norma interna que defina as atribuições do papel GESTOR? \\
\hline Q712b1 & O FISCAL é designado formalmente? \\
\hline Q712b2 & O GESTOR é designado formalmente? \\
\hline Q712c1 & São designadas somente pessoas treinadas para o papel FISCAL? \\
\hline Q712c2 & São designadas somente pessoas treinadas para o papel GESTOR? \\
\hline Q712d1 & $\begin{array}{l}\text { Há programa de capacitação específico para o exercício do papel FISCAL? } \\
\text { Há programa de capacitação específico para o exercício do papel? }\end{array}$ \\
\hline Q712d2 & $\begin{array}{l}\text { Há programa de capacitação específico para o exercício do papel GESTOR? } \\
\text { Há programa de capacitação específico para o exercício do papel? }\end{array}$ \\
\hline Q712e1 & Há algum tipo de compensação financeira adicional pelo exercício do papel FISCAL? \\
\hline Q712e2 & Há algum tipo de compensação financeira adicional pelo exercício do papel GESTOR? \\
\hline Q713a1 & monitorar a execução contratual do ponto de vista de resultados de negócio? \\
\hline Q713a2 & Área de negócio \\
\hline Q713a3 & Área Administrativa \\
\hline Q713a4 & Área Financeira \\
\hline Q713b1 & $\begin{array}{l}\text { monitorar o cumprimento das cláusulas contratuais e das obrigações fiscais, comerciais, trabalhistas e } \\
\text { previdenciárias? }\end{array}$ \\
\hline Q713b2 & Área de negócio \\
\hline Q713b3 & Área Administrativa \\
\hline Q713b4 & Área Financeira \\
\hline Q713c1 & monitorar a execução técnica dos serviços contratados? \\
\hline Q713c2 & Área de negócio \\
\hline Q713c3 & Área Administrativa \\
\hline Q713c4 & Área Financeira \\
\hline Q713d1 & gerir o contrato com base em resultados (Decreto $\mathrm{n}^{\circ} 2.271 / 1997$, art. $6^{\circ}$ )? \\
\hline Q713d2 & Área de negócio \\
\hline Q713d3 & Área Administrativa \\
\hline Q713d4 & Área Financeira \\
\hline Q713e1 & acompanhar e fiscalizar o contrato (Lei ${ }^{\circ} 8.666 / 1993$, art. 67)? \\
\hline Q713e2 & Área de negócio \\
\hline Q713e3 & Área Administrativa \\
\hline Q713e4 & Área Financeira \\
\hline Q715a & A solicitação de orçamento de TI é feita com base na estimativa dos custos das contratações previstas. \\
\hline Q715b & Há alocação de custos de TI por área de negócio. \\
\hline Q715c & A execução da despesa de TI é acompanhada pela área de TI. \\
\hline Q715d & A execução da despesa de TI é acompanhada pela Alta Administração da instituição. \\
\hline Q715e & A classificação das despesas de TI é de responsabilidade da área TI. \\
\hline Q715f & A classificação das despesas de TI é de responsabilidade da área contábil/orçamentária da instituição. \\
\hline Q715g & A gestão do orçamento de TI é centralizada na área de TI. \\
\hline Q71a & Inventariar todos os ativos de informação (dados, hardware, software e instalações). \\
\hline Q71b & Classificar a informação para o negócio (p.ex. divulgação ostensiva ou restrita). \\
\hline Q71c & $\begin{array}{l}\text { Analisar os riscos aos quais a informação crítica para o negócio está submetida, considerando, pelo } \\
\text { menos, confidencialidade, integridade e disponibilidade. }\end{array}$ \\
\hline Q71d & Gerenciar os incidentes de segurança da informação. \\
\hline Q72a & a política corporativa de segurança da informação. \\
\hline Q72b & $\begin{array}{l}\text { a designação de responsável(is) por implantar e acompanhar a política corporativa de segurança da } \\
\text { informação. }\end{array}$ \\
\hline Q76a & gestão de mudanças \\
\hline Q76a2 & constituiu um comitê técnico de gestão de mudanças \\
\hline Q76b & gestão de capacidade \\
\hline Q76c & gestão de nível de serviço \\
\hline Q76d & gestão de problemas \\
\hline Q76d2 & tem base de conhecimento de apoio à gestão de problemas e incidentes \\
\hline
\end{tabular}




\begin{tabular}{|l|l|}
\hline Q76e & gestão de incidentes \\
\hline Q76f & gestão de configuração \\
\hline Q76f2 & tem base de dados de gestão da configuração do ambiente computacional \\
\hline Q76g & gestão financeira \\
\hline Q76h & gestão de disponibilidade \\
\hline Q76i & gestão de continuidade \\
\hline Q76i2 & tem plano de continuidade de negócio em vigor (aprovado e publicado) \\
\hline Q76j & gestão de liberação \\
\hline & $\begin{array}{l}\text { houve licitação em que a empresa mais bem classificada era estrangeira e veio a perder o certame por } \\
\text { causa do exercício do direito de preferência em favor de licitante concorrente (art. } 5^{\circ} \text { do Decreto } \mathrm{n}^{\circ}\end{array}$ \\
Q79h & $1.070 / 1994)$. \\
\hline
\end{tabular}

